\title{
CIVILIZATION AND GENOCIDE
}

\author{
by \\ CHRISTOPHER JOHN POWELL, B.A., M.A.
}

\author{
A thesis submitted to \\ The Faculty of Graduate Studies and Research \\ in partial fulfillment of \\ the requirements for the degree of \\ Doctor of Philosophy \\ Department of Sociology and Anthropology \\ Carleton University \\ Ottawa, Ontario \\ November 2004 \\ (C) copyright \\ 2004, Christopher John Powell
}




$\begin{array}{ll}\begin{array}{l}\text { Library and } \\ \text { Archives Canada }\end{array} & \begin{array}{l}\text { Bibliothèque et } \\ \text { Archives Canada }\end{array} \\ \begin{array}{l}\text { Published Heritage } \\ \text { Branch }\end{array} & \begin{array}{l}\text { Direction du } \\ \text { Patrimoine de l'édition }\end{array} \\ \begin{array}{l}\text { 395 Wellington Street } \\ \text { Ottawa ON K1A ON4 }\end{array} & \begin{array}{l}\text { 395, rue Wellington } \\ \text { Ottawa ON K1A ON4 } \\ \text { Canada }\end{array}\end{array}$

Your file Votre référence

ISBN: 0-494-00806-7

Our file Notre référence

ISBN: 0-494-00806-7

NOTICE:

The author has granted a nonexclusive license allowing Library and Archives Canada to reproduce, publish, archive, preserve, conserve, communicate to the public by telecommunication or on the Internet, loan, distribute and sell theses worldwide, for commercial or noncommercial purposes, in microform, paper, electronic and/or any other formats.

The author retains copyright ownership and moral rights in this thesis. Neither the thesis nor substantial extracts from it may be printed or otherwise reproduced without the author's permission.
AVIS:

L'auteur a accordé une licence non exclusive permettant à la Bibliothèque et Archives Canada de reproduire, publier, archiver, sauvegarder, conserver, transmettre au public par télécommunication ou par l'Internet, prêter, distribuer et vendre des thèses partout dans le monde, à des fins commerciales ou autres, sur support microforme, papier, électronique et/ou autres formats.

L'auteur conserve la propriété du droit d'auteur et des droits moraux qui protège cette thèse. $\mathrm{Ni}$ la thèse ni des extraits substantiels de celle-ci ne doivent être imprimés ou autrement reproduits sans son autorisation.
In compliance with the Canadian

Privacy Act some supporting forms may have been removed from this thesis.

While these forms may be included in the document page count, their removal does not represent any loss of content from the thesis.
Conformément à la loi canadienne sur la protection de la vie privée, quelques formulaires secondaires ont été enlevés de cette thèse.

Bien que ces formulaires aient inclus dans la pagination, il n'y aura aucun contenu manquant.

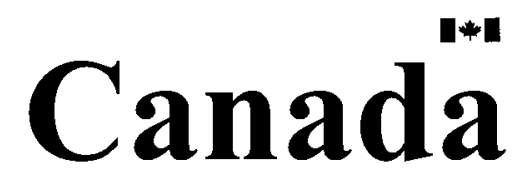




\begin{abstract}
This dissertation argues that civilization produces genocides. It begins by considering the obstacles to a sociological understanding of genocide. First among these is the metaphysics of rupture that situates genocide radically outside the field of ordinary social relations, treating it as a breakdown, rather than as a product, of social relations. A second obstacle is the essentially contested status of the concept of 'genocide', which must be understood historically, through genealogical and figurational analysis. A third obstacle is the relative over-development of heroic sociologies of genocide, which focus on the production of an intending collective subject, and the relative under-development of anti-heroic sociologies that attend to difference, to relations, and to strategies of unmaking. I theorize genocide using Norbert Elias's figurational analysis of the European civilizing process, which traces the intertwined growth of state institutions, particularly the state's territorial monopoly of military force, and of forms of self-regulation and habitual conduct that have come to be seen as civilized behaviour. Through a deconstructive reading of Elias's texts, I overcome the limits set by Elias's residual essentialism and Eurocentrism, which naively equates civilization with pacification, to produce instead an account of how the expansion of the civilizing process involves the reproduction of social violence on an ever-expanding scale. Under some circumstances, this process of 'barbarous civilization' is realized through genocidal violence, or 'civilizing genocides'. Finally, I apply this framework to the analysis of six historical examples of civilizing genocides: in Languedoc, Guatemala, Tasmania, India, Turkey, and Rwanda. I show that these examples, some of which are not usually considered genocides, can fruitfully and appropriately be treated as such, and how each of these events, usually considered examples of the failure or the breakdown or the limits of European civilization, are better understood as instances of its expansion.
\end{abstract}




\section{Acknowledgments}

I wish to extend my warmest thanks to my doctoral committee, for having vested their confidence in a certain junior $\mathrm{Ph}$. D. student with no definite theoretical platform and no plan for his dissertation, and for their unflagging support and enthusiasm through the various transformations of this project. In particular, I'd like to thank Jacques Chevalier for invaluable practical suggestions that shortened this project, and for difficult intellectual questions that strengthened it; Rianne Mahon for crucial advice on how to handle my historical examples; and Bruce Curtis for inestimable support and mentorship generously given throughout my master's and doctoral studies. The sociology program at Carleton University grants doctoral students the freedom and the responsibility of setting their own research agendas, and I'm grateful to my committee for honouring that framework and enabling me to construct this project on my own terms. All shortcomings of this work are, of course, entirely my own doing.

I am exceptionally fortunate to have been situated within a vibrant student community whose social, political, and intellectual engagements made graduate school a wonderland for me. For specific contributions to my dissertation process, I would like to thank: Melanie White, for close critical readingings of my comprehensives and proposal, and for incalculable engagement, support, and inspiration over many years; Seána Keedian, for editorial comments on drafts of Chapters II and III; Zoey Michele, for checking my use of Derrida in Chapter IV; and Sheryl Peters, for discussing Elias and genocide with me tirelessly over the last year of writing. Other friends and interlocutors I would like to recognize include Greg Gillespie, Mythili Rajiva, Serena Petrella, Kim Elliott, Paul Datta, Kevin Dahlke, and Jeff Shantz.

I would like to thank my parents, Mark and Eugenia, both for their material support and for their continued enthusiasm for my graduate studies, and my siblings, Sonya, Dave, and Sherri, for always taking an interest and rarely asking when it will be finished.

This dissertation would not have been possible without financial support from the Carleton University Graduate Scholarship, the Ontario Graduate Scholarship, and the Social Sciences and Humanities Research Council of Canada Doctoral Fellowship. 


\section{Contents, Brief}

INTRODUCTION

CHAPTER I: THE METAPHYSICS OF RUPTURE

1. Genocide Studies 14

2. METHODS 45

CHAPTER II: IDENTIFYING GENOCIDE

$\begin{array}{ll}\text { 1. POINT AND PURPOSE } & 57\end{array}$

2. WHAT IS GENOCIDE?

3. ON VALUE-FREEDOM 105

4. HOW TO USE 'GENOCIDE' 123

CHAPTER III: ANTI-HEROIC SOCIOLOGY

1. Strategies of Making AND UNMAKING 130

2. HEROIC THEORY 141

3. ANTI-HEROIC THEORY 161

CHAPTER IV: CIVILIZING GENOCIDES 189

1. TELEOLOGICAL CIVILIZATION 190

2. CIVILIZATION DECONSTRUCTED 213

3. A FIGURATIONAL SOCIOLOGY OF GENOCIDE $\quad 239$

CHAPTER V: GENOCIDAL CIVILIZATION

1. LaNGUEDOC AND GUATEMALA 258

2. TASMANIA AND INDIA 299

3. OTIOMAN EMPIRE AND RWANDA 353

CHAPTER VI: INCONCLUSIONS $\quad 404$

1. Recapitulation 404

2. IMPLICATIONS FOR UNDERSTANDING 407

3. IMPLICATIONS FOR PRAXIS 412

APPENDIX I: DEFINITIONS OF GENOCIDE

UNITED NATIONS $\quad 417$

OTHER DEFINITIONS: $\quad 417$

APPENDIX II: SOCIOLOGY AND GENOCIDE

$\begin{array}{ll}\text { SOURCES } & 431\end{array}$ 


\section{Contents, Detailed}

INTRODUCTION 1

CHAPTER I: THE METAPHYSICS OF RUPTURE

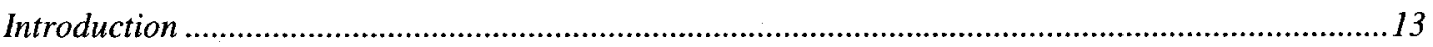

1. GENOCIDE STUDIES 14

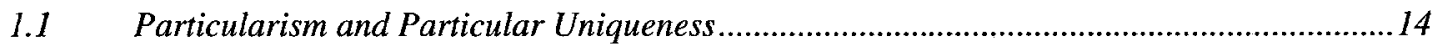

$1.2 \quad$ Liberal Genocide Studies and Generalized Uniqueness...........................................................21

$1.3 \quad$ Bridging the Theory Gap: Beyond General Uniqueness ....................................................

2. METHODS 45

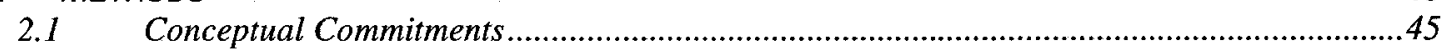

2.2 Aims

CHAPTER II: IDENTIFYING GENOCIDE

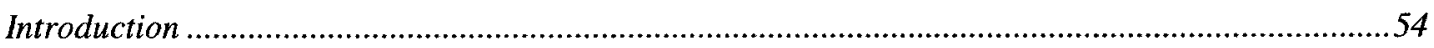

1. POINT AND PURPOSE

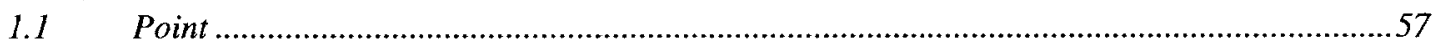

$1.2 \quad$ Purpose

2. WHAT IS GENOCIDE? 68

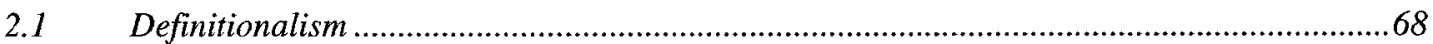

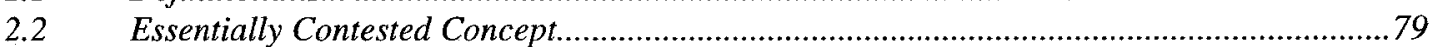

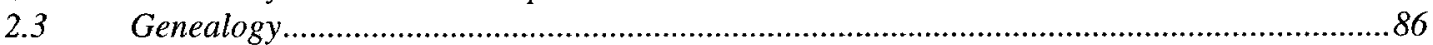

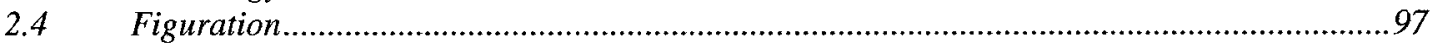

3. ON VAlUe-Freedom 105

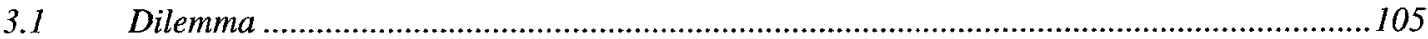

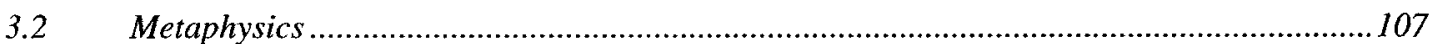

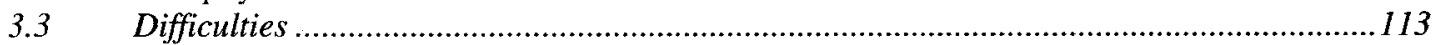

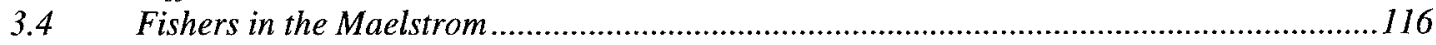

4. HOW TO USE 'GENOCIDE' 123

CHAPTER III: ANTI-HEROIC SOCIOLOGY $\quad 129$

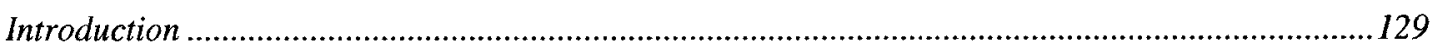

1. STRATEGIES OF MAKING AND UNMAKING 130

2. HEROIC THEORY 141

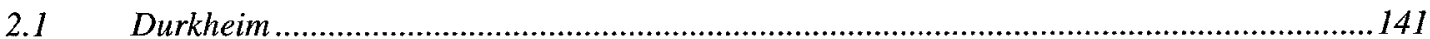

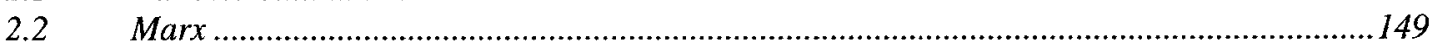

3. ANTI-HEROIC THEORY 161

3.1 Bauman

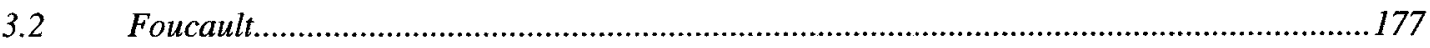

CHAPTER IV: CIVILIZING GENOCIDES $\quad 189$

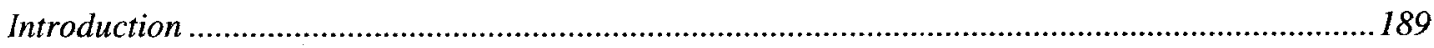

1. TELEOLOGICAL CIVILIZATION 190

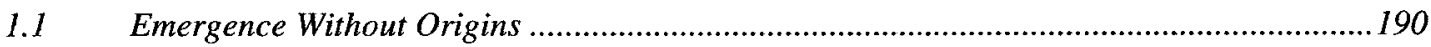

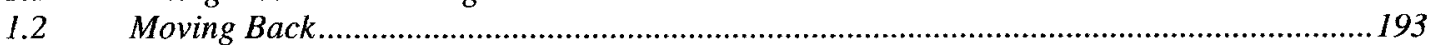

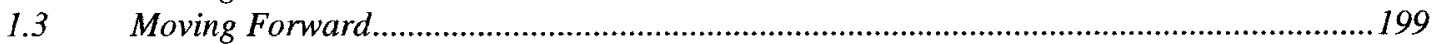

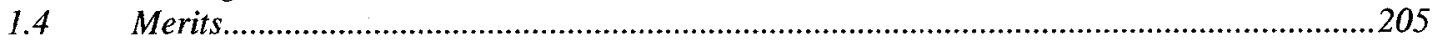

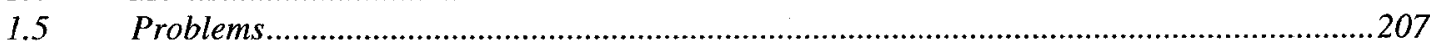


2. GIVILIZATION DECONSTRUCTED 213

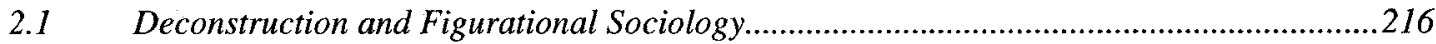

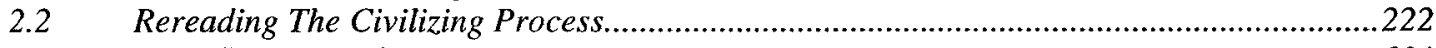

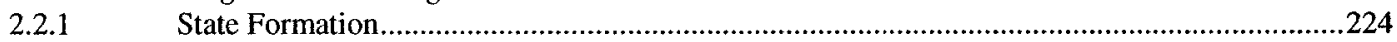

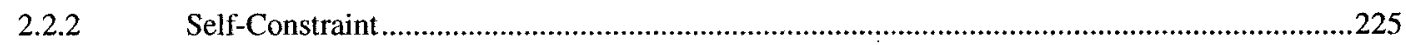

2.2.3 Différance ....................................................................................................................231

$2.3 \quad$ Displacing Civilization ......................................................................................................233

3. A FIGURATIONAL SOCIOLOGY OF GENOCIDE 239

3.1 The Barbarous Civilization of Europe and the World .....................................................239

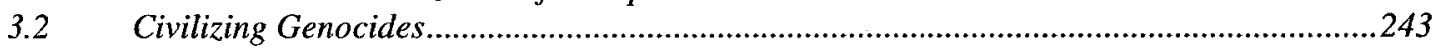

CHAPTER V: GENOCIDAL CIVILIZATION 248

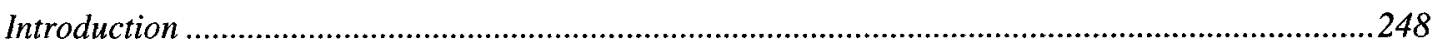

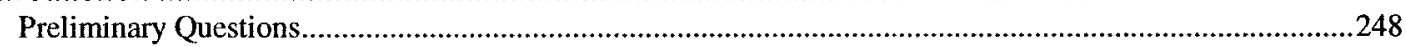

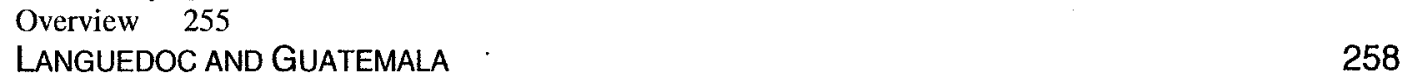

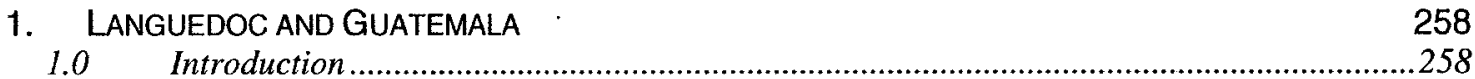

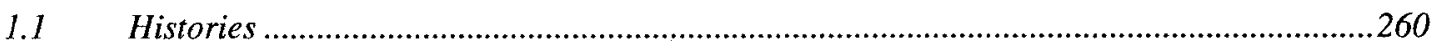

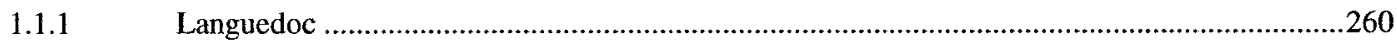

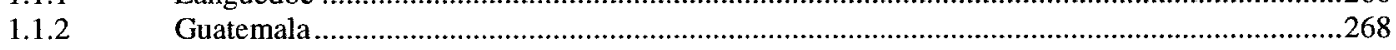

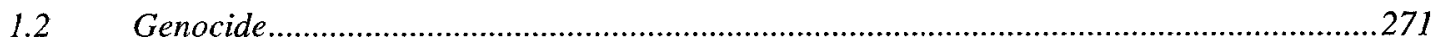

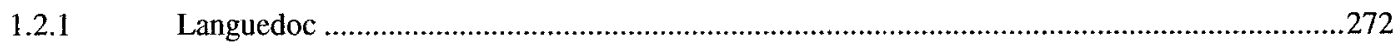

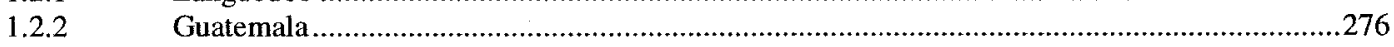

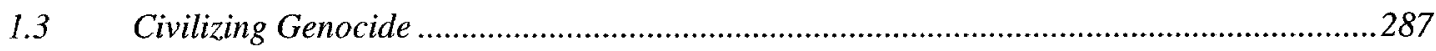

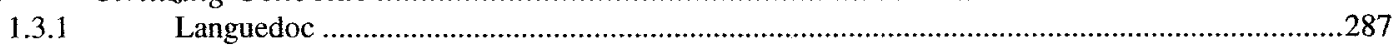

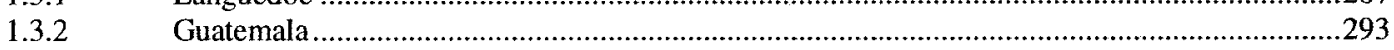

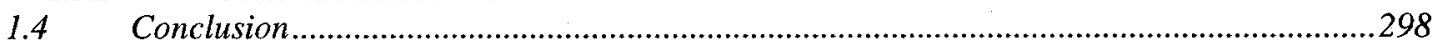

2. TASMANIA AND INDIA 299

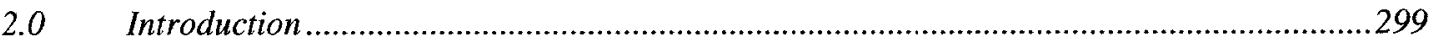

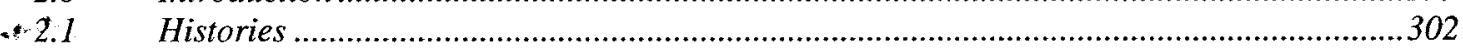

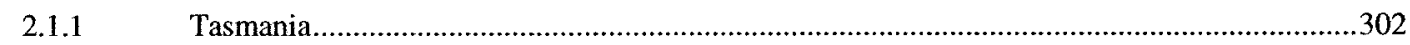

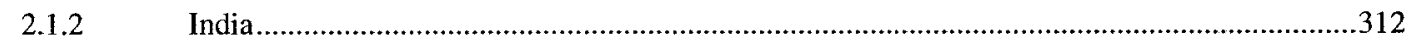

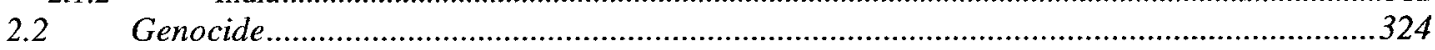

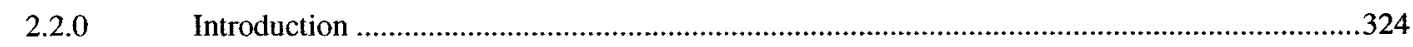

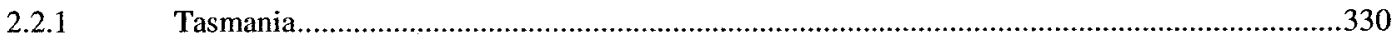

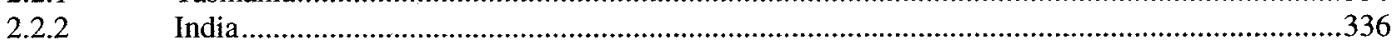

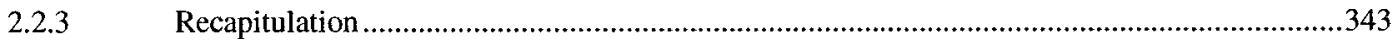

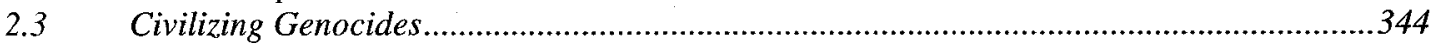

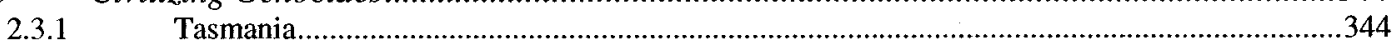

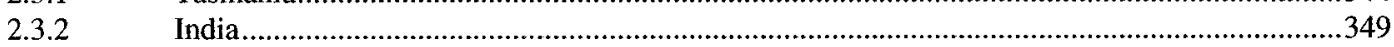

3. OTTOMAN EMPIRE AND RWANDA 353

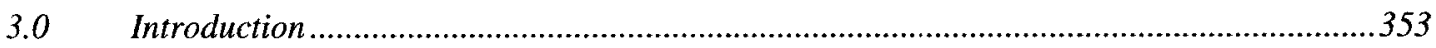

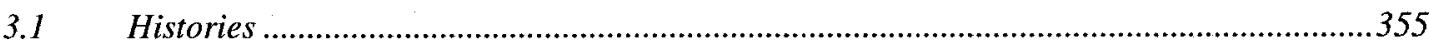

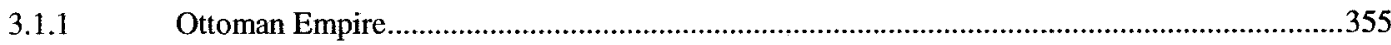

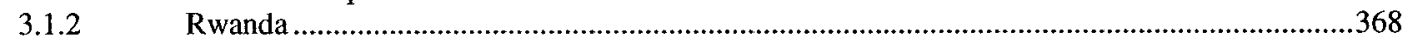

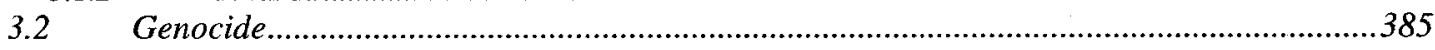

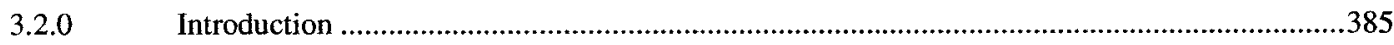

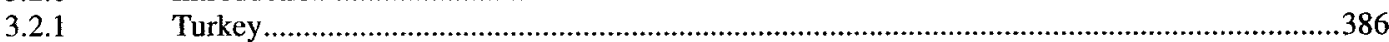

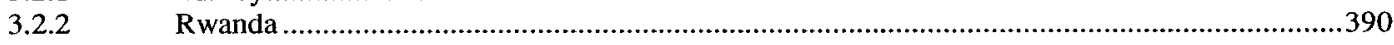

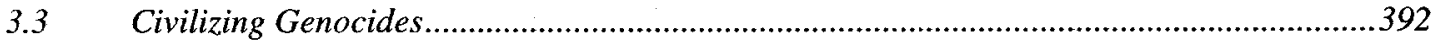

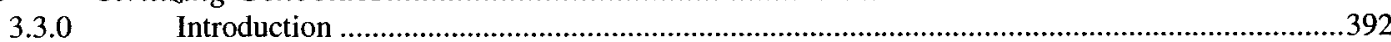

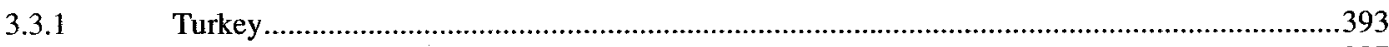

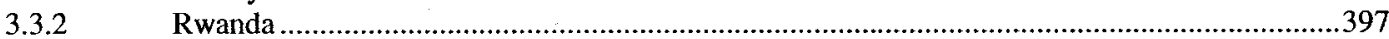


CHAPTER VI: INCONCLUSIONS

1. RECAPITULATION

2. IMPLICATIONS FOR UNDERSTANDING

407

3. IMPLICATIONS FOR PRAXIS

APPENDIX I: DEFINITIONS OF GENOCIDE

UNITED NATIONS

417

OTHER DEFINITIONS:

APPENDIX II: SOCIOLOGY AND GENOCIDE 


\section{Introduction}

In this dissertation I argue that genocide is an integral component of the expansion of Western civilization. More specifically, I claim that the dynamics of stateformation which have their historical roots in Europe of the late Middle Ages are intertwined with the production of a particular ensemble of habits and dispositions that constitute civilized subjectivity, that these two interdependent dynamics make up a single process which I call (European) barbarous civilization, and that in some circumstances barbarous civilization both produces and is produced through acts of genocide. Barbarous civilization involves a rearrangement of the operation of force or violence in social life, in which the means of military force are concentrated in territorial monopolies controlled by state institutions, and in which everyday life is increasingly characterized by a suspension or deferral of violence. Therefore, although civilization produces effects of the pacification of social life, it also produces an ever-expanding potential for violence organized in terms of collective identities. When local circumstances favour the realization of that potential, civilization produces genocide.

Chapters I-IV address theoretical questions, beginning with basic issues about how the study of genocide can be approached, and working up to a theoretical framework that explains how civilization produces genocide. Chapter V applies this framework to six historical examples of genocide in order to demonstrate both the feasibility and the utility of situating different genocides within a single long-term historical process. I describe my methodological approach in two instances: in the second part of Chapter I, which specifies three conceptual commitments that guide my theoretical inquiry, and in 
the introduction to Chapter $\mathrm{V}$, which describes the rationale informing my selection of historical examples and the approach that I have taken in my empirical research.

In the first part of Chapter I: The Metaphysics of Rupture, I situate my research within the field of genocide studies. A 'metaphysics of rupture' attributes to genocide qualities that separate it categorically from all other social phenomena, and thereby impedes a sociological understanding of genocide. I claim that most existing scholarship on the general phenomenon of genocide is marked by one of two forms of this metaphysics of rupture. The first form is the 'particular uniqueness' attributed to the Nazi genocide of European Jews, or the Shoah. Particular uniqueness claims that the Shoah is both analytically and morally incomparable with any other event in human history, either because it is different from all other genocides or because it is the only event that can properly be called genocide, and that even attempting to make comparisons with the Shoah by placing it in the same category as other events is both mistaken and immoral. Particular uniqueness relies on problematic empirical claims, and fairly overtly implies both a theological or mythical understanding of the Shoah and a partisan support for Israeli Jewish nationalism. It also makes a comparative sociology of genocide all but impossible. The Shoah must be situated firmly within the flow of human history and compared with other genocidal events if both it and genocide in general are to be understood.

More important than particular uniqueness, however, is the general uniqueness that is implicitly or inadvertently attributed to genocide as a type of social phenomenon. General uniqueness treats genocide as a breakdown of social life, which implies a radical 
disconnection between the particular phenomenon of genocide and general dynamics of social relations. Generalized uniqueness tends to be a feature of what can be described as the liberal tendency in genocide scholarship, which theorizes genocides in terms of the intentions and motives of agents, and privileges the state as the intending agent responsible for genocide. Generalized uniqueness is overcome by the post-liberal tendency in genocide scholarship, which theorizes genocide in terms of determining structural processes and social forces, without recourse to claims about agency or motive. Post-liberal approaches have their own limitations, however, especially their determinist structuralism which does away with subjectivity and agency altogether, leaving no conceptual space for anti-genocidal praxis. In the second part of the chapter, I describe the principles of method that will guide my theoretical investigation throughout Chapters II-IV, and the aims toward which the dissertation as a whole is oriented. The principles of method involve three conceptual commitments: first, to understanding genocide in terms of a continuous matrix of practices of power; second, to understanding power symmetrically - that is, to understanding the production of genocidal and non-genocidal social relations in the same theoretical terms; and third, to situating genocide in the context of a globalizing field of force relations. The aim of my dissertation is not to produce a closed theory of genocide, one that attempts to totalize the terms in which genocide can be spoken of. Rather, my aim is to produce an open-ended theory that problematizes genocide for social theorists, that makes genocide an obligatory point of passage for understanding social life in general. 
In Chapter II: Identifying Genocide, I address the question of what the term 'genocide' should be taken to mean. I begin with the claim that meanings or uses of words are necessarily bound up with the point of using them and the specific purposes to which they are directed. The point of my dissertation is to contribute to the development of social strategies for ending genocide or, in other words, to anti-genocidal praxis. The immediate purpose of my dissertation is to develop a figurational sociology of genocide. The term 'figuration' is a diachronic counterpart to the synchronic term 'structure'; it designates forms of pattern or order discernible in the dynamic motion of social interaction, as opposed to the static arrangement of social facts. Figurational sociology makes it possible to analyze genocide in terms of historical processes that unfold over the span of centuries; it also makes it possible to join the analysis of so-called 'macro' phenomena, such as the state, with that of so-called 'micro' phenomena, such as subjectivity, within the same sociological account of genocide. In the second part of the chapter, I address the definitional question more directly. I first provide an overview of the contests over what 'genocide' should mean, by discussing the term as it is defined in international law, in the writings of the person who first coined the term itself, and in the writings of contemporary genocide scholars. I go on to argue that 'genocide' is an essentially contested concept, such that definitional debates cannot be expected to lead to any singular, logically inexorable resolution. Given this essentially contested quality, the term 'genocide' can only be clarified by a historical rather than logical investigation; I provide this historical investigation by means of Foucaultian genealogy and Eliasian figurational sociology. These investigations show that the concept of genocide can be 
understood as a tactic for stigmatizing, and organizing resistance to, certain permutations of the use of state power to control the formation of collective identity, especially national identity. This tactic presumes a process of historical development; for 'genocide' to emerge as an intelligible concept, the relationship between state power and the formation of identity had to be developed in such a way as to make it both possible and problematic for a state to destroy a nation by force. In the third section of the chapter, I discuss the question of value-freedom in relation to the study of genocide. Genocide is an analytical concept with a normative point, which means that it cannot be reduced either to a pure expression of moral judgment, or to a purely protean and disinterested technique. I use the notion of metaphysics, derived in part from Comte via Elias, to critique explanations of genocide that commit the error of treating local and contingent moral standards as universal and ahistorical. I then show how the notion of 'metaphysics' itself involves a problematic ahistorical universalism. More useful to the resolution of this question is Elias's concepts of 'involvement' and 'detachment'. Because detachment, even for a scientist, is never absolute, it provides a way of saving 'genocide' from a collapse into pure normativity, without abandoning its normative point altogether. In the fourth and final section, I resolve the definitional question, not by proposing a new definition of my own, but by proposing eight rules that govern how I extend the boundaries of 'genocide' to include new events. That is, I conceive of 'genocide' as a network of events defined by relations of resemblance. Adding any given event to the network requires justifying its inclusion, not by reference to a fixed set of criteria, but by establishing a relation of resemblance or analogy between the new event 
and those already belonging to the network. I will apply this method in my discussion of historical examples in Chapter V.

In Chapter III: Anti-Heroic Sociology, I construct a bridge over what Helen Fein has called the 'theory gap' separating the study of genocide from general sociological theory. I begin by proposing the concepts of 'heroic' and 'anti-heroic' modes of theorizing social relations. Heroic modes are oriented to identity or sameness; they approach the study of social struggles by focusing on the protagonists (hence the term 'heroic') first, and relationships second or not at all; and they suggest an anti-genocidal praxis that is premised on the constitution of a collective subject capable of effective action ('strategies of making'). Despite their merits, heroic strategies suffer from this limitation: by theorizing genocide in terms of sameness, they only defer the problem of genocide without resolving it; the constitution of a collective subject may rationalize the violent obliteration of difference either within or outside that subject. Anti-heroic modes of theory are oriented to difference; they understand social struggles in terms of relations, and hence of strategies, tactics, and technologies; and they theorize anti-genocidal praxis in terms of the dismantling or radical reconfiguration of relations that produce genocide ('strategies of unmaking'). Because theoretical writing in the heroic mode is a wellestablished feature of genocide studies, I focus on elaborating and extending anti-heroic thinking. I engage with the theoretical writings of Durkheim, Marx, Bauman, and Foucault to investigate their heroic and anti-heroic potentials. Durkheimian theory can be read in an anti-heroic mode, to produce a radically relative sociology of morality capable of addressing the social production of genocidal moralities. However, such 
readings cannot incorporate a central element of Durkheim's thought, the existence of society as a functionally integrated organic whole; for Durkheim society is a collective subject whose functional requirements may not be compatible with the goals of antigenocidal praxis. Marxian theory provides a more closely balanced synthesis of heroic and anti-heroic modes of theory, by theorizing class in terms that refer simultaneously to forms of social relation and to social collectivities. However, the heroic mode tends to predominate in Marxian revolutionary praxis, in ways that also may conflict with the goals of anti-genocidal praxis. Bauman's analysis of the Nazi holocaust and its relation to modernity and Foucault's genealogical analysis of disciplinary power and bio-power both operate predominantly in the anti-heroic mode, and provide valuable models for situating genocide within a broader field of social relations. Bauman's insight is tempered, however, by his commitment to an ahistorical philosophy of morality, and by the ambiguity of his concept of 'modernity'. Foucault's analysis, on the other hand, is limited only by its historical specificity. Although disciplinary power and bio-power are undoubtedly important elements in the history of genocide, they do not suffice to explain that history or even to provide a general point of orientation on which to anchor that history. For such an anchor, I will turn to the figurational sociology of Norbert Elias.

In Chapter IV: Civilizing Genocides, I develop my main theoretical framework through the concepts of violent différance, barbarous civilization, and 'civilizing genocides'. These are produced through an interrogation and a deconstructive reading of Norbert Elias's theory of the civilizing process. In the first part of the chapter I describe and critique Elias's theory of the civilizing process. Elias's account begins by 
considering the historical development of the word 'civilization' and its antecedents 'civility' and 'courtesy'. Courtesy, civility, and civilization are produced by dynamics within the warrior class that dominated Europe during the feudal period. The reversal in the twelfth century CE of Europe's centrifugal breakup, and the expansion of the territorial domains of sovereign lords who could command the obedience of lesser knights, imposed, on a formerly autarkic class, relations of dependency that required them to regulate their own behaviour in previously unaccustomed ways. The development of the state's monopoly on the means of force, especially military force, produced a pacification of everyday life that in turn entailed the development of increasingly sophisticated mechanisms of self-constraint.

I critique this narrative for its essentialist account of civilization, in which social relations inhibit and transform natural human emotions and behaviours, and for its normative teleology that equates the progress of civilization with the progress of humanist values. In the second part of the chapter, to redeem Elias's valuable historical analysis from its grand-theoretical failings, I read The Civilizing Process deconstructively to show how the text, which superficially defines civilization in terms of pacification, also defines civilization in terms of violence and the advancement of civilization in terms of the intensification of violence. Through the advancement of the civilizing process, violence is not made to disappear altogether but is instead redistributed. Military force is concentrated in the state, where competition between states leads to the reproduction on an ever-expanding scale of the means of destruction. Direct interpersonal violence is transformed into an endlessly deferred threat of social violence. Failure to adhere to the 
codes of civilized conduct means, for members of the upper class, the possibility of expulsion from their class and hence the negation of their social existence. Civilization produces a singular privileged subject and, relative to that subject, a hierarchical network of exclusions that eventually permeates the whole of society. Subjects protect their social identity through techniques of civilized behaviour, techniques that defer violence while reproducing its possibility. In its most fully developed form, this circulating economy of deferred violence produces a relational scheme, a system of differentiations, that organizes the social identity of all members of society. Adapting Derrida's term for the production of meaning through a system of absences, I call this production of relations of identity-difference through the deferred violence of civilization violent différance.

Having produced a reading of Elias in which civilization is equated with violence, I displace the opposition between "civilization=pacification" and "civilization=violence" with the paradoxical term barbarous civilization, which suggests the simultaneous intensification of violence and production of zones of pacification within the same figuration. Finally, in the third part of the chapter I discuss civilizing genocides. These are genocides that are produced in the process of barbarous civilization. In civilizing genocides, forms of social relations and the technologies of power produced through barbarous civilization serve as enabling conditions for genocide, and genocide itself operates as a means for the further intensification and extension of barbarous civilization. In civilizing genocides, contingent developments in a local process of barbarous civilization produce a strategic situation in which genocide is rational for actors with the impunity to carry it out; in these cases, the deferred violence of social différance is 
instantiated through the production of a form of identity-difference that is located outside the universe of obligation, and the subsequent active negation of that identity.

In Chapter V: Genocidal Civilization, I apply this theoretical framework to a detailed historical analysis of six examples of genocide: the extermination of the Cathars of Languedoc between 1208 and $1321 \mathrm{CE}$; violence against civilians during the Guatemalan Civil War between 1962 and 1996, focusing especially on the period 19801983; the near-extermination of the Aboriginal Tasmanians between 1800 and 1876; megafamines in India under British colonial occupation in the years 1876-1879 and 18961902; the destruction by massacre, forced assimilation, and deportation, of the Armenian presence in the Ottoman Empire in the years 1915-1916; and the Rwandan genocide of April-July 1994. In the first part of this chapter I juxtapose the genocides in Languedoc and in Guatemala. I problematize definitions of 'genocide' which restrict it to the obliteration of national, ethnic, racial, and religious groups, showing how historically established uses of the concept destabilize this restriction and imply its extension to include the obliteration of groups defined by their political project. I also show how genocide, rather than entailing a simple breakdown of relations of civilization, can operate as a mechanism for the intensification and expansion of particular forms of civilization. In the second part of the chapter I juxtapose the genocides in Tasmania and India. Interrogating the notion of 'unintended genocide', I show how intentions can be understood in a non-logocentric manner, such that intentions can be inferred from the consequences of actions, and how intentions can operate without being present to the consciousness of the actors who produce them. I also show how genocide has been 
integral to the global expansion of civilization through colonialism. In the third section, I juxtapose the genocides in the Ottoman Empire and in Rwanda. Using these examples I show how the concept of 'genocide' is made more intelligible if the object of genocide is a figuration rather than a group of individuals. I also show how, even in the context of a partial breakdown of the institutions of civilization, genocide both relies on the capacities that civilization produces, and produces in turn a reassertion or re-intensification of civilization. In sum, I demonstrate my approach to the careful extension of the network of 'genocide', and show how genocide can be understood in positive rather than negative terms, as a result and a means of production rather than as a symptom of social breakdown.

In Chapter VI: Inconclusions, I describe the implications that my research has for the distinguishable but inseparable projects of understanding genocide and of engaging in anti-genocidal praxis. With regard to the project of understanding, my figurational analysis of genocide opens up further avenues of research into the historical relationships between identity and violence, between such diverse forms of identity as class, gender, 'race', and the history of conquest, domination, and annihilation bound up with the expansion and globalization of the European form of civilization. My analysis is only a starting-point, however. In particular, my historical investigations have focused primarily on the relations between states and subjects. To explain more fully the relationship between civilization and genocide, this analysis must be supplemented with an examination of forms of identity and practices of identification-differentiation that are not centered specifically on the state: with gender, class, race, and so on. It also remains 
to be seen, through careful empirical comparison, whether the figurational dynamics that I have theorized in relation to European barbarous civilization are unique to that figuration or may also be seen to operate in other cultural contexts, what differences and similarities pertain, and how non-European figurations have interacted with Europe's barbarous civilization of the world. Regarding the project of anti-genocidal praxis, my analysis points out the limitations of relying exclusively on state-centric tactics, including armed humanitarian intervention, as a sufficient solution to the problem of genocide. Rather, ending genocide will involve the unmaking of the figurational dynamics that bind identity-difference to the social distribution of violence, military or otherwise. In this respect, the struggle to end genocide is bound up in a wider arena and is involved in struggles to unmake relations of domination generally, even in contexts where genocide is not an immediate problem. Finally, my analysis suggests a rethinking of the relationship between states and individuals; more broadly, it suggests the rationality of a disinvestment in forms of identity that entail the negation of difference. The construction of non-genocidal social relations involves the abandonment of certain defining components of civilization, the construction of a world after civilization. 


\section{Chapter I: The Metaphysics of Rupture}

\section{INTRODUCTION}

In this dissertation I construct a general theoretical framework for explaining genocide, one that situates the particular study of genocide firmly in the context of a general analytics of social relations. In this chapter, therefore, I will accomplish two objectives: first, I will provide a review of the theoretical literature on genocide, so as to situate my particular contribution within the field of genocide studies as a whole; and second, I will provide an account of the methodological approach via which I have produced that contribution. In the first, and larger, section of the chapter I sort the field of genocide research into three categories: particularist approaches, which privilege the Nazi genocide of European Jews (the Churban or Shoah) as a categorically unique event in human history; liberal approaches, which explain genocide in terms of the intentions and agency of genocidal subjects, usually states; and post-liberal approaches, which explain genocide in terms of determining structural processes and social forces. I criticize the limitations of particularist and liberal approaches in terms of the relation between particular and general uniqueness. 'Particular uniqueness' is my term for the intellectual tactic of affirming the categorical uniqueness of the Shoah. Particular uniqueness mitigates against the very possibility of understanding 'genocide' as a general phenomenon; I will indicate a number of reasons why it cannot be taken seriously as a point of departure for a sociology of genocide. Despite these limitations, however, particular uniqueness is an important point of reference because the pernicious effects of its metaphysics of rupture are inadvertently reproduced in liberal scholarship through a 
tacit and perhaps unintended tendency to treat genocide as a unique type of social phenomenon, essentially discontinuous with and separate from non-genocidal social relations. Generalized uniqueness is manifest in the attempts of scholars to theorize genocide without recourse to a general analytics of social relations, and hence to reproduce what Helen Fein has called the 'theory gap' between genocide studies and social theory. My own approach to theorizing genocide has much in common with postliberal strategies, but differs from them in rejecting a deterministic account of social dynamics; I understand genocide in terms of the historical production of strategic situations rather than in terms of cause-and-effect mechanisms. In the second and shorter part of the chapter I indicate several basic conceptual commitments that guide my own research and describe the goals of my research.

\section{Genocide Studies}

\subsection{Particularism and Particular UniQueness}

'Genocide studies' ${ }^{1}$ can be understood broadly as including all research into events that have been or can be considered to be instances of genocide, whether or not the actual concept of 'genocide' is foregrounded, or more narrowly as research that uses the concept 'genocide' to define its primary object of interrogation. I take the latter approach. Not all studies of particular genocides are aimed at elucidating the general

1 Single quotation marks are always used to indicate when a word is being mentioned rather than used, i.e. where it is the word itself that is the object under consideration rather than the phenomenon to which the word refers: 'the Holocaust' as a concept or category vs. the Holocaust as a historical event. Single quotation marks in this dissertation, except where they appear as part of a quoted passage, are never used as scare quotes or shudder quotes to indicate ironic or disdainful usage. 
phenomenon of genocide; much research on the Nazi holocaust, for example, is mostly or entirely concerned only with explaining the Holocaust. I have mostly side-stepped the latter kind of research by choosing to focus primarily on works that make theoretical claims about genocide broadly conceived. In connection with this interest, however, one assemblage of writings stands out for taking a peculiar position: that of invoking the general category of 'genocide' only in order to minimize its generality by associating it exclusively with one particular event, the $\mathrm{Shoah}^{2}$, or else to subordinate it in importance to the Shoah. I have chosen to refer to this assemblage as 'particularism' and to its defining theoretical claim as 'particular uniqueness'.

Particular uniqueness, then, is the assertion that the Nazi genocide of European Jewry (the Shoah ${ }^{3}$ ) was a historically unique event, such that no other events belong in the same category with it or are even comparable to it. This uniqueness is not only empirical but moral, so that ultimately any attempt to compare the Shoah with other events or to situate it in a broader category such as 'genocide' is a moral offense, or even a covert form of Holocaust denial - "the equivalent of David Duke without his robes", as Deborah Lipstadt [1993: 215] puts it. A more nuanced position is taken by Yehuda Bauer, who distinguishes between 'genocide' as defined by the UNGC and 'Holocaust'

2 The Hebrew word 'Shoah' (also spelled "Sho' ah" or "ha-Sho'ah", meaning literally 'holocaust' in the sense of a consuming fire) refers specifically to the genocide of European Jews undertaken by the Nazis and their collaborators (it is also called the 'Khurbn' or 'Churban').

It is important to recognize that the Nazi holocaust involved not one but several genocides, of which the largest and most systematic were those against Jews and against Gypsies (Romani and Sinti peoples); other victims included Communists, homosexuals, and disabled persons. The expression 'the Holocaust' is fraught with confusion, inasmuch as it is often used synonymously with Shoah in order to equate the two and even to deny that other groups suffered genocide [Finkelstein 2000: 3]. In order to be precise I will use 'Nazi holocaust' to refer to all Naziperpetrated genocides taken together, and I will follow Ian Hancock's [2001: 88] use of ethnically 
understood as a category to which the Shoah uniquely belongs [Bauer 1978: 35-38; 2001:

$\left.10-12^{4}\right]$. Less moderate and more systematic than Bauer's is the particularism of Steven

Katz, whose massive The Holocaust in Historical Context (with Volume I published in

1994 and Volumes II and III forthcoming in 2005) is premised on what he calls the

"phenomenological" uniqueness of the Shoah:

the Holocaust is phenomenologically unique by virtue of the fact that never before has a state set out, as a matter of intentional principle and actualized policy, to annihilate physically every man, woman, and child belonging to a specific people. A close study of the relevant comparative historical data [shows] that only in the case of the Jews under the Third Reich was such all-inclusive, noncompromising, unmitigated murder intended. [Katz 2001: 49].

Claims to uniqueness tend to reduce to this claim of the singular, unprecedented, and unparalleled intentionality; Bauer refers to it, as do Lucy Dawidowicz [1981: 11, 14], Deborah Lipstadt [1993; 213], and Michael Marrus [1987: 24] $]^{5}$ Katz acknowledges that the uniqueness of the Shoah cannot be maintained on grounds of quantitative scale; neither the absolute number of Jews killed nor the proportion of all European Jews killed are without equal among mass murders in history [Katz 1983: 296; 1994: 65, 580]. Uniqueness is sometimes affirmed on other grounds, such as the unique religious significance of Christian anti-Semitism [Rubenstein 2001], but as claims about a concrete

specific terminology wherever such exists and is applicable: Shoah for the Nazi genocide of Jews, Porrajmos for the Nazi genocide of Gypsies, and so on. However, the sense of nuance occasionally disappears from Bauer's arguments, as when he conflates Nazi intentions with their acts, e.g.: "Total physical annihilation I prefer to call Holocaust, and that of course means that whereas that is what happened to Jews - and the fact that a percentage of Jews survived in Europe was due not to any lack of desire on the part of the Nazis to kill them, but their failure to catch all of them - it could, mutatis mutandis, happen to others as well." [Bauer 1991: 40, emphasis added].

5 For an extensive listing of authors who maintain the uniqueness of the Shoah, and of authors who deny such uniqueness, see Churchill 1998: 77 n 24. 
historical process, the significance of Christian anti-Semitism tends to reduce to a form of the claim about unique intentionality.

For all its faults, particular uniqueness at least raises a difficult and important issue for genocide scholars: that of responsibility for the political and moral implications of practices of categorization. Particularists express concern that the use of the words 'genocide' or 'holocaust' to refer to events other than the Shoah could lead to the dilution of their meaning. Their case is that, without a commitment to uniqueness, anyone is free to apply the terms 'genocide' and even 'holocaust' to war crimes in general (e.g. the Dresden bombing or the Mai Lai massacre), to ethnic discrimination in general (e.g. racism in the United States), or even to medical procedures (e.g. legalized abortion as a holocaust of the unborn) [Dawidowicz 1981: 17-18]. In this scenario, terms formerly used to signify Auschwitz and Treblinka become "frequently applied to social ills and human sufferings of diverse kinds" [Rosenfeld 1997: $122^{6}$ ], in the process losing their unique moral valence and becoming only vague terms of opprobrium. On the other hand, particularists fear that to place the Shoah in the same category as other mass murders and state atrocities (or to deny that, while belonging to this category it also belongs to another, more restrictive category in which it stands alone) is to naturalize the Shoah and even to legitimate it. To allege, for example, that the United States government, in its campaign of violence against Native Americans during its wars of territorial expansion and subsequently, committed "crimes as monumental as those of the Nazis", is to "justify 
a reverse claim: since the United States committed crimes as evil as those of Nazi Germany, then Nazi Germany committed no worse crimes than other states and was not unique among nations as a perpetrator of evil deeds" [Dawidowicz 1981: 18]. It is to say of the Nazi holocaust, as Christopher Hitchens has said of the genocide of Native Americans, "it does happen to be the way that history is made, and to complain about it is as empty as complaint about climatic, geological or tectonic shift" [Hitchens 1992: 422] ${ }^{7}$.

This line of argument makes clear the first limitation of particular uniqueness: that it entails a commitment to downplaying the moral significance of all atrocities other than the Shoah. Equating the Shoah with, for example, the extermination of Native Americans has the effect of naturalizing the Shoah only as long as colonial genocide itself is naturalized. Particular uniqueness therefore presupposes a moral parochialism which affirms in principle that whatever shock and horror the Shoah has provoked in us should not be allowed to amplify our horror at other, similar events, nor to provoke a critical reevaluation of social institutions that have been complicit in other genocides. It also presupposes an overt Eurocentrism, as when Lipstadt claims:

The Khmer Rouge's massacre of a million of their fellow Cambodians [...] was barbaric. But what they did was quite different from the Nazis' annihilation of the Jews, which was "a gratuitous act carried out by a prosperous, advanced, industrial nation at the height of its power". [Lipstadt 1993: 212, with quotation from Evans 1989: 87] ${ }^{8}$

7 Or again, "we should recognize that to condemn every aggressive military, religious, or economic action in the past is to question some of the fundaments of Western society, past and present. If everything associated with mercantilism, capitalism, evangelical religion, and armed force is beyond the moral pale, we may find it difficult, if not impossible, to approach our past - or the histories of most of the world's culture - with the requisite empathy, understanding, and disinterestedness." [Axtell 1992: 232]

8 It can also call upon more specific patriotic loyalties, as when Dawidowicz rebuts claims that the atomic bombings of Hiroshima and Nagasaki constituted genocide by saying that such claims "bespeak a vicious anti-Americanism. Their purpose is to depict America as Amerika, a Nazified 
It is with substantial justification, therefore, that Ward Churchill has accused

particularists (his term is 'exclusivists') of being genocide deniers ${ }^{9}$ [1998: $31 \mathrm{ff}$.]

Certainly, Katz for one has put considerable energy into arguing against claims that peoples other than Jews - including Gypsies and homosexuals under the Nazis, Turkish Armenians, American Indians in general, the Pequot in particular, and even Bosnian and Rwandan minorities - have ever suffered genocide [see Katz 1988: 216; 1994: 514-524; 2001: 62-67; 1994: $20^{10} ; 1991$; McMillan 1994: A13], and has done so on questionable evidentiary grounds ${ }^{11}$. Even the narrow claim that the Shoah is unique for being the only case in which a state has "set out, as a matter of intentional principle and actualized policy, to annihilate physically every man, woman, and child belonging to a specific people"; for example, as Hancock [2001] demonstrates, Nazi policies towards Gypsies were just as exterminatory as those towards Jews. The net effect of particular uniqueness, in both moral and empirical terms, is to reproduce what Chalk and Jonassohn [1990: 5-8] have called collective denial regarding genocides other than the Shoah and regarding the general significance of genocide in human history.

United States, heir as it were to the unredeemed evil which the Nazis represented" [Dawidowicz 1981: 17].

9 Interestingly, Churchill's position, and Stannard's [2001], neatly reverses the claims of Lipstadt, Katz, Dawidowicz, and other particularists by claiming that particular uniqueness is both factually incorrect and morally offensive. Worth mentioning is Katz's startling claim that "the depopulation of the New World, for all its death and terror, was largely an unintended tragedy, a tragedy that occurred despite the sincere and indisputable desire of the Europeans to keep the Indian population alive". Churchill claims that Katz "has been known to rely on the work of notorious Turkish deniers, even when they've been exposed as 'full-blown revisionists' and more accurate sources are readily available" [Churchill 1998: 33n.] 
The other major problem with particular uniqueness is that it explicitly refuses to engage with the problems of either a general explanation for genocide or a general solution to it. Dirk Moses has said of Bauer's version of particularism:

He appears to confuse two, distinct tasks: on the one hand, reflecting specifically on the burden of history and identity for post-Holocaust Jewry; on the other, explaining generally how and why genocides occur. By collapsing the latter into the former, he ends up at times proffering identity politics in the name of disinterested scholarship. [Moses 2002: 15]

This summation applies to particular uniqueness as such, for its point is to situate the Shoah at the centre of Jewish identity, thereby to grant Jews a unique moral status among peoples of the world, and, for some, to lend support to ethnically exclusive Jewish nationalism in the state of Israel. So Bauer, for example, claims that "the denial of the Holocaust as a specifically Jewish tragedy is therefore connected with the dangers of anti-Semitism" [Bauer 1980: 43] and that "all these universalizing attempts [regarding the Holocaust] seem to me to be, on the Jewish side, efforts by their authors to escape their Jewishness" [1998: 17]. The uniqueness of the Shoah is a source of "moral capital" for "the Jewish people", capital which is threatened with "plunder" by those who wish to give it a more general significance [Alexander 1980, 1994; also Bauer 1980]. And if this moral capital belongs to the Jewish people, its proper executor is the State of Israel: "the heart of every authentic response to the Holocaust - religious and secular, Jewish and non-Jewish - is a commitment to the autonomy and security of the State of Israel" [Fackenheim 1977: $212^{12}$ ]. The uniqueness of the Shoah is sacred: "whoever dissolves 
the starkly unique tragedy of the Holocaust (whether in terms psychological, sociological, historical, moral, philosophical, or theological) sooner or later blasphemes against God, man, and in any case against the Truth." [Fackenheim 1978: ix]; and this sacredness extends to include the Jewish identity and the Jewish state as well : "Those few who have continued to demur from the Zionist project even in the face of the crematoria [...] have sinned against both God and man in what can only be construed as the arrogant blindness of their own confused self-righteousness." [Katz 1992: 290]. These claims turn away from, and at times expressly forbid, any attempt to develop an effective political response the problem of genocide in general. To this end they also forbid any comparative scholarship that aims to understand or explain genocide ${ }^{13}$. In sum, particular uniqueness aims to make a sociology of genocide impossible.

\subsection{LIBERAL GENOCIDE STUDIES AND GENERALIZED UNIQUENESS}

If that were all there was to say about particular uniqueness, then there would not be much point in engaging with it at all. The metaphysics of rupture, by which particular uniqueness separates the Shoah from all other historical events, negates the intelligibility not only of the Shoah but of all genocides. However, particular uniqueness is important as a point of reference because a similar metaphysics of rupture is tacitly or inadvertently produced in much comparative genocide research. Dirk Moses [2002: 20-23] introduces the terms 'liberal' and 'post-liberal' to classify research into genocides of indigenous

Himmler's SS silences their conceptual, principled, but abstract representations." [Katz 1992: 289]. 
peoples, and by extension they can be applied to genocide studies as a whole. Liberals theorize genocide in terms of agency and intentionality, where intent is reduced to motive. Consequently, liberals "are inclined to typologize genocides according to motive, distinguishing for example between 'developmental' or 'utilitarian' genocides of indigenous peoples and 'ideological' genocides of scapegoated or hostage groups". In keeping with this assumption of a unitary agent with genocidal intentions, liberals also "insist on the primary role of the state as the genocidal perpetrator". Whereas liberals tend to valorize Western civilization and treat genocide as a form of deviance, postliberals treat genocide as the structurally determined product of the very expansion of that civilization, particularly by equating colonialism with genocide. I contend that liberal attempts to explain genocide are hampered by the unrecognized operation of generalized uniqueness: the assumption that genocide as a whole is categorically unique, fundamentally unlike and disconnected from all other social phenomena.

I have purposefully defined 'genocide studies' to be interdisciplinary in scope. A sociologist who wants to understand genocide cannot confine her reading to works by other sociologists but must engage with historians, anthropologists, political scientists, and philosophers. But if we consider only sociologists for a moment, one recurring motif in their work is that of the (perceived) marginality of their subject matter to their discipline. Helen Fein describes this situation as "the sociological theory gap", saying No stream of sociology or major theorist since 1945 has considered genocide focally, either to explain genocide or to consider its implications its comparative discussion of historical cases, saying that this constitutes "a very real problem" because it places the Shoah in a category with other historical events [Katz 1994: 129ff.] 
for theories of the state, of development, and of community and society. [Fein 1993: 32]

Zygmunt Bauman observes that compared with the "awesome amount of work accomplished" by historians and theologians, "the contributions of professional sociologists to Holocaust studies seems marginal and negligible" [Bauman 1991: 3]. Nor, it would seem, has the situation improved much after the millennium:

While there have been a few noteworthy exceptions to this omission, genocide has remained largely outside the mainstream of contemporary social science. This is surprising, to say the least. [Alvarez 2001: 1]

Consistently, authors who comment on the sociological theory gap treat it not merely as the normal concomitant of a rich vein of research still waiting to be tapped, but as a serious problem: genocide seems an intrinsically and self-evidently important social phenomenon, so why has it not featured more prominently in sociological discourse? Neglect of genocide must imply something disturbing about sociology itself. So Bauman argues that

the Holocaust has more to say about the state of sociology than sociology in its present shape is able to add to our knowledge of the Holocaust. This alarming fact has not yet been faced (much less responded to) by sociologists. [Bauman 1991: 3]

For Bauman, the Holocaust reveals sociology's naively Durkheimian faith in society as a moralizing force, and its modernist commitment to social engineering as the solution to the problem of violence. Other authors raise a more immediate problem: sociology's complicity in processes of collective denial of individual genocides, and of the historical prevalence and significance of genocide in general [Chalk and Jonassohn 1990: 5-8]. Scholarly silence about genocide then takes on moral and political significance; it can be 
situated on a continuum with the active obfuscations of Holocaust deniers. Sociological neglect of genocide is not equivalent to active denial, either morally or epistemologically, but its effects tend in the same direction: to "minimize the importance and significance of genocide" and to foster "a diminished sense of concern and urgency, thus facilitating its perpetration" [Alvarez 2001: 2-3].

This denial could spring from any number of sources: the residual triumphalism of 'history written by the victors ${ }^{14}$; a psychological reluctance to confront something as painful as genocide ('denial' in a Freudian sense); or a more insidious affinity between genocide and 'normal' political rationality. Whatever its origins, though, sociological neglect of genocide is taken to be symptomatic of a more general reticence about state violence:

There is a similar paucity of social scientists who consider state violence, terror and repression or the development of human rights: social science most often glosses over blood and victims in antiseptic abstraction, masking the nature of the state .... [Fein 1993: 32]

Fein's comment suggests that there is more at stake than just a 'well-balanced' picture of the state or of modern societies, and more is required of sociologists than simply adding on analyses of genocide and state violence to existing general social theory. At issue is the importance of violence to the constitution of social relations. With polymorphous perversity, social theorists have in various moments taken as their defining object of study a motley assortment of objects, each irreducible to the other: society, capitalism,

14 Chalk and Jonassohn explain this denial as the residue of conventional historical practice, of histories written by the winners and news made by rulers. In their brief account, this hegemony of collective denial has been broken by "the shocks of the twentieth century" in which "the gap between practice and ideals simply became too great to support the intellectual foundations of 
modernity, civilization, everyday life, patriarchy, and so on. But with respect to each of these objects one can ask a common set of questions: in its historical formation, has violence been occasional or pervasive? on a small or large scale? have the consequences of violence been transitory, or lasting? marginal, or constitutive? negative and destructive, or formative and productive? To the extent that sociology has assumed the former where historical investigation reveals the latter, it stands revealed as fundamentally misconceived. "Sociology is denied the status of a fundamental applied science ... because it rarely comes to grips with issues of life and death" [Horowitz 1982: 3].

However, if the marginality of genocide studies in sociology says something about that discipline, the persistence of the theory gap says something about genocide studies. For example, after lamenting the theory gap, Fein quickly abandons the challenge of bridging this gap, saying "not much can be expected from mainstream sociology, whether based on functionalism, conflict theories, Marxism, or symbolic interaction, to judge by past performance. We need specific and historically-grounded explanations to understand why leaders and social elites [...] elect genocide and terror" [1993: 34]. Fein observes that genocide is facilitated when the victim is placed outside the perpetrator's 'universe of obligation', a concept she has taken from Durkheim's Division of Labour In Society [Fein 1979: 169; 1993: 36], but she does not engage with Durkheim's broader theoretical project. Nor does she interrogate the historical connection between Durkheimian theory and the Turkish genocide of the Armenians, although doing so 
would have provided interesting insights on the contributions social theory can make to genocidal violence ${ }^{15}$. Similar tensions between the urge to make theoretical connections and the imperative of generalized uniqueness can be seen in the work of Chalk and Jonassohn, who conceive of genocide as essentially a crime of state and recognize that "the performance of a genocide has always required a high degree of centralized authority and quasi-bureaucratic organization" [1990: 28], but who do not then engage with theories of the state or of bureaucracy. Instead, The History and Sociology of Genocide is mostly a compendium of individual case studies, accompanied by commentary based on their typological schema (see p.30 below); the implication is that theory will be developed in the future by sheer inspection of accumulated case histories. To the extent that they do go beyond this method, they tend to resort to psychological reductionism: "It seems that mass killing is extremely difficult for ordinary people to carry out; it requires the recruitment of pathological individuals and criminals." [Chalk and Jonassohn 1990: 28]. Reluctance to situate genocide within larger social processes is also manifested in limited reception afforded to work that does do so. For example, Zygmunt Bauman's Modernity and the Holocaust (first published in 1989) attempts in an exemplary fashion to bridge Fein's theory gap: his argument that the Holocaust is a characteristic product of modernity involves a properly sociological account of the Final Solution, free of psychological reduction; Bauman articulates a radical critique of 
bureaucratic rationality and opens new avenues for a sociology of morality. Yet Bauman is mentioned only in passing by Fein [1993], and not at all by Chalk and Jonassohn [1990] or by Jonassohn and Björnson [1998] (to cite three works that aim at comprehensiveness). Investigating these connections would further the stated research objectives of genocide scholars, but a de facto commitment to generalized uniqueness prevents the comparative study of genocide from realizing its own goals.

Generalized uniqueness mandates a preoccupation with fixing a precise definition for 'genocide'. This is because uniqueness requires discreteness: to be unique, genocide must be clearly delineable against the background of other violences. The demand for definitional precision can take at least three forms: scientifically, that to have a coherent object of study one must be able to determine what is genocide and what is not; politically, that if genocide is to be punishable through international law, then one must be able to specify objectively who has committed genocide and who has not; morally, that genocide carries a unique stigma and one must be careful not to mitigate the force of that stigma through indiscriminate application. And in accordance with the needs of generalized uniqueness, one finds both liberal and post-liberal genocide studies intensely preoccupied with definitions. There are definitions that more or less accept the UNGC formulation [e.g. Fein 1979, 1984*; Porter 1982*]; definitions that supplement the UNGC with variants like 'genocidal massacre' [Kuper 1981], 'politicide' [Harff and Gurr 1988*], or 'democide' [Rummel 1994"]; definitions that broaden the UNGC definition by adding to the list of groups whose attempted extermination may properly constitute 
genocide: where the UNGC lists "national, ethnical, racial, or religious group[s]", Tal [1979] adds political and social groups generally; Legters [1984: 65] adds classes;

Hannum and Hawk [1986] allow persons belonging to the same ethnicity as the perpetrators; and Chalk and Jonassohn [1990* $]$ argue that the victim group need only exist in the imagination of the perpetrators. While all these definitions assume the need for a specific intent to destroy a group or, more narrowly still, an intent to kill members of a group because they are members of that group - to kill Jews because they are Jews, and so on - some definitions broaden the notion of 'intent': by adding degrees of genocide comparable to degrees of murder in U.S. criminal law [Charny $1994^{*}: 85$; Churchill $\left.1998^{*}: 434\right]$; or by requiring only an intent to commit actions that have the effect of destroying a group, either foreseeably [Reisman and Norchi 1988; Sartre $1968^{16}$; Huttenbach 1988] or even regardless of foreseeability [Thompson and Quets 1987: 11; $1990^{*}: 246-248$; Barta $\left.1987^{*}: 238-240\right]$. The definition espoused by Thompson and Quets, in which 'genocide' is simply "the destruction of a group by purposive action," could include genocide as the outcome of "accidents, ecological and environmental damage" [Fein 1993: 17], foreshadowing the claim of Mike Davis that En Niño famines in European colonial territories, brought on by the forcible commodification of

Citations marked with an asterisk refer to definitions that are quoted at greater length in Appendix I: Definitions of Genocide, below.

16 "The genocidal intent is implicit in the facts. It is necessarily premeditated. Perhaps in bygone times, in the midst of tribal wars, acts of genocide were perpetrated on the spur of the moment in fits of passion. But the anti-guerilla genocide which our times have produced requires organization, military bases, a structure of accomplices, budget appropriations. Therefore, its authors must meditate and plan out their act. Does this mean that they are thoroughly conscious of their intentions? It is impossible to decide. We would have to plumb the depths of their consciences - and the Puritan bad faith of Americans works wonders." [Sartre 1968: 79, emphasis added] Interestingly enough, Reisman and Norchi are discussing the Soviet war in Afghanistan; 
agriculture, were "the exact moral equivalents" of the bombings of Hiroshima, Nagasaki, and Dresden [Davis 2001: 22]. Tony Barta goes furthest in eliminating intention from the definition of 'genocide', proposing the notion of a 'relationship of genocide', a relationship which perpetrators (e.g. white Australians) may enact for the most part unwittingly. Most of the above definitions specify that genocide is committed by states, or else accept a statist distinction between legitimate and illegitimate practices of war. In keeping with the needs of generalized uniqueness, most of the above definitions try to delineate exactly the boundaries of 'genocide', to foreclose the possibility of ambiguous or indeterminate cases, to construct a semantic universe in which every historical event either is genocide or is not. And yet for any definition, ambiguous borderline cases are easy to produce. Such ambiguity can provide avenues of scientific exploration: starting from genocide, one could follow the actors through networks of relations that take us into familiar settings from a new angle, opening the black boxes in which violence and subjectivity are bundled together. There is a history of the present waiting to be told from the vantage point of the victims of genocide. Yet comparative genocide scholars still have unbounded enthusiasm for an unrealizable project: for the "quest for a fundamental formula $[\ldots]$ as to what essentially lies at the heart of genocide and the genocidal" [Huttenbach 2001: 8$]^{17}$.

This preoccupation with essences leads liberal scholars to investigate genocide by producing typologies. If genocide has a unitary fixed essence then differences among

Sartre is discussing the American war in Vietnam - similar events that have prompted similar extensions of the notion of 'genocide'.

17 I discuss the problems of defining 'genocide' in greater detail in Chapter 2 below. 
actual genocides are explicable as typological variations on that essence; concentrating study on specific types would then help isolate causal factors more efficiently. And so, for example, Chalk and Jonassohn propose four types of genocide "according to their motive:

(1) to eliminate a real or potential threat;

(2) to spread terror among real or potential enemies;

(3) to acquire economic wealth; or

(4) to implement a belief, theory, or an ideology." [1990: 29]

Typologies proposed by Fein [1984: 8-22] and by Smith [1987: 24-29] are similar to that of Chalk and Jonassohn, especially in the inclusion of 'ideological' as a type of which the Nazi holocaust and the Armenian genocide are exemplars. Typing genocides according to the apparent intentions of the perpetrators tends to reify the stated rationalizations with which perpetrators of genocide seek to legitimate their actions, while failing to inquire into the broader political projects within which genocide is situated. In Weberian terms, one could say that although explicit statements form a real component of any actual genocide understood as a meaningful social event, willingness to accept them at face value constitutes a failure of verstehen. For example, the Athenian genocide of Melos was implemented to terrorize potential enemies or neutrals, in a war in which Athens had put its own sovereignty at risk, and in which the stakes included great economic wealth. Does this make it a genocide of type 1,2, or 3 within Chalk and Jonassohn's typology? To classify it as Type 2 would abstract it from its context in the Peloponnesian war and the realization by Athens, through that war, of regional economic hegemony. Indeed, it is hard to imagine a situation in which the spreading of terror constitutes an end in itself and not part of some larger strategic project. But apart from simply being superficial, this 
typology has disturbing political connotations. For example, the Shoah is considered the paradigmatic ideological genocide. However, within the Nazi imaginary the Final Solution aimed at eliminating a racial strain that constituted a real threat to the Third Reich and humanity as a whole; furthermore, the acquisition of economic wealth was one of its presumed beneficial consequences and formed a significant part of its actual practice. For all social actors, beliefs, theories, and ideologies work to define what constitutes an actual or potential threat and who is an actual or potential enemy; ideologies also bear more than an incidental connection to structures of political economy: the notion of 'ideological genocide' begs a theory of ideology. But what is disturbing about this typology is the assumed distinction between the ideological and the real, the presumption that social scientists are unproblematically equipped to distinguish between the two, and the implication that while some threats or enemies may be ideological figments, others are real (which further implies a distinction between irrational and rational genocides). It posits a distinction between real political structures on the one hand and ideologies, beliefs, ideas on the other. Not only is this distinction arbitrary [Powell 2001], but it accepts uncritically a metaphysics with which the State project is routinely naturalized.

Within the framework of generalized uniqueness, social science's contribution to effective anti-genocidal action most readily takes the form of a search for the unique predictors of genocide. Any unique and therefore delineable phenomenon, seen against the background of a naturalized state system, must appear as a breakdown or aberration of that system: as a pathology. A unique pathology implies a unique pathogen, one 
whose presence could be detected amidst the system's natural elements. If that pathogen could be detected in the early stages of the disease, or even before its onset, palliative measures would be more efficacious. And being unique, the pathogen must be unknown, and therefore must be sought out. Generalized uniqueness therefore accounts for the curious naïveté of the search for predictors. Amnesty International Secretary General Pierre Sané writes, "None of the human rights tragedies of recent years was unpredictable or unavoidable. [...] The problem is not a lack of early warning, but a lack of early action." [Sané 2000: 8-9]. In contrast, Chalk and Jonassohn write:

A number of people have argued that the establishment of an early warning system would be a better approach to prevention. But surely the establishment of such a system presumes the availability of a number of reasonably reliable indicators. In our opinion, there has not been nearly enough research done on the preconditions of genocide to specify such indicators with any degree of reliability. [Chalk and Jonassohn 1990: 4]

More than a difference of opinion or even willful blindness separates these two statements ${ }^{18}$. There is a difference of ethos. Sané says, "only by protecting all human rights everywhere, every day, will we render the debate over humanitarian intervention obsolete" [Sané 2000: 9]. For him the problem of genocide and the problem of human rights abuse generally are continuous with one another; the former is made possible by the latter, and their remedies overlap. With a few words Sané connects the spectacle of genocide to isolated acts of torture and extra-judicial execution, political disappearance, acts of censorship and repression - and through more extended conceptions of human

18 Nor is the difference between Sane on the one hand and Chalk and Jonassohn on the other merely one of a decade of research. Chalk reiterated the need to search for predictors in his panel discussion in the Genocide and Collective Memory seminar [Chalk 2000]. Jonassohn and Björnson approach the problem differently in their 1998 text: "If we lack the means to make 
rights to clean water, housing, education ${ }^{19}$. 'Genocide' is tied to problems of global governance and state violence, of freedom and equality, of everyday life. In contrast, generalized uniqueness prescribes a search for predictors of genocide performed in isolation from any examination of dictatorship, violence, repression, more generally. To the extent that comparative genocide studies is constrained by this framework, it tends dangerously towards a praxis in which genocide is prohibited while other violences are left unaddressed ${ }^{20}$.

This statist frame of reference implies a strategy of intervention by bystander states as the remedy for genocide. For example, when Frank Chalk spoke at a panel discussion on "Genocide and Collective Memory" at the National Gallery of Canada in November 2000 , his discussion of the need for countergenocidal praxis centred entirely on the strategy of armed humanitarian intervention by the United Nations or the international community, to halt outbreaks of genocidal violence or to prevent them entirely. This was a comfortable topic for many: although three other panelists spoke on a variety of topics relating to genocide, including the uses and limitations of humanitarian photography with its 'pornography of violence' [Lavoie 2000], and the effects of

predictions credible and the actors who will rely on them as guides to action, then we need preventative measures that do not require a prediction" [Jonassohn and Björnson 1998: 94]. 19、The concept of 'human rights' includes under its umbrella not only the rights to political liberty and security of person on which Amnesty International concentrates ('first-generation' human rights), but also second-generation social rights that include the right to housing, clean water, education, etc., and third-generation rights relating to collective existence and community identity [Weston 1989: 17-18]. The need to search for predictors of genocide is also discussed in Charny 1982 and Kuper 1985; in the various contributions to Charny 1984 and Fein 1992; and elsewhere. Charny's germinal approach to the search for predictors tends away from generalized uniqueness; his Genocide Early Warning System involves the monitoring of violations of basic human rights as a key component [Charny 1982: 289]. The approach to prediction taken in Chalk and Jonassohn 1990 in effect 
memorialization as soporific rather than as spur to action [Marrus 2000], the bulk of audience questions were on the issue of intervention, and most of these were addressed to Dr. Chalk. In that discussion, the political options were framed in terms of 'to intervene or not to intervene', with intervention viewed as an essentially unproblematic solution. The vision that Chalk articulates is one in which countergenocidal praxis is conceived of in terms of military intervention by bystander states, and in which one of the primary goals of genocide scholarship should be to facilitate the effective implementation of this strategy $y^{21}$. The idea of an 'international community' from which such intervention would come is at least moderately progressive, entailing a rejection of the ideology of political realism in international relations theory ${ }^{22}$. But used uncritically it obscures the power relations at play among strong and weak states, and those exercised by states collectively upon the global community of the governed. It overlooks the dilemma that Amnesty International has observed: that "every military intervention, no matter how it is described, is linked to the strategic interests of the governments behind the troops" and that

U.N. or regional military interventions invariably reflect the interests of politically and militarily powerful states. [...] If AI supported particular military interventions, prompted by the suffering of the victims, it might, over the longer term, find that it had inadvertently supported a global or regional concentration of power and in the short term had backed action that itself contributed to human rights abuses. [Sané 2000: 7-8]

represents a movement away from Charny's more integrative approach and towards the idealtypical form of generalized uniqueness.

21 As with the search for predictors, the role of armed intervention by the U.N. or some other agent is widely discussed in the literature, and some authors have greater reservations about this idea than others.

22 See, e.g., Walker 1993, for a commentary on how political realism in international relations theory denies the possibility of community among states. 
Uniqueness, on the other hand, because it naturalizes everything that is not unique to genocide, proposes humanitarian intervention as a project of global governance without taking any account of the power through which that governance might be enacted. What would we make of a politics that succeeded in institutionalizing armed humanitarian intervention as a response to genocide, while leaving intact the underlying relations of violence that give rise occasionally to genocide, but more often to less spectacular human rights abuses? And in which humanitarian intervention served the interests of powerful states, and of the powers that move states themselves? In this scenario, science provides the tools to enable the exercise of a certain kind of power which, to the extent that it establishes itself, re-establishes the need for this science, in a cycle of mutual reinforcement; genocide scholarship becomes a power-knowledge configuration. The political problem is that this science would not critique or illuminate the workings of the power that it services. It would not account for the consequences, beyond a response to genocide, that the exercise of this power would entail. Nor would it be fundamentally opposed to a situation where intervention appears as the endlessly-unsatisfactory-alwaysreforming permanent situation, a permanent genocide-intervention situation like the prison-delinquency situation described in Foucault's writing on penality - with whatever ongoing and cumulative effects of power this situation would produce. The scientific problem would be that this politics channels research into questions that are of import to this project of intervention. This engenders the endless proliferation of a narrowing field of discourse, increasingly cut off from other scientific projects, would make for a 
degenerating research program (in a roughly Lakotosian sense ${ }^{23}$ ), but one that refuses to die a natural death. Science becomes technocracy, at which point the scientist is a servant of power whether or not he is actually in the employ of that power or is presented with explicit ideological imperatives - though these would enjoy a certain viral irrepressibility.

\subsection{BRIDGING THE THEORY GAP: BEYOND GENERAL UNIQUENESS}

Empiricist research into genocide makes valuable contributions to the understanding of the phenomenon. Detailed historical study of cases is necessary as a precondition for any more theoretically informed understanding of genocide, and the exposition of previously buried, forgotten, or neglected historical data works to puncture collective denial regarding both particular episodes and the general phenomenon of genocide. But without work that situates genocide within a general analytics of social relations, by employing rigorous social-theoretical frameworks, the work of overcoming collective denial cannot fully succeed. By tacitly accepting the premise of generalized uniqueness, empiricist research construes genocide as a dysfunction or breakdown or pathology, in any event as an outlier phenomenon, something opposed to and removed from normal social relations - and therefore as a phenomenon the explanation of which is a separate task from the explanation of everyday life, of well-functioning institutions, of

For Imre Lakatos, a research program is theoretically progressive if it continues to generate new predictions that anticipate and drive empirical research, and is degenerating if it can only respond to new observations ex post facto [Hacking 1983: 117]. In a social scientific context, where prediction is rare, the notion of a degenerating research program might be reinterpreted to suggest a program in which modifications to the theoretical scheme are driven by external critique and new empirical discoveries or events, while in a progressive program new empirical researches are driven by theoretical innovation. 
class struggle, and so on. Ontologically separate from the main objects of any general social theory, genocide is epistemologically fated for the ghetto of specialization.

Within a broadly liberal framework, however, there are to be found works that make significant progress towards overcoming this ghettoization. These works attempt to move beyond reducing genocide to agents' motives and to analyze genocide as a product of power struggles, of the tactics of power employed by elite social groups operating in strategic situations fundamentally conditioned by the effects of state power. Although these works attempt seriously to analyze genocide in relation to state power, they remain within the broad framework of liberalism inasmuch as they refrain from systematizing the potentially radical implications of such analysis.

One implication of the liberal emphasis on the intended and agential quality of genocide is the assumption that genocide must be perpetrated by a singular agent, specifically the state. As Moses observes,

Because the state is conceived of in Rankean terms as an individual personality, genocide is held to issue from ideologies about it (like fascism) rather than a prior cause in civil society. [...] Liberal theories of genocide are really theories of totalitarianism. [Moses 2002: 21]

Partly in consequence of this, Moses asserts, liberal scholars tend to marginalize colonial genocides by prioritizing "the 'great genocides' of the twentieth century, based as they were on totalitarian ideologies" and by attributing the primary cause of genocide to "totalitarian drive to perfection, a deviant form of modernity resisted heroically by the West" [ibid.: 21]. Rummel's work situates genocide within a broader context of democide, "the murder of any person or people by a government", thereby placing genocide within a matrix of state practices of lethal violence [Rummel 1994: 31, 34]. 
Horowitz builds on and adds nuance to Rummel's approach: observing that "The attempt to locate 'bad' practices in bad states is as flawed an approach as is the attempt to locate 'good' practices in good states" [Horowitz 2002: 297-298] and that type of regime is not a sufficient explanation for the state's use of violence against its subjects, Horowitz builds an eight-point linear typological scheme based on how societies deal with dissent and difference. At one end of the scheme are 'genocidal societies' in which the state routinely takes the lives of its subjects for dissident or deviant behaviour, and at the other are "permissive societies in which norms are questioned and in which community definitions are transformed as needed" [Horowitz 2002: 154-155]. Both authors admit that Western states, through colonialism, have practiced democides of their own [Rummel 1994: 57-60; Horowitz 2002: 154-155]. However, both entirely neglect the genocidal effects of imperialism, neo-imperialism, and modernizing development in the twentieth century. As Alvarez observes, both Horowitz and Rummel neglect to account for Western liberal democracies that provide support and assistance to repressive regimes engaged in genocide or democide [Alvarez 2001: 45-46]. Both authors conceive of genocide solely in terms of killing, and of its perpetration primarily in terms of a Rankean state. Rummel's claim that "the way to end war and virtually eliminate democide appears to be through restricting and checking Power (sic), i.e., through fostering democratic freedom" [Rummel 1994: 27] leads not to an investigation of power relations broadly conceived but to a celebration of particular political regimes, as when Horowitz concludes that "anti-democratic states are the unique carrier of the poison of genocide [and] conversely, that democratic states are the societies that embody anti-genocide 
premises and principles" [Horowitz 2002: 399]. In sum, both authors fail to situate their account of the exercise of state power within a rigorous analytics of the social relations through which that power is produced and reproduced.

Markedly more successful attempts to overcome the theory gap produced by generalized uniqueness are made by Kuper [1981], Alvarez [2001], and Marchak [2003]. All three authors move beyond treating states as self-contained entities to situating state power with the global state system. All three refuse to exonerate Western liberaldemocratic states from responsibility for genocide, noting especially the role of the United States in facilitating genocidal violence in client regimes to further its own transnational hegemony. Kuper and Alvarez discuss genocides against indigenous peoples, although Marchak ignores this topic. In short, these authors take a more critical and more theoretically ambitious approach to the study of genocide than most liberal scholarship, and attempt to situate genocide theoretically within the matrix of social relations generally. Each account has important limitations, however. Alvarez's criminological approach implicitly reproduces generalized uniqueness by treating genocide as deviance and by reifying its criminality and immorality. For example, he discusses the morality of genocide only in terms of the suppression of forms of morality that would inhibit participation in violence, and treats the production of moralities that legitimate genocide under the heading of 'ideology ${ }^{24}$ [Alvarez 2001: 72-77, 95, 106-107, 112]. His discussion of intervention [136-146] treats intervention as an unproblematic 
solution to genocide without interrogating the ways in which it, too, can serve as a vehicle for domination and violence. Overall, his excellent synthesis of existing genocide scholarship ultimately produces a description of how genocides are implemented, rather than an explanation of the broader social forces that produce genocidal violence. Kuper and Marchak are more successful in this respect. Kuper arguably breaks with liberalism altogether by asserting that

the sovereign territorial state claims, as an integral part of its sovereignty, the right to commit genocide, or engage in genocidal massacres, against peoples under its rule, and [...] the United Nations, for all practical purposes, defends this right. [Kuper 1981: 161]

His account situates the state's sovereign right to genocide within structures of inequality and identity that extend beyond state institutions to constitute what he calls 'plural societies'. Plural societies are those with "persistent and pervasive cleavages" between identifiable social groups, particularly where those cleavages are also the fault lines of “superimposed" social inequalities" [Kuper 1981: 57-58]. Plural societies set the structural preconditions for genocide, which is triggered by more contingent factors. Marchak also theorizes genocide as a product of social inequality, especially where class cleavages coincide with other forms of collective identity, such as ethnicity or religion. In her broadly Weberian account, "state-sponsored crimes against humanity occur when those in control of state institutions are unable to sustain the existing system, with its embedded inequalities" [Marchak 2003: 274]. Marchak also discusses some of the problems associated with intervention as a solution to genocide and human rights abuses, situating the politics of intervention within structures of global inequality [ibid.: 148152]. The work of Kuper and Marchak involves a substantial break with the principle of 
generalized uniqueness, and elements of their approach are embedded in the account of civilizing genocides that I present in Chapters 4 and 5 below. Nevertheless, their explanation of genocide is still distinctly partial, based primarily around the paradigmatic cases of the Turkish genocide of the Armenians and the Nazi holocaust. In this respect, genocides against indigenous peoples and colonial subjects tend to be marginal to their analysis. Moreover, for both authors genocide is produced by the ensemble of state power, social inequality, and collective identity, but both only theorize the relationship between the first two terms, leaving the operation of collective identity up to contingency.

Finally, there are those authors whom Moses categorizes as 'post-liberal', not only for their conception of genocide as structurally determined rather than agentially chosen, but also for their willingness to demolish the "foundation myths" [Moses 2002: 22] of Western liberal democracies. Important landmarks in this literature are the works of Ward Churchill [1998] and David Stannard [1992]. By documenting the enormity of colonizers' genocides against indigenous people in the Americas, these works affirm the centrality of genocide to the formation of the nation states of the western hemisphere and, indeed, of the modern world as such. However, beyond documenting the importance within European and American culture of racist and religious attitudes that legitimated the cultural and physical obliteration of indigenous peoples, these works do not attempt any substantial theoretical account of the genocides they describe.

Such an account is provided by Sartre in his essay on the deliberations of the International War Crimes Tribunal that was initiated by Bertrand Russell and which 
pronounced the United States guilty of genocide in its conduct of the war in Vietnam.

For Sartre, genocide was inherent to the totalizing mode of war made necessary by the logic of bourgeois nationalism since the beginning of the twentieth century [Sartre 1968:

61]. The inherently genocidal tendencies of this mode of war are held in check only by locally contingent infrastructural conditions: within Europe, by the deterrent potential each nation-state possessed, that of "the power of applying the law of 'an eye for an eye"" [62]; outside Europe, by the value of indigenous populations as "an almost unpaid labour force" [64] or, occasionally and temporarily, by logistical obstacles to its implementation [77]. Therefore, when colonial or neocolonial subjects attempt to refuse their labour to imperialist capital, for example by socialist revolution, they are threatened with a choice between extermination and capitulation [75]. In this sense imperialism and capitalism are essentially genocidal, and on a global scale: "little by little the whole human race is being subjected to this genocidal blackmail piled on top of atomic blackmail, that is, to absolute, total war" [84]. A similarly structural and essentialist account of genocide against indigenous peoples is Tony Barta's brief but potent theorization of the 'genocidal society’ [Barta 1987]. Barta quotes Marx as saying:

In the investigation of political conditions one is too easily tempted to overlook the objective nature of the relationships and to explain everything from the will of the persons acting. There are relationships, however, which determine the actions of private persons as well as those of individual authorities, and which are as independent as the movement in breathing. [Marx, quoted in Barta 1987: 239]

Barta criticizes Horowitz's conception of 'genocidal society' for conflating society with state, and for mistaking a transitory political regime for the structural foundation of a society. In a genocidal society, the state may be nominally committed to the protection 
of innocents, but "a whole race is nevertheless subject to remorseless pressures of destruction inherent in the very nature of the society" [240]. Genocide, though not strictly unintended, is not strictly intended either; rather, a relation is genocidal objectively, by virtue of its consequences whether these are intended or not. Barta's thesis is that

all white people in Australia do have such a relationship; that in the key relation, the appropriation of the land, it is fundamental to the history of the society in which they live; and that implicitly rather than explicitly, in ways which are inevitable rather than intentional, it is a relationship of genocide. [Barta 1987: 239].

With these formulations, Barta and Sartre break entirely away from generalized uniqueness, situating genocide firmly within the milieu of everyday social relations.

One strength of post-liberal accounts is their ability to bypass the vexed question of intentionality. Liberal scholars tend to require that genocidal or, more narrowly, exterminatory intent be demonstrated before an event can be classified as genocidal; postliberals look for genocidal effects or consequences, a more powerful approach where genocide is produced by a decentralized ensemble of perpetrators (as in settler genocides against indigenous peoples) or where perpetrators actively disguise their intentions (as in the Ottoman and Rwandan genocides, for example). Focusing on objective relations rather than subjective intentions steers the analysis of genocide away from psychological reductionism, and from the tendency to treat genocide as the result either of individual or collective psychopathology. The notion of 'objective relationships', which exist prior to our consciousness of them and hence prior to our normative evaluation of them, also mitigates against reduction to normative categories and the reification of the immorality 
of genocide. Understanding genocide as one objective relationship among others seals the breach produced by generalized uniqueness and its metaphysics of rupture. Nevertheless, these post-liberal approaches suffer from their own severe limitations. As Moses [2002: 26] observes, the notion of objective relationships "bypasses rather than confronts the problem of exterminatory consciousness". In Sartre's account, either genocidal intent is determined by structurally objective interests, as it is for the bourgeoisie, or it is the result of ideology and propaganda, as for the working classes [Sartre 1968: 60]. This model seems to leave no room for effective anti-genocidal praxis, short of victory in a global class struggle that itself will necessarily take on genocidal dimension. Likewise, Barta's claim that genocide in Australia proceeds inevitably, as the result of forces inherent to the very nature of Australian society, offers no hope for Aboriginal survival. More broadly, these accounts suffer from the weakness of any purely structural account. The notion of 'objective relationships' implies that a social relationship can have a form entirely independently of any perceiving human subject. It suggests an ontology of free-floating social relationships, existing prior to concrete human beings. This ontology is just as open to the charge of being metaphysical as is an ontology of free-floating individual subjects existing prior to social relationships. I would like to appropriate the insights of objectivist epistemological strategies without falling into the trap of the dualist metaphysics that they share with their antithesis. To this end, I will discuss the relation between subjectivity and social relations that can be developed from Norbert Elias's theory, in Chapters 2 and 4 below. Nevertheless, my project is more in sympathy with the spirit of post-liberal genocide studies than with its 
liberal counterpart, and seeks to build on its strengths and to surpass its limitations rather than simply to dispose of it.

\section{Methods}

\subsection{Conceptual Commitments}

My analysis of genocide proceeds by way of three conceptual commitments.

These commitments overcome generalized uniqueness with its metaphysics of rupture by establishing a fundamental continuity between genocidal and non-genocidal social relations; genocide is understood as a form of social relation rather than as a rupture with or breakdown of those relations. First, genocide is situated in the context of a continuous matrix of practices of power. At a minimum, continuity involves an examination of "the relationship between genocide and other violations of life integrity: political killings, disappearances, torture, arbitrary imprisonment and denial of due process, and forced labour" [Fein 1993: 98]. But genocide is also continuous with nation-building, state formation, racialization, patriarchy. In a more extended sense, it is also continuous with democratic elections, free markets, projects of moral regulation, and other tools of liberal governance. Any or all of these elements, and others, may be linked aspects of an overall strategic situation, of a configuration of social relations, or even of a specific political project. For example, genocidal violence in Guatemala and El Salvador and elections in Costa Rica were complementary components of the project of American hegemony in Central America in the 1980s. Although the notion of a 'political project' suggests an intentionality that implies a complementarity among its components, the notion of an 
'overall strategic situation' does not, and it is up to the researcher to determine empirically the relation between genocide and other practices of power within such a configuration. The point of the principle of continuity is that genocide is not assumed $a$ priori to obey a unique logic: indeed, one explains genocide by investigating its situatedness within other forms taken by power struggles.

Second, power is understood symmetrically, such that both good and evil powers, legitimate or illegitimate uses of power, are understood in terms of the same order of causal processes. There is not one ontology for good powers and another ontology for bad powers. My not placing 'good' and 'bad' within ironic shudder quotes reflects more than a distaste for the device: it recognizes that any researcher is bound to consider some uses or effects of power to be good, or productive, or emancipatory, and others as bad or repressive. Any countergenocidal praxis, and any science that feeds that praxis, involves a reconfiguration of power relations and therefore the production of certain relations at the expense of others. Symmetry does not imply a value-neutral science, but it does mitigate against the tendency for researchers' political allegiances to predetermine the limits of scientific inquiry ${ }^{25}$. More pointedly, symmetry means that not only genocide is

25 For example: In the journal Internet on the Holocaust and Genocide, February 1991, Israel Charny and Helen Fein argue over a definition of genocide proposed earlier by Fein, one which Charny thinks is too restrictive. Charny states: "I am also uncomfortable that her [Fein's] definition is used to exclude a number of classes of mass murders such as [...] mass murders of civilians in wartime strikes against an enemy such as by saturation bombing, nuclear bombing, or chemical and biological weapons." Fein replies by saying "To equate Auschwitz and Hiroshima belies the distinctive ends and root of each plan, focusing instead on the number of victims and the common bureaucratic instrumental rationality used in implementing both plans. ... Further, ignoring the context and intent of the carpet bombing and atomic bombing of World War II and equating the latter with genocide comes dangerously close to accepting the revisionist argument that what happened in Auschwitz was nothing special." [The discussion is quoted in Fein 1993: xixii]. These comments suggest that Fein is personally loyal to the American state, and that this loyalty conditions her evaluation of the Hiroshima and Nagasaki bombings as genocidal or as non- 
taken as problematic but also non-genocide; the nonoccurrence of genocide is equally in need of explanation as its occurrence. This applies especially to the project of countergenocidal praxis itself. What configuration of power is implied by a scheme of armed humanitarian intervention and effective international law envisaged by Chalk and Jonassohn? Or by a regime of the observance of all human rights everywhere sought by Amnesty International? Or by Kuper's [1981: 189] non-genocidal society? Any solution to the problem of genocide becomes itself a problem to be investigated, a question in need of explanation. Symmetry implies a perpetually ongoing reflexive critique of power and of the scientist's relation to power.

Third, genocide is analyzed in the context of a globalizing field of force relations. Philip Mirowski [1989] has observed the parallel shift in physics and in economics from theories of energy or value as a substance that can be accumulated or dispersed, hoarded or expended, to theories of energy or value in terms of a field of relations, a field that produces effects of energy or effects of value. A similar shift from substance to field occurs in Michel Foucault's treatment of a certain form of power: the disciplinary power that produces the delinquent and the homosexual [Foucault 1980; 1990: 92-102; 1995 : 24-31]. Inquiring into the production of certain modes of subjectivity, Foucault turns away from the substance form of power associated with the sovereignty of the state to focus on a form of power that is "exercised from innumerable points," that is immanent to other types of relationships, that cannot be possessed and exists only in its continual

genocidal -thereby constraining her willingness to engage in scientific inquiry of causal mechanisms common to these bombings and (other) genocidal events. This loyalty also prompts her to assume that attaching the label 'genocide' to an act committed by a state to which one is 
deployment, that is inescapably bound up with the resistance it evokes. Of this form of power he says:

It is in this sphere of force relations that we must try to analyze the mechanisms of power. In this way we will escape from the system of Law-and-Sovereign which has captivated political thought for such a long time. And if it is true that Machiavelli was among the few [...] who conceived the power of the Prince in terms of force relationships, perhaps we need to go one step further, do without the persona of the Prince, and decipher power mechanisms on the basis of a strategy that is immanent in force relationships." [Foucault 1990:97]

And yet while these comments suggest the beginnings of a general theory of power, Foucault provides no such theory ${ }^{26}$; if he theorizes anything, it is subjectivity, and his comments on power are a means to that end (although one can also read his work in terms of a preoccupation with power, domination, and freedom that runs deeper than his inquiry into subjectivity, one that is never realized but that unites his various particular investigations into a tragically incomplete whole). More to the point, his conception of power as a field-effect applies only to disciplinary power, and what little he says about the sovereign power of the state tends to juxtapose it against disciplinary power as if the two were different modalities, one a substance and the other a field. I prefer to imagine them (and to imagine this as the logical extension of the Foucaultian insight) in common terms, to see sovereignty and discipline as overlapping or intersecting configurations of the field of force relations. In this field we can see at work the state project,

personally loyal would necessarily constitute a legitimation of genocide, not a critique of that state or of state politics as such.

"In studying these power relations, I in no way construct a theory of power. But I wish to know how the reflexivity of the subject and the discourse of truth are linked - 'How can the subject tell the truth about itself?' - and I think that relations of power exerting themselves upon one another constitute one of the determining elements in this relation I am trying to analyze." [Foucault 1998: 451] 
monopolizing to itself a certain kind of force with which we associate the soldier and the police officer - although that monopoly may be eschewed in certain contexts, those in which husbands beat wives, straight boys go gay-bashing, white men lynch black men, and so on. This monopolization is organized according to a territorial schema that takes the superficial form of a plurality of states, but which is really a unitary project, and one that now covers the entire face of the globe. That is, through a plurality of states the State-form monopolizes to itself globally the force, or violence, of the soldier and the police officer, although there are always important exceptions to this monopoly. From this territorially organized global field of force relations emerge both genocidal and nongenocidal moments in the global unfolding of statism. Indeed, it is from this field that would emerge an international humanitarian intervention aimed at halting genocidal outbreaks. The global state movement organizes a particular economy of violence, in the sense of a system of circulating elements, and the construction of a regime of humanitarian intervention involves a reconfiguration of this economy the consequences of which have not been explored. Seen in these terms, the specific question of preventing or thwarting genocide is changed, enlarged: it becomes a question of the overall configuration of the field of that power arising from the forces of life and death, of the overall configuration of the means of destruction.

\section{$2.2 \quad$ AIMS}

Given what I have been saying, it would be reasonable to expect that I intend to construct a theory of genocide. However, this is what I will not do. That is, I will not construct 'a theory' in the sense of a closed and total or totalizing system of concepts that 
aims at completeness. Rather, I want to construct an analytics of genocide that is rigorously theoretical but that is open-ended and, hopefully, protean: a theoretical reading of genocide that serves as a starting-off point or a first word rather than trying, as any finished theory implicitly tries, to be the last word.

I have several reasons for this. One is pragmatic: a theory that is closed and totalizing has the effect of asking the reader to accept or reject the theory in its entirety. A closed theory requires the assertion of a metaphysics or philosophical stance in the form of a set of thesis about questions of an irresolvable or essentially contested nature 'sticking points', to use Ian Hacking's apt terminology [Hacking 1999: 63]. Even in formulating something as modest as an analytic, it is inevitable that I will take or imply a position on any number of sociological or philosophical sticking points. But a systematic attempt to provide a foundation for a theory increases the number of these positions and decreases both the writer's and the reader's freedom to be agnostic or to see it both ways. To propose 'a theory of genocide' therefore constrains the scope of appropriation and of application of whatever I might write about genocide. In keeping with my desire to bridge the theory gap and to provide resources for anti-genocidal praxis, I hope to see my text appropriated widely, used not only by genocide specialists and not only for genocide studies, but read and misread, mangled, mutated, grafted onto other texts, to pursue lines of flight, produce hybrid and miscegenational offspring - all of which the strict genre of 'theory' inhibits. In this respect, the distinction between theoretical writing or open theory and grand or closed theory can be understood in the same terms with which Tolkien describes the distinction between 'applicability' and allegory: "the one resides in 
the freedom of the reader, and the other in the purposed domination of the author"

[Tolkien 1991: 11]. Bridging the theory gap seems to me to involve a necessary appeal to the freedom of the reader.

The other, more substantive reason - and here I am forced to take a stand on a sticking point - is that a closed or totalizing theory seems to me to demand an epistemological realism that I consider untenable. By presenting itself as a an account of things that is possessed of finality and of some degree of completeness, a total or closed theory relies on the assumption of some fixed relation, e.g. of correspondence, between itself and objective reality. I do not think such a determinate relation is possible between a text and its various objects, and so I am pessimistic at best concerning the possibility for theory to succeed on its own terms. Following Rorty [1989: 106], I would say that total theory aims at foreclosing the possibility of its own overcoming; it is an "attempt to write something which will make it impossible for one to be redescribed except in one's own terms". Rorty argues that this impossibility of redescription is unachievable, in which case I can no longer write total theory except as parody or play. Denied sublimity, my text must vindicate itself on more pragmatic grounds. These grounds are pithily articulated by Brian Massumi in his preface to Deleuze and Guattari's 1,000 Plateaus. Concepts, he says,

do not reflect upon the world but are immersed in a changing state of things. A concept is a brick. It can be used to build the courthouse of reason. Or it can be thrown through a window. ... The question is not: is it true? but: does it work? What new thoughts does it make it possible to think? [Massumi 1987: xii, xv]

Which of course begs the question: what is it that this text is trying to do? 
My project aims at problematization, in a sense of the term that is taken from Actor-Network Theory. Michel Callon describes an approach to the study of scientific knowledge that is at the same time an approach to the study of power - in effect, a 'sociology of knowledge' that does not radically separate knowledge from other kinds of social relations. He provides an account of a scientific controversy in terms of a general process of translation, a process through which "the identity of actors, the possibility of interaction and the margins of maneuver" - in sum, the configuration of strategic possibilities in a given milieu - are reconfigured through the implementation of a scientific programme [Callon 1988: 203]. Translation has four moments: First, problematization, in which researchers seek to make their research program indispensable to other actors by establishing it as an "obligatory point of passage" [ibid.: 204] through which those actors must pass if they wish to realize their interests; second, interessement, in which researchers 'lock into place' or stabilize the identity with the network of those actors; third, enrolment, the outcome of successful interessement, in which "a set of interrelated roles is defined and attributed to actors who accept them" [ibid.: 211]; and fourth, mobilization, in which the researchers establish a limited set of actors as speaking for or representing larger, silenced collectivities. In a word, then, the goal of my text is to effect a problematization that establishes genocide as an obligatory point of passage for general social theory. What sort of actor-network then forms, I leave open to contingency.

At the same time, there is a simpler way of expressing this goal. The notion of problematization indirectly invokes the concept of interests as it is used in the strong 
programme of sociology [Bloor 1976; Barnes 1977; Barnes, Bloor and Henry 1996]. In my reading of these texts, the concept of 'interests', which is admittedly somewhat ambiguous, resolves neither into the gross and grubby interest of power or capital, understood as an external or corrupting influence on the pursuit of scientific truth, not to the ethereal and disinterested interest of pure intellectual curiosity. Rather, I invoke yet another principle of symmetry and refuse to make any radical a priori distinction between the two, which anyway always seem to mix and mingle in science as elsewhere. We can therefore construe the persistence of collective denial, as manifest in the marginality of genocide to social theory and the corresponding ghettoization of genocide studies, in terms of the historical nonoccurrence of any act of problematization that would channel the interests of social scientists through the obligatory point of passage of genocide. My task, then, is to make genocide interesting. 


\section{Chapter II: Identifying Genocide}

\section{INTRODUCTION}

In the field of genocide studies, the very definition of the term 'genocide' is hotly contested. At stake is the question of which acts, events, or episodes are to be understood as instances of genocide and which acts, however atrocious, are not to be counted as specifically genocidal. In this chapter I propose my own way of resolving this question. My solution involves a shift in the way the signifier 'genocide' is to be used. This shift can be understood in terms of a spatial metaphor: rather than treating 'genocide' as defining a contiguous Euclidean space with a definite boundary, with everything that is genocide being located inside the boundary and everything that is genocide being outside it, 'genocide' should be understood as designating a network of resemblances that tie together not only different genocidal events, but also texts about genocide, practical responses to genocide, and the purposes or strategies that orient both genocide and opposition to it. This network operates to define or identify particular social processes and not others as genocide; it has no definite continuous border, but neither is it allinclusive, amorphous, or capricious.

For example, I can say that slavery is not genocide because the network of resemblances, including the set of historical events that we would call slavery, the set of texts in which slavery has been defined or described, the point of calling something slavery, and the practical history of struggles against slavery, are mostly quite different from the corresponding considerations for genocide, even though slavery could involve or entail genocide in many instances. Attempts to specify this distinction in terms of 
principles or defining characteristics can succeed, in limited contexts: we can say that slavery involves treating people as property, and genocide involves the violent annihilation of a social identity. But statements like these are always only local performances; they are instantiations of the networks which they represent and efface by the same gesture ${ }^{27}$. To attribute a foundational status to them is to stand things on their head. The question of whether any given historical process should count as genocide requires more than simply going through a checklist of attributes: it involves careful comparison with elements already established as belonging to the network 'genocide'.

This network-based approach therefore changes the procedure for deciding how an event is to be identified as genocide or not genocide. Rather than appealing to a single set of abstract and universal principles that can determine objectively what is and is not genocide, I decide on a case-by-case basis whether and how any given event can be joined to the network, on the basis of its relation to elements that are already accepted as belonging to that network. In Chapter 5, I will illustrate this method by applying it to six historical examples. That discussion will rely heavily on appeal to precedents, to events that are already recognized as genocide and to texts that represent influential attempts to define 'genocide'. Prominent among these precedents will be events such as the Nazi holocaust, the Cambodian genocide, famine in the Ukraine under Stalin, and so on, as well as texts such as Raphael Lemkin's Axis Rule in Occupied Europe, the 1948 United Nations Convention on the Prevention and Punishment of the Crime of Genocide

27 My concept of network is drawn from Michel Calllon's presentation of Actor-Network Theory. Callon notes that when networks are successfully constituted, those who represent or speak for other elements in the network also, and thereby, displace and silence those whom they represent [Callon 1988: 214-219]. 
(UNGC), and works by Helen Fein, Frank Chalk, Ward Churchill, and Dirk Moses. These objects in effect provide a core or centre of gravity for the network which 'genocide' designates, a network that I then extend to my six examples, some of which are already recognized as genocide and some of which are bound to be disputatious.

The current chapter is divided into four sections. In the first section I claim that the meaning or use of 'genocide' depends crucially on the point of using it and the purposes to which it is put. The point of using 'genocide' is to oppose genocide, to bring about the end of the practices designated as genocidal; my more immediate purpose in this dissertation is to develop a figurational sociology of genocide. The second section discusses more specifically the contests over what 'genocide' should be taken to mean or how it should be used. I provide a brief historical overview of the use of the concept, focusing on the contributions of Raphael Lemkin, who coined the term; the UNGC; and disputes among scholars who study genocide. I argue that 'genocide' is an essentially contested concept, in the sense specified by W. B. Gallie, so that there is no single logical solution to the question of what principle should define it. I then explore the contributions that Foucault's genealogical inquiry and Elias's figurational sociology make to taking us beyond the impasse of essential contestedness. In the third section, I grapple with the place of the researcher's values in a sociological study of genocide. Such study cannot be simply value-neutral if the point of genocide research is to end genocide. But, as a positivist critique of metaphysics reveals, the researcher must be reflexive in order to avoid reifying and universalizing their own values, and thereby overlooking the production of moralities that authorize genocide. The notion of 
'metaphysics' presents its own difficulties, however; the critique of metaphysics can itself be shown to rely on metaphysical and Eurocentric assumptions. I overcome these difficulties with a modified form of Elias's concept of 'detachment', in which complete detachment and objective knowledge are recognized as impossibilities, and in which both the object of genocide and the process by which it is studied are informed by the question of difference. Finally, in the fourth section I resolve the definitional issue by stipulating how I will use 'genocide'. In this use I tie together the concepts explicated in this chapter - essential contestedness, genealogy, figuration, detachment, and difference, and add to this the notion of genocide as a network as I have already described it above.

\section{Point and Purpose}

The purpose of this dissertation is to articulate a theoretical basis for a figurational sociology of genocide. The point of doing this is to contribute to the elimination of practices of genocide.

\subsection{PoInT}

Ian Hacking approaches the complex debates around the concept of 'social constructionism, ${ }^{28}$. in an interesting way: "With so many inflamed passions going the rounds, you might think that we first want a definition to clear the air. On the contrary, we first need to confront the point of social construction analyses. Don't ask for the meaning, ask what's the point." [Hacking 1999: 5] To ask for a definition, for the necessary and sufficient conditions for the truth of a statement, is to assume ahead of time that the point of a concept is description. But the point of many concepts is something 
else entirely. The point of the concept 'exploitation', for example, "is to raise consciousness ... to change how we see" a social relation. And changing consciousness “relies not on necessary and sufficient conditions for claims about exploitation, but on fruitful analogies and new perspectives" [ibid.: 6].

There is a lot going on in this short passage. First, the use of a concept is determined not by its meaning but by its point. Use does not ensue from meaning, but meaning from use. Precise definitions will be possible only for some concepts, those that have certain points (or, particular use-values) such as description. Even descriptive concepts may not have precise categorical boundaries, for example when their ultimate point is consciousness-raising. Such concepts may be organized as open-ended networks, with network ties consisting of relations of association by analogy or by illumination. For these concepts, the formulation of precise definitions will always leave important remainders, remainders that only grow with time.

Second, however, this formulation contains a contradiction, or at least a tension, that Hacking glosses over (and this gloss somewhat undermines the whole of The Social Construction of What?). This contradiction has been around at least since Marx's famous theses on Feuerbach ${ }^{29}$; it is the contradiction between the truths of the bystander and the participant, between detached truths and involved truths. It is a contradiction because the effectivity of an involved truth both depends on and tends to undermine its relation to a detached truth. Consider exploitation. Marx defines it very precisely, as the opposed to its use in signifying some object. Double quotation marks indicate direct quotations. "Philosophers have hitherto only interpreted the world in various ways; the point is to change it." [Marx 2000: 174]. 
appropriation of surplus labour-value in the context of commodity production. Its forcefulness as a tool for consciousness-raising comes precisely from this quality of specificity: 'exploited' is more than a mere expression of disapproval, it identifies a set of concrete circumstances that can be identified according to impersonal criteria. Its consciousness-raising effectivity results from the fact that it retains the same descriptive effectivity across different instances of use; it is both portable and reliable. But it is also unsatisfying: housewives, for example, cannot be said to be exploited because they do not produce commodities. And yet the analogy between housewives and factory workers is so fruitful as to be overwhelmingly tempting: they form a class, constituted by a common subjugation; they expend labour-power, the benefits of which another class reaps; and so on. If we call housewives exploited, we begin a process for which there is no logically determined end-point short of 'unfair', 'I disapprove' - that is, vacuity. But if we halt this process at any point we can do so only by privileging description over consciousnessraising - or by privileging the political struggles of certain subjugated groups over others, a privileging which can only be arbitrary.

The same considerations apply to the concept of genocide, which is, in exemplary fashion, a descriptive concept with a political point. The point of my work is to end genocide. That point will govern the questions I ask, the analogies I draw, and how I treat phenomena that sit on the boundaries of a definition. To begin with a pseudoobjective definition of genocide would assume that the concept could be defined independently of the point to which its use is directed; in effect, it would require a disavowal of the specific commitment to using 'genocide' to end genocide. This 
consideration is not generally recognized in scholars' debates over the term. Moreover, even this point - ending genocide - is elastic or protean. It begs a further question: to end genocide, on what terms? For example, some genocides happen in the context of power struggles in which the dominance of an elite is threatened by the claims to equality or self-determination by a subjugated group. In such situations, would it be satisfactory to prevent genocide by bolstering the power of such elites and preventing any challenge to the status quo? My answer is 'no'. My commitment to ending genocide is therefore subtended by my commitment to a broadly emancipatory and egalitarian politics, and hence to such normative projects as feminism, socialism, human rights, and so on. These normative commitments are not externalities, to be pushed aside as much as possible for the sake of detached scientific investigation. They are the raison d'être of that investigation, that science, that detachment.

I will not resolve the contradiction built into the use of descriptive concepts in the service of sociopolitical change. It is a historical contradiction: it works its effects in the historical time of linguistic practice rather than the instantaneous time of pure logic. The best that $\mathrm{I}$, or anyone, can hope for is be to manage the contradiction so as to create a discourse that is temporarily meaningful and effective. Though, temporarily can be a long time if one is both skilful and lucky.

\subsection{Purpose}

The point of a concept or of a dissertation is external to it, something that it works towards or contributes to but that it cannot accomplish by itself. On the other hand, a dissertation can accomplish its purpose, at least if all goes well. The purpose of this 
dissertation is to articulate a theoretical basis for a figurational sociology of genocide. Two questions immediately present themselves: what is a figurational sociology? and, why a figurational sociology in particular?

The concept 'figuration' is used in the sociological writing of Norbert Elias [2000; 1970]. Elias uses 'figuration' where other sociologists would use 'structure', to designate identifiable regularities or stable patterns in social interaction. But, whereas Elias regards 'structure' as an essentially static or synchronic concept [Elias 2000: 456457], 'figuration' is by definition diachronic or process-oriented [ibid.: 403]. Elias illustrates the use of 'figuration' by analogy to a dance [482]. The choice of analogy is telling. Many games, for example, can be abstractly reduced to their synchronic elements in a way that a dance cannot. Chess can be plotted as the set of its board, pieces, and rules, or as the larger set of these plus all important or possible configurations of game play. Movement occurs instantly between consecutive static conditions; or more precisely chess has no movement, only iteration. All possible strategic information is contained in the instantaneous arrangement of elements, so that if a game is stopped part way through and one of the players replaced with another, the new player is not disadvantaged by not knowing what moves have already been played; the current arrangement of pieces tells her everything she needs to know to proceed. In a game like bridge, on the other hand, things are different:

the strategies of a 'player' and everything that defines his 'game' are a function not only of the volume and structure of his capital at the moment under consideration and of the game chances [...] they guarantee him, but also of the evolution over time of the volume and structure of this capital, that is, of his social trajectory and of the dispositions (habitus) constituted 
in the prolonged relation to a definite distribution of objective chances. [Bourdieu and Wacquant 1992: $99^{30}$ ]

This quality is even more apparent in a game like soccer, or in a dance, both of which are constituted by movement. A waltz, for example, is less a series of synchronic states joined by rule-governed transitions, than a series of movements joined by rule-governed synchronic states. Whereas a photograph of a chessboard tells us all we need to know, a photograph of dancers frozen in mid-motion tells us little. We must unstop time, observe movement as movement. The same is true, says Elias, for social action. We must understand the social as essentially in motion, essentially dynamic. In this way the problem of social change vs. social order that is necessarily ${ }^{31}$ troublesome for stasisoriented analysis is resolved for Elias in a synthesis of the two: social life is order in motion, structured change, figuration.

I need to make a few points telegraphically to situate 'figuration' within Elias' broader conception of sociology. First, Elias insists on the relational quality of social action. To do otherwise, he says, is to subscribe to a fallacious notion of the human self as existing in isolation, apart from its relations with others. 'Homo clausus', the isolated

30 In this passage Bourdieu and Wacquant are discussing their concept of 'field', not Elias's concept of 'figuration'. I wanted to cite them to bring out the resemblance between the two and the extent to which Bourdieu has built on Elias. Nevertheless, I think that the dance-figuration concept remains more interesting than the game-field concept, inasmuch as the former is more purely oriented toward diachronic analysis than the latter, in which synchronic elements still predominate, if only slightly, over diachronic ones.

31 Necessarily because stasis-oriented analyses require two entirely different ontologies, one for states and one for the transitions between them. Parsons [1951] goes even further, dispensing with the latter almost entirely. Parsons is tormented by the question "how does order exist at all" because he conceives of any change or movement only as threatening chaos; he cannot imagine structure in change. From this starting point Elias mounts a devastating critique of Parsons [Elias 2000: $453 \mathrm{ff}$.], all the more devastating because it is framed entirely in the terms that Parsons stipulates as his own criteria of vindication: dispassionate scientific rationality. 
and autonomous individual prior to social relations, is entirely mythical; the essential human condition is that of being with others [Elias 2000: 473-4; 1978: 13 ].

Second, the problem of the relation between the self and society is fictive because there is no such relation; social subjects relate directly only to other social subjects. What prevents the reduction of social life to the mere individual and secures the necessity of sociology is not the mystical emergence of a reality sui generis but the relational quality of social life. Structure or figuration does not exist within individuals, singly or in aggregate, nor does it exist outside them as social facts; it exists between them, in their interactions with each other [Elias 1987: 166]. More precisely, it exists in the power relationships that emerge through trials of strength among individuals [Elias 1978: 78].

Third, the macro/micro problem is also fictive. It is a vestige of egocentric sociological models, or models that place 'the individual' (homo clausus) at the center of an expanding series of concentric circles representing social contexts of increasing scale. Egocentric models are in turn vestiges of the anthropomorphism that underlies all prescientific modes of thought [Elias 1978: 16]. For the concentric-circles model with its ascending 'levels of analysis', Elias substitutes a network model with no center and no definite periphery, the network ties representing not static relationships but interactions, interdependencies, balances of power [Elias 1978: 15]. Order is immanent to this network as the pattern of motion and change within it; there are no transcendent structures 'outside' anything.

Fourth, social structures or figurations are distinguished from their individual elements, just as human individuals are distinguished from their biological elements and 
living organisms from atomic elements, not by levels of analysis but by their complexity, and in particular by the relations of dependency among individuals. Any process ${ }^{32}$ takes on a degree of irreversibility when sufficiently complex relations of dependency emerge among its elements. Irreversibility implies irreducibility: processes characterized by the complexly differentiated dependence relations cannot be broken down into their constituent elements because doing so would destroy the relationships among elements and hence the process itself ${ }^{33}$. In this way, Elias secures the necessity of sociology against reductionism without resorting to clumsy 'levels of analysis' schema or introducing semi-mystical concepts like that of reality sui generis.

'Figuration' includes these four points (the relational quality of social phenomena; the immanence of society to social relations; the rejection of egocentric thinking; and the use of complexity and dependence to explain irreducibility) bound up into a concept of structure-as-process. The result is an extraordinarily supple and protean sociology, oriented towards formal analysis in the same fashion as the work of Lévi-Strauss or Parsons ${ }^{34}$, but also fundamentally oriented towards process, dynamism, fluidity, change.

32 33 34
One could say, "in any entity"; but Elias insists that any entity - a star, a living cell, a person, a dance - is always also a process.

Elias refers to any relationship of dependency as 'functional', defining function as the need or use that one entity has for another [Elias 1978: 76-78]. So what I am calling 'complexly differentiated relations of dependence' he simply calls 'complex functional differentiation'. However, although Elias tries to eliminate the ideological overtones of the concept of 'function' by defining it in way that eliminates the blatantly normative dichotomy 'function/dysfunction', he nevertheless commits the fallacy of treating society as an organism, in the sense of claiming that the survival of the whole is necessary to the survival of the parts [Elias 1987: 128], and so drastically overstates or misconceives the operation of functional interdependence in social relations. I will not replicate his use of 'function', therefore; Elias's concepts of figuration, the relational quality of social life, and non-egocentric thought are not dependent on or improved by his sporadic and problematic reference to functions.

Foucault [1998: 433-435] identifies formal analysis as the intellectual substance uniting the bodies of work labeled 'structuralism' and 'post-structuralism', labels that he considers somewhat vacuous. 
It is also a sociology in which it is possible to pose questions regarding the formation of the self and the formation of social structures, or the formation of subjectivities of social orders, using only a single set of terms. Elias himself seems to have half-recognized this latter quality of his own work. The Civilizing Process describes simultaneously the formation of the nation-state system and the development of complex emotional responses in individuals. Still partially bound to egocentric habits of thought, The Civilizing Process repeatedly evokes Freudian theory whenever individuals are spoken of, to make 'macro' processes in society link up with 'micro' processes internal to individuals. But in his subsequent work he lays out the elements of a solution that dispenses with any need for psychological theory, even if he does not present that solution fully-formed. If figurations exist in the relations among social actors, then subjectivity can be imagined as constituted at the point - or the dense network, rather where multiple figurations intersect one other at the site of an individual body-mind ${ }^{35}$. Subjectivity could be nothing more or less than the tangle of social ${ }^{36}$ threads that wrap around or pierce the body-mind, pull on it and are pulled on by it; or alternately as the localized field-effect generated by the confluence of the multiple force vectors of multiple power relationships. Elias' use of Freudian theory can therefore be regarded as ornamental: subjectivity is a constitutively relational open system, so that no egocentric reference to dynamics 'internal' to 'the individual' is necessary.

35 The concept of 'body-mind' is found in the practice of yoga. (See, for example, Farhi 2000.) I am using it, idiosyncratically, to refuse on monist grounds the distinction between physical and mental bases of human individuality.

36 Here, and everywhere throughout my text, 'social' should not be mistaken for 'societal'. My argument is not that subjectivity is constituted by society or any similar holistic entity, but that subjectivity is constituted relationally through meaningful social interaction. 
Let me turn to the second question: why figurational sociology in particular? Why not, for example, Bourdieu's sociology of habitus and field? Why not genealogy?

Part of the answer has to do with continuity and discontinuity, a point on which Bourdieu distinguishes his own work from that of Elias. Bourdieu states that one of the crucial differences between Elias' work and his own is that whereas Elias emphasizes continuity, his own concern is to identify points of rupture or discontinuity in structured social processes [Bourdieu and Wacquant 1992: 93-94]. There is nothing wrong with this approach in general, but it is not right for the study of genocide, in which there has been more than enough emphasis on discontinuity and the problem is precisely to establish a framework of continuity that makes a sociology of genocide possible at all. As I have discussed in Chapter 1 , genocide studies is riven by a double discontinuity: first, by a discontinuity between the Nazi Holocaust and all other events, expressed as the uniqueness and incomparability of the Holocaust, a uniqueness that has just barely and still somewhat tenuously been dispensed with by serious scholars; second, by a discontinuity (and offspring of the first) between genocide and other social events, a discontinuity that is both epistemological, referring to the radical distinctiveness of genocide as a class of events, and ontological, referring to a presumed separateness or disjuncture between the social relations of genocide and the social relations of nongenocidal life. Figurational sociology identifies the threads or flows that link together events widely disparate in space, time, and quality. It can trace the links between the blood-soaked territory-grabbing of Norman warlords in the $13^{\text {th }}$ century and the table manners of a Parisian countess half a millennium later. By the same stroke, it links the 
terror of genocidal violence to the humdrum of everyday social relations in civilized society.

In addition to its facility for identifying continuities between the banal and the spectacular, figurational sociology has another virtue. Like Foucaultian genealogy, it brings to light the hidden history of words and concepts and their involvement in the construction of power relations. But whereas genealogy has focused on discourse, that is on collections of statements or signifying practices joined to a disciplinary matrix, figurational sociology casts a somewhat wider net. It is important that The Civilizing Process presents itself at the outset as an inquiry into the meaning of the word 'civilization', and that this hermeneutic inquiry is understood automatically, without question or even comment, as a historical inquiry, one that proceeds by examining the concrete processes through which the word 'civilization' has come to be meaningful. The 'civilizing process' is simultaneously the process by which European social formations acquire certain particular characteristics, and the process (the same process) by which the concept of 'civilization' comes to be intelligible according to its current sense. So rather than specifying an essence, no matter how provisional or mutable, Elias uncovers instead a vast social metamorphosis unfolding with glacial inexorability, one that by inverting the magician's trick (so that the hand is now slower than the eye) has produced, as if from nowhere, an effect of meaning that is suddenly obvious, unquestionable, and yet strangely elusive and unspecifiable: 'civilization'. In the next section, I will attempt something similar, on a much smaller scale, with 'genocide'. That 
is, I will provide a historical discussion of the term 'genocide' and situate it in relation to the development of the practices of power which it is intended to criticize.

\section{What is Genocide?}

\subsection{DEFINITIONALISM}

There is a different definition of the word 'genocide' for every scholar who writes about it, and nobody is happy with the situation: everyone wants to see the debate settled and 'genocide' fixed once and for all. Foremost, though not first, is the definition given in the 1948 United Nations Convention on the Prevention and Punishment of the Crime of Genocide ${ }^{37}$ : genocide is any of several acts committed with intent to destroy "in whole or in part" a national, ethnic, racial, or religious group. The relevant acts include direct killing; the causing of bodily or mental harm; imposing "conditions of life" calculated to inflict "physical destruction" on the group; preventing births; and the forcible transfer of children [Chalk and Jonassohn 1990: 44-45]. This definition contains two important emphases: genocide involves the physical destruction of a group, or the destruction of a group at least partly through physical means; and genocide is a matter of intent, acts become genocidal by virtue of the intentions behind them.

Two emphases, three essentialisms. First essentialism: in the specification of types of groups protected, or more precisely in the forms of social identity that are to be concerned about. Homosexuals, for example, are not protected from liquidation. Neither are communes. Neither are classes, and not just because of Soviet lobbying. Nation,

\footnotetext{
37 Abbreviated as "UNGC".
} 
ethnicity, race, religion: these are four cornerstones of nation-statehood in the modern era, and hence four traditional objects for the operation of state power. The illegality of genocide sets a limit on what has already been crucial to state-formation, the state's use of violence (its one essential resource) to control and manipulate identity. If nationalist discourse has mythologized the nation, with its defining ethnic, racial, and religious characteristics, as the essential foundation of the state, then we can infer a reverse effect: that the forms of collectivity and of identity designated by 'nationality', 'ethnicity', 'race', and 'religion' have become important, have been made to stand out from among other possible ways of identifying people, because of the state's interest in them, because of their importance to the formation of nation-states. The attack on these forms of identity, therefore, stands out as an attack on that form of collective life that is privileged above all others by the very notions of 'international law' and of 'united nations'. More than just a crime of state, then, genocide is a crime of state formation.

Second essentialism: in the specification of means. Genocide is defined by the use of physical violence to inflict biological destruction on a social group. Proscriptions against language, dance, artwork, traditional practices; censorship of artwork and literature; destruction of cultural monuments: none of these are genocidal. Neither is forced deportation or dispersion, so long as children are not separated from their parents and individual human life is respected. Social groups are imagined in their biological aspect; the life of groups is treated as biological life. The UNGC reflects a literal organicism regarding the social. 
Third essentialism: in the importance of intent. Genocide can never be accidental or inadvertent; behind genocidal acts there is always a specifically genocidal intent. This requirement generates all sorts of sticky questions. Are Palestinian suicide bombings against Israeli Jews genocidal, because some Palestinian leaders have expressed a desire to cleanse Palestine of its Jews? Are Israeli policies in the Occupied Territories nongenocidal, simply because Israeli officials have not openly expressed any comparable desire? Arab Palestinians pose a much smaller threat to the collective existence of Jewish Israelis than vice versa, but it is easier to make the charge of genocide stick to the former than to the latter ${ }^{38}$. Or to consider another example: policies of the U.S. government over the past two centuries have brought about substantial and in some cases total destruction of Native American groups, but the charge of genocide can be opposed by claims that the state's intent was always something other than this destruction. The practical outcomes of a course of action are not decisive. Put another way, the experiences of the victims are not what makes genocide. The focus of the UNGC definition is not on victims at all but on perpetrators. Nor is this surprising, after all, because international law is concerned only with the provable guilt or innocence of concrete individuals. Rather than being a problem, or a woe, or a calamity, or even a structure or a process, genocide is essentially an offense.

With these three essentialisms (genocide is an offense, it attacks the organic basis of social groups, it is an aspect of state formation) the UNGC is surprisingly consistent

See, for example, the debate on $\mathrm{H}$-Genocide regarding the genocidal character of Palestinian suicide bombings, initiated by R. J. Rummel in the post "Re: Genocide bombing of Jews" on 19 August 2003 and continuing until 7 September 2003 (viewable at http://h-net.msu.edu/cgibin/logbrowse.pl?trx=lm\&list=H-Genocide). 
with the very first formulation of the term 'genocide', which appears in Raphael Lemkin's Axis Rule in Occupied Europe $e^{39}$ - surprisingly, because of the political contingencies that determined its wording. An earlier draft of the resolution included political groups among the groups whose destruction could constitute genocide, but this was opposed by representatives of the Soviet Union and others [Kuper 1981: 23-30]; an entire article delineating criteria of cultural genocide was removed at the urging of U.S. representatives [Churchill 1998: 365]. But these cynical expediencies had the effect only of synchronizing international law with Lemkin's earlier formulation. That formulation specified a range of "fields" in which the German genocides were being carried out: political, social, economic, biological, physical, religious, and moral [Lemkin 1944: 8290]. However, as Dirk Moses [2004] has pointed out, the physical field (which included mass killings, endangering of health, and restriction of food supply) was essential to Lemkin's conception of genocide as distinct from other crimes. "Denationalization", for example, was an inadequate term because, among other considerations, "it does not connote the destruction of the biological structure" [Lemkin 1944: 80]. The same is true for terms like "Germanization", "Magyarization", and so on; the Germanization of the Poles, for example, "means that the Poles, as human beings, are preserved and that only the national pattern of the Germans is imposed on them. Such a term is much too

39 Lemkin's germinal book, nearly 700 pages in length, provides a detailed, country-by-country account of the practices by which Nazi Germany and its allies governed social life in the territories under their control, and describes the violence and destruction inflicted on persons and on social, political, economic, and cultural institutions of various subject peoples, including Jews and other groups. Chapter IX of this text proposes the new concept of 'genocide' to refer certain aspects of this occupation, and by implication to any similar actions by other states. After the war, Lemkin was a key participant in the U.N.'s deliberations to criminalize genocide in international law. As 
restricted to apply to a process in which the population is attacked, in a physical sense, and is removed and supplanted by populations of the oppressor nations". Although Lemkin's conception of genocide includes the destruction of cultural institutions and of the "national pattern" of a group, physical destruction is also a necessary component of genocide, and so cultural genocide on its own is not genocide in terms of the 1944 formulation. And Lemkin's conception is explicitly concerned with national or ethnic groups and not with social groups more broadly conceived. Lemkin states clearly, "By 'genocide' we mean the destruction of a nation or of an ethnic group" [Lemkin 1944: 79]. Moreover, the point of 'genocide' for Lemkin is specifically to protect the collective right to existence of national groups, in the same way that the individual's right to life is already protected, because of the unique value of national groups:

The world represents only so much culture and intellectual vigor as are created by its component national groups. [...] The destruction of a nation, therefore, results in the loss of its future contributions to the world. Moreover, such destruction offends our feelings of morality and justice in much the same way as does criminal killing of a human being: the crime in the one case as in the other is murder, though on a vastly greater scale. [Lemkin 1944: 91]

Whether politically sovereign or not, the nation for Lemkin has a right to life equivalent to that of the sovereign individual. The concept of 'genocide' is designed specifically to protect that right.

If it is recognized that Lemkin defines genocide in terms of the violation of a nation's right to its collective existence, then there emerges clearly a feature of Lemkin's formulation that is important because of the confusion it has occasioned, and because it is 
repeated in subsequent definitions. This feature is its twofold structure, involving a semantic component and a theoretical component. The semantic component specifies relations among terms: "by 'genocide' we mean the destruction of a nation or of an ethnic group". The theoretical component describes historical objects to which the semantic formulation may apply and constructs a model of the inner structure of those objects. This same twofold structure is found in many, if not all, definitions of genocide: for example, Fein defines genocide as "genocide is the calculated murder of a segment or all of a group defined outside the universe of obligation of the perpetrator" [Fein 1984: 4]. This a formulation directly conflates a specification of what the thing is, or of how to recognize it, with an explanation of why the thing happens. In Lemkin's case, the semantic and theoretical components are more easily separable. Genocide "is" the destruction of a nation. However, it may happen in two ways: immediately, through the "mass killings of all members of a nation" [Lemkin 1944: 79] (but "generally speaking" it "does not necessarily" involve this); or it may involve "a coordinated plan of different actions aiming at the destruction of essential foundations of the life of national groups". The different fields described on pages $82-90$ are fields in which genocide "is being carried out" [ibid.: 82] by the German occupiers; they do not form part of the semantic specification of genocide but are an example of its use and a theoretical explication of what are the "essential foundations of the life of national groups". That these foundations include moral, religious, cultural, etc. practices as well as physical facts is a sociological claim, not a definitional statement. In other words, Chapter IX of Axis Rule can be read 
as defining its terms (in the sense of semantic specification) in its opening two sentences and then proceeding to a theoretical exposition of how and why nations or ethnic groups are destroyed, an exposition that involves certain sociological claims about the nature or structure of nations and their conditions for survival. As Moses observes [2004: note 21] these claims are of a communitarian nature and so "baffle" American liberals who think in individualistic terms; they entail an organicism about the social that is reproduced in the UNGC. And if one wishes to use the term 'genocide' but to employ a different sociological theory, then one will depart from part or most of what is presented as definitional (in the sense of providing rules for usage) in Axis Rule. This problem is at the heart of the current definitional debate.

Axis Rule, then, marks the first appearance of the word 'genocide'. However, this is not the origin of the concept. In 1933, Lemkin submitted a proposal to the International Conference for the Unification of Criminal Law in Madrid "to declare the destruction of racial, religious, or social collectivities a crime under the law of nations" [Lemkin 1947: 146]. This proposal included two crimes: 'barbarity', defined as "action against the life, bodily integrity, liberty, dignity, or economic existence" of a person, if taken "out of hatred towards a racial, religious, or social collectivity, or with a view to the extermination thereof"; and 'vandalism', defined as destruction of cultural or artistic works for the same reason. Both sets of terms were deployed in response to specific historical events: 'genocide' to the unfolding Nazi Holocaust; 'barbarism' and 'vandalism' to the Young Turks' forced deportation and massacre of Turkish Armenians in 1915. One could view 'barbarism' as the direct precursor to 'genocide' and 
'vandalism' as an early conception of what would later be called 'cultural genocide', in which case it seems that Lemkin, fashioning two separate instruments, abandoned one in order to sharpen the other. But it is also possible to reverse this operation: to take 'barbarity' and 'vandalism' as an ensemble, and to see that ensemble as a derivation of 'genocide'. This helps us to go beyond a preoccupation with determining the concept's point of origin. Axis Rule is the best candidate for that point, but the existence of the 1933 precursors disrupt its claim to originary status without providing an alternative. So instead of seeing 1944 as an immaculate conception followed by the degenerate proliferation of variants, we can regard it as a moment of transition, a figurational watershed. If the historical artifact 'genocide' combines together a number of conceptual or semantic threads, 1944 was the moment of their tightest interweaving: because for the last time Lemkin's definition was singular and without competitors, and because it was narrower than any previous formulations. From that moment those threads branched out again, not only forward in time but backwards. In 1933 they had loosened substantially but still combined in one double term disparate significations regarding the integrity, dignity, and rights of persons; the possible criminality of state action; the necessary bases of social life and collective identity. These conceptual elements did not come from nowhere: they were already circulating thickly in discourses of state and right, and Lemkin had only to assemble them. Genocide scholars have not examined much the conditions that made this assembly possible, nor traced those threads past the point where they entered Lemkin's hands. The prehistory of 'genocide' is still waiting to be written. 
Regardless, after coming together in 1944 the conceptual threads of 'genocide' loosened again: first slowly, in the negotiations up to the 1948 Convention and in the long quiet afterwards in which the term was little used, and then more quickly as the word entered wider circulation in three broad and overlapping fields of discourse. The least variation occurred in legal discourse, where the law was not used until the 1990 s. Neither was it modified, except by the terms of its ratification by individual states. Most notable of these is the American ratification, which did not happen until 1988 and only then with modifications that narrowed the definition of the crime of genocide, and stipulated that the United States must consent to any prosecution of itself under the terms of the convention.

Greater variation has appeared in public, politically oriented uses of the term. These variations have tended to emphasize either mass destruction of human life or the willful destruction of a group. For example, Black Americans in the civil rights movement in the 1950s expressed fears of a genocide by white supremacists [see e.g. Griffin 1977]. Later on, both slavery and the general condition of Blacks in racist America would be called genocide. During the Vietnam War, Sartre accused the Americans of genocide in Southeast Asia [Sartre 1968]. Of course Aboriginal peoples throughout the Americas, whose historical experiences fit closely both the 1948 and 1944 formulations, have used 'genocide' to describe both their past and present circumstances [Churchill 1998]. And in arguably the most problematic appropriation, the term has drifted into debates over reproductive rights and new reproductive technologies: the phrase "genocide of the unborn" is applied to abortion in general [e.g. Cunningham 
1998], medical research on fetal tissue [Colson 2000], and selective abortion of female fetuses for the purposes of having male children [Subramaniam 2003]. At the same time, all of these and other deployments ${ }^{40}$ have been contested by partisans of those who would be indicted by them. They have also been contested by those who wish to retain for themselves exclusive or privileged access to the peculiar moral capital that comes from the status of being a victim of genocide.

But it is in the field of scholarly discourse that the concept of 'genocide' has undergone the greatest proliferation of variations, through the endless production (one for each scholar, seemingly) of definitions, each of which by its very precision and its attempt at mastery manages to produce a new combination of elements and deploy them along a new vector. Nor are these scholarly productions isolated from legal and public discourses; they are intimately concerned with them, and especially with the need to master them: to halt the wanton overuse and enfeebling of the term 'genocide' in public use, and to waken from slumber and put into action its legal use. The ambivalent project of the scholars has been simultaneously to depoliticize 'genocide' (giving it a rigorous meaning) and to render it effective (incorporating it into praxis). Three general tendencies have emerged between the 1970s and the new millennium: particularism,

40 My list is far from exhaustive. Jack Nusan Porter, for example, claims that the term genocide "has been applied to all of the following: 'race mixing' (integration of blacks and non-blacks); drug distribution; methadone programs; the practice of birth control and abortions among Third World people; sterilization and 'Mississippi appendectomies' (tubal ligations and hysterectomies); medical treatment of Catholics; and the closing of synagogues in the Soviet Union. In other words, when one needs a catch-all term to describe 'oppression' of one form or another, one often resorts to labeling it 'genocide' [Porter 1982: 9-10]. Helen Fein claims that "the wave of misuse and rhetorical abuse parallels the alphabet: abortion, bisexuality, cocaine addition, and dieting have also been labeled as examples of genocide - as well as suburbanization" [Fein 1994: 95]. However, these and other authors who cite the range of public uses of the term 'genocide' do so 
ChAPTER II: IDENTIFYING GeNOCIDE

liberalism, and post-liberalism ${ }^{41}$. Particularist scholars regard the UNGC as too broad already and want to narrow the notion of genocide until it includes only one event: the Holocaust of the Jews, the Shoah. Even the attempt at restriction leads to a conceptual proliferation, however. Bauer [1978: 35-38; 2001: 10-12] distinguishes between holocaust and genocide, Katz [1994: 131] between genocide and cultural genocide. Both oppositions attempt to reinscribe the uniqueness of the Shoah through the first category which includes it alone, the second - derivative, supplementary - category extending to events which resemble but do not equal it. Liberal and post-liberal scholars, on the other hand, both reject the categorical uniqueness of the Shoah in favour of genuinely comparative scholarship. For liberal scholarship, an act is genocidal in virtue of its perpetrators' specific intentions (to destroy a group, to kill according to group membership); for post-liberal scholarship, genocide is identified by its structural outcomes (the destruction of a group, the obliteration of a collective identity). Moses [2002] distinguishes between two groups of scholars, liberals and post-liberals, but it is perhaps more apt to think in terms of liberal and post-liberal thematics that recur in texts and groups of texts. For example, Fein, a liberal who defines genocide as "calculated murder" also builds a structural criterion into her definition: exclusion from the "universe of obligation" [Fein 1984: 4$]^{42}$. Churchill, a post-liberal who highlights the structural similarities between colonial genocides and the Holocaust, proposes a new legal 
definition of genocide that distinguishes among four degrees of genocide, differentiated by the presence or absence of forms of premeditation [Churchill 1998: 432-435]. If intentionality, the UNGC's third essentialism, serves as one pole of an axis for which the other pole is complete structuralism, then a given definition may combine conceptual elements from differing points along that axis. And if the other two essentialisms define similar axes, then the range of possible variations is vast. Hence the proliferation of terms: in addition to the differing ways that 'genocide' is defined, it is supplemented by an ever-expanding lexicon: ethnocide, linguicide, gendercide, cultural genocide, autogenocide, politicide, democide, mass murder, genocidal murder, genocidal relations, genocidal society. Each term, by establishing its difference from the term 'genocide', alters the meaning of the original term and of all the others. In addition, not all of these terms are equally established: not all are widely used, or used the same way; they overlap, they substitute for one other, they are all susceptible to being subsumed under 'genocide' even as they both affirm and undermine its primacy. For example, is gendercide a special case of genocide, or a related but separate phenomenon, or both? If ethnocide is more widespread than genocide, which of the two is the master category and which the subcategory? The meaning of the word 'genocide' varies with every new definition that is proposed in every new work on the subject, and also with every new supplementary or qualifying term.

\subsection{EsSentially CONTESTEd CONCEPT}

Perhaps 'genocide' should be regarded as an essentially contested concept [Gallie 1956]. One conspicuous feature of the definitional debates regarding 'genocide' is the 
importance of its extratheoretical function. How 'genocide' is defined affects not only which events are labeled genocides and which are not, but by implication how the moral, political, and legal energies mobilized by 'genocide' will be applied: which perpetrators will lose and which victims will gain the greatest moral capital; which projects of memorialization or rehabilitation will receive the greatest support; which existing governments will be de-legitimated; ultimately, who will or will not be charged under the terms of the UNGC. The very existence of these energies is one of the stakes invoked in the debates whenever it is claimed that broad usages dilute or dissipate the unique value of the term or, conversely, that narrow definitions prevent its ever being used effectively. The definitional debates involve a strong element of partisanship: the conceptual differences between liberalism and post-liberalism, for example, roughly correspond to a narrower or broader recognition of genocides against indigenous peoples, and hence to differing valuations of patriotism, European civilization, modernity, and Enlightenment. These functional disagreements (disagreements over what work 'genocide' is expected to do) are more or less openly recognized, and yet this recognition does not end the debate with contestants agreeing to go their separate ways. Instead,

Each party continues to maintain that the special functions which the term [... ] fulfils on its behalf or on its interpretation, is the correct or proper or primary, or the only important, function which the term in question can plainly be said to fulfill. Moreover, each party continues to defend its case with what it claims to be convincing arguments, evidence, and other forms of justification. [Gallie 1956: 168]

When we encounter this situation in everyday life, Gallie says, we are tempted to view the situation as a straightforward conflict of interests and the reasons offered by the differing parties as simple ideological justifications. In philosophy, the same situation 
may hinge on metaphysical disagreement. In both situations argument is wasted because the crucial issues at stake are actually beyond argument. However, Gallie points to the existence of a third case: disputes "which, although not resolvable by argument of any kind, are nevertheless sustained by perfectly respectable arguments and evidence" [ibid.: 169]. These are essentially contested concepts. 'Genocide', it turns out, is an essentially contested concept par excellence.

Gallie specifies five primary and two supplementary conditions for the essentially contested quality of a concept. First, the concept must be appraisative. That is, it must imply a strong value-judgment ${ }^{43}$. Although not all authors conceptualize genocide specifically as an offense, all agree that it is an evil. Second, its object must be of an internally complex character; third, the object must be initially variously describable, in that its particular value can be accounted for by any number of different ways of arranging and prioritizing its component elements. Genocide involves a diverse array of elements: state power; mass murder; victims' defenselessness; collective identity; and so on. Its evil can be differently accounted for through different arrangements of these elements, in which one element figures more prominently than the others or in which a particular arrangement of elements is specified. Particularists, for example, combine elements of intent, murder, the totality of destruction, and collective identity, with the totality of physical destruction repeatedly emphasized as the most important single

$43 \quad$ Gallie speaks directly only of concepts that make positive value-judgments. However, nothing specifically prevents expanding the use of 'essentially contested concepts' to include also negative appraisals. 
factor $^{44}$ [Bauer 1991; Katz 1991; 2001]. Though many authors prioritize "mass death" as a criterion of genocide, not all do: Thompson and Quets, for example, do not specifically mention death or murder in their definition [Thompson and Quets 1990: 248]. Fourth, the concept must be open to modification in the course of changing circumstances, in ways that cannot be predicted in advance. For example, the massacres and mass starvation inflicted on Cambodians by the Khmer Rouge government did not involve a relationship of national, ethnic, racial, or religious difference between perpetrators and victims, but in manifold other ways resembled a genocide. Despite the absence of this one crucial criterion, the events were labeled a genocide and even prompted the invention of a new derivate term: 'autogenocide' [Lacouture 1978], genocide against a group committed by members of that group. Fifth, the different parties to the dispute must recognize that the concept is disputed and engage "aggressively and defensively" [Gallie 1954: 172] with other usages to maintain their own. In other words, they must be engaged in definitional debate.

To distinguish an essentially contested concept from a concept that is simply confused, Gallie introduces two supplementary conditions. First, the concept must be derived from an original exemplar, an event or example that all participants to the dispute agree represents an appropriate and unqualified application of the concept. In genocide studies this event is the Shoah. Despite disagreement over whether the Holocaust includes only the Shoah or also includes Nazi mass murders of other groups - Gypsies,

$44 \quad$ Sometimes the intentions and the actual accomplishments of the Nazis are conflated, e.g.: "Total physical annihilation I prefer to call Holocaust, and that of course means that whereas that is what happened to Jews - and the fact that a percentage of Jews survived in Europe was due not to any 
Poles, homosexuals, disabled persons, etc. - all are united in affirming that what happened to the Jews of Europe was genocide. To say otherwise is to be a Holocaust denier and, as such, is the only form of denial that counts as automatic and unquestioned grounds for exclusion from the domain of credibility. Finally, recognition of the status of the exemplar must also have a certain open-ended quality to it, such that continued contestation of the usage of the term must be plausibly considered to extend the salience of the term, to further the point of having called the exemplar by that term in the first place. Superficially this appears to be one of the stakes in the debate between particularists and others. Katz, for example, says directly that referring to other events as genocide undermines to the point of sacrilege the entire value of having called the Shoah a genocide in the first place. On another level, however, Katz is endorsing the continued contestation of the term. By affirming his preferred usage of 'genocide' he claims to be sustaining the point of speaking about genocide and not just about Shoah, just as authors who disagree fundamentally with his usage also claim be doing the same thing [Moses 2004].

If a concept is essentially contested, then logic will not avail to resolve definitional disputes, because no general principle for deciding which usage is best can be found or specified [Gallie 1956: 189]. Where does this leave us with respect to 'genocide'? One possibility is that the definitional debate should be seen as reducing to a simple political contest between those who wish to stigmatize and those who wish to normalize certain historical and contemporary instances of violence: against Native 
Americans, or Gypsies, and so on. In terms that I laid out at the beginning of this chapter, this view sees the polemical effectivity of 'genocide' as essential and its descriptive effectivity as secondary or derivative. Definitional questions reduce to the question, 'whose side are you on?'. By the standards of practice or praxis this is unsatisfactory, because for any term to have some political or consciousness-raising effectivity it must invoke a relatively stable (portable, reliable) descriptive effect; it must indicate more than disapproval.

A similar possibility is to regard 'genocide' in purely performative terms: for whatever idiosyncratic reasons of my own, I wish to call some event or events 'genocide', and so I proceed by proposing a definition of my own and by trying to enroll some community of speakers who will establish this definition simply by using it. This approach is also profoundly unsatisfying. For one thing, it lacks ambition. It would be worthwhile to attempt something more interesting than adding one more term to the interminable and slowly proliferating game of juxtaposed and competing essences. Any move within this game that simply says "I don't quite like your definitions; here is another" only substitutes one essence for others, elaborates one more variation of the elements or takes one more position in the grid already evoked by the three essentialisms of the UNGC. What is more interesting, and perhaps more politically effective as well, is to think 'genocide' in a way that takes into account the existence of this grid - and then displaces it. Rather than formulate yet another roving ahistorical essence, I would like to 
define 'genocide' in relational terms, not so much to resolve the definitional debate but to recast it.

In any case, Gallie points towards a solution. He distinguishes between the "logical" and the "historical" senses of what it is to understand a concept. The distinction is that of synchronicity versus diachronicity: the logical sense involves being able to state and conform to the rules governing a concept's use, while the historical sense involves knowing about "the whole gamut of conditions that have led to, and that now sustain, the way we use it" [Gallie 1956: 196-197]. For certain types of concepts, for example scientific concepts vindicated solely by their predictive accuracy, the logical sense is sufficient. However, for appraisative concepts a purely logical understanding is insufficient, precisely because the rules of use may be essentially contested. In these cases a logical understanding must be supplemented by a historical understanding:

For, if we want to see just what we are doing, when we apply a given appraisative concept, then one way of learning this is by asking from what vaguer or more confused or more restricted version (or ancestor) our currently accepted version of the concept in question has been derived. [Gallie 1956: 198]

This is not a search for origins. Prior versions may be vague or confused or perhaps unduly restrictive. The point of history is not to find an essence accidentally lost, but to identify the conditions that produced and sustain a signifying practice. Or, it is tempting to say: an essentially contested concept can be clarified by unearthing its buried usages, mapping out the system of dispersions that has been disguised behind attempts at functionalist coherence, by revealing or producing a formerly subjugated knowledge of its strategic operation. 


\subsection{GeNEALOGY}

Given this essentially contested quality of the concept 'genocide', should clarification proceed by way of genealogy? Genealogy does offer useful insights into how investigation of genocide operates in relation to strategies of power. However, if the point of investigating the historical and political situatedness of 'genocide' is to facilitate its effective use, then genealogy on its own is an insufficient basis for such investigation. The point of genealogical examination of discourses is, in part, to disrupt their efficacy, to make it more difficult to go on using terms or signifiers in their accustomed ways, without necessarily providing a new and better way of using them ${ }^{45}$. Because I want to go on using 'genocide', if in a modified fashion, and because I am not interested in anything as metaphysical as the idea that "contemporary man" has of "himself", I will have to go beyond a strictly genealogical account of 'genocide'. In this section, then, I explain the insights that genealogy does contribute to the problem of using 'genocide' coherently, and will discuss some of its specific limitations.

To be schematic, and perhaps over-simplistic, one could say that Foucault's conception of genealogy has seven qualities laid out neatly in "Nietzsche, Genealogy, History" [Foucault 1984]. First, it proceeds through exhaustive documentation of events, on the assumption that no detail and no type of detail can be said to be trivial in principle. Second, it opposes itself to any search for origins, for any definitive starting point which

\footnotetext{
45 "When the book [Discipline and Punish] came out, different readers - in particular, correctional officers, social workers, and so on - delivered this peculiar judgment: 'The book is paralyzing. It may contain some correct observations, but even so it has clear limits, because it impedes us; it prevents us from going on with our activity'. My reply is that this very reaction proves that the work was successful, that it functioned just as I intended. [...] The readers have simply found themselves involved in a process that was under way - we could say, in the transformation of
} 
is not preceded by any prior historical development. Third, instead of searching for origins it traces lines of descent, lines that wrap around and imprint on human bodies. Fourth, instead of origins again it identifies points of emergence, moments of arising or of entry of particular forces, violences, power plays that rearrange the relation between knowledge and bodies. Fifth, it proceeds by effective history, in two senses: that of a history of effects, in which an event "is not a decision, a treaty, a reign, or a battle, but the reversal of a relationships of forces, the usurpation of power, the appropriation of a vocabulary turned against those who had once used it, $[\ldots]$ the entry of a masked 'other"' [Foucault 1984: 88]; and second, in the sense of a history that has effects (though this is less explicit), that overturns traditional histories with their dependence on metaphysics, that affirms the perspectival nature of knowledge and so creates space for the insurrection of subjugated knowledges [Foucault 1980: 81-83]. Sixth, in the same vein, genealogy rejects any attempt at a philosophy of history. And seventh, it redeploys to new, critical, effect the three modalities of history identified by Nietzsche in opposition to those of Plato: parody, dissociation, and sacrifice. What is parodied are the monuments of the past as emblems of an enduring, transcendent reality; what is dissociated is the identity of disparate events that joins history into an unbroken continuity; what is sacrificed is the subject of knowledge: that disinterested and just subject, who judges the past by a standard of justice held in the present, is sacrificed to a recognition of the violence and injustice of knowledge, on which it is always founded, and of the maliciousness with which it wraps around the body and threatens to stop up the very motion of life itself. 
Genealogy, then, recognizes the formation of knowledge as a power struggle, the will to knowledge as a variant of the will to power. But it does not simply celebrate this power; more precisely it does not celebrate domination. Neutral, disinterested, objective history is unmasked, its aspirations to totalitarianism are revealed [Foucault 1980: 80]. This is done precisely to open space for the insurrection of subjugated knowledges, a power play that involves two elements. One is the archaeological unearthing of the buried and disguised historical contents of knowledge; the other is the rehabilitation of the knowledges held by those who have been previously disqualified as knowers: the mad, the sick, the delinquent, the sexually deviant - and even those who work with them directly, the nurses and doctors, for example, "parallel and marginal as they are to the knowledge of medicine" [ibid.: 82]. This insurrection is carried out not in the name of a transcendent justice that, standing outside merely historical relations, provides the standard by which they may be brought into their appropriate balance. It is carried out in terms of the will to power itself, as that will is activated by subordinated groups [Chomsky and Foucault 1997]. And this genealogical mobilization of a will to power that is not rationalized in terms of anything but itself is not simply a reactionary antimodernism; Foucault identifies genealogy precisely with Enlightenment and with critique. Against those who, either for or against Enlightenment, identify it with rationalism and with fidelity to fixed doctrinal elements, Foucault traces out a "thread" that consists of "the permanent reactivation of an attitude - that is, of a philosophical ethos that could be described as a permanent critique of our historical era" [Foucault 
1988: 312]. This ethos involves a limit-attitude, a concern to analyze and reflect upon limits. But whereas for Kant the limit-attitude took the form of knowing the limits beyond which knowledge could not go, Foucault believes that "today" the Enlightenment ethos requires a questioning of limits, a search for indeterminacies, and an exploration of transgression [ibid.: 315]. Genealogy is one form of a broader project that "requires work on our limits, that is, a patient labor giving form to our impatience for liberty" [ibid.: 319].

A genealogy of 'genocide', then, does not precisely reject rationalist attempts to specify a fixed set of elements that define once and for all what 'genocide' is to mean; rather it takes those attempts as part of its object of interrogation, as standing as much in need of explanation as do the various phenomena to which the term refers. Genealogy emphatically rejects any hint of that metaphysical operation through which the meaning of a term is treated as existing independently of its merely actual use, such that the task of the framer of definitions is one of discovering, for example, what genocide really is. But it should not be confused with that thoroughly nominalist social constructionism for which 'genocide' may mean anything at all, on the grounds that it means simply what some community of speakers uses it to mean, because for the genealogist speakers are not self-sufficient rational individuals deciding freely, but social actors located within matrixes of power, engaged in strategic contests, and faced continually with prospects of failure. Genealogy investigates the operations of power that give 'genocide' its capacity for truth-telling. 
Genealogy, then, is quick to note that the first appearance in print of the term 'genocide' is not a point of origin but a moment of arrival, of re-presentation. Particular forces that had been more or less diffusely related, that had been drawing closer together for decades and, in a different way, for centuries, were assembled tightly together by Lemkin, not once but twice: first in 1933 under the labels 'barbarism' and 'vandalism', and again, with some elements trimmed away, in 1944 under the hail of 'genocide'. And it was possible for Lemkin to perform this labour because the materials were ready at hand. Modern state-formation had already done most of the work by constituting itself on the basis of the gens, on the distinctive genre of people proper to its nationhood, and even (especially from 1850 onwards) of distinct genetic populations. The prehistory of 'genocide' (the history before it is written as "genocide") involves the history of nationalism, of the laborious production of the category 'ethnicity' and its various kin. It also involves the history of racism, and not only because the criminalization of genocide is part of the delegitimation of racism. Significantly, the UNGC does not repudiate racism but enshrines a liberal, egalitarian racism, in which the naturalness of race is assumed but the destruction of races is prohibited. There is nothing anomalous about this. For persons to have a legal protection against racial extermination, racial identities first had to be constituted as such through the historical labour of racialization. Lemkin coined 'genocide' to affirm the right to survival of new forms of collective identification that only recently had been assembled by the modern nation-state.

Nor does this history begin with the modern state: the prehistory of genocide involves the history of Europe's varying practices of difference, the drawn-out and 
spastic mutation of its self-identity and of its relation to its various others - in the Islamic world, in the New World, and so on. It extends to the life-and-death struggles waged by competing bands of northern European barbarians in the long years before their Christianization; it extends even to the anxieties of the civilized Roman Empire in its days of decay as it stood threatened by, among others, the Vandals whose name Lemkin used for his term for cultural genocide. But just as these varied forms of heterophobia were not predestined to evolve into racism (understood as a specifically biological essentialism), the anguish of collective survival and collective holocaust was only contingently transmuted into the criminality of genocide. Between acts of cultural obliteration celebrated in ancient European mythology ${ }^{46}$ and the modern codification of a law prohibiting the murder of nations, stand any number of contingencies and discontinuities, events not in the history of an idea but the genealogy of a power/knowledge formation.

What happened in 1944 (or 1933, or 1948) was not so much a culmination as a new inflection. If 'genocide' was a novel recombination of elements lifted from the matrix of state practices, then with the UNGC those elements were re-introduced into that matrix - only to do nothing. Or, almost nothing: they incited a certain tension. But for nearly half a century the law against genocide could only strain against its leash, and not for lack of recognizable genocides. By its very design the law requires that state sovereignty be compromised, and state sovereignty is the very material basis of the 
United Nations; to prosecute a member nation for genocide would entail a contradiction that is both conceptual and practical. So despite, or because of, this legal inactivity, the concept of 'genocide' has enjoyed a complex proliferation outside legal discourse. Very hastily, it can be said that 'genocide' is sustained through three sets of practices. First, it is deployed in practices of state politics as a token that can legitimate or delegitimate, a token that can be used by non-state actors as well as states themselves (and perhaps more easily). Ward Churchill invokes a history of genocide as a basis for the aims and means of the American Indian Movement; Sartre accuses the United States of genocide in southeast Asia to oppose the invasion of Vietnam. Second, it is invoked in practices of memorialization through which past events are actively remembered as genocide. In the most conspicuous examples, different actors attempt to construct or assemble out of myriad traces - documents, survivors' narratives, physical sites - a unitary truth about a unified event; but it is also possible to recognize an irreducible multiplicity in memory. Third, 'genocide' is mobilized in practices of identification, projects of the formation of collective identities. For Jews, Armenians, Aboriginals, African-Americans, and others, the existence of a genocidal past both modifies and reaffirms identity. The uses of this are many: anti-choice activists who talk of a "genocide of the unborn" affirm an embattled Christian identity through this accusation that they do not make on their own behalf. All three practices come together most vividly around the State of Israel, the only state formed explicitly by survivors of genocide since the term has been in use. (Yet here of course 'genocide' appears ambivalently, sometimes as a general category but often as secondary or derivative of 'Shoah'.) 
Practices of scholarship with respect to genocide must constitute themselves in relation to these other fields of practice. But they also have their own distinct mission, everywhere expressed in terms of ending the actual practice of genocide. On this point a Foucaultian critique of genocide studies makes its most compelling point. Scholars of genocide quite explicitly seek to construct a power/knowledge formation so as to govern genocide. Particular events that previously were known by a variety of labels must be reconstituted as genocides so that genocide may be studied. Knowledge about genocide must serve the needs of a power over genocide, a power that will intervene into sovereign bodies politic to halt its pernicious mechanism in the early stages. Effective and economical intervention depends on surveillance, on a gaze that knows what to look for so that genocide may be detected before it erupts, on a gaze that also is known to be looking so that would-be genocidaires are deterred. The operation of this surveillance requires and enables an extension in the scope of knowledge: the types and the stages of genocide are distinguished, and these tables will become more refined and extensive as knowledge progresses. Scholarly work to end genocide will form part of a disciplinary matrix through which states themselves are disciplined, tamed, made docile. And even if the state is to be tamed, the scholars have still not quite managed to cut off the head of the $\mathrm{king}^{47}$, for this disciplinary power still needs to be underpinned by the juridico-political superpower: for most, the United Nations; for some, the United States ${ }^{48}$. 
I think that any properly sociological account of genocide and 'genocide' must include or at least recognize those historical processes that, with the aid of genealogy, I have briefly sketched above: the interactions, both complementary and contradictory, among various projects of state formation and identity formation through which emerges the concept of 'genocide'. I think also that to think of genocide scholarship in terms of its attempted construction of a power/knowledge formation raises important and difficult questions regarding the relation between scholarship and that state power whose crimes or excesses it seeks to curb, and I will return to these questions in Chapter 5 below. However, I think that regarding genocide scholarship as a discipline in the way that Foucault has examined the disciplines also makes clear why a strictly genealogical account of genocide or even of 'genocide' is insufficient.

This insufficiency has three aspects. First, genealogy is primarily or irreducibly an inquiry into knowledge ${ }^{49}$, and I do not so much wish to explain knowledge of genocide as to produce it. It is true that genealogy not so much transgresses as demolishes any opposition between knowledge and practice or knowledge and power and that Foucault's analyses of discourses have produced an analytics of power that has generated important substantive insights into the workings of power under conditions of modernity, not least of which are his comments on biopower and its relation to

times he seems to state plainly that discipline is underpinned by sovereignty and operates partly as an extension of it [1980: 104-106; 2003: 241]. refused to give it immunity from the newly formed International Criminal Court in the Hague. In a post to H-Genocide on 25 September 2003 titled "Democracies and Genocide", genocide scholar R. J. Rummel argued in support of this measure on the grounds being subject to the ICC might hamper the American state's ability to combat terrorism [Rummel 2003]. See, for example, Foucault 1994: 284-291. 
genocide $^{50}$. However, these insights are produced through an investigation that takes knowledge as its central object of inquiry, and that maps the topographies of power/knowledge networks by tracing outwards from assemblages of texts. If genealogy shows that the concept of 'genocide' is not determined by the simple existence of diverse acts of violence - deprivations, prohibitions, murders - that band together and cry out for a name, it is also clear that the performance of those acts is not determined by the deployment of that concept, which has until recently been confined largely to museums and libraries and occasional moments of public accusation. In short, discourses of genocide do not govern their object as do discourses of penality or madness or sexuality. In any case, genealogy is never exhaustive (nor does it aim at totality); there are always other discourses or other forces at work beyond those of a particular disciplinary matrix, which require a study that is not strictly genealogical. ${ }^{51}$

Second, if the discourse of genocide is regarded as a disciplinary matrix in the same way as discourses of penality or of madness are so regarded, then its most striking feature is its incompleteness. Foucault's work examines discourses that have succeeded in establishing a formidable array of tactical relationships that assemble together elements of state power, professional expertise, and generally distributed normativity to

$50 \quad$ I further discuss biopower in Chapter 3 below.

51 'Require' is probably too strong a word. Genealogy is a form, and forms can be made to do all sorts of things: some of the most interesting effects are produced by the application of a form to contents for which it was not intended. The sociology of genocide (or of anything else) could be cast entirely as a problem in the sociology of knowledge: How do perpetrators come to know themselves and their victims in ways that entail genocidal actions? In this case 'knowledge' refers not only to information used to facilitate genocide (lists of names, maps of communities, networks of informants, etc.) but also to identity/identification understood both as information and as practice. If we abolish the opposition between the material and the ideal then every way of acting can be treated as a form of knowing This is very nearly the path I actually will take (see page 97 
make subjects subject to the exercise of a discipline that, while never total, is certainly extensive and intensive. Discourses of genocide have not enjoyed comparable successes as yet. Until the establishment of the International Criminal Tribunals in the former Yugoslavia in 1993 and in Rwanda in 1994, and the more recent institution of an International Criminal Court, disciplinary knowledge of genocide has not been joined to any means for the actual deployment of force on bodies. Perhaps these developments do amount to the beginnings of a discursive formation; undoubtedly the operation of knowledge about genocide in relation to power over genocide already reproduces forms that appear prominently in studies of governmentality in other arenas. But beyond these resemblances there is another important difference: 'genocide' aims to govern not the subjects of states but states themselves. It seeks to place certain limits on processes of subjectification. Perhaps it does this in order to secure the very conditions of possibility for subjectification, to protect subjects' rights to their subjectivity. But for this reason 'genocide' is a more contradictory concept than 'sexuality' or 'delinquency'.

Third, if genealogy is an aspect of the patient labour giving form to our impatience for liberty, then genocide scholarship is already partly genealogical. Research on genocide proceeds precisely by the archaeological methods of, on the one hand, patiently and meticulously unearthing the discarded and suppressed contents of history, the gray and banal documentary record of acts of state committed for reasons of state, and on the other hand of rehabilitating of the disqualified knowledges of the survivors. At the same time as it seeks to fix the immutable and ahistorical necessity of 'genocide', this 
scholarship opposes the necessity of genocide and calls into question supposed immutables regarding sovereignty and identity whenever these get in the way of genocide. Discourses of genocide operate partly through metahistorical attempts to define 'genocide', but partly by a critique that resembles genealogy, and one that aims to mobilize the military violence of states precisely in order to oppose the absolute right of states over the life and death of their subjects. Genealogy can reveal the contingency of 'genocide' but it is less useful in accounting for the potential conditions of its effectivity. To that end something more than genealogy is required.

\subsection{Figuration}

Elias's conception of figurational sociology provides that 'something more' by connecting a history of signifying practices with a history of sovereign power, which is the particular form of power that 'genocide' is most directly concerned with. The Civilizing Process opens with a question: what are the social origins (what is the sociogenesis) of the concept of 'civilization' as opposed to the concept of 'culture'? Elias explores the difference in meaning between the German words 'kultur' and 'zivilisation'; he traces the relation of the latter to the French concept of 'civilité' and of also of 'courtoisie'. To explain the history of these related terms he investigates etiquette manuals and other documentary evidence regarding what is considered polite and rude, seemly and gross, refined and repulsive among the elite classes of Europe from the late middle ages to the nineteenth century. And then he turns to a history of the formation of nation-states over the same time period. In short, to explain the sociogenesis of

ourselves to thinking through the lens of 'knowledge'. 
'civilization' Elias provides three histories: a history of concept formation, a history of subjectification, and a history of state formation. But these are not three histories, they are one and the same history: the history of a figurational process (or set of processes, but customary usage privileges the abstract singular) that can be called the civilizing process: a process that at one and the same time is the process of the formation of a concept of 'civilization' understood both in terms of personal behaviour and public institutions, and the formation of those phenomena to which the concept refers. Developments in these three spheres - the conceptual, the subjective, and the institutional - are not merely separate processes that interact causally in some more or less complex set of feedback interactions; they are distinguishable but inseparable elements of a singular dynamic process, steps in the same dance. For Elias, I think more thoroughly than for Foucault, the distinction between the study of knowledge and the study of social relations in general is dissolved; or rather, 'the study of knowledge' denotes not a limited and closed domain within the broader field of social science but a point of entry from which anything can be studied.

This is easier to understand if we consider the picture of human subjectivity and social structure that Elias presents in What is Sociology?. In this work he criticizes sociology for containing a pernicious anthropocentrism manifested through its reliance on an egocentric model of social relations [Elias 1978: 14]. The egocentric model takes as the starting point of sociological investigation an individual conceived of as isolated, complete, and self-sufficient, existing in itself and for itself prior to social interaction. Elias calls this hypothetical individual 'homo clausus' and regards it as a useless fiction. 
Human beings always exist in social contexts, that is in relation to others; the essential human condition is not 'being' but 'being-with-others'. Subjectivity is not something that exists prior to social interaction and is affected by it from the outside; it is fundamentally constituted through social interaction. This conception radically alters the conception of the relation between self and society from that of the egocentric model. Egocentric thinking situates the individual as the bounded and self-contained centre of a series of concentric circles representing successively broader social environments: family, school, industry, nation, etc. Social structure is external to the individual, existing as a reality sui generis.

The very concept of society has this character of an isolated object in a state of rest, and so has that of nature. The same goes for the concept of the individual. Consequently we always feel impelled to make quite senseless conceptual distinctions, like 'the individual and society', which makes it seem that 'the individual' and 'society' were two separate things, like tables and chairs, or pots and pans. [Elias 1978: 113]

The relationship between the individual and social structure is therefore problematic: how do phenomena such as beliefs, habits of action, and so on pass across the boundary between self and society, either to move into the individual from outside as socialization or vice-versa as the individual's effect on society? For this concentric-circles model Elias substitutes the image of a horizontal network of interactions between interdependent individuals: a figuration. Patterned or structured elements in social life exist diachronically as movements or flows: dialogues, exchanges, power contests, and so on. Structures or figurations exist therefore not outside individuals but between and through individuals. Society is not a transcendent reality sui generis but a dynamic form immanent to a complex interactive matrix, so that "societies are composed of 
individuals" at the same time that "individuals can only possess specifically human characteristics such as their abilities to speak, think, and love, in and through their relationships with other people - "in society" [ibid.]. The problem of how society affects the individual and vice versa no longer pertains because there is no boundary separating an interior self from an exterior society. Social structures and psychological structures both exist as aspects of the same interactive processes; developments in social structures are developments in subjectivity, and vice versa. This explains the method of The Civilizing Process: Elias makes no sustained distinction between a history of the concept of 'civilization', of civilized etiquette and the deeply felt affects that go with it, and of the statist territorialization of the means of military violence: all three are distinguishable but inseparable aspects of the same thing, which he calls a figuration ${ }^{52}$.

Here I must confess to thinking that Elias has made a really brilliant move, and yet a move that is only partially completed. It is maybe a personal preoccupation of mine to consider the rejection of anthropocentric thinking to be the single most characteristic feature of the scientific imagination, and to insist that sociology be non-anthropocentric seems both stubbornly perverse and entirely sensible at the same time. Elias's elaboration of a non-egocentric model displaces the opposition between individualism and holism in sociology: neither individuals nor structures have disappeared by being subsumed or reduced to the other, but instead both are placed on the same plane of

52 Even the term 'figuration' reflects this fundamentally diachronic orientation. Like Derrida's neologism 'différance', which operates simultaneously as a noun referring to an existing difference and a verb referring to action (differing, deferring), 'figuration' combines the senses of an object and a process. For Elias the process is more important; he complains of the limitations of existing language that privilege static conceptions over dynamic ones [Elias 1978: 21]. I 
reality, no longer divided by clumsy levels-of-analysis schema. This displacement enables a certain critique of both left-wing and right-wing structuralisms that does not need to resort to its own philosophy of history: if subjectivity is formed through the operation of social interaction, then homo clausus models that take a particular subjectivity as a given can be seen to naturalize a particular social milieu, the one that produces the subjectivity in question.

To digress for a moment: it may be objected that, by excising Elias's use of Freudian psychoanalysis and his insistence that sociogenetic processes are complemented by psychogenetic ones, I am reading into Elias a post-structuralist account of subjectivity that is not altogether his. However, Elias' own rejection of egocentrism provides grounds for this excision. By distinguishing between psychogenesis and sociogenesis (where the latter is understood not in terms of operations of 'society' but in terms of social interaction broadly conceived) and using psychoanalysis to account for the former, Elias is trying to account for the mechanism that enables human bodies to operate as a site of subjectivity. However, in the process he weakens his own sociology with a residual egocentrism: bringing psychoanalysis into the picture, besides needlessly tying sociology to the phallogoeurocentrisms of Freudian theory, reproduces the firm boundary between the inside and outside of subjectivity and reinstates homo clausus at the centre of analysis. A fully non-egocentric figurational sociology conceives of all meaningful phenomena, including those examined by psychoanalysis, as constituted through social interaction. Biological human bodies do not disappear and are not simply overwritten by 
society; they appear instead as material components ${ }^{53}$ that articulate and are articulated through social relations. Bodies are distinctive because they are the localized sites for effects of mind, not because they operate as natural factories for the autonomous production of pre-social meanings (the natural meanings on which the social order is or should be founded). Only by insisting on the thoroughly relational basis of psychological phenomena can Elias' move towards a non-egocentric sociology be completed.

A figurational sociology of genocide and 'genocide', therefore, traces the historical development of those social processes that have occasioned both particular forms of violence and use of the term 'genocide' as a label for them. It potentially includes all of the insights of genealogy; figurational sociology can be performed in a genealogical spirit. However, figurational inquiry is less centrally preoccupied with knowledge than genealogy is; it is not primarily addressed to the disciplines; and does not rely on the insurrection of subjugated knowledges for its emphatic force. Its particular virtue is its capacity, through the examination of long-term historical movements, to situate familiar events in new contexts, and especially to bring back down to earth those events that are so shocking as to seem unique.

For example, if one situates 'genocide' and genocide in relation to what Elias has already examined as the civilizing process, then one can trace a history that extends back to the time, after the eleventh century CE, when the centrifugal tendency of European state power began to reverse itself. (This is merely a convenient watershed; like

\footnotetext{
53 formulation.

Though the phrase 'material component' is somewhat vacuous if the opposition between material and ideal is not maintained.
} 
Foucault, Elias repudiates the notion of a final origin [Elias 2000: 52; 1987: 121].)

Viewed through this extended frame of reference, the Nazi holocaust takes on an altered significance. Instead of being the unprecedented event that gave birth to a new concept which we can or cannot apply retroactively to other events, it is the culmination of a long figurational development. This development involves the emergence of conditions that effect a shift in the equilibrium between two competing conceptualizations of war: one in which war automatically and unproblematically involves the massacre of enemy noncombatants and one in which war is between states and massacre of civilians is an outrage (what Lemkin calls the 'Rousseau-Portalis Doctrine' [Lemkin 1944: 80]). These competing forms have an interesting and complex history that is not confined to the modern period $^{54}$.

But for Lemkin to be successful, by the middle of the twentieth century a shift had to occur in this balance that made certain uses of massacre and of violence both all the more rational and all the more irrational at the same time, so that that century witnessed both the institutionalized illegality of genocide in international law and genocides on a scale and frequency to stun the imagination. This polarization may have had something to do with the fact that, once the imperial scramble for Africa was complete, there was suddenly no longer any outside to the nation-state system. The colonial genocides of the nineteenth century and earlier, in some ways far greater in scope and intensity than the European genocides of the twentieth, did not suffice to call forth 'genocide'. More

54 It would be interesting to investigate, for example, different views within Christendom of the massacre at Béziers; or the varying use of massacre in the wars among European princes both barbaric and civilized (from the Vikings to Charlemagne, and so on); or varying forms of the 
specifically, the polarization of genocide (its illegality and its virulence) serves to reinforce the forms of identity generated by the internalized spaces of the modern state and the partitioning of identity by state borders. The general privileging of Nazi genocide against Jews over that against Poles, for example, reflects more than the assertiveness of the survivors or the gruesomeness of the statistics, for the former was a genocide against a population that was in principle internal to the German polity and the latter was to some extent an external or colonial genocide ${ }^{55}$. And this difference between internal and external sites of genocide helps to explain the curious ambivalence, between uniqueness and universality, both of the concept 'genocide' and of the Holocaust as its exemplar. The difficulty of broadening 'genocide' beyond the Holocaust, and the difficulty in seeing the Holocaust as one example among many, derives from more than mere Eurocentrism or even liberalism. If the viability of 'genocide' is secured by the fact that, after so many centuries of having been displaced outside the nation-state, genocide began finally to eat at the nation from within, then it is hardly surprising that genocide within states would be recognized more easily than colonial genocide. But this recognition involves a kind of optical inversion, appearing "upside-down as in a camera obscura", to use Marx's phrase [Marx 1988a: 8].

warrior ethos in antiquity (both the Iliad and the Odyssey, for example, portray massacre as not inherently objectionable), and so on. those on European soil, in his treatment of the Nazi atrocities, even if subsequent commentators have not always done so. See Moses 2002, 2004. 


\section{On Value-Freedom}

\subsection{DiLEMMA}

I hope that by now I have established a more complex historical view of 'genocide' than one in which Lemkin's work represents a discrete origin. Before I provide my own answer to the question of how to use this term 'genocide', there is one other issue that I must consider. This question is conventionally presented as a dilemma regarding the appropriateness of value-freedom in sociological research. Elias provides a unique and fruitful means of re-framing or displacing this dilemma, but one that has problems of its own.

The problems of value-freedom are more acute in genocide studies. Or rather, the contradictions in the notion of value-free social science come to the fore more clearly in genocide studies than in most other contexts. More dramatically than usual, scholars are torn between the contradictory imperatives to tell the truth simply as it is, and to tell a truth that has a particular effect. These desired effects include: preventing future genocides; activating international law; bringing perpetrators to justice; rendering moral judgment, including the condemnation of perpetrators and the vindication of victims; effecting the psychological and social rehabilitation of survivors; and preserving the memory of historical events. These various effects form a network, one that could tentatively be labeled rendering justice. To study genocide without regard to justice seems outrageous. And yet in the course of pursuing justice through knowledge scholars represent genocide as an objective phenomenon, one whose causal mechanisms can be discovered. The pursuit of this causal knowledge that will be used to prevent genocides 
positions the scholar in the relation of knowing subject to the object of genocide; the knowledge so produced is conventionally understood to be an objective knowledge, determined by the structure of a reality prior to the knower's will and so prior to her purposes and values.

This is a paradox familiar to social scientists: to achieve a value (prevention, justice) one must produce a value-free knowledge. Or, more precisely, one must produce a knowledge whose truth is vindicated without reference to value, and hence without reference to its sociopolitical effects. And so there is no guarantee that this value-free knowledge would not make claims that support values counter to the point of that knowledge: statements, for example, that relativise the term 'genocide', mitigating its horror or its moral gravity and so undermining the intended political effectivity of the term. A truly value-free sociology of genocide might even make it more clear how and under what circumstances one could commit genocide successfully. In fact, any truly value-free account of genocide could not help but have a radically protean effectivity in terms both of discourses of legitimation and of the practical uses of violence. This is the dilemma of any value-free science: its mercenary, soulless, or Frankensteinian openended potential, both at what is called the level of ideas (material effects of legitimation or of imagination) and the level of practice (material effects conventionally understood). And there is yet a worse possibility: that this so-called value-free science be taken itself as a metanarrative of politics, that the impersonality and indifference of the nonhuman universe be taken as authorization for the negation of the meaningful quality of social life. In this scenario, science becomes the engine of a praxis oriented to the blind 
worship of causality and probability, a negation of morality that ushers in a totalitarian nihilism.

\subsection{METAPHYSICS}

Although the notion of value-free social science is often associated with positivism, the Comtean notion of metaphysical thought actually provides a more complex and useful way of addressing the relation between science and morality than one that simply pushes morality to one side for the sake of science. Despite its limitations, the positivist critique of metaphysics makes one important contribution to the debates around how to conceptualize genocide: it reveals the inadequacy of conceptualizing genocide as essentially immoral rather than attending to the production of moralities that authorize genocide.

This critique can be approached by way of the notions of ideology and of myth. One response to dilemmas over the relation between science and value would be to say that such dilemmas are ill-conceived, because they ask for a knowledge that is ideological rather than scientific. The demand that science serve the ends of justice, then, can be construed as ideological in two ways. First, to ask science to serve justice is ideological in the crass sense of submitting and censoring science in the name of a political program. Second, it is ideological in the more refined sense of inscribing within scientific knowledge concepts that are mythical or metaphysical rather than scientific. This second point needs some explaining. In saying that a form of knowledge is mythical, I am 
invoking Lévi-Strauss" claims regarding the "totalitarian ambition "of mythical thinking 56 [Lévi-Strauss 1978: 17]. Myth is characterized by its aspiration to totality: in myth, statements do not qualify as knowledge unless they relate to an account of the universe as a whole; "if you don't understand everything, you don't explain anything". Science, according to Lévi-Strauss, is characterized by a precisely opposite tendency towards particularity, "to proceed step by step, trying to give explanations for very limited phenomena, and then going on to other kinds of phenomena, and so on" [ibid.]. If scientific statements used to elaborate the mechanical processes of genocide are allowed to produce effects of legitimation, regardless of whether these effects further or undermine the ends of justice (or of antigenocidal praxis), they can be said to transpose science into the realm of myth. This objection does not quite succeed, however. LéviStrauss advocated the rehabilitation of myth and proposed that in his time the divergent paths of myth and science were re-converging, so that "the entire process of human knowledge thus assumes the character of a closed system" [Lévi-Strauss 1966: 269]. Whether or not one agrees with this project, there is no way short of a metanarrative to forbid the appropriation of scientific statements by mythical narrative - and of course we are denied that recourse [Lyotard 1984]. Nevertheless, the distinction between mythical and scientific thought in terms of its relation to totality is useful inasmuch as it brings to the fore the different uses and domains of use to which statements produced by scientific

56 Lévi-Strauss's phrase is "the totalitarian ambition of the savage mind". It may be objected that this terminology is Eurocentric. Lévi Strauss anticipated this kind of criticism by putting the term 'savage' in scare quotes, and certainly the overt intent of his work was to undermine ethnocentric and especially racist claims regarding the inferiority of peoples labeled primitive or savage. Still, there is no way to use the word 'savage' without suggesting some kind of inferiority vis-à-vis the term 'civilized', so I have performed the little white lie of cutting it out. 
research may be put. The problem of value-freedom is practical rather than simply conceptual, a problem of the relation between the effects of statements within the limited domain of scientific inquiry and the effects of the same statements in the broader arenas where justice or praxis must operate.

One could take a different approach and say that a justice-oriented sociology of genocide is ideological because it depends on certain metaphysical conceptualizations. This is the approach implied by Elias' reading of Comte ${ }^{57}$ in What is Sociology?. Comte proposes three stages in the development of knowledge: the theological, the metaphysical, and the scientific. In both theological and metaphysical thinking, subjective phenomena are projected into the external universe and treated as objective, either in the theological stage as supernatural beings (e.g. when, in the Iliad [19.10019.175], Agamemnon blames the gods for filling him with the madness to insult Achilles) or else in the metaphysical stage as "personified abstractions" [Elias 1978: 39] like Nature or Reason. Now, there are enormous problems associated with taking on uncritically Comte's historical schema: it is universalizing, frankly normative, and teleological; it is offered without any historical evidence as to its actual universal validity (a defect that Elias does not rectify); and it is obviously based on a particular moment in European culture. In sum it is Eurocentric in the worst way. However, if we strip this

$57 \quad$ It may seem odd to invoke Comte in relation to the problem of theorizing genocide given that the term 'positivism' which he proposed has come to be associated with anti-theoretical empiricism. However, Elias reminds us that Comte's own writings affirm the mutual dependence of theoretical and empirical modes of inquiry [Elias 1978: 40]. Comte himself puts it plainly: "If it is true that every theory must be based upon observed facts, it is equally true that facts cannot be observed without the guidance of some theory. Without such guidance, our facts would be desultory and fruitless; we could not retain them: for the most part we could not even perceive them." [Comte 1998: 73]. 
schema of its claims to universality and necessity and understand it not as a sequence of historical stages but as three modes of thinking available within the problematic of 'knowledge' as it has been formulated in European culture since the Enlightenment, then it can offer some useful insights. Most important of these is the critique of the role that concepts like 'justice' and 'morality' play in accounts of genocide ${ }^{58}$.

To borrow a term from Marxism we can say that metaphysical concepts are reifications of our particular, historically situated experiences. This reification is built right into our everyday language; for example, when something happens that makes us feel sad we say "that is a sad thing", in which case the sadness of the thing moves from our own (subjective) emotions to the (objective) thing itself. If something outrages us or offends our sense of justice or morality we don't say, "that made me feel outraged", we say "that is outrageous", "that is immoral" and so on. This is more than just a semantic slip; it produces a performative effect. "That is outrageous" demands that others should also be outraged; "that is immoral" demands that others condemn what the speaker condemns. It is a direct extension of this kind of linguistic practice to talk and think as if there is just a thing as Morality or Justice existing independently of anyone's will or consciousness, i.e. objectively. The metaphysical writers whom Comte opposed actually flagged what they were doing by putting these terms in capital letters. But this same kind of reification is still a feature of twentieth century thought.

An aside: from a Derridaean point of view, another interesting feature of Comte's pejorative concept of the metaphysical is that it complicates the binary of 'scientific vs. non-scientific' through the interposition of a third term between the theological/mythic/primitive and the scientific. 
For example, throughout Eichmann in Jerusalem Hannah Arendt refers to the actions of Eichmann and others responsible for the Final Solution as immoral and even criminal. At first glance that seems unproblematic; she considers their acts immoral and criminal, and so do we. The problem is that Arendt is trying to do more than pass judgment: she is trying to understand the conditions of possibility for the genocides. Again and again she asks how it was possible for human beings to engage in this sort of behaviour. Standing in the way of her answering this question is her more or less explicit assumption that there is a Morality and even a Law independent of human knowledge and will. For example, she calls the Final Solution criminal and its perpetrators criminals, even though what they did was entirely in accordance with German law (Arendt says, paradoxically, "it was not an order but a law which had turned them all into criminals" [Arendt 1994: 149]) and contravened no international law to which Germany was a party (which created some difficulty when it came to trying the perpetrators afterwards). This is more than just a petty paradox, though. Metaphysical thinking intervenes in her attempt to explain the causes of the Final Solution and how so many otherwise normal people could have been made active participants in it. Arendt's explanation is that Eichmann and others like him acted "under circumstances that make it well-nigh impossible for him to know or to feel that he is doing wrong" [Arendt 1994: 276]. This is as far as she can go, and even this claim was controversial, but as social science it is totally unsatisfying. Arendt never seriously considers the implications of a fact which her own chronicle makes clear: that Eichmann and others like him felt strongly that they were doing right and held themselves to be acting, to the point of self-sacrifice, in accordance 
with the demands of morality. For example, Eichmann's statements repeatedly attest to his strong sense of duty. To pick another example, the Nazis explicitly exhorted people to be strong, overcome their animal pity, and resist being "tempted not to murder, not to rob, not to let their neighbours go off to their doom" [Arendt 1994: 150]. So we could say that Arendt's metaphysical thinking prevents her from inquiring deeply into the situation and asking crucially important questions that were right there in front of her: how did the perpetrators understand their own actions? were they blunted to moral sensibility, for example, or were they acting in accordance with a moral code that happened to be different from Arendt's (and ours)? if so, what was the content of that code? And most importantly, how did it come into being, what are its historical causes and so on? These questions invalidate the practice of reifying morality by attributing our moral sensations to the operation of an objectively existing Morality - not because they assume that morality is heterogeneous and relative, but because they treat its heterogeneity or homogeneity as an open question.

In Modernity and the Holocaust Bauman commits a similar lapse of sociological imagination. He frames the problem of the Holocaust and morality in terms of the question of how modernity contributed to the breakdown of forms of morality that inhibit genocide, without also asking what were the conditions that contributed to the production of a morality that valorized genocide ${ }^{59}$. 'Morality' is equated with what Zygmunt Bauman considers to be moral and so is falsely universalized in two ways: empirically, in the assumption that this particular morality was present for the perpetrators of the Nazi

59 I discuss this criticism of Bauman in more detail in Chapter 3 below. 
holocaust and had somehow to be overcome; and normatively, in the assumption that if the perpetrators considered their actions to be moral they were, objectively, mistaken. The first universalization makes an empirical claim that happens to be false in many individual cases; the second is besides the point of sociological inquiry, unless it could somehow be shown that objective morality - as opposed to what is socially established as moral - exerts a constraining influence on social action. Bauman, like Arendt, avoids the most challenging implication of the Nazi holocaust. Milgram observed that "human nature" cannot be counted on to insulate us from "brutality and inhumane treatment at the direction of a malevolent authority" [Milgram 1974: 189]. Arendt's portrait of Eichmann shows clearly that even morality cannot be counted on to protect us from genocide.

\subsection{Difficulties}

Despite the insights it prompts, Elias' use of the Comtean scheme of theological, metaphysical, and scientific thought is problematic in at least three major ways. First, the scheme is Eurocentric in the manner that I have already described This defect can be provisionally corrected for if theological, metaphysical, and scientific thought are understood as moments or strategic options within a specific knowledge culture rather than as universal historical stages of development. Second, however, these terms are too broad and baggage-laden to be trustworthy. Qualifiers like 'metaphysical' and 'scientific' are "elevator words" (to borrow Hacking's [1999: 21-23] useful term): words that raise the intellectual stakes of argument without adding much in terms of intellectual content. Foucault's comment on humanism is also applicable here: metaphysics is "too supple, too diverse, too inconsistent to serve as an axis for reflection" [Foucault 1997: 
314]. To call an argument metaphysical is to practice guilt by categorical association and to divide the world of statements into armed and hostile camps. It is better to be precise and to name specific problems. Arendt reifies her own sense of law, of justice, and of ethics; she treats her personal sense of right and wrong as reflecting or corresponding to something that exists independently of her. Bauman universalizes his particular sense of what is moral and what is evil and treats it as a historically omnipresent object with fixed and invariable effects. Both are thinking egocentrically. There seems to be no particular gain, other than a polemical one, from adding 'metaphysical' to the bundle of terms.

Third, Elias' use of the three Comtean stages of thought depends on a notion of objective truth that in turn depends on a rigid opposition between the subjective and the objective, and a conception of truth as correspondence to the objectively real. Ironically, Elias' own critique of metaphysical thinking can be turned against these dependencies. The thinking that he labels metaphysical involves a suspect operation, the egocentric projection of one's own experience into the universe at large; this operation gives rise to a number of specific problems, such as empirically false universalizing claims, the conflation of normative and causative propositions; the refusal of certain important questions. But for Elias what is really wrong with metaphysical thinking is that it is not "realistic" [Elias 1978: 15, $23 \mathrm{ff}$.] or "reality-congruent" [Elias 1987: viii]. This terminology is a bit ambiguous. The term 'reality-congruent' could refer to the adequacy of truths to some particular reality and to the pragmatic requirements thereof. ${ }^{60}$ But most often it seems to refer to a universal, undifferentiated reality, to reality as it simply is,

60 See section 3.4 below for more on this. 
devoid of the exigencies of human action under constraint. In this reading, a realitycongruent truth is one that simply is true, and metaphysics is bad because it gets in the way of true accounts or at least of accounts that are more true, closer to truth. ${ }^{61}$ This universalizing conception of truth is common both to Comte and to later positivism, despite the other substantial differences between them, and Elias does not take issue with it in his major writings on truth and knowledge. Rather, he seems to objectify the experience of truth, as Arendt and Bauman objectify their experience of morality. In other words, the problem he hasn't solved is that of reconciling his insistence on process and relativity with the notion of absolutely objective and hence absolutely detached knowledge, a knowledge that is so detached that human subjects vanish from the picture altogether. Elias exempts science from that operation which he does not hesitate to perform on a non-scientific concept like 'civilization': the meticulous and thorough inquiry into the concrete historical conditions that produce in subjects that sense of truthfulness, and that give to statements the social status of truth.

Elias's work seems to reproduce that sociological asymmetry between scientific and non-scientific forms of knowledge that has been obsolete since the appearance of the Strong Programme in the sociology of knowledge [Bloor 1976; Barnes 1977; Barnes,

Elias' account of truth mixes relative and absolute conceptions, but absolute truth seems to trump relative truth in the last instance. For example: "... it is crucial that criteria such as 'true' and 'false', 'right' and 'wrong', have moved from the centre to the periphery of the theory of science. Of course, it is still possible for research findings to be proved absolutely wrong. But in the more developed sciences the main yardstick is the relationships of newer findings to older available knowledge. This is not something which can be expressed in static polarities like 'true' and 'false', but only by demonstrating the differences between old and new; this becomes apparent through the dynamics of scientific processes, in the course of which theoretical and empirical knowledge becomes more extensive, more correct, and more adequate." [Elias 1978: 53] Here Elias has substituted a dichotomy between absolute truth and absolute falsity for a gradual 
Bloor, and Henry 1996]. Although his use of Comte's schema affirms the historical and sociogenetic quality of scientific knowledge, Elias affirms an apparently ahistorical notion of reality-adequacy. This affirmation implies that the conditions of the vindication of knowledge, the conditions by which statements acquire the status of truth in a community of rational subjects, are non-sociogenetic: they are the conditions of reality itself. This reading is qualified but not contradicted by his use of scare-quote marks around the phrase "reality-congruent" and by his occasional effort at a relative conception of truth.

However, a more consistently relativistic reading of the phrase is suggested by the essay "The Fishermen in the Maelstrom" in Involvement and Detachment. The way that this essay frames the problem of science suggests a reading of the phrase "realitycongruent" in which reality is relative to the exigencies presented by a concrete situation and adequacy is relative to a practical goal. Situated within Elias' overall displacement of the problem of value-freedom, this essay provides the last material that I need to resolve the question of 'genocide'.

\subsection{FISHERS IN THE MAELSTROM}

The choice facing sociologists of genocide is not between the production of a value-free knowledge and one that is value-laden, but between relative degrees of involvement and detachment. Knowledge cannot be value-free, says Elias:

Like other human activities, scientific inquiries into nature embody sets of values. To say that natural sciences are "non-evaluating" or "value-free" is a misuse of terms. But the sets of values, the types of evaluations which 
play a part in scientific inquiries of this type differ from those which have as their frame of reference the interests, the well-being or suffering of oneself or of social units to which one belongs. The aim of these inquiries is to find the inherent order of events as it is, independently not of any, but of any particular, observer, and the importance, the relevance, the value of what one observes is assessed in accordance with the place and function it appears to have within the order itself. [Elias 1987: 6]

Here I must bracket off for the moment Elias' claim that the object of science is a structure inherent to events. With this bracketing in place, the passage quoted makes several important claims: science is a practical activity like any other; as an activity it involves differential valuation of varying outcomes; in science these values are defined in relation to the purpose of scientific inquiry, such that what to observe and how observations are translated into fact and theory are determined by these values in combination with the current state of actually existing science. So far this picture is the same as that presented by Barnes [1977]. What distinguishes science is not the absence but the type of values employed. They are internal to the aims of scientific practice, to the goal of the production of scientific knowledge, and as such they do not directly address questions of personal or collective well-being. In institutional terms science is a sphere of autonomous values, "protected by firmly established professional standards against the intrusion of heteronomous evaluations" [ibid.: 6].

At the same time, however, this scientific detachment is never total [Elias 1987: 226-227]. This allows the detached activity of science to produce knowledge that has value according to those external heteronomous evaluations from which it protects itself. Detachment and involvement are not binary opposites but relative positions on a continuum. Complete detachment would mean indifference to existence, and could not 
form the basis of an activity of knowing. Science is detached only in relation to forms of knowing that are more involved, more caught up in immediate impressions and urgent needs.

Elias illustrates involvement and detachment and their complex relation to practice with a parable of two fishers, brothers, whose boat is caught in a whirlpool [Elias 1987: 45-46]. The boat is on the inside wall of the funnel and is being inexorably drawn down to the point of disappearance. Both are frightened and are caught up in an urgent need to act in some way that will save their lives. One brother observes bits of wreckage also caught in the funnel and, partially overcoming his fear, he notices that smaller bits are drawn downwards less rapidly than larger pieces. He tries to communicate this to the other brother, but the latter is too involved in the urgency of the situation to take in this information; he cannot detach himself enough to listen to what his brother is telling him. Associating the boat with safety, he refused to leave it. The first brother jumps overboard. The boat is drawn underwater and the man still on board drowns. After a time the whirlpool subsides, and the other brother floats free.

Elias reads his own parable in terms of the use of observation and theory to develop a solution to a life-or-death problem. The parable illustrates the role of detachment in freeing humans from the constraints that are placed on them by objectively existing structures, whether in nature or in social relations. Elias notes that a relative detachment, enough to enable humans to reverse their dependency on and vulnerability to structured processes, has been achieved in the natural sciences but not in the social sciences[Elias 1987: xvi]. The reasons for this differential development are those 
identified by Comte: the objects of the social sciences are not only more complex, but they are closer to home, more intimate [Comte 1998: 94]. Regardless, however, the process of detachment involves the development of certain forms of subjectivity, most notably the ability to subordinate affective responses to ones based on reflection [Elias 1987: 47] - which not coincidentally is one of the abilities fostered by the civilizing process.

No amount of detachment is absolute however, and in the parable knowledge is vindicated not simply by correspondence but by a practical outcome: the ability to survive threat to one's existence. Nor is this an accidental feature of the parable. Elias argues that the human species is caught in its own maelstrom, produced not by a natural process but a social one over which human actors have no effective control [Elias 1987: viii-xv, 73, 74-115]. This process is the organization of humanity into nation-states based on territorial monopolies of military violence and relations of mutual antagonism among those monopolies. Nation-statism poses a chronic threat to individual survival through the recurrence of war, a threat that culminates in the possibility of human extinction through nuclear war. This situation is partly the result of the uneven development of the sciences, in which control over natural processes has not been matched with a corresponding control over social processes; physical technologies of destruction have flourished out of proportion with social technologies of pacification. Elias claims that the development of a relative detachment of sociology from immediate problems and concerns is necessary to the formation of a scientific knowledge that gives humans effective control over their own social conditions. There is a hint of the dialectical in his 
argument: the increase in the military capacity of states and the achievement of a globally closed state system has created the possibility of nuclear omnicide; at the same time, state-formation engenders the pacification of everyday life which makes it possible for subjects to develop a self-disciplined habitus, which in turn is a precondition for detached scientific knowledge. In this way, Elias diagnoses the contradiction of the civilizing process, the crisis it has reached in our time, and the means to the positive resolution of that crisis $^{62}$.

Elias succeeds in articulating a way in which science can be detached and yet serve the public good. Detachment from immediate crises represents a longer-term investment in developing a faculty of control that will increase human freedom ${ }^{63}$. However, he does not address the crucial question of who will have the control that scientific knowledge provides. Rather, Elias refers only to universal, undifferentiated 'humans ${ }^{, 64}$. He does not engage with the deep differences produced by capitalism, by patriarchy or racism or heterosexism, or by the nation state itself. He writes as if the threat of war is bad for everyone equally, and does not explore the question of who benefits from the perpetuation of the threat of war, of the interests that make rational for certain persons a figuration that is irrational when viewed from the standpoint of humanity taken as a whole.

\footnotetext{
62 I am tempted to say, a resolution that will do away with that crisis itself, inasmuch as it does away with the nation-state and hence with civilization. But Elias does not explicitly say this.

63 "Natural scientists seek to find ways of satisfying human needs by means of a detour - the detour via detachment." [Elias 1987: 6] If I seem always to be citing the same few passages from Involvement and Detachment, it is a reflection of how the book is written. Elias presents his central arguments in concise form at the outset of each chapter and then spends the rest of his time going over them again in detail and with illustrations.
} 
This error has several implications. One is simply that Elias overstates the role of involvement in the perpetuation of the war system and hence the potential for detachment as the means to its remedy. Another is that he seems to be smuggling a residual egocentrism back into his own sociology, in the form of a humanism that puts all subjects in an essentially common relation to certain problems in the global military figuration despite the sociogenetically produced differences in their positions within it. ${ }^{65}$

Third and most important, this residual humanism explains that universalism in Elias' epistemology which I had bracketed off at the beginning of this section. Elias says of science: "The aim of these inquiries is to find the inherent order of events as it is, independently not of any, but of any particular, observer" [Elias 1987: 6]. Here he is rejecting any notion of absolutely objective knowledge, just as later he rejects ontological dualism between subject and object as "misleading" [ibid.; 49] (because it implies that subjects could exist independently of objects). However, he affirms that knowledge can have an intersubjective validity common to all human beings. Order is inherent not to the nonhuman universe in itself but to the universe as all humans stand in common relation to it and to each other: a relation of functional ${ }^{66}$ interdependence. This ontological For example, "So far no central agency has emerged which is able and authoritative enough to survey and control, in humanity's own interest, its chaotic rule over non-human nature [...]." [Elias 1987: xxix]. Another way of putting this is to say that although Elias has done away with the individual as a subject of knowledge, he has not done away with the subject of knowledge altogether but has substituted a unitary 'society" or 'humanity' for the individual. For example, he says "The transition from a philosophical to a sociological theory of knowledge, which Comte accomplished, is chiefly apparent in the replacement of the individual person by human society as the 'subject' of knowledge. If questions concerning thought were for him still central to the problems of sociology, he had nevertheless 'sociologized' our conception of the thinking subject." [Elias 1978: 38] My criticism is that the replacement that Elias refers to is still an incomplete sociologization of the problem of knowledge. Regarding Elias' use of the term "functional" see footnote 33, above. 
interdependence is, arguably, the closest thing in Elias' thinking to ultimate reality. It is the ocean on which maelstroms may form. But by glossing over the deep differences that exist among human beings Elias ignores the potential for reality-adequacy to vary from one figurational context to another according to the exigencies that power contests of local and global scale impose on particular networks of individuals. If reality-adequacy can vary, then science can be put to uses other than the collective benefit of humanity, not just by ideological appropriation or the subjection of autonomous science to intrusive heteronomous evaluations, but rationally. In such situations, scientists would only notice a violation of their own professional project if a totalitarian demand for efficiency began to compromise the inherent inefficiency of scientific innovation [Lyotard 1984: 64].

One solution to this problem would be to disavow it. This is done by uncoupling the scientific endeavour from any claims to any particular practical outcomes or any particular praxis. Scientists can choose to be indifferent to the location and effects of science within relations of domination. Even if those effects could be eliminated, for example by a complete renunciation of the pursuit of technological applicability (which is of course impossible, since technology is what pays for science), a science disconnected from any involvement in concrete problems would devolve into a fetishized ritual, an incestuous elaboration of formal movements vindicated only by its own obsessive autonomy. And since, in any case, they cannot be eliminated, ignoring them is no more apolitical or value-neutral than the decision of factory workers to focus on their work and ignore their own exploitation is apolitical - or than the equivalent decision by the line supervisors, managers, and share holders is apolitical. 
A better solution is to incorporate questions of difference into the mission of (figurational) science. In Elias' example of the fishermen in the maelstrom, two systemprocesses share a common identity in relation to the merciless life-threatening otherness of a third. In another situation, the two fishers, brothers though they are, could find themselves in a relation of difference, opposed to each other as implacably as they were to the maelstrom. It is part of the task of my sociology to map the complex and shifting topographies of those relations of identity and difference, and in so doing to come closer to formulating what it means to be 'involved' and 'detached' in a way that does not depend on sameness. With respect to this problem, genocide makes a fortuitous topic of study. The claims of even a detached sociology of genocide are still vindicated relative to the problem of anti-genocidal praxis. My challenge is to operate with a conception of this praxis that does not depend on sameness.

\section{How to use 'genocide'}

This weaning of dependence on sameness extends even to the use of the term 'genocide' itself. I began section 1.1 by deferring the question of a definition. At this point, having worked through so much material, I might be expected to end this deferral and offer my definition of 'genocide'. Instead, however, I will offer something a little different: a guide to use. The term 'definition' has connotations of essentialism that I would like to avoid. It is not that I want to do away with definitions altogether, only take away their privileged status. Definitions are useful in many circumstances, but they are not a necessary foundation for communication. If justice, or politics, can no longer depend on consensus, neither can science. And if consensus over the meaning of 
'genocide' were a precondition for the advancement of knowledge of genocide then all the excellent literature already produced on the subject could never have existed.

So here is how I will use 'genocide': First, as an essentially contested concept. Deployment of competing usages is fruitful; reflecting on the differing merits of these usages is fruitful; what is not useful is any insistence that the contest somehow be brought to an end. Second, genealogically. Certain historical developments associated with European modernity have made it both possible and urgent to speak in terms of 'genocide'. These developments include most notably the use of the powers of nationstates to modify the formation of identity, to produce certain uniform effects of subjectivity. (They also include the concern with subjects as biological populations, the cultivation of biopower [Foucault 1990: 139ff.; 2003: 242-243, 260]. However, genocide and 'genocide' are only partly concerned with biology.) 'Genocide' does not have a distinct point of origin and an ahistorical, universal applicability; it is intelligible within a particular strategic situation that we happen to occupy. Third, as figuration. The formation of state power, of particular forms of subjectivity, and of a concept 'genocide' are inseparable aspects of a long-term historical development. The spectacular genocides of the twentieth century that prompted the formulation of laws against genocide (the Nazi holocaust and the elimination of Turkish Armenians) are not unique and unprecedented, but neither are they simply repetitions in new settings of an age-old process. They are linked to earlier (and subsequent) genocides through a process of development, one that involves an element of differentiation such that no two genocides can be exactly the same. Fourth, with a measure of detachment. Genocide demands action, but my 
sociology of genocide is not an under-labourer to politics. It maintains a partial autonomy in which the value of understanding is on par with that of intervening. Although the point of scholarship is an anti-genocidal praxis, this point cannot form part of a scholarly definition because the concept 'object of praxis' assumes some given state of knowledge that praxis uses as a resource, whereas the purpose of scholarship is precisely to advance knowledge. To overcome the limits of actually existing knowledge, scholarship has partially to defer the political request for immediate technical solutions and for consciousness-raising speech acts. This deferral produces a contradiction that, as I stated in Section 1.1 above, can be managed not resolved over the short term; it has to be worked out in the historical time of linguistic practice rather than the instantaneous time of pure logic. And fifth, as oriented to difference. Both knowing about genocide and acting against genocide must find a way to move forward without needing to erase all difference to do so, a consideration all the more salient given that it is genocide itself that demonstrates the hazards of using sameness as a guarantee of legitimacy.

Sixth, rather than specify a fixed set of criteria, I will say that 'genocide' refers to a network of events that includes certain agreed-on exemplars, especially the Shoah, that is open to indefinite though not arbitrary extension, and that is constituted by the capacity for these events to serve as heuristic devices to illuminate each other. Thinking of 'genocide' in this way does not mean that criteria of genocide disappear or that one no longer uses criteria to decide whether an event is or is not genocide. Rather, there is no single list of fixed and necessary criteria; the network of 'genocide' is based on a set of resemblances, no one of which is either necessary nor sufficient. This usage will enable 
me to analyze as genocide events not usually considered to be genocides, such as famine in colonial India; it may even enable me to find genocidal processes at work where there is not a single event and so to speak of, for example, genocidal anticommunism as a certain dimension of American-supported counterinsurgency warfare in Central America of the 1980s. However, each new event added to the network must be justified on a caseby-case basis

Seventh, given that any use of 'genocide' is bound to reference the United Nations definition, I propose that the central elements of that definition should be redeployed as themes rather than as essences. Rather than claim that genocide is essentially a crime of state formation, one can employ 'genocide' to examine the relation between the use of violence, the formation of subjectivity, and the establishment of particular social orders. Rather than re-assert the organic reality of particular forms of identity, 'genocide' can point to certain inflections or moments in the processes through which forms of identity are established and through which differences are either naturalized or problematized. And rather than define 'genocide' as something that is, $a$ priori of its status as genocide, necessarily an offense, one can observe how particular events arouse a sense of offense both among those who are directly affected (the victims) and among bystanders at various degrees of remove, and how this offense is constituted as opposition: among victims as more or less organized forms of resistance, survival, memory, and so on; and among bystanders as outrage, delegitimation, intervention, criminalization, and so on. (In this regard, it is interesting to reflect on the complex relation between the desperate struggles of a person attacked by violence and the more or 
less passionate outrage of a scholar who writes about that struggle, who even speaks publicly of it to an unreceptive audience that prefers denial. To account for this relation by attributing an essential criminality or even immorality to the event is to lapse quickly into tautology.)

Finally, there is one feature of genocide that I especially wish to foreground. This is way in which genocide effects the violent categorical obliteration of difference. This obliteration is neither a necessary nor a sufficient condition of genocide; by specifying it I do not wish to smuggle back into my analysis an essentialising definitional practice. Rather, among its various uses the concept of 'genocide' can serve to bring into relief the historical use of violence to resolve various problems associated with difference and hence with identity. This historical association can serve as an axis of reflection that is neither exclusive to the field of genocide nor comprehensive of it, but that joins the study of genocide to broader questions of social theory. It is not just that genocide has been crucial in the development of institutional formations that we associate with modernity, such as the nation state and the capitalist world-system. For thinking of genocide as the violent obliteration of difference, of different identities, puts genocide in a matrix that includes all forms of violence that aim at the elimination of a social identity, even an oppressive one: with the nationalist revolution that aims to eliminate from the social field the subject position of 'colonial oppressor', or the socialist revolution that aims to do away with the bourgeoisie. This matrix also includes the violences that operate in the socalled micro level interactions of everyday life, the allegedly minor violences through which hegemonic identities (heterosexual masculinity, for example) are policed and 
various subordinate identities are maintained as necessary differences. In other words, studies of genocide can serve as one cluster in a network of inquiries into the difficult and troubling relations between violence and difference, and hence between violence and identity in general, throughout the cultural arenas impacted by European modernization or the European civilizing process - a relation that, lacking the urgency imparted by its connection to genocide, might otherwise remain submerged or marginal. 


\section{Chapter III: Anti-Heroic Sociology}

\section{INTRODUCTION}

In Chapter 2, I suggested that what Fein identifies as the sociological theory gap may be as much a function of genocide scholars' reluctance to engage with theory, as of social theorists' reluctance to engage with genocide. Regardless of its basis, however, I will begin to bridge this gap in Chapter 3 by interrogating the theoretical projects of Durkheim, Marx, Bauman, and Foucault with regard to the question of genocide and of anti-genocidal praxis. I will identify two modes, partially complementary and partially antagonistic, through which this praxis can be theorized: the heroic mode, which focuses on the resolution of difference into sameness, and on the constitution of a unified collective subject capable of resisting genocide by force; and the anti-heroic mode, which focuses on the multiplication and dissemination of difference, and on the un-making of the relations of power through which genocide is produced. Because I perceive the heroic mode to be already predominant and well-developed in genocide studies and in sociology generally, my concern in this chapter will be to critique its limitations and to develop the anti-heroic mode. The heroic mode on its own can solve the problem of genocide only up to a point: because difference is sublated into sameness, the possibility of genocide is displaced onto internal and external others who, by virtue of their difference, cannot be included in the terms of the heroic solution. At its most simplistic, the heroic mode tends to reduce the problem of genocide into a struggle between good and bad collective subjects, for example by attributing genocide to the "totalitarian drive to perfection, a deviant form of modernity resisted heroically by the West" [Moses 2002: 
21]. More subtly, the possible universality of a heroic solution to genocide depends on a pre-existing universal human sameness, in the form of a transcendental, ahistorical morality that genocide ignores or suppresses or deviates from. Anti-heroic theory, on the other hand, attends to the social production of genocidal moralities, or the moralization of genocide. This mode of theory understands genocide in terms of structured social relations that do not necessarily belong to any one type of political regime or collective subject, and defines the goal of praxis as addressing genocidal relations rather than genocidal actors. This approach allows me to go beyond the limitations of liberal genocide scholarship with its implied metaphysics of rupture, and to begin to theorize genocide in terms of social relations broadly conceived, a task that I continue in Chapter 4.

\section{Strategies of Making and Unmaking}

Before engaging directly with the heroic and anti-heroic contents of social theory, I can most easily illustrate what I mean by 'heroic' and 'anti-heroic' modes of thought, and the dilemma or impasse that the heroic mode entails, by reference to J. R. R. Tolkien's extended fairy-story for adults, The Lord of the Rings.

In order that my use of what is conventionally regarded as a fantasy novel for the purposes of a theoretical investigation of genocide not seem objectionable or at least inappropriate, I should say a few words about the nature of the work in question. First, it is not simply a work for children: successfully or otherwise, Tolkien wrote this work for an adult audience [Carpenter 1990: 216, 220, 249, 310]. Second, it is not simply an 
exercise in escapism, as has often been alleged by its critics. In his essays "Beowulf: The Monster and the Critics" and "On Fairy-Stories" Tolkien defends the literary device of the fairy-story as a "very practical" and even "heroic" tactic for resisting the alleged necessity and inevitability of actually existing conditions, of defending, in effect, a beleaguered life-world ${ }^{67}$ against the impositions of modernist realism and its teleological ecstasies [Tolkien 1997a; 1997b, esp. pp. 148-150]. Third, unlike most genre fantasy fiction, The Lord of the Rings is grounded on a rigorous matrix of linguistic (or philological) invention, from which its fantastic or mythological elements are derived [Shippey 1992]. The cosmological and cultural history of Tolkien's invented world, the essential qualities of the characters that inhabit it, and every incident of plot all adhere rigidly to a complex scheme based on the meanings of individual words, including not only words in modern English but words in ancient Anglo-Saxon, Gothic, and in languages Tolkien invented. Fourth, through this linguistic basis, the book engages with the cultural legacy of pagan and barbarian Europe. This engagement connect Tolkien indirectly to Nietzsche, Wagner, and Hitler ${ }^{68}$, and thence to Norbert Elias. In The Lord of

67 Tolkien does not use the concept of 'life-world', but it expresses what he is talking about. For example: "In any case the expression 'real life' in this context seems to fall short of academic standards. The notion that motor-cars are more 'alive' than, say, centaurs or dragons is curious; that they are more 'real' than, say, horses is pathetically absurd. How real, how startlingly alive is a factory chimney compared with an elm tree: poor obsolete thing, insubstantial dream of an escapist! For my part, I cannot convince myself that the roof of Bletchley station is more 'real' than the clouds. And as an artifact I find it less inspiring than the legendary dome of heaven"

68 [Tolkien 1997b: 149].

This connection is mainly one of opposition. Tolkien and Nietzsche both admire the pagan virtue of courage, but Tolkien abhors where Nietzsche celebrates its ferocity and its indifference to the suffering of others; Tolkien wants to Christianize it [Shippey 1992: 140-143]. Tolkien disliked Wagner's second-hand appropriation of sources that he himself knew firsthand [ibid.: 298]. And he was deeply angry at the Nazis' misappropriation of Germanic mythology, castigating "that ruddy little ignoramus Adolf Hitler" for "ruining, perverting, misapplying, and making for ever accursed, that noble northern spirit, a supreme contribution to Europe, which I have ever loved, and tried to present in its true light" [Carpenter 1981: 55-56]. 
the Rings, Tolkien attempts to reconcile the Christian virtue of compassion with the pagan European virtue of courage. In such works as Beowulf, the Elder Edda, and the Kalevala, Tolkien found the elements of a "theory of courage" which he regarded as "the great contribution of early northern literature" [Tolkien 1997a: 20]. In this respect, and despite its substantial limitations, his work provides a fertile starting-point for the inquiry into violence that I will pursue in this and the following two chapters.

The characters in Tolkien's story face a genocidal threat: military conquest by Sauron will mean their political, cultural, and eventually physical annihilation. Like many historical peoples facing a colonizing invader they are ethnically, politically, and geographically divided; unlike their real historical counterparts they succeed in constructing an overarching unity premised on the recognition of a common Enemy, and in mounting a coordinated military resistance. This is what I call the heroic solution: resistance to violence and genocide through the constitution of a sovereign collective subject. In Tolkien's story, this resistance is necessary - Sauron cannot be combated by pacifism - but it is also in the last instance insufficient. Sauron's might is simply too great. Only the One Ring, forged by Sauron but lost, and secretly possessed by the hobbit Frodo, could give Sauron's opponents the power to achieve a military victory. However, the One Ring is not a neutral instrument, to be used just as one likes for whatever purpose one likes: "If any of the Wise should with this Ring overthrow the Lord of Mordor, using his own arts, he would then set himself on Sauron's throne, and yet another Dark Lord would appear" [Tolkien 1991: 285]. In other words, using the One 
Ring to defeat Sauron would only reproduce a new Sauron among the victors ${ }^{69}$. But only in this way can Sauron's power be overmatched. This is what I call the heroic dilemma. The solution Tolkien presents is that the One Ring must be unmade: the hobbit Frodo must carry the Ring into the very heart of Sauron's domain, to the place of its forging, and there destroy it. Only this antiheroic solution can resolve the heroic dilemma. The two solutions complement each other: military resistance to Sauron makes Frodo's dangerous journey possible. But only the antiheroic solution can provide a final resolution to the problem of evil, one that does not reproduce it in the very terms with which it is defeated.

Tolkien's story offers more than an idealistic parable in which evil cannot be defeated by evil means. At issue is not the morality of actions but the moral effects of technologies. The idea that technology, or the works of craft, can gain an effectivity autonomous from the intentions of its makers, and even gain power over its makers, is central to the radical critique of modernity that runs throughout all of Tolkien's writings. This critique is epitomized in the character of Saruman, the wizard who starts out as Sauron's opponent but becomes his quisling. Saruman is associated with craft, cunning, and technology; originally a servant of Aulë (the god of the forge in Tolkien's invented cosmology), his name is derived from the Old English word "searu", meaning "device, design, contrivance, art" [Shippey 1992: 153]. He engages in industrial production, ecological destruction, and technological invention; he uses machinery, gunpowder,

69 With even worse consequences than outright victory by Sauron; in a marginal note to an unsent letter Tolkien writes "Thus while Sauron multiplied evil, he left 'good' clearly distinguishable from it. Gandalf would have made good detestable and seem evil" [Carpenter 1990: 333]. 
propaganda, and genetic engineering. Saruman's corruption results from his having studied "too deeply the arts of the Enemy", which is perilous whether done "for good or for ill" [ibid.: 282]. Tolkien suggests also that even Sauron (also a former servant of Aulë) was corrupted by the Ring of his own making, saying that "as long as it is in the world it will be a danger even to the Wise. For nothing is evil in the beginning. Even Sauron was not so" [ibid.: 285]. Other Rings also exist, and they too corrupt their users, in keeping with the purposes for which they were made: as the One Ring corrupts its wearer towards domination, the Seven Rings of the Dwarves inspire an obsessive desire for gold, and the Three Rings of the Elves, made to heal and preserve, tempt the Elves to nostalgia and stasis. Other examples abound in his more obscure work, The Silmarillion [Tolkien 1977]: the Nauglamir; the sword of Turin; and especially the three Silmarils of Feanor. In each of these instances, the fruit of labour and of craft "changes into a thing which transcends sensuousness" [Marx 1990: 163], stands on its head, evolves its own grotesque ideas - and dooms its maker.

But how does this happen? The usual interpretation is that "the center of his story is the Ring and the maxim that "power corrupts"" [Shippey 1992: 156]. That the Ring corrupts is indisputable; Elrond says "the very desire of it corrupts the heart" [Tolkien 1991: 285] and this is proved true repeatedly throughout the story. But the claim that power corrupts does not hold consistently true, for The Lord of the Rings is full of powerful characters who are not corrupt, including Aragorn, Legolas, and Gimli ${ }^{70}$; the

$70 \quad$ E.g. 'Dangerous!' cried Gandalf. 'And so am I, very dangerous: more dangerous than anything you will ever meet, unless you are brought alive before the seat of the Dark Lord. And Aragorn is dangerous, and Legolas is dangerous. You are beset with dangers, Gimli son of Glóin; for you are dangerous yourself, in your own fashion." [Tolkien 1991: 521] 
reincarnated Gandalf (more powerful but no less virtuous than his earlier incarnation); and the Valar. Rather, Tolkien draws a distinction between power and domination, saying in his letters that "in view of this tale and mythology Power - when it dominates or seeks to dominate other wills and minds (except by assent of their reason) - is evil" and elsewhere "Of course my story is not an allegory of Atomic power, but of Power (exerted for Domination)" [Carpenter 1981: 237; 246]. And it is the quality of dominating "other wills and minds" that is the chief characteristic of the One Ring, in which case the applicable aphorism is not that power corrupts but that means overcome ends. The One Ring is created for the purpose of dominating the other wills, especially the wills of those who wear the other Rings: "One Ring to rule them all" [Tolkien 1991: 64]. Supremely efficacious to this end, the Ring brings its user into a relation of domination over the entire social field. Because domination in itself is limited only by the resistance that dominated subjects can offer, then given a sufficiently powerful means of domination the limit to its exercise is the last possible resistance of a tortured body: death. ${ }^{71}$ So the end result of domination is tyranny, cruelty, and genocidal nihilism, no matter what the character or intentions of the person exercising it. All of the Rings of Power fundamentally alter the strategic possibilities through which their user relates to others. In Bourdieu's terms, they radically reconfigure their user's relation to the field 
and so occasion a fundamental modification of his habitus. We can say, in Nelson Goodman's phrase, that Rings of Power are "ways of worldmaking", and observe that Hacking's comment on weapons research holds true for Rings, as for technology in general:

If content is what we can see, and form is what we cannot, but which determines the possibilities of what we can see, then we have a new cause to worry about weapons research. It is not just the weapons [...] that are funded, but the world of mind and technique in which those weapons are devised. [Hacking 1999: 185]

In the case of the One Ring, the world of mind and technique that is fostered is premised on the domination of others. The Ring is evil, not because of a Manichean force that imbues it with malice, but because it objectifies an evil social relation. In this view, the Ring is more than just a vague moral allegory for evil means that we cannot use without becoming what we despise and so on; it is a specific example of the emergent determination of self-reproducing social relations.

Why does the heroic solution require the One Ring at all? More than narrative convenience is at work. I propose that the heroic dilemma in Tolkien's fiction stems from an affinity between the technology of the One Ring, which objectifies relations of domination, and the terms of the heroic solution, which requires that difference be sublated into sameness. Tolkien portrays this sublation without evidencing any critical awareness of it, ${ }^{72}$ for the book celebrates heroism, not naively or for its own sake, ${ }^{73}$ but

glaringly spurious element into his thought. At least it is dualist, distinguishing between the willed resistance of conscious subjects and the physical resistance of material bodies. that "does not parallel the traditional lines between the cognitive and the noncognitive, the moral and the aesthetic, or the 'literary' and the nonliterary" [Rorty 1989: $143 \mathrm{n}$. . Relaxing books are those that "gear in with their readers' fantasies without suggesting that there might be something 
without acknowledging the social contradictions that make possible the particular mode of heroism in question. Legolas and Gimli are princes; Frodo is bourgeois; Aragorn becomes a king; but the foundations of their class privilege are never explained, only romanticized away. Faramir says that he desires to see his city in peace: "Minas Anor again as of old, full of light, high and fair, beautiful as a queen among other queens: not a mistress of many slaves, nay, not even a kind mistress of willing slaves" [Tolkien 1991: 698], but we are left to wonder just how the peasantry will be induced to forfeit their surplus product to pay for this, if the queen among other queens does not expropriate it by force. Tolkien says of himself, "My political opinions lean more and more to Anarchy (philosophically understood, meaning abolition of control not whiskered men with bombs) - or to 'unconstitutional' Monarchy" [Carpenter 1981: 63], and Curry makes much of the anarchist quality of governance in Middle-Earth [Curry 1997: 48-53]. It is a nice fantasy to think that anarchy can coexist with nobility, but it is a measure of the book's romanticism that the contradictions between "decisions ... taken at the lowest possible level" [Curry 1997: 50] and "the fact that the order of the monarchy is based on oppression, on ... the misery of the poor and those who are reduced to grunt and sweat under a weary life" [Itwaru 1994: 33] is never seriously considered. Gender inequalities are glossed over just as blithely: In Middle-Earth, men and women are understood to have essentially different natures that dispose them to essentially different social

wrong with those fantasies, or with the person who has them," and this is definitely true of The Lord of the Rings.

73 See e.g. Faramir's speech to Frodo in Ithilien: "I do not love the bright sword for its sharpness, nor the arrow for its swiftness, nor the warrior for his glory. I love only that which they defend ..."

[Tolkien 1991: 698] 
locations. ${ }^{74}$ The possibility that these locations can be unequal is not mentioned, except in one telling instance. Eowyn, a princess and shield-maiden of Rohan, is assigned to guard the home front while her brother and father march away to war. She protests:

All your words are but to say: you are a woman, and your part is in the house. But when the men have died in battle and honour, you have leave to be burned with the house, for the men will need it no more. [Tolkien 1991: 816]

To this Tolkien has no effective reply. Eowyn's speech is treated as a form of vice, the result of Saruman's corruption, and by the end of the story Eowyn has accepted her feminine status, "a shieldmaiden no longer" [ibid.: 1001].

These various sociological lacunae can be summarized as a problem with difference. A common misreading of Tolkien finds the novel a boring conflict between absolute good and absolute evil. In fact, none of the characters and neither side of the conflict fits into either pole of the dichotomy (unless fighting for survival constitutes absolute good) ${ }^{75}$. Sauron is not evil "in the beginning" but is a fallen being still capable of moral choice and of redemption, just as Aragorn and Gandalf are morally fallible, capable of being tempted by the Ring, tempted to despair, and so on. Denethor, Boromir, and even Saruman are strikingly ambivalent. What is not ambivalent, what is absolute, are the sides in the conflict, and what is at issue is not morality but difference. In the story, difference is effaced in two ways. First, externally, the threat of difference can be resolved only by its elimination. Sauron cannot be negotiated or compromised with, so

It is important to note that Tolkien conceived this essential difference to be spiritual and emphatically not biological: "It is the view of the Myth that in (say) Elves and Men 'sex' is only an expression in physical or biological terms of a difference of nature in the 'spirit', not the ultimate cause of the difference between femininity and masculinity" [Carpenter 1981: 285]. 
his very existence is a threat to the very existence of the protagonists. Second, internally, differences of class, culture, gender, and so on are sublated as I have described. These differences are so decisively secondary to the difference presented by the Enemy, that they disappear with hardly a whimper. The result is the disappearance of politics, the production of a smooth, undifferentiated collectivity - of a sovereign subject without contradictions.

The heroic solution to the problem of genocide is only one of two strategies the protagonists adopt. The other is the anti-heroic solution of destroying the One Ring. Only by unmaking the Ring can Sauron's genocidal threat be decisively eliminated. Tellingly, it is the most modern characters, the hobbits, who must do this, by carrying the Ring to the site of its creation and throwing it into the fires of its forging. The price for this is heavy: when the One Ring is unmade, so too are all the other Rings, so Sauron's demise means also the demise of the earthly kingdoms of the Elves. In the process, the world is disenchanted; we enter real historical time, in which the dominance of Men and thus the eventual emergence of modernity are made inevitable ${ }^{76}$. Whether by failure of imagination or because of the limits of Romance as a narrative mode, Tolkien cannot suggest a real-world equivalent to the unmaking of the Ring. However, as readers we are left free to derive our own applicability, and the one I perceive has to do with the tension between heroic and anti-heroic strategies, or strategies of making and unmaking. Heroic strategies are necessary: without them, anti-heroic

For Tolkien's own comments on politics and sides in The Lord of the Rings, see Carpenter 1981: 239-244.

The Lord of the Rings is fictionally set, not in an imaginary world, but in an imaginary distant past of the real world. 
strategies have no space to operate. But by themselves they are insufficient to resolve the threat of genocide. Constitution of a sovereign collective subject can defend an identity against the threat of obliteration, but the question of difference is only displaced; this same identity can always become the basis for a new genocidal project. A theoretical inquiry into anti-genocidal praxis needs to recognize the dangerous ambivalence of sides, of good guys and bad guys, so to speak. Genocidal practices are the products not of particular identities, but of particular forms that the project of identity-construction can take. This ambivalence applies to the state as well: genocide is not the product only of certain states or of certain types of regimes, but of dynamics of power that are general to nation-statism as a global social movement. However, and this is where sociology becomes crucial, it is not clear what exactly needs to be unmade to eliminate the threat of genocide. Social theorists have barely begun to consider how genocide is produced, what relations of power occasion it, and how those relations have reproduced themselves so perniciously despite Enlightenment, despite democracy, despite the emancipation of labour and capital from "all fixed, fast-frozen relations, with their train of ancient and venerable prejudices and opinions". ${ }^{77}$ In the remainder of this chapter I will discuss the works of Durkheim, Marx, Bauman, and Foucault, to interrogate their heroic and antiheroic thematics, and to draw out the latter so as to add to genocide studies an anti-heroic theoretical dimension that it has been lacking.

$77 \quad$ To quote out of context Marx and Engels [1988a: 23] 


\section{Heroic Theory}

\subsection{DURKHEIM}

Durkheim's theory has much to contribute to an anti-genocidal praxis, and particularly to an anti-heroic theorization of genocide. Its anti-heroic potential comes through especially in Durkheim's account of the social origins of morality. Durkheim can be read as refusing to take a transcendental view of morality, instead adopting a sociological relativism that treats 'morality' as being whatever is established as moral within a definite network of social relations, and that attempts to inquire into the concrete origins of moral sentiments in actually existing social relations. On this reading, we can compare Durkheim's discussion of individual rights in Professional Ethics:

The reason why [the individual] has more or fewer rights, certain rights and not others, is not that he is constituted in a particular way; it is because society attributes this or that importance to him and attaches a higher or a lower value to what concerns him. [Durkheim 1992: 65-67]

with Rorty's claim that "a child found wandering in the woods, the remnant of a slaughtered nation whose temples have been razed and whose books have been burned, has no share in human dignity" [Rorty 1991: 201]. The point in common is not that the individual should have no rights or the child no dignity (this would require smuggling the transcendental perspective back in), but that if they are to have such things, if rights and dignity are to be real, they must be given them through their relations with other social actors. In this sense there is a continuous trajectory from Durkheim's sociology of rights to Foucault's assertion that human rights are fundamentally a means for opposing the power of the state and the state's claim to the right of life and death over its subjects. For all three authors, rights and dignity, even - especially - for the survivor of genocide, do 
not simply exist: they must be established. In that case, a second advantage in Durkheim's sociology of morality, following from the first, is that it implies a constructive understanding of genocide. Rather than assume a universal, transcendent, or essential morality and ask how genocidaires could violate it, Durkheim's conception of morality allows us to begin by asking how genocide comes to be understood as moral (or as immoral). Third, it is important to note that Durkheim ascribes the origins of morality to collective or social relations, but not automatically to societal relations, to "Society writ large" [Bauman 1991: 235]. There is, admittedly, some ambiguity on this point. Sometimes he does seem to tie morality to Society [Durkheim 2002: 59; 1984: 331-332]. At other times, however, he construes it in terms of social relations in a more open-ended sense [Durkheim 1982: 80-81]. In the latter case, Durkheim's sociology of morality offers a way of understanding how different collectivities within a genocidal state are variously situated with respect to the morality of the genocidal project. Taking these three advantages together, Durkheim's analytic approach allows us to frame the task of building a non-genocidal society in terms of the social production of a non-genocidal morality, and to inquire into what real conditions or life circumstances are favourable to the cultivation of such a morality.

One of the most challenging implications of Durkheim's sociology concerns the morality of genocide. Consider his conceptualization of 'morality' in Rules of the Sociological Method:

To decide whether a precept is a moral one or not we must investigate whether it presents the external mark of morality. This mark consists of a widespread, repressive sanction, that is to say a condemnation by public opinion which consists of avenging any violation of the precept. 
Whenever we are confronted with a fact that presents this characteristic we have no right to deny its moral character, for this is proof that it is of the same nature as other moral facts. [Durkheim 1982: 80-81]

This suggests that where genocide is supported by "widespread, repressive sanction" and opposition to it punished through "condemnation by public opinion", then genocide is moral, according to Durkheim. The idea that genocide could ever be moral is deeply counterintuitive, but it is logically implied by Durkheim's conceptualization of morality with one possible exception. If genocide is dysfunctional, and therefore constitutes a breakdown or failure of the moral reasoning of society, then it could be located outside the bounds of morality even where it "presents the external mark of morality". This position is taken by Mamdani, who says that "We may agree that genocidal violence cannot be understood as rational; yet, we need to understand it as thinkable" [Mamdani 2001: 8]. It is taken by Chalk and Jonassohn, who try to demonstrate that genocide is ultimately damaging to the society that perpetrates it [1990:415-421]. There are two problems with this recourse to the dysfunctionality of genocide, however. The first is that it is open to empirical falsification, in which case we classify 'unsuccessful' genocides, e.g. Rwanda, as immoral, and 'successful' genocides as moral, e.g. the 19041907 German genocide of the Herero, and colonial genocides in general. The second problem is that it relegates genocide once again to the margins of study to which all dysfunctional phenomena tend to drift, that it understands genocide in terms of breakdown and therefore prohibits a priori the application of the bulk of sociological theory. 
So we are left with this very challenging notion of the morality of genocide. It is important to emphasize that for Durkheim, morality is by definition that which is socially established as moral [Durkheim 1992: 67; 1982: 81]. Consequently, where the moral legitimacy, even the moral necessity, of genocide is socially established and validated minimally by generally unopposed state policy, or, most stringently, by "widespread, repressive sanction" backed up by the condemnation of "public opinion", then "we have no right to deny its moral character". If the Nazi genocides do not provide a sufficiently clear-cut example of this (if one still wants to construe the genocide as a conspiracy of elites that would have been opposed by public opinion) then one only has to look at Rwanda, where the attempt by elite instigators to construe the killing of Tutsis as a moral obligation was successful, where one confronts not a few criminals in power but "a criminal population" [Mamdani 2001: 7], where thousands of ordinary Rwandans from every location in the social structure participated in face-to-face killings of their neighbours. Mamdani says that "rather than run away from it, we need to realize that it is the 'popularity' of the genocide that is its uniquely troubling aspect." [Mamdani 2001: 8] In Durkheimian terms, we would say also that its morality needs to be confronted, and the morality of genocide or genocidal morality in general. This needs to be understood, again, not as a transcendental standard smuggled back in to produce a normative claim that we should consider genocide as moral, but as recognition that genocide is taken by some as moral; that is, the morality and immorality of genocide is relative, an empirical fact of social relations and not a universal and ahistorical truth.

This position gives us a way to understand the social functionality of genocide: 
We must say that what is moral is everything that is a source of solidarity, everything that forces man [sic] to take account of other people, to regulate his actions by something other than the promptings of his own egoism, and the more numerous and strong these ties are, the more solid is the morality. [Durkheim 1984: 331]

If we take this as a further definitional statement (rather than a potentially false empirical assertion) then genocide is ambivalently moral: immoral to the extent that it constitutes a victim group as outside the universe of obligation and encourages other members of society specifically to take no account of them; moral to the extent that it constitutes a perpetrator group and intensifies solidarity within that group. One might say, then, that genocide is moral to the extent that it is successful, or that its success is measured by the extent to which it provides the basis for a (new) moral order. On this basis we could take a Durkheimian functionalist approach to the study of genocide, asking how genocide is socially produced and exploring the actual social functions it performs, what kinds of solidarity it fosters.

All of this fits in the framework of anti-heroic theory, until we add to it a consideration of the organic unity that Durkheim attributes to society - in which case we are once again left with the persistent suspicion that by saying genocide is functional or moral we are valorizing it. With the claim that society forms an integrated organic whole, Durkheimian theory pursues the heroic mode of theory at the expense of the antiheroic. On the one hand, Durkheim consistently attributes to society a functional unity similar to the functional unity of a living organism. If we take as a point of reference Deleuze's comments on the difference between using scientific concepts as metaphor and using them directly as concepts [Deleuze 1995: 29] we can see that the organic unity 
Durkheim attributes to society is not a metaphor but a literal application of the concept.

This attribution is made a priori of empirical investigation and is elevated, in Rules of the Sociological Method (especially in Chapter III on the normal and the pathological) to a standard methodological principle. The assumption of the organic unity of society undermines the relativism of a Durkheimian conception of morality: not absolutely, to be sure, but on balance. It tends to encourage the conviction that the perpetuation of society is in the interests of the individual and that this shared interest represents a real limit to the otherwise unfettered pursuit of individual self-interest. This is exemplified in his writings on anomic suicide [Durkheim 1979: 284-287] and mostly explicitly in Moral Education [Durkheim 1961: 38-46]. By the same token, the organic unity of society represents a real limit to the pursuit of the interests of sub-collectivities or secondary groups within societies, the groups that Durkheim valorizes in Professional Ethics as a necessary brake on the power of the state. In Moral Education Durkheim says:

Moral goals, then, are those the object of which is society. To act morally is to act in terms of the collective interest. .... Above and beyond me as a conscious being, above and beyond those sentient beings who are other individual human beings, there is nothing else save that sentient being that is society. By this I mean anything that is a human group, the family as well as the nation, and humanity, at least to the extent that they constitute societies. [Durkheim 2002: 59-60]

It is difficult not to infer the reappearance of a transcendental measure of morality: the good of societies, in which case we are left with the conclusion that genocide is moral, absolutely, where it fosters the development of society - a conclusion that of course is unacceptable. 
In addition to claiming the organic unity of society as the objective and literally super-human foundation of morality, Durkheim identifies the state unproblematically as the "very organ of social thought" and the "organ of moral discipline" of society [Durkheim 1992: 51, 70]. It would be superficial to say that Durkheim is simply a conservative theorist or a theorist of conformity: in The Division of Labour he is concerned to establish a rational basis for the existence and proliferation of difference in society, to describe a well-functioning society that overcomes the reliance on sameness associated with mechanical solidarity [Durkheim 1984: 84-85], and in Professional Ethics he is equally concerned to reconcile the development of individuality with the growth of the modern state, to describe a well-functioning society in which individual liberty is protected by a balance of power between a plurality of secondary organizations (the professional associations) and the unified sovereign authority of the state [Durkheim 1992: 63-64]. His insistence on the importance of secondary institutions is comparable to the insistence of contemporary civil society theorists on the importance to democratic functioning of a strong civil society. However, the moral significance of these secondary institutions tends to wane in the face of his repeated assertions to the effect that "it is through the State, and the State alone, that they [individuals] have a moral existence" [Durkheim 1992: 64]. How do we read this statement? As an empirical claim, a normative assertion, or a definitional tautology? Durkheim repeatedly justifies the value of society by referring to the benefits it confers: individuality, for example. In so doing, he suggests that we read his claim (that it is through the State alone that individuals have a moral existence) as not a definitional tautology, as either a normative or an empirical 
assertion. If it is a normative assertion, that the only truly (transcendentally) moral existence for individuals is that which finds its expression through the state, then there is no basis in Durkheimian thinking for saying that any particular form of solidarity is evil, or that any particular society should fall apart rather than be allowed to perpetuate itself through genocide.

On the other hand, if we take Durkheim's statement that the state is the "very organ of social thought" to be an assertion of fact, then the effect is to collapse all differences within a modern, differentiated society beneath the transcendent unity of the morality of state. This culminates in Durkheim's insistence that the democratic quality of a state is guaranteed not by the power of individuals to control or to sanction the state, but by the degree of closeness of communication between the state, as the organ of social thought, and the diffuse consciousness of the mass of society [Durkheim 1992: 82-84]. In the well-functioning, rational state, therefore, morality is not a heterogeneous distributed network or a matrix of overlapping strata, in which real contradictions can appear; instead it forms a single-celled organism with a diffuse cytoplasm and a single nucleus. Contradiction disappears and with it, real politics. Either genocide is dysfunctional, in which case it is marginal to the study of the functioning state and must be studied in terms of breakdown or pathology; or it is a necessary part of the functioning of a society. In either case, for a group threatened by genocidal violence the only defense is the heroic strategy: to attempt either to colonize the nucleus by taking over the state and reconstituting its sovereign unity according to a new principle; or else to divide the 
cell, produce a new nucleus, and so find safety in the reproduction of society (and the state) on a smaller scale.

Thus the heroic strategy predominates in Durkheim's work to the extent that society and morality are organized, in the last instance, by a principle of unity that overrides difference, a principle that could require sociologists to affirm the morality of genocide. At the same time, there is in Durkheim the potential for an understanding of morality as fragmented, heterogeneous, discontinuous, even contradictory within societies as well as between them. One can find therefore the basis for a relativistic sociology of genocidal morality. To realize this potential, one needs to dispense with or radically rethink his assumption of the organic unity of society and the consequent identification of morality with society. It is also necessary to understand the rationality of the state, not in terms of calm and disinterested reflection on the interests of society, but in terms of power and of the cleavages in morality and social solidarity that are manifested in the effects of power. On this basis it is possible to inquire into the question of what actual, concrete life circumstances foster the growth of genocidal moralities, and what forms of action might encourage the development of anti-genocidal moralities. This question, implicit in Durkheim, can be posed more explicitly within the framework of Marx's thought, to which I now turn.

\subsection{MARX}

It may be worth mentioning at this point that my objective has not been simply to criticize Durkheim, which would be somewhat pointless, but to use his writings as a basis for thinking through the contours of a particular problem, the problem of solidarity 
and difference. For social theory read in heroic terms, solidarity trumps difference, which is twice displaced onto external and internal Others, to be dealt with, in extremis, by war and by genocide. In other words, the heroic logic in Durkheimian theory is capable of producing a normative valuation of genocide or, if not, it leads to an impasse in which the solution to genocide is premised on the establishment of sameness, and hence the negation of difference. Applying a heroic reading to Marx illustrates the same problem from a different angle.

It is immediately clear that Marx's writings bring to the project of anti-heroic theory certain resources not readily found in Durkheim's. For one thing, conflict and contradiction are at the heart of Marx's analysis, and he is centrally preoccupied with violence and suffering in a way that Durkheim is not. The ultimate goal of Marxian praxis lends itself to an anti-heroic interpretation: the aim of revolution is the unmaking of the class relation, and so of 'capital' understood as a material social relation through which domination is effected. Marxian revolutionary praxis aims, not to substitute one dominating class for a better one, but to unmake the technology of domination that is capital in order to abolish the socially objective basis for class relations [Marx and Engels 1988b: 17; 1988a: 30; Marx 2000c: 281, 284]. Furthermore, by asserting a relation of determination between violence and material interests, historical materialism offers a ready-made matrix for a general theory of genocide. That is, one could seek to explain genocide (at least in the modern era) in terms of the interests of capital. Colonial genocides fit very neatly into this framework, down to a certain level of approximation. Using this matrix we could ask some new questions about so familiar and so persistently 
mysterious an event as the Nazi holocaust. For instance, proponents of its uniqueness allege that what sets it apart from other events is the extent to which physical extermination was made 'an end in itself'. If that is true, then could we say that the Nazis, making genocide an end in itself, only mystified the real efficacy of genocide, its real function in the constitution of the overseas empires of Spain, France, and Great Britain? Or alternatively, might we find that the economic expropriation of the Jews, which involved substantial quantities of wealth, and which continued into the gas chambers and even after, served in a limited way the same function that wealth expropriated from the colonies served for the successful imperialists, as both a means of capital accumulation and a device for displacing and defusing Germany's internal class struggle? Might we find that the Nazi holocaust can be understood as a kind of introverted and so terribly concentrated colonialism, in which case its modernity is considerably more extensive than even Bauman has recognized?

Marx even provides, in The $18^{\text {th }}$ Brumaire of Louis Bonaparte, a kind of general template for the process by which, in a modern democratic state, power devolves into the hands of a dictator as political violence becomes widespread. Marx shows how the collapse of French democracy can be understood as a historically contingent inflection of class struggle: how various factions of the bourgeoisie and petit-bourgeoisie deemed it in their own interests to restrict political liberties progressively and to curtail the authority of the legislative branches of government in favour of the executive, painting themselves into a corner where even the narrowest forms of republicanism gave way to the authority concentrated in the President. It is a brilliant analysis of the way in which an elite class 
may undermine the conditions of its own political rule, with political terror as the outcome:

Society is saved just as often as the circle of rulers contracts, as a more exclusive interest is maintained against a wider one. Every demand of the simplest bourgeois financial reform, of the most ordinary liberalism, of the most formal republicanism, of the most shallow democracy, is simultaneously castigated as an "attempt on society" and stigmatized as "socialism". And finally the high priests of "religion and order" themselves are driven with kicks from their Pythian tripods, hauled out of their beds in the darkness of night, put in prison-vans, thrown into dungeons or sent into exile; their temple is razed to the ground, their mouths are sealed, their pens broken, their law torn to pieces in the name of religion, of property, of the family, of order. [Marx 1979: 111-112]

Marx could as easily be writing of Idi Amin's Uganda, of Guatemala under the generals, or of Nazi Germany, as of France under Louis Napoleon Bonaparte. Though he is not writing about a genocide, the parallels with genocidal events are striking, including the state's infiltration of the economy [ibid.: 139], the important role of militia recruited from the lumpen-proletariat [148-151], the decision of the 'finance aristocracy' to view the dictator as the "guardian of order" [170-171], the special relationship between peasants and the army [192], and so on. If there is not quite a general template for the analysis of genocide, The $18^{\text {th }}$ Brumaire is at least an extraordinarily fertile starting-point. And indeed, the kind of detailed, historically specific class analysis that Marx performs in The $18^{\text {th }}$ Brumaire is employed to great effect by many genocide scholars, especially in the literature on the Rwandan genocide (for example: Prunier [1995]; Uvin [1998]; Melvern [2000]; Mamdani [2001]; Jeffremovas [2002]).

In its anti-heroic mode, Marxian theory addresses the task of unmaking the relations of domination that are coded as 'capital' and, more broadly, as 'alienated 
labour, ${ }^{78}$. In this mode, class is a relationship: "capital and wage labour are two sides of one and the same relation" [Marx 2000c: 282]. In its heroic mode, Marxian theory addresses the same task in terms of collective subjects, and conceptualizes classes as social collectivities. Not surprisingly, this mode comes to the fore in The Communist Manifesto: "the immediate aim of the Communists is the same as that of all the other proletarian parties: formation of the proletariat into a class, overthrow of the bourgeois supremacy, conquest of political power by the proletariat" [Marx and Engels 1988a: 31]. These modes are not necessarily antagonistic; they can be complementary. Classes as social collectivities are the product of class relations:

The relationship of the worker to his labour creates the relationship to it of the capitalist, or whatever else one wishes to call the master of the labour. Private property is thus the product, result, and necessary consequence of externalized labour, of the exterior relationship of the worker to nature and to himself. [Marx 2000a: 93]

The world-historic character of the proletarian class under capitalism derives precisely from the fact that, in order to abolish its domination by the bourgeoisie, it must abolish the class relation itself [Marx and Engels 1988b: 19; 1988a: 29-31]. This synthesis of the analysis of social relationships with the analysis of social groups, of anti-heroic and heroic modes of analysis, is, of course, one of Marx's enduring and powerful legacies, a central element of his genius. The proletarians are constituted as a social group by the operation of the class relation; the more that capitalists inflict violence on workers, the more intensely they perform this relation, and therefore the more they work to turn labourers into a working class, and labour into a collective force. That is, the more that

78. "[...] although private property appears to be the ground and reason for externalized labour, it is 
capitalists exploit workers, oppress them by law and by force of arms, exclude them socially and culturally, the more they activate the relation of alienation that transforms the working masses into a heroic collective subject whose self-realization entails the abolition of that class relation, and thereby of class domination as such: "what the bourgeoisie, therefore, produces, above all, is its own gravediggers" [Marx and Engels 1988a: 31].

Nevertheless, Marx's synthesis of heroic and antiheroic theoretical concerns suffers from three general limitations that make it not wholly adequate for a sociology of genocide or an anti-genocidal praxis. The first limitation concerns the operation of sameness and difference within Marxian revolutionary praxis. Labour, as an alienated mode of activity and as a social collectivity, is constituted through difference, through a historical process of differentiation that separates concrete human beings from the products of their labour, from their species-being, from each other, and from themselves [Marx 2000a: 86-91]. Under feudalism this differentiation had produced "a complicated arrangement of society into various orders, a manifold gradation of social rank" [Marx and Engels 1988a: 21], but in the capitalist mode of production this manifold gradation is held to resolve itself into a binary opposition, "into two great hostile camps, into two great classes directly facing each other: Bourgeoisie and Proletariat" [ibid.; see also pp. 29-30]. The operation of capitalism is said to efface all other forms of difference, including those of gender as established in the family, of peoples as established in the nation, and of religion [Marx and Engels 1988a: 34-36]. The movement of labour 
towards its fulfillment and its abolition (through the abolition of its alienation) is therefore a movement towards the abolition of difference and the constitution of an undifferentiated human collectivity united by the realization of its common speciesbeing. That is, revolutionary praxis assumes a universalizing essentialism: beyond all merely contingent differences exists an objective foundation for human identity, which is the capacity for praxis, or world-altering activity as such [Marx 2000a: 88-91; Marx and Engels 1988b: 4]. The revolutionary movement constitutes a movement towards the (re)realization of this essential sameness. In practical terms, this involves the constitution of the revolutionary proletariat as an internally undifferentiated subject, one that is capable of seizing the state and using state power in its own interests [Marx and Engels 1988a: 37-38]. This constitution requires that real cleavages within the revolutionary movement - of gender, racialization, nationality, religion, and so on - must be secondary to the unity of this subject. In other words, Marx does not theorize any relation of difference or process of differentiation as fundamental, except that of alienated labour and class domination. Politics within the proletariat disappears. This has already been observed by theorists engaged with feminist, anti-racist, and indigenous peoples' social movements, and serves as an obstacle to conceptualizing those social struggles entirely within a Marxian framework. Historical capitalism has not sufficed to eliminate gender, the nation, religion, and so on. The history of social struggle, civil war, and genocide in post-colonial Africa abundantly attests to this. Moreover, the struggles of indigenous peoples to preserve their cultural existence from obliteration is precisely a struggle 
against this homogenizing tendency; these struggles resist precisely that historical movement which Marx conceives as a prerequisite for revolution. In this respect, concrete struggles against domination and against genocide violate the requirements of Marx's teleological claim that history must converge on a single point.

The second obstacle, implied by the first, is the analytical inadequacy of reducing relations of genocide to relations of production. Feminist theorists have already remarked on the inadequacy of reducing relations of reproduction, that is, bearing and raising children, domestic labour, and so on, to relations of production ${ }^{79}$. Genocide, on the other hand, is intimately bound up with what we might call the relations of destruction, or relations of force. Within the strict framework of Marxian historical materialism, these relations are treated as derivatives of the relations of production. The monopoly of military and police force institutionalized by the modern state is therefore only the "practical-idealistic expression" of the "rule of a definite class of society, whose social power [derives] from its property" [Marx and Engels 1988b: 18]. Relations of force have no fundamental autonomy, but are always "ultimately" determined by "the production and reproduction of real life"; at most, they can "influence" the course of historical class struggles or even "in many cases preponderate in determining their form" [Engels 1988a: 69]. It involves a departure from, or at least a substantial modification of, historical materialism to recognize that state institutions can themselves become the basis for a new form of class domination, as they did in the Soviet Union [Resnick and Wolff 1995]. Moreover, it is possible to reverse the analytical priority that positions the 
economy as base to the state's superstructure, and theorize control over the relations of force as the basis of control over the relations of property [e.g. Tilly 1985]. Within capitalist states, Foucault's argument that power is not always in a subordinate position relative to the economy, that there exist situations in which the interests of the bourgeoisie might reasonably determine two or more antithetical rationalities for the application of power [Foucault 1980: 88, 101], applies just as well to genocide as to madness or sexuality. Although one can frequently identify class interests that are served by it, genocide is also economically destructive and not infrequently rebounds against its perpetrators in both economic and political terms [Chalk and Jonassohn 1990: 417-420]. And under conditions of genocide, military elites often display an autonomy that puts them in an ambivalent or event antagonistic relationship with important segments of the property-owning classes, as in Uganda under Idi Amin, for example, or in Guatemala under the generals. At all times, genocide has an intimate relationship with class struggle, but it cannot always be deduced, even retrospectively, from the arrangement of the relations of production.

Third, if we treat Marxian revolutionary praxis as a form of anti-genocidal praxis, then we can see that it falls victim to the heroic dilemma whereby the solution to the problem of genocide reproduces the terms of the problem within itself. As a totalizing philosophical account of human nature and human social existence, through its account of the essential human species-being and the teleological movement of history towards the realization of that being, Marxian theory prescribes what in other contexts would be

79 In a way this is a very curious failure for Marx the materialist: if humans must eat before they can 
called a morality. That is, Marx implies an absolute normative privilege for action that works to abolish alienation; such action does not need the sanction of the concept of 'morality', which is subsumed within that of 'revolutionary praxis'. In this respect, revolutionary praxis provides an objective normative sanction for social action in the same way that the organic unity of society does within Durkheimian thought. And just as that organic unity can in principle make genocidal moral under some circumstances, revolutionary praxis can make it rational. This can be shown by way of Fein's conception of genocide as "the calculated murder of a segment or all of a group defined outside the universe of obligation of the perpetrator by a government, elite, staff or crowd representing the perpetrator in response to a crisis or opportunity perceived to be caused by or impeded by the victim" [Fein 1984: 4]. Marxian praxis implies the radical exclusion of the bourgeoisie from the community of obligation of the revolutionary proletariat, and at same time implies a reciprocal movement whereby the revolutionary proletariat removes itself from the community of obligation of the bourgeoisie. This reciprocal exclusion implies a twofold rationality of genocide. First, it implies that in some circumstances it would be rational for the revolutionary force to achieve its victory by genocide of the bourgeoisie. In anti-heroic terms, the object of revolutionary praxis is the negation of the relation of capital, a relation that is not dependent on the specific individuals who perform it. But the heroic constitution of the proletariat as a collective philosophize, they must be born before they can eat. 
subject implies a translation of the struggle over social relations into a struggle between social groups, and this latter struggle could in principle involve genocide ${ }^{80}$.

Second, and perhaps more problematically, the revolutionary movement's withdrawal from the bourgeois universe of obligation implies the rationality of genocide as a counterrevolutionary technique. Engels considers this possibility:

And there is only one means by which the steady rise of the Socialist fighting forces in Germany could be momentarily halted, and even thrown back for some time: a clash on a big scale with the military, a bloodbath like that of 1871 in Paris. In the long run that would also be overcome. To shoot out of the world a party which numbers millions - all the magazine rifles of Europe and America are not enough for this. [Engels 1988b: 73]

With the benefit of hindsight, we can say that Engels was over-optimistic. For example, in 1965, the Indonesian Communist Party (PKI) was eliminated as a viable political force (at least for a time) through the slaughter of 500,000 people and the arrest of another 500,000 [Chalk and Jonassohn 1990: 381]; the United States was implicated in this genocide through the provision of intelligence information that helped the Indonesian state identify victims [Keefer 2001]. So it has proven possible to "shoot out of the world a party which numbers in the millions". More broadly, Engels' concern that military violence could be used systematically to delay revolution has proven true in Guatemala and El Salvador [e.g. La Feber 1993]. Sartre [1968] has commented on the use of genocidal violence to undermine revolution in southeast Asia. Again The $18^{\text {th }}$ Brumaire

80 Consistent with this, one finds at times a kind of ecstasy of violence in Marx's writings, as in this passage, crossed out in the manuscript but telling nonetheless, from The German Ideology: "The holy father ['Saint Bruno'] of the church will be greatly surprised when judgment day overtakes him, the day when all this is to come to pass - a day when the reflection in the sky of burning cities will mark the dawn, when together with the 'celestial harmonies' the tunes of Marseillaise and Carmagnole will echo in his ears accompanied by the requisite roar of cannon, with the 
casts light on the subject, in its analysis of how political terror is unleashed by dominant classes insecure in their dominance. At this point Marxian theory involves a praxical paradox, since the point of revolution is precisely to undermine the security of dominant classes. The revolutionary movement properly so called must constitute itself as the radical Other of the hegemonic social order.

In Marx's writings, as in Durkheim's, heroic tendencies or strategies of making tend to eclipse anti-heroic tendencies and strategies of unmaking. Shifting the balance between the two tendencies involves an attempt to synthesize revolutionary praxis with anti-genocidal praxis. Each of these two modes of praxis addresses itself to the unmaking of relations of domination, of technologies that are coded as 'capital' in the one case and as 'genocide' in the other. I suggest that there are two main respects in which the needs of anti-genocidal praxis carry us beyond the usual boundaries of Marx's thought. The first involves taking force relations themselves as an object of interrogation, without reducing them to relations of economic class. I take up this inquiry in the following section. However, it would be unsatisfying to displace an analysis of relations of capital that refers to a capitalist system, in favour of an analysis of relations of force that remains embedded in local particularities. Therefore my second move will involve situating capitalism in relation to another object of comparable scope and generality: the 'civilizing process'. That interrogation will begin in Chapter 4.

guillotine beating time; when the infamous 'masses' will shout ça ira, ça ira and suspend 'selfconsciousness' by means of the lamp-post" [Marx and Engels 1976: 53 n.]. 


\section{Anti-Heroic Theory}

\subsection{BaUman}

So far I have examined the writings of Durkheim and Marx, bringing out antiheroic and heroic readings of their texts and emphasizing the limitations that the heroic currents in these texts present for anti-genocidal praxis. I could go on to repeat this process for other theorists, investigating the ways in which their theory both promises to explain genocide and shies away from doing so. If I were to repeat on Weber the analysis I performed on Durkheim and Marx, it would be to see how heroic and anti-heroic solutions to genocide can be read out of Weber's theory, to weigh the impulse to resolve the threat of genocide by constructing a unified subject against the task of resolving it by unmaking the effective social relations that generate it. Rather than do this, however, in the remainder of this chapter I will try to formulate more clearly some basic elements of an anti-heroic theorization of genocide. I begin with Zygmunt Bauman, whose Modernity and the Holocaust makes important contributions to this solution, and then continue with an examination of Foucault, who provides some tools for overcoming certain shortcomings in Bauman's text.

Bauman begins by taking issue with the idea of the Nazi holocaust as a breakdown of social relations, of Western civilization, or of modernity. He observes two ways of marginalizing it and so disregarding its troubling implications. The first is to treat the Nazi holocaust ${ }^{81}$ as an event that belongs only to Jewish history; the second is to 
treat it as an extreme case of a certain class of phenomena which is bound to be stamped out by the advance of our modern society. Sociologists, including the foremost sociologists of genocide, have taken the latter approach. This decision is the product of sociologists' assumption that morality is socially produced, that "society is best understood as a morality-producing plant" and that the Nazi holocaust has therefore to be understood as a withering of the plant, as "a failure, not a product, of modernity" [Bauman 1991: 5, 173]. The implied solution to genocide is therefore more modernity, more civilization, more rationality: "What we need is better technology of the old - and in no way discredited - activity of social engineering" [ibid.: 4]. Bauman takes issue with both the solution and the diagnosis, arguing that the Nazi holocaust is fundamentally modern and civilized. Modern civilization is a necessary though not a sufficient condition for its occurrence [ibid.: 12]. More significantly, the Nazi holocaust can “provide an insight into the otherwise unnoticed 'other aspects' of the societal principles enshrined in modern history"; it is a test of the "hidden possibilities of modern society" [pp. 11-12] $]^{82}$. Bauman's project, therefore, is to theorize the Nazi holocaust, not as a catastrophe or breakdown or failure or lapse of modern Western civilization, but as one of its many possible products. In so doing, he commits himself to an analysis of the social relations that make genocide possible, and to some exploration of the means by

mentally ill persons, and his general analysis applies to the Nazi holocaust in its entirety. I have therefore chosen to use Finkelstein's terminology instead of Bauman's.

Many of the passages I quote from Bauman are italicized in the original. Bauman uses italics to set apart whole passages that are of particular importance in his overall text, rather than to emphasize particular words or phrases. Because this typographical function is lost in the translation from the original Bauman to the quoted Bauman, and because a literal reproduction of it would lead to an overabundance of emphasis and interfere with my ability to emphasize key parts of my own text, I have eliminated Bauman's emphasis in cases where all or most of a quotation would be italicized. 
which these relations can be unmade so as to remove the persistent threat of its possible recurrence.

Bauman's argument for the modernity of the Nazi holocaust has two main aspects. On the one hand, he establishes the distinctly modern quality of Nazi antisemitism, as distinguished from the broader phenomenon of 'heterophobia' [Bauman 1991: 62]. With the rise of modernity, the incongruous status of Jewish populations within European societies - as neither insiders nor outsiders, neither true nationals nor true foreigners - became more problematic in that it contradicted not just the homogenizing tendencies implicit in nationalism but the very principles of 'clarity' and 'order' as they were coming to be understood. Jews were "the opacity of the world fighting for clarity, the ambiguity of the world lusting for certainty. They bestrode all the barricades and invited bullets from every side" [ibid.: 56]. And so it became imperative to fix and essentialize Jewish difference, to fence it safely within the conceptual categories of the national state. But as modernity created new possibilities for social mobility, as the ghetto dissolved and Jews were assimilated into Gentile society, this fixing became more difficult. The attributed basis of Jewish difference was therefore shifted from cultural and religious practices to individual Jewish bodies; at the same time, this difference became all the more threatening for its lack of an external sign. And as modernity progressed, antisemitism was enrolled in strategies of social engineering, in the whole project of trying to impose on society a rational order:

Racism stands apart by a practice of which it is a part and which it rationalizes: a practice that combines strategies of architecture and gardening with that of medicine - in the service of the construction of an artificial social order, through cutting out the elements of the present 
reality that neither fit the visualized perfect reality, nor can be changed so that they do. [Bauman 1991: 64]

It was only in the context of this kind of social engineering, Bauman argues, that antisemitism could escalate from persecution, massacres, and pogroms to a systematic project of total extermination. "The murderous compound was made of a typically modern ambition of social design and engineering, mixed with the typically modern concentration of power, resources and managerial skills" [ibid.: 77].

The Nazi holocaust was also modern because it was both characterized by and depended upon an instrumental rationality, a dispassionate and logical calculation of means-ends efficiency, that is one of modernity's defining attributes and is incarnated in that most distinctively modern of social institutions, bureaucracy. The rational character of the organization of the Final Solution is one of its most famous and terrifying properties: the compilation of strict formal definitions of racial groups; the use of bureaucratic procedures to catalogue and demarcate target populations; the relentless organization and logistical efficiency of the deportation process, the liquidation of the ghettoes, the gas trucks, the trains to the concentration camps, the camps themselves, the gas chambers; and the remorseless bureaucratic procedure, especially including meticulous documentation, that pursued the victims from their homes and workplaces to the crematoria - all of this lends the Nazi holocaust a great part of its seeming uniqueness and its particular moral horror. To this standard picture Bauman adds the rational conduct of the executioners themselves: that

special care was taken to weed out - bar or discharge - all particularly keen, emotionally charged, ideologically over-zealous individuals. We know that individual initiatives were discouraged, and much effort was 
made to keep the whole task in a businesslike and strictly impersonal framework. ... On more than one occasion Himmler expressed deep, and in all likelihood genuine, concern with maintaining the mental sanity and upholding the moral standards of his many subordinates engaged daily in inhuman activity .... [Bauman 1991: 20]

And this rationality was not an incidental characteristic of the Nazi holocaust, but was in some measure a necessary precondition of its accomplishment. For one thing, the sheer scale of the genocides, the resources they demanded and the potential logistical complexity of their implementation, demanded the techniques of modern bureaucracy. Killing by mob violence of the sort that occurred during the Kristallnächte would, if repeated daily, have required two hundred years to equal the scale of the Shoah; the 'spontaneous' mob fury of that event was inadequate to the task of systematic genocide [Bauman 1991: 89-90]. And bureaucracy was a precondition for the Nazi holocaust in a subtler way also. Bauman cites Karl Schleuner's [1970] thesis of 'the twisted road' to genocide, "a road which was neither conceived in a single vision of a mad monster, nor was a considered choice made at the start of the 'problem-solving process' by the ideologically motivated leaders" [Bauman 1991: 15]. Schleuner describes how the Final Solution emerged gradually in the course of bureaucratically organized attempts to achieve Hitler's objective of making the Reich "judenfrei, i.e., clear of Jews". This objective was first achieved through the forced deportation of Germany's Jewish subjects, but as the territory of the Reich expanded to include those spaces to which the Jews had been expelled, this tactic became insufficient. Exportation to Madagascar was seriously considered [ibid.: 16], but logistical considerations of a wartime context made this unfeasible, and so physical extermination was eventually chosen as the most efficient 
resolution to the problem. In a Tolkienian instance of means shaping ends 83 , "the very idea of the Endlösung was an outcome of the bureaucratic culture" [ibid.: 15].

It is with respect to this last point that Bauman's analysis hits its stride. For Auschwitz to happen, the moral invisibility of its victims and the moral indifference of its perpetrators had to be socially produced. Bureaucracy provided the means of and the impetus for that production; "the space extending between the idea and its execution was filled wall-to-wall with bureaucratic action" [Bauman 1991: 105]. Bauman points to the peculiar failure of the Kristallnächte and of other Nazi policies aimed at inciting widespread grassroots anti-Semitism among the German people. Instead, "the perpetration of the Holocaust required the neutralization of ordinary Germany (sic) attitudes toward the Jews, not their mobilization" [ibid.: 195]. The first element of this neutralization was the expulsion of Jews from ordinary social life: the taking away of their citizenship, their employment, their property, along with their physical separation from their non-Jewish neighbours, their concentration in ghettoes and expulsion beyond the boundaries of Germany [ibid.: 189]. Bureaucracy not only facilitated this process of expulsion from the universe of obligation but, through its own intrinsic negation of morality, made possible the escalation to exterminatory violence. The perpetration of the genocides involved the construction of a vast social machine in which most of those

83 This quality comes through more clearly when Bauman discusses the extent to which the genocidal program fell victim to "the tendency of all bureaucracies to lose sight of the original goal and to concentrate on the means instead", even to the extent of undermining the German war effort: "But nowhere was the morbid tendency of substituting the means for the ends more visible than in the uncanny and macabre episode of the murder of Romanian and Hungarian Jews, perpetrated with the Eastern Front just a few miles away, and at an enormous cost to the war effort: priceless rail carriages and engines, troops and administrative resources were diverted from 
responsible for violence were separated from the consequences of their actions: filling out reports, procuring supplies, planning rail shipments, modifying and repairing vehicles, and so on - all of these were performed by functional specialists who could concentrate only on the task at hand (and who would be disciplined or replaced if they refused) [ibid.: 98]. Moral considerations were excised from the performance of technical tasks; moral responsibility gave way to technical responsibility; ordinary individuals participated willingly and even enthusiastically in atrocity. The end result of one's daily labour disappeared - as did its victims, not only through the social distance that separated a clerk in Berlin from an inmate at Birkenau, but through the dehumanization that ensued from that inmate being inscribed into the quality-free technical language of bureaucratic discourses [ibid.: 102]. This bureaucratic negation of moral affect extended to the choice of means of execution and was necessary for killing to take place on an exterminatory scale:

The Germans employed the phrase Seelenbelastung ("burdening of the soul") with reference to machine-gun fire...directed at men, women, and children in prepared ditches. After all, the men that were firing these weapons were themselves fathers. How could they do this day after day? It was then that the technicians developed a gas van designed to lessen the suffering of the perpetrator. [Hilberg 1980: 90-91]

Even in the death camps, the technology of gas chambers facilitated the dissociation of moral responsibility from the performance of technical tasks. In his famous experiments, the psychologist Stanley Milgram [1974] showed that ordinary Americans could be induced to apply electric shocks at seemingly painful and even life-threatening levels, if

military tasks in order to cleanse distant parts of Europe for the German habitat which was never to be." [Bauman 1991: 106] 
they were asked to do so by a technical expert in a situation framed as a scientific experiment. They did so even when face-to-face with their victims' suffering. In Auschwitz, and throughout the Reich, the same technical authority and even greater social distance allowed ordinary people to be enrolled in atrocity.

The chilling implication of Bauman's analysis is that the mechanisms that made the Nazi holocaust possible, mechanisms through which instrumental rationality silenced the voice of moral responsibility, are still embedded components of contemporary modernity. If anything, their potential virulence is greater; the progress from the firebombing of Dresden, to the high-altitude carpet-bombing practiced during the Vietnam war, to the cruise missiles and laser-guided cluster bombs of the second Gulf War, has dramatized the ongoing refinement of social technologies that produce social distance, substitute technical for moral responsibility, and segregate and separate populations. All these are "further strengthened by the principle of sovereignty of state powers usurping supreme ethical authority on behalf of the societies they rule" [Bauman 1991: 199]. Repetition of the Nazi holocaust is prevented only inasmuch as the spark of utopian social engineering is kept away from the fuse of bureaucratic rationality.

When the modernist dream is embraced by an absolute power able to monopolize modern vehicles of rational action, and when that power attains freedom from effective social control, genocide follows. A modern genocide - like the Holocaust. [Bauman 1991: 93-94]

The implications for anti-heroic strategy are clear. If we do not wish to go on living in a protogenocidal powder keg, we must dismantle or unmake the "morality-eroding mechanisms" of 
social production of distance, which either annuls or weakens the pressure of moral responsibility; substitution of technical for moral responsibility, which effectively conceals the moral significance of the action; and the technology of segregation and separation, which promotes indifference to the plight of the Other which otherwise would be subject to moral evaluation and morally-motivated response. [Bauman 1991: 199]

Where modernist social theory has viewed society as a morality-producing plant and, by implication, has understood evil as a failure or breakdown of society, a reappearance of the "'jungle law' or the 'law of the fist"” [ibid.: 198], Bauman reveals how the forces naively assumed to produce morality may also produce genocide. As a corollary of this argument, he also asserts that "powerful moral drives may have a pre-societal origin" [ibid.]. It is on this point that I wish to open up my comments on the limitations of Bauman's analysis and of its implications for the sociology of genocide and for antigenocidal praxis.

Bauman is concerned to overturn what he reads as the Durkheimian assumption of the inherently moralizing quality of social relations, an assumption that he regards as ultimately circular [Bauman 1991; 172]. I have said earlier that it is possible to read in Durkheim, rather than mere circularity, an anti-humanist and sociologically relativist conception of morality as being whatever is socially established as moral in any particular context, and thence to inquire into how genocide comes to be moral in some context and immoral in others. At the same time, Durkheim's texts also support what I have called the heroic reading in which transcendental morality, that which is really moral, happens to be produced by social relations and more particularly by Society. The theory of morality that such a reading generates is indeed susceptible to Bauman's criticism that "the need of society being the only substance of morality, all moral systems 
are equal in the sole respect in which they can be legitimately - objectivity, scientifically - measured and evaluated: their utility for the satisfaction of that need" [ibid.: 172], with obviously unsatisfactory implications for the evaluation of Nazi genocides. But Bauman, concerned to unseat the universalizing, Eurocentric view that modern society is a factory of morality, and of morality as "attained and sustained by the imposition of constraints upon natural (a-social, pre-social) predilections of society members" [ibid.], proceeds by standing Durkheim on his head. Bauman takes up Levinas to argue that morality has an existential, and hence pre-social, basis in the essential responsibility towards others, or 'responsibility for the Other,' which is the fundamental structure of subjectivity [ibid.: 183]. Morality, therefore, "is not a product of society. Morality is something society manipulates - exploits, re-directs, jams". And Bauman explicitly directs the reader not to employ analytical symmetry in the sociological analysis of morality and immorality, to analyze morality and immorality as both produced through social interaction. Immoral behavior, as "conduct which forsakes or abdicates responsibility for the other" is necessarily a socially produced obstruction of the essential moral impulse. "It is therefore the incidence of immoral, rather than moral, behaviour which calls for the investigation of the social administration of intersubjectivity" [ibid.: 183, emphasis added]. The implications for the sociology of genocide are clear:

The Holocaust could be accomplished only on the condition of neutralizing the impact of primeval moral drives, of isolating the machinery of murder from the sphere where such drives arise and apply, of rendering such drives marginal or altogether irrelevant to task. [Bauman 1991: 188] 
Bauman's anti-heroic praxis is then aimed at unmaking social structures that constrain these allegedly primeval moral drives. In the face of genocidal social relations, "Moral duty has to count on its pristine source: the essential human responsibility for the Other" [ibid.: 199].

Bauman has substituted one breakdown narrative for another, the failure of natural morality for the failure of society. This is enormously problematic. On the one hand, it is not very thorough sociology to reduce an important dimension of social life to a pre-social atavism. The relation between hunger and eating illustrates this aptly. While hunger is to some extent a pre-social impulse, eating is a social practice; what is eaten, when, by whom, and so on - not to mention table manners - are all conditioned by the entire social milieu in which the eater is situated. One can say that eating is a practice, situated in a field and conditioned by a habitus of which hunger forms only a part. If one does not have too determinist a notion of 'production' then it can be said that social relations produce eating, as well as forms of diet, cuisine, and so on; they also produce starvation and famine. Hunger, though it does not have infinite plasticity, can of course be modified by lived experience, by social relations. If there does exist in humans an atavistic impulse to abhor the suffering of others, or to feel responsible for them, then it stands to reason that this impulse is taken up in social relations in ways that are comparably complex. It would make no sense to say that eating is hunger or that eating, being the natural expression of hunger, is pre-social while starvation and famine are social; so, too, with morality. Recognition of this requires us to engage with the morality of genocide - the fact that genocide is sometimes considered moral, even a moral duty - 
and also, simultaneously, with the immorality of genocide, the fact that we (I the writer, you the reader) consider it immoral and are engaged in the attempt to eliminate it. These engagements are required not only for a fetishistically pursued standard of sociological consistency and completeness, but for the sake of the efficacy of our anti-genocidal praxis.

On the other hand, Bauman re-introduces a curious modernism into his antimodernist argument. Rather than take, for example, the Rortyan position of "saying that we have to work out from the networks we are, from the communities with which we presently identify" [Rorty 1991: 202], Bauman reasserts the God's-eye view, the universalizing imperial gaze with which "various moral systems can be compared and differentially evaluated" [Bauman 1991: 172]. In this respect his theory is no less Eurocentric than heroic Durkheimianism, perhaps more so, since he implies that sociology can "legitimately, objectively, scientifically" pass judgment on the universe of moral systems according to a transcendental standard developed by a European philosopher. Nor does Bauman provide any particular basis for accepting as empirical fact the claim that responsibility for the Other is the universal foundation of subjectivity. His claim is that unless we can identify a universal, ahistorical basis for morality, we are necessarily bound to accept as objectively valid all the various local and contingent forms that morality takes ${ }^{84}$. This assumes a totalizing metaphysics of morality in which claims

$84 \quad$ I like to call this "Star Trek relativism". Whereas the original Star Trek series that came out in the 1960 s espouses a classic modernist universalism about values, the series that came out in the 1980s and 90s ("Star Trek: Next Generation", "Star Trek: Deep Space Nine", and "Star Trek: Voyager") temper this, increasingly with each new series, with a pseudo-relativism in which the claim "but this is part of my culture/society/tradition" trumps all form of moral argument where the contestants come from different cultures (or, worse yet, different 'races'). This is pseudo- 
that " $x$ is moral" are objectively true or false. My own view is that only empirical claims that " $x$ is established as moral by $y$ " can be objectively true or false, and that moral claims are performative and not constative. I hold, contra Durkheim and, seemingly, Bauman, that constative claims, e.g. about the social production of morality, do not trump performative claims, e.g. that a particular socially produced moral scheme is objectionable and immoral to me; I also hold, contra. Durkheim and Bauman, that performative moral claims are a legitimate part of sociological discourse and that sociologists do not need to justify their moral projects by claiming that they reflect an objective reality. In saying that the Nazi holocaust was evil, I am engaging in a performative act, a political effort, that actively opposes the claims of the Nazis and their apologists ${ }^{85}$. Whatever will vindicate my claim, it will not be correspondence to some universal, ahistorical reality. The idea that it could is "a result of Enlightenment scientism, which was in turn a survival of the religious need to have human projects underwritten by a nonhuman authority" [Rorty 1989: 52]. Performative declarations of the immorality of genocide are not invalidated by the absence of this authority, but in fact are all the more urgently necessary.

My final criticism of Bauman bears not on his concept of morality but of modernity. The strength of Bauman's analysis is that it provides a sociological account

relativism because the claim that culture, society, or tradition are necessarily to be valued is, of course, a universalistic claim. Indeed, it finds expression in the discourse of universal human rights, of which the right to cultural integrity is one. An example of a self-consciously performative deployment of moral claims is Harriet Martineau's statement on the legal and political disenfranchisement of women: "I, for one, do not acquiesce. I declare that whatever obedience I yield to the laws of society in which I live is a matter between, not the community and myself, but my judgment and my will. Any punishment inflicted on me for the breach of the laws, I should regard as so much gratuitous injury; for to those laws I have never, 
of how genocide is socially produced. This account can be generalized to other cases, if not concretely, then at least methodologically; one can study how genocides other than those of the Nazis have been socially produced, how they have been modern and civilized. Bauman recognizes the survival of the possibility of modern genocide: "those once-familiar features of our civilization, which the Holocaust had made mysterious again, are still very much a part of our life. They have not gone away. Neither, therefore, has the possibility of the Holocaust" [Bauman 1991: 84]. This recognition helps account for the repetition of genocide since 1945 and links this to the intrinsic dynamics of modern Western civilization. In so doing, Bauman helps to establish genocide as an obligatory point of passage for the understanding of modern society and hence for social theory. He observes that "we live in a type of society that made the Holocaust possible, and that contained nothing which could stop the Holocaust from happening" [ibid.: 88, emphasis added]; accounting for this fact becomes necessary for a complete understanding of the basic character of 'our' type of society ${ }^{86}$.

At the same time Bauman places limits on the potential generality of his analysis; he foreshortens its applicability to cases in which scientific racism and bureaucratic rationality do not appear or in which their role is different than it was in the Nazi holocaust. For example, Mamdani observes of the Rwandan genocide:

Unlike the Nazi Holocaust, the Rwandan genocide was not carried out from a distance, in remote concentration camps beyond national borders, in industrial killing camps operated by agents who often did no more than drop Zyklon B crystals into gas chambers from above. The Rwandan

actually or virtually assented" [Martineau 1966: 204]. In this passage, Martineau invokes her own agency, rather than any transcendental order, as the basis of the immorality of the laws of society. "And the knowledge of saltpeter, sulphur or charcoal is not complete unless one knows and remembers that, if mixed, they turn into gunpowder" [Bauman 1991: 94] 
genocide was executed with the slash of machetes rather than the drop of crystals, with all the gruesome detail of a street murder rather than the bureaucratic efficiency of a mass extermination. [Mamdani 2001: 5]

Equally important differences distinguish the 1992 Bosnian genocide of Serbs from the Nazi holocaust. Whereas, as Bauman observes above, the Nazis discouraged individual and personally motivated violence against the victims of their genocides and attempted to weed out from the Einsatzgruppen and similar groups "all particularly keen, emotionally charged, ideologically over-zealous individuals", Danner records that

At Omarska such men would have been cherished; the out-and-out passion with which a guard administered beatings and devised tortures could greatly bolster his prestige. Acts of flamboyant violence, publicly performed, made of some men celebrities of sadism. [Danner 1998]

These details are important because, for Bauman, they separate the Bosnian and Rwandan genocides categorically from the Nazi holocaust. Bauman repeatedly emphasizes the uniqueness of the Nazi holocaust, saying for example that "it is unique among other historic cases of genocide because it is modern" [Bauman 1991: 94] ${ }^{87}$. And modern genocide is unique, says Bauman, because it is

genocide with a purpose. Getting rid of the adversary is not an end in itself. It is a means to an end: a necessity that stems from the ultimate objective, a step that one has to take if one wants ever to reach the end of the road. The end itself is a grand vision of a better, and radically different society. [Bauman 1991: 91, emphasis in original]

If this makes the Nazi holocaust unique or nearly so, then Bauman is saying that other genocides do not have a purpose, or at least that they do not have the same element of social engineering "meant to bring about a social order conforming to the design of a perfect society" [ibid.]. 
And indeed he makes precisely this claim about colonial genocides, saying that their legitimating ideologies do "not go much further than a simple 'us or them' vision of the world, and a precept 'There is no room for both of us', or 'The only good injun (sic) is a dead injun"" [ibid.]. This claim is questionable on two grounds: first, because it excludes from the category of 'modern genocides', genocides committed with modern means, carried out in the name of civilization and modernization, genocides whose perpetration was an integral part of the process by which the modern world was constituted; second, because it is not clear how a project of clearing a territory of its indigenous inhabitants in order to build a colonial society is anything other than a project of social engineering, an act of weed-clearing according to the gardening mentality of social governance. In the same vein, it seems to me that, for example, the extermination of the Cathars of Languedoc, instigated by Pope Innocent III in order to revitalize the decayed Roman Catholic Church, should qualify as ‘modern' by Bauman’s criteria. As R. I. Moore shows, the end of persecution was not the simple removal of heretics; persecution aimed at the institution and ongoing vitalization of an entire social order premised on the spiritual hegemony of Roman Catholic Christianity and, to varying degrees, on the temporal power of the Roman Catholic Church. In this respect, Languedoc of the Albigensian Crusade and the French Inquisition was the "foyer of persecution par excellence" [Moore 1987: 145]. But if genocide in twelfth-century Languedoc meets the criteria of 'modern genocide', then the notion of modernity has been stretched out of shape. Bauman seems to rely on teleological assumptions about 
pre-modern times and non-European settings that belong more appropriately to modernist discourse than to its critique.

With the notion of 'modern genocides' and his emphasis on their categorical uniqueness, Bauman introduces a new metaphysics of rupture that once again threatens to obstruct the project of a general sociology of genocide. This rupture can be sutured by dispensing with the uniqueness Bauman wants to attribute to the Nazi holocaust (and perhaps a few other select events), and asking of all genocides the questions that Bauman asks of the Nazi holocaust: How is it rational? That is, how is it rationalized and what rationality is it situated within? And, how is it civilized? That is, how does it relate to civilizing processes? To which project of social transformation does it belong integrally? Or, to use Elias' language, what figurational movement gives rise to it, and how does it affect the trajectory of that movement? In Modernity and the Holocaust Bauman is concerned to critique Eliasian theory on the grounds of its naïve celebration of the virtues of civilization. I pursue a similar critique of Elias, though on slightly different grounds and with a substantially different result, in Chapter 4 below. On the basis of that interrogation I will argue that the relation between civilization and genocide is deeper even than Bauman fears.

\subsection{Foucault}

Bauman's critique of modernity is a bit like Marx's critique of capitalism in that its anti-heroic engagement with the local and concrete mechanisms through which domination is effected arises from an overall orientation toward the whole apparatus

category of 'modern genocides' [e.g. Bauman 1991: 92-93]. 
within which those mechanisms operate. And while Bauman does not, as Marx does, devolve the responsibility for praxis onto a heroic unitary subject, he also does not reproduce Marx's success in developing a distinct analytical language for the anti-heroic analysis of technologies of domination. In this respect the contributions of Michel Foucault are especially valuable. Foucault does not construct a theory of power but an analytics ${ }^{88}$ that re-conceptualizes 'power' in distinctly anti-heroic terms. These terms are by now familiar and are roughly summarized in the five methodological propositions found in the first volume of The History of Sexuality: first, that power is not a substance that can be acquired, held, or lost, but is a field-effect, "exercised from innumerable points, in the interplay of nonegalitarian and mobile relations" [Foucault 1990: 94]; second, that power is both immanent to other types of social relationships (economic, knowledge, sexual), and yet has a distinct productivity of its own; third, that "power comes from below", from the "manifold relationships of force that take shape and come into play in the machinery of production, in families, limited groups, and institutions" [ibid.], and that major structures of domination are the effects of particular configurations of these innumerable local relations; fourth, that power relations are both intentional, strategic, calculated, and nonsubjective, socially objective, exigent in the way Durkheim conceived 'social facts' to be exigent; finally, that power necessarily entails resistance, that power and resistance are always necessarily co-present and embedded within each other. The sum of these is a conception of power, or of a form of power, that is not at all

88 "In studying these power relations, I in no way construct a theory of power. But I wish to know how the reflexivity of the subject and the discourse of truth are linked - 'How can the subject tell the truth about itself?' - and I think that relations of power exerting themselves upon one another 
located or hoarded up in some central location, but is distributed through a large dispersed network, or is the product of a field of force relations - in short, a 'field' as opposed to a 'substance' conception of power, just as neo-classical economics moved from a 'substance' to a 'field' theory of power and twentieth-century physics moved from a 'substance' to a 'field' conception of energy [Mirowski 1989]. And one significant feature of this form of power is that it is intimately connected to the body; it exists as a field of relations of force that are exerted on concrete human bodies. It is provocative and interesting to think of genocide in terms of this analytic, as a particular form in which the operation of innumerable dispersed force relations on the body may be organized into a totalizing stratagem, a stratagem that operates alongside, in varying relations of contradiction and complementarity with, other strategic projects that aim at producing other configurations of this same field.

This possibility is especially attractive in light of Foucault's running engagement with Carl Schmitt's notion of politics as war by other means. In The History of Sexuality Foucault says:

Should we turn the expression around, then, and say that politics is war pursued by other means? If we still wish to maintain a separation between war and politics, perhaps we should postulate rather that this multiplicity of force relations can be coded - in part but never totally - either in the form of 'war,' or in the form of 'politics'; this would imply two different strategies (but the one always liable to switch into the other) for integrating these unbalanced, heterogeneous, unstable, and tense force relations. [Foucault 1990: 93]

constitute one of the determining elements in this relation I am trying to analyze." [Foucault 1998: 451] 
This formulation is troubling because it suggests a certain futility in attempting to think beyond war, of aspiring to eliminate the heavy hand of war, and of warriors, from the conduct of social life. However, it also opens the door to two interesting problems. First, if 'war' is something that is waged between princes, or at least something that princes wage, then thinking of politics as a recodification of relations of war raises the issue of what we who are not princes might want to try to do about the situation. How much of what we have taken for popular or democratic politics has actually been the politics of princes, a transmutation of the struggle between princes for the right to sovereign dominance? And what kind of praxis would break away from this dynamic of war, would suffice to put an end to this endless war? Second, in light of the division I am drawing between princes and subjects, genocide takes on a new importance. If one wishes to privilege the conflicts between princes and subjects over the conflicts among princes, then the paradigmatic case of organized violence, of the explosive deployment of force relations in a life-or-death struggle for mastery, is not international war but genocide. In a Schmidtian mode I could say that politics is genocide pursued by other means; in Foucault's more subtle inflection, I would say that there are not two but three codifications of the multiplicity of force relations, three strategies for integrating these heterogeneous and unstable networks: politics, war, and genocide. In such an event, the question of anti-genocidal praxis assumes an even greater significance for, like war, its hidden hand, its potential recodification of the innumerable relations of everyday life, is everywhere implicit in politics - "confined, crammed, inextricable" [Calvino 1974: 125]. 
There is a difficulty in the reading I have just sketched, inasmuch as Foucault emphasizes a fundamental discontinuity between relations of power as they appear in the Middle Ages up to the time of the ancien regime and the new forms that they take following the Enlightenment, and especially with the rise of disciplines in the nineteenth century. In particular, Foucault stresses the discontinuity between power as it is invested in princes, power described by Machiavelli, and the form of power associated with the state and with 'reason of state': "the aim of this new art of governing is precisely not to reinforce the power of the prince. Its aim is to reinforce the state itself' [Foucault 1988: 150]. Let me shelve this objection for a moment and concentrate on the concept of 'reason of state'. Up to the time of modern absolutist regimes the power of the prince, in the form of the prince's right of life over his or her subjects, involves a dissymmetry in its exercise:

The sovereign exercised his right of life only by exercising his right to kill, or by refraining from killing; he evidenced his power over life only through the death he was capable of requiring. The right which was formulated as the "power of life and death" was in reality the right to take life or let live. Its symbol, after all, was the sword. [Foucault 1990: 136]

But in the nineteenth century this right came to be complemented by a new right based on a new form of power. This was "the right to make live and let die" [Foucault 2003: 241]. Its basis was neither the juridical-political power of the sovereign nor the disciplinary power, but a third form that Foucault calls at first 'bio-politics' [Foucault 2003: 243] and later 'biopower' [Foucault 1990: 138]. Against the backdrop of the sovereign power of the ancien regime, disciplinary power effected a "first seizure of the body in an individualizing mode"; it attempted to rule subjects in their multiplicity and their 
individuality, laying hold of their bodies in order that they might be "kept under surveillance, trained, used, and, if need be, punished" [Foucault 2003: 242]. Biopower, on the other hand, attends to subjects not in their multiple individuality but as "a global mass that is affected by overall processes characteristic of birth, deaths, production, illnesses, and so on"; it is "not individualizing but, if you like, massifying, that is directed not at man-as-body but at man-as-species" [ibid.: 242-243]. Biopower is the art of governing populations; it is concerned with "the problems of birthrate, longevity, public health, housing, and migration" [Foucault 1990: 140]. It relies on many of the same technologies that characterize disciplinary power - medicine, sanitation, mental health, as well as surveillance, spatial distributions, and so on, and operates through some of the same forms of subjectivity - sexuality, most especially. But it seems that biopower is more closely connected in Foucault's thought with 'reason of state' and thereby with war and genocide.

The appearance of reason of state involves, as I have just said, a shift of attention from the prince to the state itself. It is a complex shift that involves the emergence of a new relation between politics as a practice and politics as knowledge, of a new competency and knowledge specific to the politician, based on the assumption that the state is "something that exists per se", "a kind of natural object" [Foucault 2003: 151]. It also implies a new relationship between politics and history, a break with the old idea that the different states would one day be reunited in "one last empire just before Christ's return to earth", and the acceptance instead of "an irreducible multiplicity of states struggling and competing in a limited history" [ibid.: 152]. But most importantly for my 
purposes, it involves a new articulation of the relationship between governments and individuals. Governments no longer have to worry about individuals, says Foucault, or government has to worry about them only insofar as they are somehow relevant for the reinforcement of the state's strength: what they do, their life, their death, their activity, their individual behavior, their work, and so on. ... From the state's point of view, the individual exists insofar as what he does is able to introduce even a minimal change in the strength of the state, either in a positive or in a negative direction. ... And sometimes what he has to do for the state is to live, to work, to produce, to consume; and sometimes what he has to do is die. [Foucault 2003: 152]

The individual may have to die in war, war that is no longer waged in the name of the sovereign but is waged "on behalf of the existence of everyone", or more precisely on behalf of the organization of the forces of life and death that biopower produces. For the modern state, whether capitalist or socialist, dictatorial or liberal-democratic, has, through the operation of biopower, become fundamentally informed by and dependent on racism. This racism does not simply take "the traditional form of mutual contempt or hatred between races"; nor is it simply an ideological operation through which hostility towards a class or the State are diverted, transferred onto a "mythical adversary" [Foucault 2003: 258]. It is primarily a way of dividing populations, of introducing breaks or caesurae within "the biological continuum addressed by biopower" [ibid.: 255]. It is secondarily a way of justifying the State's continuing to exercise the traditional right of princes to take life, both by its own direct action and by requiring its subjects to sacrifice their own lives in its service. "Once the state functions in the biopower mode, racism alone can justify the murderous function of the state" [ibid.: 256].

Significantly, Foucault identifies the origins of this historically novel form of racism with colonization or, what is the same thing, colonizing genocide. In the mode of 
biopower, only the quasi-Darwinian notions of racial hierarchy, of more and less fit races, and of the need to weed out the less fit, could justify the murder of populations, the destruction of civilizations [Foucault 2003: 257]. But this same racism can also be applied to criminality, to mental illness, to class antagonisms, and so on. Socialist states on the Soviet model, which took over wholesale "the idea that the essential function of society or the State ... is to take control of life, to manage it, to compensate for its aleatory nature," reproduced this racism not on ethnic terms but in their orientation to the ongoing 'internal' dimension of the class struggle, in their way of dealing with "the mentally ill, criminals, political adversaries, and so on" [ibid.: 261-262]. And whereas Bauman identifies the genocidal capacities of the Soviet Union and of Nazi Germany with "the pronounced supremacy of political over economic and social power, of the state over society" [Bauman 1991: 112], Foucault is more specific, observing that in the Nazi state the ancient sovereign right of life and death and the new mechanism of biopower came to coincide exactly, resulting in "this fantastic extension of the right to kill and of exposure to death" [Foucault 2003: 260]. Bauman identifies the Nazi holocaust as the product of two assemblages usually kept somewhat separate: the morality-eroding mechanisms of bureaucratic rationality, and the utopian aspirations of social engineering. Foucault's analysis at once specifies and re-frames the latter component of this duality. It is not the utopian quality of biopower, its ideologies of perfect societies, that gives it a genocidal impetus, but the intrinsic momentum of its ceaseless taking-into-itself of the forces of the life and death of human populations.

If genocide is indeed the dream of modern powers, this is not because of a recent return of the ancient right to kill; it is because power is situated and 
exercised at the level of life, the species, the race, and the large-scale phenomena of population. [Foucault 1990: 137]

Nor is genocide the end point or natural limit at which biopower exhausts itself in its own profusion. The existence of nuclear weaponry - and, one might add, other weapons of mass destruction - creates a problem of altogether unprecedented scale:

... as the technology of wars has caused them to tend increasingly toward all-out destruction, the decision that initiates them and the one that terminates them are in fact increasingly informed by the naked question of survival. The atomic situation is now at the end point of this process: the power to expose a whole population to death is the underside of the power to guarantee and individual's continued existence. [ibid.]

To the three forms in which violence can be codified - politics, war, and genocide - a fourth must be added: omnicide [Goodman and Hoff 1990]. One might say that domination, amplified beyond all measure by the proliferating technologies of destruction and given impetus by the political rationality of biopower, reaches its culmination only in the negation of human life itself.

Foucault's analysis makes a number of important contributions to an anti-heroic theorization of genocide. Needless to say, by relating genocide on the one hand to political rationalities that imbue every aspect of the contemporary state, and on the other hand to the danger of omnicide, Foucault effects a problematization (in actor-network terms) that could situate genocide as an obligatory point of passage for social theory. In his analysis of power, and especially of biopower, Foucault provides some indication of the object of anti-heroic praxis, of what needs to be unmade to eliminate the threat of genocide. His analysis directs our attention, as Bauman's does not, to direct force relations, their spatial and temporal organization and their operation on the body. Its 
emphasis on the decentralized quality of power relations offers a way of moving beyond state-centric analyses of genocide without retreating to the social-psychological analysis of 'ancient ethnic animosities' or to the analysis of mere ideologies. It offers, in principle, a symmetry of explanation between genocidal and non-genocidal social relations, since both are equally the product of strategic operations in the field of power. It both de-centers and re-emphasizes the state, or rather it situates states within multiple, overlapping, and competing networks that they never totally control. Like Bauman, Foucault situates the Nazi genocide in the context of a whole situation common to modern society, but unlike Bauman he avoids over-reliance on the concept of 'modernity' (let alone of 'modernism'), and he avoids attributing to the Nazi holocaust a uniqueness that leads to a metaphysics of rupture. As a result, the reader has greater freedom to generalize Foucault's analysis to other genocides, to inquire into the operation of disciplinary power and biopower and their interaction with sovereignty in a wider variety of contexts, as his own comments about colonial genocides make plain.

At the same time, there are limits to this general applicability. Foucault is concerned to examine historically specific formations of power, namely disciplinary power and biopower. The first stirrings of these are seen in Europe of the seventeenth and eighteenth centuries, and they fully blossom in the nineteenth century, in those countries in which the processes of European modernization or civilization have progressed the furthest. It cannot simply be assumed that discipline and biopower are today universal and that they are determining conditions of all contemporary genocides; at the very least, specific empirical case study is required to trace their operation in 
Rwanda, in Guatemala, and so on. And however successful and fruitful these various applications might be (I suspect they would be very fruitful, that, for example, to observe the operation of biopower in Rwanda from colonial times to the present would be extraordinarily revealing), there would always be something not just unfinished but incomplete, something lacking, from the explanations they would produce. For one thing, they are temporally circumscribed. The roots of genocide in 1980s Guatemala, for example, extend back not to the nineteenth or even the seventeenth century but to the arrival of the conquistadors in the sixteenth century; and as Stannard [1992] shows, that genocidal fury was the product of features of European society that date back into the Middle Ages.

For another thing, Foucault's analysis is oriented primarily to the operation of expert knowledges, of power/knowledge relations understood from the perspective of questions about knowledge rather than questions about power. As I have argued in Chapter 2 above, Foucault's work provides a philosophical history of knowledge rather than a historical sociology of power; however well he theorizes power, he always does with an eye to other questions - of ethics, subjectivity, knowledge. The question that ties together his various studies is not "what are the wellsprings of social violence?" but "how can the subject tell the truth about herself?". For me at least there is something cramped or some quality of taking the long way around, in approaching the study of the social production of genocide through the lens of the history of forms of thought. At the very least, an anti-genocidal praxis that operates in a critical relation to the projects of international law and of armed humanitarian intervention as the proposed solution to 
genocide, requires something more than a strictly Foucaultian approach. As I will argue, that 'something' is found in the sociology of Norbert Elias, and the distinctive reading of his work that I offer in Chapter 4. 


\section{Chapter IV: Civilizing Genocides}

\section{INTRODUCTION}

In this chapter, I propose a new concept in the sociology of genocide: civilizing genocides. This term is built up from a deconstructive reading of Norbert Elias's figurational sociology of the European civilizing process. My deconstructive reading proceeds by inverting and displacing the hierarchical binary opposition between 'civilization' and 'barbarism'. In the first part of the chapter, I provide an exposition of Elias's account of the European civilizing process. Once this explanation is complete, I pause to identify some of the particular merits of this theoretical framework, and to identify important points of weakness. One crucial weakness of a theory of civilization is its potential to reproduce the normative and teleological connotations of the word 'civilization' itself, thereby degenerating into a grand theory or a philosophy of history. Such a grand theory would fail to meet Elias's own goal of a non-metaphysical and nonegocentric process-oriented sociology. It would also carry a disguised theodicy. Unfortunately, Elias's own writings after The Civilizing Process support a normativeteleological reading of that work, as do the works of prominent interpreters of Elias. To rescue figurational sociology from the sinkhole of grand theory, I re-read The Civilizing Process, stressing elements of the text that attach a negative normative value to civilization by emphasizing how violence is crucial to the advancement of civilization. Having shown how the text of The Civilizing Process overturns the normative connotations of 'civilization', I proceed to displace altogether the opposition between 'civilization' and its counterpart 'barbarism'. I suggest that 'civilizing processes' be 
reconceived as 'barbarous civilization', in order to render explicable the link between civilization and genocide. Finally, I propose the term 'civilizing genocides' to refer to genocides engendered by the expansion and intensification of barbarous civilization. The presentation of this new concept sets the stage for the following chapter, which will show how six historical episodes of genocide can be understood as products of European barbarous civilization.

\section{Teleological Civilization}

\subsection{EMERGENCE Without ORIGinS}

In the universe as Elias imagines it, everything moves and changes constantly. Phenomena appear fixed or stable only in relation to particular time-frames employed by observers; a sufficient widening of an observer's temporal frame of reference will inevitably bring out the dynamic and processual quality of seemingly stable objects. In this universe of dance, no object (and possibly not even the universe itself) has an ultimate point of origin [Elias 2000: 402; 1978: 111; 1987:xxxix-xl, 140, 158]. Accordingly, the narrative of The Civilizing Process begins not at some putative beginning-point of the European civilizing process, but in the author's present. Elias opens his discussion by considering the antithesis between the concepts 'Kultur' and 'Zivilisation' as these terms were used in his milieu, which is to say in Nazi-era Germany. The antithesis in question opposed universalist with particularist cultural values. 'Zivilisation' emphasized cultural accomplishments possessing general human significance, whereas 'Kultur' described accomplishments of specific interest to one 
nation or people, especially the German people. The usage of Elias's day privileged 'Kultur' over 'Zivilisation', the latter being used as an epithet with connotations of duplicity and effeteness. This usage reversed the privilege accorded by other contemporary European languages, especially French and English. It epitomized a broader development in German political culture since 1870: the defeat of middle-class liberal humanism and the militarization of everyday life for the middle classes. In The Germans, Elias claims that precisely these developments served as enabling conditions for the rise of Nazism [Elias 1996: 134]. In other words, Elias begins The Civilizing Process by examining a linguistic peculiarity forged in the crucible of the unfolding Nazi catastrophe.

We should note also Elias chooses a word in use, rather than a neologism, to serve as the germ of his examination of the civilizing process. This accords with his account of scientific detachment in Involvement and Detachment [1987]: Elias's scientist does not possess the complete detachment and God's-eye point of view celebrated by objectivism, but remains embedded in the world, achieving only a relative detachment from the immediate exigencies of involvement. Elias's theory of the civilizing process does not descend on that process as if from the heavens, but instead, standing within it, picks one thread - a word in use, a linguistic practice - and follows it in all its branches to illuminate a network that stretches back a thousand years and today covers the globe. This approach has an important contemporary relevance (unforeseen by Elias). According to Elias, 'civilization' expresses “the self-consciousness of the West” [Elias 2000: 5]. By implication, universalizing the term 'civilization' to refer to non-Western 
figurations, without supporting linguistic and historical evidence, could entail a pernicious anachronism. More disturbingly, however, this attribution would reproduce a tacit imperialism:

It ['civilization'] sums up everything in which Western society of the last two or three centuries believes itself superior to earlier societies or 'more primitive' contemporary ones. By this term Western society seeks to describe what constitutes its special character and what it is proud of: the level of its technology, the nature of its manners, the development of its scientific knowledge or view of the world, and much more. [Elias 2000: 5]

'Civilization' binds technology, manners, knowledge, "and much more", into a distinctly supremacist endeavour. Fernand Braudel, also inquiring into the history of 'civilization', observes that the heyday of this particular usage was the eighteenth century and that

in about 1819 the word 'civilization', hitherto singular, began to be used in the plural. From then onwards, it 'tended to assume a new and quite different meaning: i.e., the characteristics common to the collective life of a period or group'. [Braudel 1994: 6-7]

Braudel notes that 'civilization' in the singular once designated virtues "confined to a few privileged peoples or groups, humanity's "elite"" and that the increase in the plural use shows that "the twentieth century, happily, has abandoned a certain number of such value-judgments" [ibid.]. However, the recent vitality of Samuel Huntington's 'clash of civilizations' thesis [Huntington 1993, 1996] indicates that the older, supremacist connotations still operate. If 'civilization' designates, on the one hand, a project of superiority in technology, manners, knowledge, etc. and, on the other hand, the selfconsciousness of the West, then the plural term 'civilizations' may carry a sinister connotation. In addition to undermining the uniqueness of the West and recognizing the accomplishments of non-Western cultures, 'civilizations' may also project onto those 
cultures a specifically Western expansionist imperialism. That is, the shallowly buried meanings of the term 'civilizations' may suggest a specific danger: that the various Others beyond the West resemble ourselves, and therefore we should fear them. Elias's epistemological strategy tends to defuse this paranoia by exposing the historical specificity of 'civilization' 89 .

\subsection{Moving BACK}

'Civilisation', in French, has developed from 'civilité' ('civility' in English, 'civiltà' in Italian, 'Zivilität' in German [Elias 2000: 48]), which in turn bears a close relation in its meaning and use to words like 'politesse' and 'courtoisie'. 'Civilité' refers to a particular mode of the conduct of certain mundane social interactions and to the quality of character exhibited by a person who adheres to this mode of conduct. The proliferation of instructional handbooks in etiquette in Europe after the $16^{\text {th }}$ century suggests to Elias the depth of concern that certain groups in European society feel for questions of civility. Many of these handbooks derive from De civilitate morum puerilium by Erasmus of Rotterdam, first circulated in 1530, which gave 'civilité' its specific meaning [Elias 2000: 47]. Erasmus "gave new sharpness and impetus" to a set of practical questions that had also "occupied the people of the Middle Ages, of GrecoRoman antiquity, and doubtless also for the related, preceding 'civilizations"' [Elias 2000: 48, 52]. Erasmus's text marks a watershed, but not an origin. To use genealogical terms, it indicates the moment of entry for 'civilité', which then partially overlaps with and partially supplants the older 'courtoisie'. 'Courtoisie' (in French) or 'courtesy' (in

89 It does this inadvertently; Elias's writings do not explicitly address this point. 
English) or 'cortezia' (in Italian) or 'hövescheit' (precursor in German to 'Höflichkeit'), all express "aristocratic self-consciousness and socially acceptable behaviour" [Elias 2000: 53-54]. In a documentary tradition going back to the $13^{\text {th }}$ century, 'courtesy' designates behaviour considered acceptable by the secular upper classes, and especially behaviour acceptable at court. In the sixteenth century, Erasmus recognized that the princely courts operated as the "real nurseries of what was regarded as good manners" [Elias 2000: 63]. By Erasmus' day the courts had operated in this way for at least three centuries, and they could continue to do so until 1792 in France, and even later in Germany. By the time that 'civilization' replaced 'courtesy' and 'civility' as the keyword expressing the dominant self-consciousness of European societies, its elements had incubated for half a millennium in the internecine power struggles of court society. The existence of civility handbooks attests to the non-naturalness of behaviours and emotional reactions that have become so deeply ingrained in modern civilized subjects as to seem natural. Elias finds it remarkable that adult persons would need a manual telling them not to smear snot on their clothes or on tablecloths; not to urinate or defecate in the staircases, corridors, or closets; or not to slurp from a spoon that someone else is using $[51-52,122,111-112,73]$. That these handbooks addressed an elite audience implies the ubiquity and normalcy, among the non-elite classes in Europe of the late middle ages and the Renaissance, of acts that most contemporary Europeans would find disgusting or at least embarrassing. Moreover, the handbooks exhibit a clear developmental tendency towards the increasing elaboration and intensification of the codes of required conduct, especially from the sixteenth century onwards. Especially in 
France, this shift in the rate of intensification of manners accompanies a shift in the structural situation, relative to the central sovereign authority, of the aristocratic class that practiced those manners. In the late middle ages, when favour at court was only one aspect of a knight's overall power base, the cultivation of this good favour mainly required the knight to avoid practices that some others might find unpleasant. The recommendations of manuals of courtesy in this era were accordingly minimal and rudimentary. As rules of courteous conduct become established, however, they become more than a way to avoid giving offense: they become a strategic tool, inasmuch as one could win favour by being more courteous than others, or cause rivals to lose favour by showing them up as rude and uncultivated. But by the time of Erasmus, the knight's independent power base was eroded and life at court became correspondingly more important. After the Renaissance, the aristocracy was increasingly dependent on the sovereign authority for the maintenance of its privilege. This change was accompanied and epitomized by an increase in the importance of court life in aristocratic life generally. At court, powerful or at least privileged individuals were impelled to cultivate the good will of their peers and especially their superiors. As the aristocracy became more dependent, the competition for favour at court became more intense and the strategic value of civility increased. Over time this continual jockeying for one-upmanship, combined with the decline of alternative power resources, resulted in more and more elaborate codes of civility, reaching a sort of pinnacle at the court of the Sun King. And at the same time as courtesy and civility allowed individual knights or aristocrats to gain advantage over one another, they also served as an impediment keeping members of other 
classes out of court society, and as a means for legitimating aristocratic privilege in general.

If one observes the formation of codes of civil and courteous conduct in reverse chronological order, starting in the $19^{\text {th }}$ century and moving backwards into the middle ages, they seem to decompose, requiring less and less elaborate self-control from individuals and regulating fewer aspects of everyday life. This de-civilizing movement reached a kind of apogee in the area of the former western Frankish empire by the beginning of the twelfth century $\mathrm{CE}$. The territory was dominated by a "loosely integrated secular upper class of warriors, with its symbol, the castle on the autarkic estate" [Elias 2000: 256]. Members of this warrior class granted nominal allegiance to a king, but such kings were mainly war leaders without substantial mechanisms of permanent centralized government at their disposal [198-202, 236]. In peacetime their vassals enjoyed a more or less unlimited autonomy. Elias paints a vivid picture of the way of life of members of this class, which differed little from that of their social inferiors as far as civilized conduct went: eating, sleeping, belching, farting, snorting, spitting, voiding of bladder and bowels, sexual play and intercourse, all lacked the intense emotional charge and the potential for embarrassment or repugnance that they came to possess for the civilized subject of the $20^{\text {th }}, 18^{\text {th }}$, or even $16^{\text {th }}$ centuries. Concomitant to this, emotional life was comparatively unregulated and spontaneous: where courtiers at Versailles of the Sun King learn to mask habitually their most extreme feelings [405], knights and commoners alike in the decentralized remnants of the Holy Roman Empire freely laugh, cry, shout, embrace immediately as they are moved to do so $[180,374]$. 
And just as the emotional self-governance or tact of the Versailles courtier was a byproduct and component part of the power structure of the centralized absolute monarchy, so the spontaneity of the medieval subject was part and parcel of the power relations of that social context. In $12^{\text {th }}$-century France, where forks were unheard of and snot was not degrading, joy led readily to laughter and conflicts to blows, and social domination was naked, shameless, direct, and brutal.

If this way of life marked the definite beginning of the civilizing process, then it might also be taken to represent an instance of essential human nature as it is practiced free of major social restraints. Elias, however, claims that civilization has no zero point: “The process has no beginning, and here we cannot trace it back indefinitely. Wherever we start, there is movement, something that went before." [Elias 2000: 52; see also 421, 482] The way of life of medieval subjects is itself a figuration, a dynamic structure in process. Some of its conditions of possibility can be inferred from Elias's brief account: compared with earlier and later periods, death was immediate and relatively uncontrollable $[165,370,531-2]$; the direct, personal domination of the knight over his ${ }^{90}$ subjects was unmediated by the remote and comparatively impersonal domination of monarchs [163, 239]; and most importantly, direct interpersonal violence was a far larger part of both everyday life and the foundations of social privilege than it was later to become. The ruling class was a warrior class, and members of this class had to cultivate a capacity for immediate and overwhelming violent fury. Elias describes the contrast

$90 \quad$ Throughout this chapter I use the masculine pronoun when speaking of medieval knights, on the grounds that the figure Elias takes as the ideal-typical subject of the civilizing process is a specifically male or masculine subject (see page 212 below). I hope that this use will underscore, 
between two dukes: one, the Duc de Saint-Simon at the court of Louis XIV, who desires to convince the Dauphin that the King is in error on some point; the other, living a generation earlier, the Duc de Montmorency who rebelled against the authority of Richelieu. Both dukes are in some respect opposed to the central authority. But whereas Saint-Simon exhibits the utmost subtlety and tact working from an extremely vulnerable position at court, Montmorency displays a relative lack of self-control on the battlefield. Elias relates a scene in which Montmorency, engaged in battle with the King's army, fails to make any tactical assessment of the situation, but instead works himself up into a battle-fury at the sight of the enemy army, and charges into combat - only to be cut down by musket fire, taken prisoner, and executed. Elias claims that the difference in the actions of the two Dukes characterizes the shift in habitus from the era of the partially autonomous knight to the era of the dependent aristocrat. Regarding the former he observes:

To give way directly to impulses and not to take thought of the further consequences was, in the preceding phases when warriors could compete more freely with each other [...] adequate to the social structure as a whole and therefore to 'reality'. Martial fervour was a necessary precondition of success and prestige for a man of the nobility. [Elias 2000: 405]

The medieval knight "not only loved battle, he lived for it" [164]. But this affective structure played an important part in social relations in peacetime as well. Such battlefury helped knights to reproduce their dominance over class and gender inferiors [175177, 242, 246-247, 371]. In any event, Elias's insistent refusal of origins and his

not naturalize, both the patriarchal quality of aristocratic power and the androcentric bias of Elias's analysis. 
attention to the sociogenesis of affective structures militate against the teleological reading of his work, as I will discuss further in Section 2 below.

\subsection{MOVING FORWARD}

What happens to impel the autarkic medieval knight to adopt courteous

behaviour? In other words, what compels him to spend time at court? Elias answer is: domination by a more powerful warlord. The twelfth century CE marked the low ebb, in the western remnants of the Holy Roman Empire, of centralized political authority. From the twelfth century onwards, powerful regional lords found themselves increasingly able to expand their domains and render local knights subservient to themselves. The centrifugal breakup of Charlemagne's empire was succeeded by the centripetal formation of regional suzerainties [Elias 2000: 237]. Over the course of centuries this centripetal process led to the total subordination of the warrior class to central authority, to the establishment of effective monopolies of military force ${ }^{91}$, and thereby to the infrastructure of the modern nation-state [303-312]. En route, this process subjected the formerly autarkic knight to a twofold subordination. The political, military, and class subordination of the knight is the first and most obvious of these subordinations. More interesting, perhaps, is the subordination that the knights endure at court, where they were made vulnerable to an immediately present community of their peers and betters. At

\footnotetext{
91 Elias speaks most often of monopolies of physical force or violence, broadly understood. However, within the overall context of state-formation there have persisted important forms of violence that states have been slow to prohibit or have prohibited only intermittently: wife-battery; gay-bashing; strike-breaking; lynching and other forms of terror against racialized minorities; and so on. Elias does not consider these lacunae in the process of force-monopolization. They deserve more attention than I can give them here, but after reading this chapter the reader might be able to infer how they could be explained in their relation to civilizing processes.
} 
court they were initially inflicted with, and eventually inflicted on themselves, restraints on a range of everyday behaviours, especially those having to do with the body and emotions. They suffered "the constraint to self-restraint" [365], and this constraint transformed them from heroes into civilized persons.

What is interesting about this is that the mechanisms that bring about the gradual transformation of the heroic subject into the civilized subject are the same that make up the process of state formation: the subordination of the warrior class to a single centralized authority. State formation and subjectification are extensively intertwined or, more strongly, are distinguishable but indivisible aspects of the same figuration [Elias 2000: $x i, 407,411 ; 1978: 41]$. The contemporary term 'civilization' reflects this inseparability by referring equally to qualities of individual behaviour (politeness, humaneness, honour) and to qualities of collective life (cultural accomplishments, political and economic structures). Elias's analysis fuses what are conventionally referred to as 'macro' and 'micro' social phenomena [Mennell 1989: 94]. Members of the warrior class are made courteous, or civil, or civilized, by being deprived of their autonomy and brought into relations of dependency with others; the habituation of local lords to their dependent station within a larger order facilitates the further expansion of military monopolies. Both state formation and subjectification are simultaneously macro, involving the rearrangement of extensive social networks and affecting large social collectivities, and micro, expressing themselves in face-to-face interactions between individuals, in the conduct of everyday life, in subjectivity. 
This refusal of an ontological division between macro and micro has a further implication: that what are usually conceived as different structures of oppression - class and gender, for example - may also be usefully understood as distinguishable but inseparable aspects of the same figuration. At court, the knight pursued his own strategic self-interest, but the 'self' in question was defined by its precise location in an extended network of relations of domination and subordination. At his most autarkic, he maintained his location through force of arms: as a warrior in battle with rivals from his own class; as a lord who lived off the surplus product expropriated directly or indirectly from agricultural producers; as a patriarch who expropriated from women the male heirs that carried on his family line, for example. This fusion of relations of domination in a single figure, a fusion that surely has its own complex and interesting history, was carried forward into the civilizing process. It even enjoyed various accretions over the centuries as various forms of otherness were reactivated or invented: as Christianity authorized its Crusades, as the 'blood' of nobility became the 'blood' of white races, and so on. Figurational sociology allows us to analyze differing forms of domination as extensively overlapping though non-coterminous networks, distinguishable by the different ways they anchor themselves in bodies or by the different effects of identification-differentiation that they entail, none more foundational than the others, all mutually inextricable by the contingent fact of their common historical development.

In Elias's account the knight functions as the privileged subject of the civilizing process. It is on and through this military class that the civilizing process operates. Knights enter Elias's frame of reference as organized gangsters, to use Tilly's analogy 
[1985]. Their control over the means of production is based on their ability to command directly the disposition of physical force, and is crucially supported by their own personal capacity for direct physical violence.. Among innumerable small local knights each fighting for the expansion of their holdings, a few succeed brilliantly and forge large domains for themselves. As these few jockey with each other for advantage, they progressively swallow up the autarkic estates. In time, a territory governed by innumerable local bosses becomes a territory with a few big bosses and many henchmen. Eventually only one boss remains, to whom everyone else is at least nominally subordinate [Elias 2000: 309-310, 344]. But the knightly class retains its distinctiveness within this more centralized social order. It still maintains its independent economic base in terms of its direct expropriation of surplus from local producers. Importantly, it maintains this distinctiveness long enough for mechanisms of courtesy and civility to evolve gradually at court. In general, direct personal violence recedes from day to day life as the civilizing process advances $[415,423]$; this tendency is most marked at court, where spontaneous brawls become prohibited, or ritualized as formal duels [Elias 1996: $51-52,106]$. This special zone of nonviolence that emerges from the general violence of knightly life becomes the nursery, not just for manners, but for the transformation of elementary social interactions. Importantly, it also opens up a space in which women may take a greater part in public life. As direct violence subsides and knights are enrolled in relations of dependency and interdependency, opportunity exists for other dependent individuals to assert their social agency, notably women [248]. This foreshadows the involvement of other subordinate groups - the merchants, the industrial 
workers, minorities - in the power centers of social life. However, civilization is not a purely negative process defined by the declining hegemony of the warlords. Those same warlords, to hang on to their privilege as long as possible despite their loss of power, innovate mechanisms of self-governance that become crucial to the modern nation-state, even in its democratic forms.

In Elias's account, the longue durée history of the European civilizing process involves at least two major epochal transitions after the $12^{\text {th }}$ century. The first comes in the sixteenth century $\mathrm{CE}$ and involves a qualitative increase in the power position of the central sovereign authority relative to the aristocracy, and the consequent increase in dependency and decline of autonomy of the latter. This transition marks the onset of a progressive intensification of codes of civility. We can understand this intensification in terms of fetishization [Marx 1990: 163]: codes of conduct, for a long time subservient to the practical needs of the warlords, become more indispensable and so gain a power of their own which they exert over their practitioners. Courtesy, civility, civilization, produced through social interaction, achieve the status of autonomous objects. From the sixteenth century onwards the intensification of codes of civility is driven by the increasing importance of court as a site of intra-class power struggle, and also by the gradual rise of the urban bourgeoisie a counterweight to aristocratic power [330-333]. For a long time the monarchy in France maintains its dominance by pitting the aristocracy and third estate against each other. In the process of this struggle, the bourgeoisie learns to adopt civil behaviours as a means of entry to society, and the aristocracy innovates new standards in the attempt to keep them out [424-425]. The 
second major transition takes place in the late $18^{\text {th }}$ and early $19^{\text {th }}$ centuries, as the two major industrial classes, the bourgeoisie and the industrial workers, wrest control of the state from the monarchy and the aristocracy. In this process, a substantial part of aristocratic civility is taken on, in a modified form, by the elite of the bourgeoisie as a tool for the maintenance of its own class distinction. Aspirations to upward mobility then impel members of the middle classes to school themselves in the civilized behaviour of their betters. With the rise of nationalism in the $19^{\text {th }}$ century, civilized codes of conduct become national codes of conduct and 'civilization' is intertwined with 'national character' $[380,428]$. Through these mechanisms, aristocratic civility disseminates through the entire class structure.

Elias closes his account within the epoch of capitalist class relations and the modern, territorially sovereign nation-state. It is tempting to see this account as providing a large framework within which, or in relation to which, one can situate more narrowly focused studies of the relation between violence and self-constraint, such as Bourdieu's analysis of cultural capital and symbolic violence, or Foucault's studies of discursive formations, disciplinary power and governmentality. At the same time, it is not necessary to treat Elias's account as a grand theory, in the sense of the term used by postmodernists. The Civilizing Process does not particularly invite essentialist or foundationalist readings; not everything that is intertwined with the civilizing process can be reduced to it (class and gender are obvious examples). Nor does an analytical span of centuries imply aspirations to universality or totality: a thousand years in the social life of Western Europe is still firmly local relative to the span and complexity of human history. 
In sum, Elias presents a theoretical account of the formation of 'civilization' and civilization as a contingent and local figurational development, but one that unfolds over the historical span of centuries and that, through European imperialism, has become global in its territorial scope. Faced with the problem of violence in the contemporary global arena, Elias's account shows how our current situation is shaped by the carry-over, into modernity, of a mechanism forged in the depths of the medieval era.

\subsection{MeRITS}

I want to mention two particular respects in which Elias's theory of 'the civilizing process' seems especially strong.

First, it can be read as a complement to the entire corpus of Marx's theory in that it takes as its primary focus a form of concrete, material social relation that Marx only considers secondarily: the relation of direct physical force. It may seem bizarre to say that Marx only considered force secondarily, given the overwhelming and fundamental importance of class domination to his conceptual scheme. But Marxian thought asserts the priority of the field of production over all other social fields, including famously the field of reproduction occupied primarily by women, and also including the field of destruction or violence. Although Marx wrote abundantly about state politics, he never subjected the state and especially its military aspect to anything like the sustained treatment he gave capitalism in Capital, and he certainly did not systematically theorize physical force as an autonomous system of relations possessing its own mechanisms not reducible to the relations of production. Elias's analysis of state formation enables us to do just that, because it situates the state as one specific byproduct of an overall network 
of force relations circulating throughout a figuration. This enables us to analyze the state without taking it as a given, and to come to grips with the means by which states can exert an autonomous influence over the form that capitalist exploitation takes in differing situations (to explain the influence of military elites, for example). At the same time, this analysis addresses violence not directly organized by the state. Elias himself analyses the operation of violence in court society $[2000,1983]$, for example, or in sports $[1969,1970$, 1986], or in an ethnically diverse working-class neighbourhood [1994], and one could extend this analysis to any number of different sites: to the patriarchal family, to gaybashings, racist violence, and so on (see footnote 91 on page 199 above). Furthermore, this structural or figurational analysis of violence bridges the gap between modernity and pre-modernity, and so avoids a metaphysics of rupture that treats the modern world as having sprung fully-formed out of the shell of its predecessor.

Second, figurational sociology provides a means for conducting a formal analysis of social life without resorting to structuralism and, especially, structural functionalism. In fact, Elias mounts a stunning critique of Parsons in the 1968 postscript to The Civilizing Process. Without specifically accusing Parsons of conservatism, he is able to show that the synchronic conception of 'structure' reproduces a specifically bourgeoisnationalist conception of 'society', and that Parsonian system theory operates as an idealized image of that society rather than as a tool for empirically based sociological analysis [Elias 2000: 466-467]. This criticism locates the basis of this normalization not in an extratheoretical bias covertly smuggled into Parsons' theory but in the theoretical and empirical inadequacy of static concepts as such. Exclusively synchronic analysis of 
elementary system components ('pattern variables', for example) obliterates the historical process through which social forms come into being, and so abandons the task of explanation as such [453-455]. Elias ties his criticism of static analysis to his rejection of egocentrism: that is, to his critique of Parsons' (and Durkheim's) conception of 'the individual' and 'society' as existing independently of one another and subsequently somehow interpenetrating [469-473]. The special merit of this critique is that it can problematize the philosophy of history implicit in functionalist sociology without invoking, as critical theory tends to do, an alternate philosophy of history. In the latter case, where different philosophies of history compete, the incommensurability of their basic concepts makes the choice between them irresolvable, in which event functionalism can persist as a valid choice for sociology ${ }^{92}$. Criticizing functionalism in terms of values internal to sociology narrowly defined provides a more effective demolition of its target. On the one hand, it grips the target more firmly, since structural-functionalism claims to be scientific and is thereby vulnerable to criticism on grounds of scientific insufficiency. On the other hand, criticism couched in terms that themselves have no particular political attachment provides a flexible and open-ended vehicle with which to effect the work of interessement $^{93}$.

\subsection{Problems}

The obvious problem with a notion, like 'the civilizing process', having a broad temporal and territorial scope is that it runs the risk of being a grand theory in the

92 In other words, if the only alternative to functionalism is another philosophy of history, then functionalism cannot be decisively prohibited on rational grounds. 
pejorative sense, of containing its own philosophy of history and in particular its own normative teleology. If conservatism is the frequent trap into which synchronic analyses fall, teleology is the special vice of structured synchronic analysis. I must therefore consider the question: is Elias's theory of the civilizing process teleological?

If 'teleology' is taken to refer to a determined historical sequence of developmental stages with a fixed outcome, then the answer to this question is a qualified no. Although Elias strongly favours developmentalism in his later writings [1987: xl], and in particular affirms Comte's claim the development of intellectual culture necessarily proceeds from the theological to the metaphysical to the scientific if it proceeds at all [1978: 40-41], the proviso 'if it proceeds at all' remains essential: Elias repudiates the idea that history proceeds forward inexorably to a predetermined end point. In any case, The Civilizing Process does not even claim that its object develops along a predetermined track with a fixed sequence of stages. Elias is careful to distinguish his conception of structured social process from 'evolution' in its nineteenthcentury conceptions [2000: 452, 459].

However, there is another respect in which Elias's account could be read teleologically: if the concept of 'civilization' designates a normative value, especially a positive value. In this case, figurational sociology is teleological in its practical implications since history becomes the history of the realization of an essential human value, and social theory defines the necessary ends that all rational subjects should pursue. The evidence regarding this question is ambivalent. In The Civilizing Process 
itself, Elias attempts to produce a non-judgmental sociology of civilization: that is, a sociology that is equally valid whether one values civilization positively or negatively. In the Preface he states that:

I have not been guided in this study by the idea that our civilized mode of behaviour is the most advanced of all humanly possible modes of behaviour, nor by the opinion that 'civilization' is the worst form of life and one that is doomed. All that can be seen today is that, with gradual civilization, a number of specific civilizational difficulties arise. [Elias 2000: xiv]

The term 'civilization' is often put within quotation marks to suggest an ironic or guarded use. It is rarely opposed with the term 'barbarism', less often with 'savagery', and more often than not both of these terms appear within quotation marks to indicate skepticism or agnosticism about the implied value-judgment $[42,48,51,54,81,210,450]$. Although he claims that civilization brings about certain consequences that the reader might be expected to value, such as the recession of direct physical violence from the conduct of everyday life, these values do not define what 'civilization' is. Instead, 'the civilizing process' is conceptualized in terms of definite structured processes, such as the formation of codes of etiquette and of territorial military sovereignty. In this respect, Elias's use of the concept 'civilization' appears to carry no particular normative connotations.

However, if The Civilizing Process is read in conjunction with Elias's later writings, and especially with the secondary Eliasian literature, then 'civilization' acquires a definite positive normative value. In The Germans, and especially in the 1962 essay “The Breakdown of Civilization" [Elias 1996: 299-402], civilization is strongly equated with pacification $[173,279,302,308]$, occasionally with humanism [417], and sometimes 
with a specifically compassionate conscience in particular $\left[139-140,158,365^{94}\right]$. The term 'barbarism' appears often and is used without quotation marks; it refers overtly to brutality and cruelty in social relations [302-304, 308-310, 314-315, 330, 345-346, 355 , $\left.359,381,402^{95}\right]$. The irruption of violence into civilized life, as represented by the Nazi holocaust, is explained as the result of decivilizing processes, and in particular of barbarizing or brutalizing processes $[1,196,197,288,444$ n. 8]. (The prominent secondary literature on Elias tends to reproduce this equation of civilization with positive values and of barbarism or decivilizing processes with negative values [Fletcher 1997: 24, 1982-1985; van Krieken 1998: 70-71; Mennell 1989: 247-248; Mennell and Dunning 1996: xv], although not without expressing some recognition of the problem [Fletcher 1997: 180-181; van Krieken 1998: 119].) Finally, the argument in Involvement and Detachment presents detachment as a necessary condition for reality-congruent or realityadequate knowledge [Elias 1987: vii-lxxii]. Since detachment requires emotional selfcontrol and this is in turn fostered by the civilizing process, civilization entails the transformation in practices of knowledge (from theological and egocentric to scientific and non-egocentric) that makes the theory of the civilization possible [55-73]. And in

94 This point requires care. For the most part Elias uses of the term 'conscience' non-judgmentally, to indicate the type of self-constraint associated with an individual's we-identity (as opposed to her I-identity) [Elias 1996: 379]. Sometimes, therefore, he explains the Germans' obedience to Hitler as the result of particular features of Prussian conscience-formation, which included e.g. intense loyalty to the state $[415,419]$. At other times, however, he describes the process by which Germans handed over decision-making authority to the Fuhrer as the breakdown of conscience [383-6]. The text of The Germans, if taken as a whole, permits two readings: one in which humanism is one form of conscience among others and one in which it is equated with conscience as such. However, it is probably more precise to say that the different essays in the book take different positions on this question. 
"Reflections on the Great Evolution", Elias revives Durkheimian functionalism ${ }^{96}$ and nineteenth-century evolutionism by explicitly drawing together the growth of civilization and the growth of scientific knowledge within the overall growth of functional interdependency among human beings, and stating that this developmental process has reached (in effect) its moment of world-historical crisis, via the threat to human survival posed by the nuclear arms race between the Cold War superpowers. Only the further growth of civilization can prevent catastrophe: directly, through the extension of interdependency between the warring parties, and indirectly, through the growth of a detached, non-egocentric worldview among human beings [33-34]. At this point figurational sociology has become a full-blown philosophy of history.

As a normative term, 'civilization' is enormously problematic in ways that Elias does not seem to recognize at all: it is classist, androcentric, and Eurocentric. The Civilizing Process focuses almost entirely on processes of sociogenesis and psychogenesis localized in the aristocratic class and occasioned by its class struggles with the monarchy and, later, the bourgeoisie. Class conflict between the aristocracy and the peasantry is not explored, and the effects of the monopolization of force, or their own separation from the means of violence, on peasants' own behaviour is never mentioned, and when peasants are mentioned it is always to illustrate the rude lives of persons not

$96 \quad$ Elias makes the Parsonian claim that functional integration in social systems is higher than in biological organisms [128-133]. However, he rejects the notion of society as a reality sui generis. Still, it is interesting to read him in counterpoint to Durkheim's comments on civilization in The Division of Labour [see esp. Durkheim1997: 276-277]. Durkheim can be read as saying that the advancement of the division of labour brings the real interests of individuals and secondary groups into harmony with the real interests of society as a whole; Elias in Involvement and Detachment can be read as claiming that the civilizing process creates a common human interest that all individuals share in common. 
subject to the civilizing pressures of court [Elias 2000: 89, 100, 173-180, 217-218, 242, $382,389,391]$. The aristocratic subject in question is also by default a masculine subject, and though Elias's examination of women and their dominance by men is much fuller than his treatment of peasants [Elias 2000: 142-160, 230, 236-256], women are still absent from his account of the central mechanisms of civilization. And of course the civilizing process takes place within Europe until it is exported to the rest of the world through colonialism and imperialism, which is to say through violent conquest; again, Elias deals only briefly with the civilization of colonized subjects [384-386, 430-432]. These various omissions seriously undermine the credibility of the theory of the civilizing process. On one hand the theory appears simply too partial and limited for comfort. On the other hand, if the civilization of medieval barons is effected by their increasing dependence on a superior power and their increasing interdependence in lateral and hierarchical social networks, then we should expect that subjects in an even more dependent situation should exhibit a greater degree of civilization, defined in terms of abstention from interpersonal violence and capacity for emotional self-control. In other words, we would expect peasants to be more civilized than lords, women more civilized than men, colonial subjects more civilized than their masters. (This is more or less the claim that Wollstonecraft makes when she argues that despotic power corrupts virtue and renders its recipient childlike [Wollstonecraft 1997: 122-123, 156; see also Durkheim 1973: $37 \mathrm{ff}$.$] .) Elias does not explore this implication of his own theory.$

However, such omission could be provisionally justified by the claim that Elias wishes to study a highly localized process that happens to be specific to an elite social 
group. In this case, his lack of attention to other groups implies only a need for further study. That is, one could extend Elias's framework by investigating the forms of selfregulation and affect-control, as well as the circulation of relations of violence, specific to peasants or women or non-Europeans or any other subaltern group. If 'civilization' refers to a universal value, however, then this excuse is invalid. In this case, the privileging of aristocrats as the subject of civilization becomes a celebration of that subject. By implication, the omission of peasants, women, and non-Europeans from an account of the civilizing process designates these various subjects as uncivilized, which is to say: unable to take into account the needs of others, unable to regulate their own affective behaviours or to think in a detached manner, and prone to violence and cruelty. Whatever qualities of civilization they do possess have been disseminated to them from the male European aristocracy and its successors among the elite of the bourgeoisie. That is, the transmission of civilization to subaltern groups through domination is a normatively positive process. Figurational theory thereby articulates a justification for class domination, sexism, and imperialism grounded either in theodicy (justification of violence by a supposed greater good), or a denial of the irreducibly violent aspect of domination.

\section{Civilization Deconstructed}

Where does this leave us with Elias? The argument that I have just presented seems to support dismissing his work altogether. The cost of this dismissal would be high, however. Elias does establish that, in at least some contexts, the disposition of 
force relations in a social network is intimately connected with the cultivation of habits of self-governance in the conduct of everyday life. I think that we can rehabilitate Elias by reading his work against itself. That is, if we are prepared to suspend questions of authorial intent and allow that Elias's reading of his own work is not authoritative, then I can show how the text of The Civilizing Process contains elements that dismantle a teleological theory of civilization. In other words, The Civilizing Process is open to a deconstructive reading, and this reading allows us to recover much of value from Elias's theory. In particular, it allows me to propose a framework for explaining genocides in terms of the advancement of civilizing processes.

In this part of the chapter, I will begin by describing what deconstruction is and how I position my own use of it in relation to the broader field of deconstructionist writings. I also elaborate on Derrida's concept of 'différance', which forms a key part of my deconstructive account of the civilizing process, and I draw out several points of affinity between deconstruction and figurational sociology. Having sketched out these additions to my conceptual toolkit in Section 2.1 , I will apply a deconstructive reading to The Civilizing Process in Section 2.2. This involves showing how Elias's text produces a normative teleology, in which the advancement of civilization is equated with the advancement of the pacification of social life, and how it inverts this teleology, linking the growth of civilization with the expansion and intensification of relations of violence. Elias's text can be read against itself to produce an account in which civilized subjectivity is produced through violent différance: the organization of force relations into a hierarchical system of social distinctions, maintained by the power of the state and by 
tactics of civility. In Section 2.3, I take the further step of displacing the opposition between civilization, identified with state-formation and pacification, and barbarism, linked to autarky and violence. Rather than simply reverse the polarities of these terms, privileging barbarism over civilization, I propose a third term, barbarous civilization, which designates an ambivalent process in which the intensification of relations of violence goes hand in hand with the production of zones of the suspension or deferral of violence. Certain instances of genocide can therefore be seen as products of, or as contributing to, the intensification of barbarous civilization. I discuss these civilizing genocides in Section 3.

I should also note that my discussion of Elias is devoid of reference to his Freudianism. As I have already discussed in Chapter 3, I consider Elias's use of Freudian theory to be a deficiency, relative to the project of relational and non-egocentric sociology as he defines it in The Civilizing Process and in What is Sociology?. I read Elias as rejecting in principle the dualist division of social action into a psychological sphere internal to the consciousness or mind and a sociological sphere external to the mind, in favour of a relation conception in which effects of mind or consciousness are produced through social interaction. However, he also lapses back into that dualism, through a view of human psychology as characterized by boilingly unruly impulses held in check by the threat of violence. Deconstruction, through its critique of logocentrism (the analytical privileging of thought over speech and action), provides an avenue by which civilized forms of inhibition or self-constraint can be understood in relation, not to any essential violence in human nature, but to socially produced violence. Barbarous 
civilization inhibits a violence which it also produces. My account of barbarous civilization is intended to explain how individuals are enrolled in the reproduction of violent différance without recourse to psychologism, Freudian or otherwise.

\subsection{DECONSTRUCTION AND FIgURATIONAL SOCIOLOGY}

Part of the difficulty with using deconstruction as a sociological tool or of doing a deconstructive sociology springs from the contested, ambivalent, uncertain quality of deconstruction: it is not clear what deconstruction is. The question is all the more fraught since deconstructive writings problematize being, identity, and hence definitions. Any definition of 'deconstruction', or of anything else, risks invoking the metaphysics of presence that deconstructionism works radically to call into question. We also encounter the more prosaic difficulty of intense disagreement among deconstructionists over what deconstruction says or doesn't say, what it does or doesn't include, and what it can or cannot be used for. To adapt an image from Deleuze and Guattari [1987: 40], I think that the amorphous network of writings about deconstructionism exhibits a double articulation. The first articulation is between deconstruction as a specialized set of procedures or techniques for reading texts, and deconstruction as a broadly focused political project. The second articulation is between esoteric and lay uses of deconstruction. Rorty, for example, claims that Derrida should be read as an esoteric writer, someone whose work is so difficult and inaccessible because it is basically a private form of play, potentially interesting to many but certainly not a form of political philosophy [Rorty 1989: 125; 1993]. Derrida, on the other hand, states that: 
What is somewhat hastily called deconstruction is not, if it is of any consequence, a specialized set of discursive procedures, still less the rules of a new hermeneutic method that works on texts or utterances in the shelter of a given and stable institution. It is also, at the very least, a way of taking a position, in its work of analysis, concerning the political and institutional structures that make possible and govern our practices, our competencies, our performances. [Derrida, quoted in Culler 1982: 156]

Derrida's statement would seem to decide the issue, except that deconstruction refuses the author any final authority over the texts she or he has written, and Rorty's claim about the esoteric quality of deconstruction does accord with an important dimension of Derrida's own work and of deconstructive writing generally. In addition, any attempt to privilege the politics of deconstruction over its technical or formal aspect would itself be subject to a deconstructive reading: it is just as easy or difficult to position deconstructive politics as dependent on the technical innovation of deconstructive reading as the other way round. I prefer to see both as mutually dependent but irreducible aspects of the overall network or field of deconstructive discourse. The same is true for the second articulation, between esoteric and lay tendencies in deconstructive writing. These two articulations are not simple binary oppositions, since each tendency feeds off and impacts upon the other. Nor does the second articulation reduce to the first, as might be presumed. Homi Bhabha, for example, works along the political-esoteric extension of the double articulation, interrogating the relation between domination and identity in postcolonial subjectivity through a relatively introverted play with signifiers [e.g. Bhabha 2001]. Culler's [1982] exposition of deconstruction emphasizes its technical side in a non-esoteric way. So the four claws of this double articulation (technical-esoteric, technical-lay, political-esoteric, political-lay) map out a set of irreducible tendencies 
through which practitioners of 'deconstructionism' extend the overall field of their discourse. My own interest is in political and lay extensions of deconstruction for the purposes of an empirically oriented sociology.

This interest requires some exposition of what a deconstructive reading involves, of the "specialized set of discursive procedures" associated with it. At its simplest, deconstructive reading involves the identification, reversal, and displacement of a binary opposition that is in some way crucial to a text. Such reading does not deconstruct a text so much as show how a text deconstructs itself. For example, Derrida's reading of Saussure's Course in General Linguistics observes that Saussure privileges speech over writing: writing is simply a means of representing speech [Culler 1982: 101; Derrida 1976: 30]. More strongly, writing is said to be corrupt and parasitical on speech, while speech is the proper object of linguistic analysis because it has closer and more pure relationship to meaning and to thought: "words issue from the speaker as the spontaneous and nearly transparent signs of his present thought, which the attendant listener hopes to grasp. Writing, on the other hand, consists of physical marks that are divorced from the thought that may have produced them." [Culler 1982: 100]. This phonocentrism is remarkable in light of two important claims made by Saussure regarding language: that the relation between signifier and signified is arbitrary, and that the meaning of signs is a function of the relationships among signs, relationships that make one sign different and distinguishable from the next [Culler 1982: 98]. Ordinary speech acts (parole) are possible due to the operation of a system of signs (langue) that operates as a system of differences, and hence of absences. Saussure's phonocentrism therefore seems to be an 
attempt to maintain within his conceptualization of language a form of presence that can serve as a ground for meaning. Thought is alleged to be present in speech as it is not in writing. Yet in order to demonstrate the differential or relational quality of language, Saussure uses writing as his example: a given mark counts as the letter ' $t$ ', for instance, not because of essential features but because it can be distinguished from 'l', 'f', 'i', 'd', and so on [Culler 1982: 101]. By using writing in this way, as an illustration of the nature of language, Saussure's argument overturns the privilege of speech and treats speech as a subspecies of writing. But this inversion is also unstable, since it appears precisely as an effect of Saussure's phonocentric arguments [Derrida 1976: 56]. To cope with the inability of either writing or speech to serve as a secure foundation for the other, Derrida introduces the term 'archi-writing', which embraces both speech and writing as operations through which language both invokes and produces a system of differences. To invoke a more complicated neologism of Derrida's, archi-writing is the "movement of différance" [Derrida 1976: 60].

Explaining différance will enable me to give some indication of the broader political articulation of deconstruction. Différance also forms a crucial element in my deconstructive account of the civilizing process. The term 'différance' is a neologism coined by Derrida [Culler 1982: 97]. In French it is homonymic with 'différence', which translates to English simply as 'difference'. However, 'différance' is formed by adding the ending '-ance', which is used to make verbal nouns (as '-ing' is in English), to the verb 'différer', which translates both as 'to differ' and 'defer' (in the sense of postponing), so that 'différance' in French has connotations in English of differing and 
deferring. It is also both a noun and a verb, like the English word 'spacing', so that 'différance' refers simultaneously to a synchronic structure and a diachronic process. 'Différance' expresses Derrida's deconstructive displacement of Saussure's opposition between 'parole', concrete speech events, and 'langue', the linguistic system that makes any given speech event intelligible. Since neither langue nor parole can serve as a foundation for the other (each presumes the other), both together presume an active production of the system of differences; 'différance' designates both this production and its product. The term expresses Derrida's critique of the metaphysics of presence that informs Western philosophy; this metaphysics is manifested in Saussure's residual phonocentrism and in the logocentrism of Western philosophy generally. Logocentrism assumes that thought exists prior to speech, writing, or action, and that practices of speaking, writing, or acting only express that pre-existing thought more or less transparently. Logocentrism occasions an indefinite series of hierarchical binary oppositions: soul vs. body, intelligible vs. sensible, transcendental vs. empirical, nature vs. culture, and so on, in each of which the first and "superior term belongs to the logos" and the second or inferior term marks a "complication, a negation, a manifestation, or a disruption of the first" [Culler 1982: 93]. Logocentrism in turn assumes a metaphysics of presence in the sense that thought is held to be present within speech, and consciousness to be present within the mind (or self-present) [Culler 1982: 92; Derrida 1976: 12]. Saussure's linguistics conceptualizes meaning as the product of a system of relations, differences, and hence absences, and so contains a potential radical rejection of the metaphysics of presence. This radical potential is blocked by Saussure's residual 
phonocentrism, and released by Derrida's deconstructive reading. Deconstructive readings in general work to convert presence into absence; in more ordinary terms, they reveal the relational quality of supposedly absolute concepts, and show that every supposed foundation for meaning (that could serve as a transcendental signified) depends on something that came before. The effect is to deny the priority of thought over activity and to assert the irreducibly practical and, by implication, social basis of the production of meaning. The hierarchical binary oppositions of logocentric thinking are then shown to have political connotations or, more strongly, to be bound up with historical projects of domination: of men over women, 'whites' over 'blacks', and so on. Deconstruction then operates as a tool for exposing and undermining power relations through textual engagement.

Deconstruction and figurational sociology, then, share several points of affinity. Both use the term 'metaphysics' to designate tendencies in Western thought that they seek to overcome in the pursuit of scientific understanding. Both treat that metaphysics as permeating the very language in which any objection to metaphysics must be articulated. Elias does little more than rail against the severity of the problem [Elias 1978: 111-122]. However, the terms of the solution that he implicitly asks for overlap with those of the one Derrida provides, for the metaphysics that Elias objects to is defined substantially by its egocentrism, which treats human consciousness as having an existence prior to and independently of social interaction [13-19]. Derrida's attack on logocentrism works well as an antidote to egocentrism. In particular, his refusal of the self-presence of consciousness and the co-presence of self and other accords neatly with 
Elias's insistence on the fundamentally relational quality of both individual subjectivity and social structures, the distinction between which tends towards disappearance in Elias's account, and with his concomitant refusal of the opposition between self and environment. In light of Derrida, figurational sociology can be reread as a sociology of absence. Finally, figurational or process sociology enjoys a somewhat uneasy complementarity with the concept of différance. As Elias uses it, the term 'figuration' shares with 'différance' a dual connotation of process and thing; civilization, for example, is both the process of becoming or making civilized and the product of that process. The connotation is uneasy because Elias emphatically privileges process over stasis, inverting the structuralist binary without displacing it altogether. It is more uneasy still to the extent that Elias does not definitively break with the logocentric epistemology of representation; although Elias tends to use the terms 'reality-congruent' or 'realityadequate' rather than 'objective' when speaking of the superior virtue of scientific as opposed to metaphysical knowledge [e.g. Elias 1978: 25-26; 1987: xix-lxxii, 37, 55, 62, $95,101]$, this terminology still assumes a reality present to itself and at least suggests a correspondence-based conception of knowledge. Elias's attempt to develop a nonegocentric account of scientific knowledge, in the "Fragment on the Great Evolution", still depends on this metaphysical standard of 'reality-adequacy' and so devolves, as I have already argued, into a philosophy of history.

\subsection{Rereading The Civilizing Process}

Deconstruction, then, offers one way of accomplishing a task that Elias began but did not complete, that of developing a non-egocentric and non-metaphysical account of 
knowledge, on which to base actual sociological investigation. In the section that follows I will apply a deconstructive reading to Elias's historical sociology, in order to redeem the insights of that sociology from its own egocentrism. In particular, I will address the teleological account of civilization, in which civilization is equated directly with the pacification and humanization of social life. This account deconstructs itself in two ways. First, the growth of the European civilizing process necessarily involves the growth of military monopolies, and hence the growth of the overall violence-potential available to the figuration. The formation of the organized and continuous military capacity necessary to modern nation-states serves as an obvious precondition for the conduct of systematic genocides involving millions of people. Moreover, this intensification of military capacity has produced, in the twentieth century, the unprecedented danger of total human extinction from military action, via the possibility of global thermonuclear war. Second, the civilization of European subjects relies on the strategic, economic deployment of violence through the possibility of embarrassment and shame. In a close reading of Elias's account, shame is the affective concomitant of a threat to both the sense of self and the social status of individual subjects. The threat of shame becomes more important as the dependency of the privileged civilizing class (the aristocracy) increases, which is to say as the material consequences of social exclusion increase. In other words, shame threatens the privileged individual with exclusion from the particular universe of obligation that underpins his privilege; inclusion in that universe is conditional on the cultivation of a specifically hierarchical, authoritarian, and conformist regulation of emotional and bodily practices. In these two ways, at least, the 
European civilizing process involves an expansion and intensification of relations of violence. In the next few pages I describe this process in detail.

\subsubsection{STATE FORMATION}

The deconstructive account of state-formation can be stated briefly. Stateformation proceeds through the establishment of territorial monopolies of military force. Elias asserts that "when a monopoly of force is formed, pacified social spaces are created which are normally free from acts of violence" [Elias 2000: 369]. The growth of these monopolies, therefore, implies a growth in these pacified social spaces, the logical endpoint of which is the complete pacification of global social life:

We see the following movement: first one castle stands against another, then territory against territory, then state against state, and appearing on the historical horizon today are the first signs of struggles for an integration of regions and masses of people on a still larger scale. We may surmise that with continuing integration even larger units will gradually be assembled under a stable government and internally pacified, and that they in turn will turn their weapons outwards against human aggregates of the same size until [...] world society is pacified. [254]

Thus far, violence and civilization seem opposed to each other, the former receding with the advance of the latter.

However, Elias also states that civilizing processes depends on violence:

What finally meets its end in such conflicts or merges into new formations [...] is no less indispensable to these new formations than the victorious opponent. Without violent actions, without the motive forces of free competition, there would be no monopoly of force, and thus no pacification, no suppression and control of violence over large areas. [311]

Violence is the motor of the civilizing process; there can be no civilization without violence. This holds regardless of the historical period: the free competition Elias 
mentions is the competition for social dominance, carried out initially by a warrior class that dominates by direct force, but taken up by the dominant classes of the nation-state era. In the course of this competition, the formation and extension of monopolies of force requires the production of concentrated military capacity capable of subduing competitors. Powerful lords, and later sovereigns, use their taxation privileges to hire ever-larger armies, to maintain permanent military institutions, to develop intensified military techniques [192]. In other words, the territorial monopolization of force requires the reproduction of the means of military violence on an expanding scale, to use Marx's phrase, and of the means of their rational administration. We can see how the logical development of this civilizing process produces the massive military and logistical capability necessary for the spectacular genocides, involving millions or people, distinctive to the twentieth century $\mathrm{CE}$. This same figurational movement has created the potential for omnicide [Goodman 1990], the extinction of the human species through global thermonuclear war - not coincidentally, the "specific civilizational difficulty" [Elias 2000:xiv] that Elias addresses in Involvement and Detachment.

\subsubsection{SELF-CONSTRAINT}

A teleological understanding of the constraint to self-constraint is subject to a similar inversion. The pacification of social spaces occasioned by the formation of monopolies of force compels individuals to constrain their own actions, refrain from outbursts of violence, and cultivate skills for pursuing their objectives without resort to direct physical force. 
The moderation of spontaneous emotions, the tempering of affects, the extension of mental space beyond the moment into the past and future, the habit of connecting events in terms of chains of cause and effect - all of these are different aspects of the same transformation of conduct which necessarily takes place with the monopolization of physical violence, and the lengthening of the chains of social action and interdependence. It is a 'civilizing' change of behaviour. [Elias 2000: 370]

Again and again Elias describes this process in terms of the imposition of restraints on allegedly spontaneous or uninhibited drives, such as feelings of "savage joys, the uninhibited satisfaction of pleasure from women, or of hatred in destroying and tormenting anything hostile" [371]. The formation of monopolies of force occasions the taming of these purportedly uninhibited joys, lusts, and hatreds, and this increases the space for social action available to types of persons who cannot use force so readily: women [142-160] (of the upper classes, at least), the bourgeoisie [413], and eventually the industrial working class [461-3]. Again, with respect to the cultivation of individual self-constraints, the relation between civilization and violence seems to be a zero-sum game, so that violence simply recedes as civilization advances.

Yet Elias inverts this account in two ways. First, the supposedly spontaneous and uninhibited behaviour of the knight turns out to have also been the product of social constraint. Elias says that

Just as in every psychogenetic enquiry it is necessary to take account not only of the 'unconscious' or the 'conscious' functions alone, but of the continuous circulation of impulses from the one to the other, it is equally important in every sociogenetic study to consider from the first the whole figuration of a social field that is more or less differentiated and charged with tensions. [Elias 2000: 411] ${ }^{97}$

97

Note also: "At any rate, the psychic life of 'primitive' peoples is no less historically (i.e., socially) stamped than that of 'civilized' peoples, even if the former are scarcely aware of their own history. 
And although the sociogenesis of knightly violence is tangential to Elias's main topic, he provides some description of its components. "The majority of the secular ruling class of the Middle Ages", he says, "lived the life of leaders of armed bands. This formed the tastes and habits of individuals" [164]. This situation placed the knight in relations of perpetual tension with the classes he dominated, which is to say all those by whom he was immediately surrounded: women whom he mistrusted and objectified, and peasants from whom he demanded servility [242]. The situation was even worse with other members of his own class, those who were the most like him in their social identity: these were a constant threat to him; they coveted his lands, as he coveted theirs [219]. In these rivalries, "the actual social existence of all the participants is at stake. That is the compulsion behind these struggles". If a knight is conquered he faces, in the extreme case, "imprisonment, violent death or material distress, perhaps starvation", but in the mildest cases "social decline, loss of independence, absorption by a larger social complex; and thereby the destruction of what gave their lives meaning" [305]. I have already mentioned Elias's juxtaposition of the two dukes, Montmorency and SaintSimon, who lived on different sides of a watershed in the civilizing process (see page 198 above). Montmorency's ultimately fatal inability to restrain his martial favour was actually a "necessary precondition of success and prestige for a man of nobility" [Elias 2000: 405]; this necessity was maintained by the tactical relations that made the mounted and armoured knight a potentially decisive force on the battlefield, and the social relations that derived from and depended on his personal martial prowess. The 
uninhibited and spontaneous emotional behaviours of the knight, therefore, turns out in Elias's account to be socially structured. The civilizing process, therefore, does not involve the superimposition of socially produced constraints on essential human drives, but the reorganization of relations of violence and of affect from one figurational movement to another.

Even so, does not this reorganization entail a decline in the importance of violence to social life? Not at all, says Elias:

Even in this form as a control organization, however, physical violence and the threat emanating from it have a determining influence on individuals in society, whether they know it or not. [...] a continuous, uniform pressure is exerted on individual life by the physical violence stored behind the scenes of everyday life, a pressure totally familiar and hardly perceived, conduct and drive economy having been adjusted from earliest youth to this social structure. [Elias 2000: 372]

Through monopolization, members of the warrior class are literally forced not to use force in their conflicts with other classes and with each other. But the "structure of social tensions", formerly expressed in warlike actions, persists even when the opportunity for their martial expression is denied [423]. The aristocrat faces the same structure of interand intra-class tensions that had formerly required knights to be perpetually ready for war, but under monopolistic conditions these tensions can be expressed through physical violence "only at infrequent climaxes or turning points". Instead they operate "as a continuous pressure that each individual member of the nobility must absorb within him or herself", turning from a flame that can flare up and die away quickly into a 
"permanently smouldering fire whose flame is hidden and seldom breaks out directly"

[ibid.]. And at the same time

Forms of non-physical violence that always existed, but hitherto had always been mingled or fused with physical force, are now separated from the latter; they persist in a changed form internally within the more pacified societies. They are most visible so far as the standard thinking of our time is concerned as types of economic violence. In reality, however, there is a whole set of means whose monopolization can enable people as groups or as individuals to enforce their will upon others. [369]

As domination through direct physical violence recedes into the background, control over the means of production (itself guaranteed by the monopolistic authority) comes to the fore. And if, after the end of the feudal era, the aristocracy had lost control of the means of violence to the monarchy, it also began more slowly to lose control of the means of production to the urban bourgeoisie. Lacking the means to directly oppose the bourgeoisie in the struggle for social dominance, the aristocracy became increasingly dependent on the monarchy to maintain its privileged status, just as it was at times dependent on the bourgeoisie for support against royal power [312ff]. Under the pressure of this dual dependency, the use of symbolic means to reinforce aristocratic privilege became increasingly vital. The court became an increasingly important site for strategic encounters, codes of civility became increasingly elaborate, the consequences of shamewhich could involve not only embarrassment but loss of status, marginalization, or even expulsion -became more and more serious.

If the actual social existence of the feudal knight was at stake in his competitive struggles with others of his own class, the same is true for the civilized aristocrat.

Only life at court opened to individual nobles within this social field access to economic and prestige opportunities that could in any way 
satisfy their claims to an existence of upper-class distinction. [...] only life amid courtly society could maintain the distance from others and the prestige on which depended their salvation, their existence as members of the upper class, the establishment or the 'Society' of the country. [Elias 2000: 395]

But there were always more nobles who were vying to be at court than were invited to attend, and competition to obtain and retain the favour of Society was intense. In this context, civilized behaviour formed a battleground on which aristocrats fought for stakes that paralleled those of their knightly predecessors: in the extreme cases, eviction from court, loss of lifestyle and of social status, material distress, the forced choice between genteel poverty or a degrading exchange of aristocratic for bourgeois status, or no choice at all and poverty without status; in the mildest cases, social humiliation, loss of status in Society, harm to that which gave their lives meaning. And this threat is all the more powerful because it originates as much from the aristocratic subject himself, as from the social milieux in which he moves. Like the knight before him, the aristocrat is chiefly threatened by others of his own class, by the very people who are most like him. And under conditions of advancing civilization, this self-threat takes on an added intensity. "Physical clashes, wars and feuds diminish", and anything recalling them - down to the use of knives at the dinner-table - is banished from view or severely circumscribed. But "at the same time the battlefield is, in a sense, moved within. Part of the tensions and passions that were earlier directly released in the struggle of man and man, must now be worked out within the human being" [375; see also 424]. The civilizing process entails the entire formation of the entire complex of emotional and cognitive structures that Freud analyzes in terms of id, ego, and superego. Civilization is more than an economy 
of violence, wealth, status, and prestige: it is an economy of affects, a circulating network of fear and desire, esteem and contempt, love and hate. Shame therefore pits individuals against themselves:

The conflict expressed in shame-fear is not merely a conflict of the individual with prevalent social opinion; the individual's behaviour has brought him into conflict with the part of himself that represents this social opinion. It is a conflict within his own personality; he recognizes himself as inferior. He fears the loss of the love or respect of others [...]. Their attitude has precipitated an attitude within him that he automatically adopts towards himself. [415]

And one crucial feature of this affect-structure that enables and impels feelings of shame in the European aristocrat is its intensely hierarchical character, its immanence to relations of domination and subordination inherent to class society, with all the violence they imply.

\subsubsection{DIFFÉRANCE}

At this point I would like to take the liberty of grafting into Elias's text a small scrap of Derrida's writing, a single word: 'différance', which, as I mentioned earlier, has connotations of 'difference', 'differing', and 'deferring'. Briefly, civilization as Elias conceives it operates simultaneously as a system of social differences and as an economy of deferred violence. It involves the production and instantiation of relations of difference and of distance between the privileged subject of civilization and all of those various others whom he or she dominates, differences that establish the basis of his or her social identity. And there exist also differences and distances between among civilized subjects, who all resemble each other but who, by virtue of that very resemblance, are pitted ruthlessly against each other. These differences establish the individuality, the 
egocentric isolation, of the civilized/civilizing subject. In both respects the identity of the civilized subject, like the meaning of a signifier, is established through this network of differences, this system of absences. On the other hand, the nexus of that identity operates as a site of intense deferral or deferring. Violence, physical or otherwise, does not after all take place continually, but remains implicit or potential in a multiplicity of relations sustained on an ongoing basis. Since the violence through which so many differences are established takes place only occasionally, it is perpetually being deferred. The defining labour of the civilized subject is in the maintenance of that deferral, maintaining the presence-through-absence of the violence upon which his or her difference-identity relies.

The shame of the civilized subject is a self-inflicted violence in a dual sense: inflicted by those with whom the subject most identifies, and inscribed in the subject's own structure of affects through his or her sense of self. At its most extreme, shame threatens the entire social existence of the subject, and is therefore a life-or-death proposition. At its most basic it is a threat of social negation, exclusion from the universe of obligation. But if we consider that the privileged subject of civilization has been historically the male European aristocrat (without pausing to specify just who has succeeded that now-deposed subject), then we can see that the exclusion with which that subject threatens itself requires and produces still greater exclusions. The hierarchical network of civilizing différance entails classes of persons who are always partially outside the universe of obligation: women, commoners, heretics, non-Christians, nonEuropeans, barbarians. These persons are positioned as essentially incapable of becoming 
fully civilized. Yet by their very otherness they are necessary to the maintenance of civilization, for civilization is a relational scheme; the civilized subject cannot exist (materially as well as symbolically) without the network of absences that define him. And the continuous maintenance, through violent différance, of this hierarchical network of exclusions (relative to the privileged subject) implies a more fearsome possibility: total exclusion. This total exclusion does not mean simply that subjects are placed outside the civilizing figuration, to be separate from and uninvolved in it. Rather, it entails an intense relationship of negation in which the deferred violence of civilization is finally instantiated. The radically excluded subject must be actively negated, which is to say subjected to repeated acts of negation through which all the fears of the civilized subject - social isolation, economic expropriation, personal violence, death - may be performed on the other. It may unfold in an orgy of affective expression or in an orgy of rational calculation, but in either case, the differential logic of civilization may find expression in genocide.

\subsection{Displacing Civilization}

It is naïve and one-sided, then, to equate civilization with pacification or humanization. As civilizing différance proceeds, the socially produced spontaneous and local violence of the autarkic warlord is subdued, and, just as when the polar icecaps increase during an ice age the sea's water withdraws from the land, so the monopolistic concentration of the means of force draws direct physical violence away from the conduct of everyday life, and new social spaces emerge in which new forms of life are innovated. But the same figurational process also creates or intensifies other forms of 
violence, concentrated in the increasingly centralized military capacity of states, and distributed in economies of shame and exclusion. This intensification of violence operates as an enabling condition for, amongst other things, genocide, and creates the potential for omnicide, even as the pacification of everyday life operates as an enabling condition for the stigmatization and criminalization of genocide.

Shall I conclude that civilization is simply pernicious? This conclusion would echo the claims about modernity taken by Bauman, for example. It amplifies the doubt about civilization expressed so eloquently by Walter Benjamin ${ }^{98}$, and extends that current of European skepticism regarding both the virtues of civilized conduct and the value of developmental progress which finds passionate articulation in Rousseau's second discourse [1993a: 84]. It is a tempting conclusion, especially if 'civilization' is taken to refer to a specifically European process, in which case the simple equation of civilization with militaristic expansionism, colonialism and imperialism appears more feasible.

However, a simple inverstion of the usual positive evaluation of civilization gives rise to several problems. This inversion is as essentialist and, in Elias's terminology, metaphysical, as its reverse. I have argued that civilization involves a redistribution of force relations, intensifying them in some respects, diffusing or displacing them in others.

98 "Whoever has emerged victorious participates to this day in the triumphal procession in which the present rulers step over those who are lying prostrate. According to traditional practice, the spoils are carried along in the procession. They are called cultural treasures, and a historical materialist views them with cautious detachment. For without exception the cultural treasures he surveys have an origin which he cannot contemplate without horror. They owe their existence not only to the efforts of the great minds and talents who have created them, but also to the anonymous toil of their contemporaries. There is no document of civilization which is not at the same time a document of barbarism. And just as such a document is not free of barbarism, barbarism taints also the manner in which it was transmitted from one owner to another. A historical materialist therefore dissociates himself from it as far as possible. He regards it as his task to brush history against the grain." [Benjamin 1969: 256-257] 
As well as establishing circuits of violence, civilization creates zones of pacification within which violence (or certain forms of it) become anathema. This dual quality of civilization accounts for the ambivalence of the twentieth century, distinguished by both the unprecedented magnitude and the unprecedented illegality of genocidal violence. It also accounts for the contradiction by which "a Native American like Ward Churchill could eventually occupy an academic position at a state university of the perpetrator society" [Moses 2002: 27]. An essentialising effacement of such contradictions and ambivalences would be especially unfortunate for another reason: after colonialism and decolonization, the mechanisms of European civilization have gone global. Like capitalism, it has achieved a kind of totality; at least, it lacks a territorial or demographic outside. This being the case, an analysis that construes civilization as simply pernicious can hardly attempt to formulate solutions to the problems it poses. Still, this analysis does at least pose the right question: that of escape. It should be clear that the solution to the problems of civilization is not simply, more civilization. We need to find ways to excuse ourselves from the self-annihilating dance of the civilizing process.

Another option would be to consider the civilizing process in dialectical terms, not as the civilizing process but as the civilizing-barbarizing process through which the antitheses of pacification and violence work inexorably to produce their own synthetic overcoming $^{99}$. This formulation has the attraction of connoting the quality of a figuration that produces both pacification and violence through its own extension. If this is a dialectic, it is certainly a grim one, marching us to our doom or at least into greater and 
greater danger of annihilation, and we must find a way to escape it before that danger is actualized. The conditions for transcending such a dialectic could be understood in terms of open and closed systems: like capitalism, civilization can exist only as long as it can expand, and when it encounters the limits to its growth the very logic of its existence can no longer be fulfilled. This formulation, too, is as unsatisfactory as the previous one, however. In the place of one essentialism, it merely substitutes two, assimilating the lateral differential network of a deconstructive sociology to a Procrustean bipolar scheme. A dialectical understanding of civilization overtly evokes a teleological determinism, and hence another grand narrative in which human agency disappears. However, it does raise another important point: that the civilizing process creates the conditions for its own overcoming.

The inversion of a binary opposition does not mark the conclusion of a deconstructive reading. Since the inversion of the binary is effected using the terms of the original hierarchical opposition, the inversion does not count as a refutation or a replacement of that hierarchy. A restoration of the original scheme remains equally plausible or implausible; strictly speaking the priority of the two opposed terms is shown to be undecidable, aporetic. Nor does a dialectical treatment resolve the issue. Rather, deconstructive readings take the further step of displacing altogether the binary opposition in question. This opens up new interpretive possibilities that the binary, with its claims to totality, had foreclosed. In our case, this involves displacing altogether the opposition between 'civilization' and its rarely mentioned opposite, 'barbarism' 
The etymology of 'barbarous' is interesting in its own right. Elias [2000: 42, 51] attempts to use the word non-judgmentally, and to describe civilized and uncivilized societies in terms of their "different structure of affects, the different standard of repugnance" without invoking a valuation of one over the other. The negative connotations of the words make this difficult, and in The Civilizing Process he rarely uses 'barbarian' or related terms without quotation marks. This may be because the word 'barbarous' itself takes a specifically evaluative attitude towards difference, as its etymology indicates:

f. L. barbar-us, a. Gr. $\beta^{\prime} \alpha \beta \alpha \rho o \varsigma+{ }_{+}$OUS: preceded in use by the simple BARBAR(E, without suffix. The Gr. word had probably a primary reference to speech, and is compared with L. balbus stammering. The sense-development in ancient times was (with the Greeks) 'foreign, nonHellenic,' later 'outlandish, rude, brutal'; (with the Romans) 'not Latin nor Greek,' then 'pertaining to those outside the Roman empire'; hence 'uncivilized, uncultured,' and later 'non-Christian,' whence 'Saracen, heathen'; and generally 'savage, rude, savagely cruel, inhuman.' The later uses occur first in Eng., the L. and Gr. senses appearing only in translators or historians. [OED 2004] ${ }^{100}$

The term 'barbaric' connotes a relation of difference as much as a particular standard of conduct. If 'civilization' expresses "the self-consciousness of the West", 'barbarism' expresses the negation of that self-image. However, again this negation is an intimate one, a self-negation rather than a genuine encounter with the other. The term 'barbarous' connotes the speaker's incomprehension of the other, in light of which the usual attribution of cruelty and violence to barbarians tells us more about those doing the separate origin, but it has much the same connotations. Ibn Khaldun, for example, claims that 'Barbary' in Arabic originally meant "those who speak 'bar bar'", i.e. those who jabber or cannot speak properly [Ibn Khaldun 1996: 45]. 
attributing than about the barbarians themselves. Like 'civilization' although for different reasons, 'barbarism' is an effect of absence.

With this in mind, we can reread Elias with the assumption that 'civilization' and 'barbarism' refer not to opposed figurational tendencies but to aspects of the same figurational movement. In the same way that the terms 'identity' and 'difference' require each other and are deployed in the joined term 'identity-difference', we can speak of 'civilization-barbarism' or, in a less cumbersome phrase, of barbarous civilization. This new term designates an overall organization of relations of violence and nonviolence. However, neither violence nor pacification simply correspond to either civilization or barbarism. Rather the dual terms indicate forms of violence and nonviolence, along with forms of self-constraint, structures of affect, or standards of repugnance, that extend or negate the self-consciousness of the speaker. Taken as a whole, barbarous civilization designates, amongst other things, an overall problem-situation: the unresolved and everincreasing dilemma of violence. Without decisively resolving this problem, the historical trajectory of European barbarous civilization has created zones of the suspension or deferral of violence; these zones are always unstable, but while they exist they create openings for a critique of violence, and hence for the pursuit of figurational solutions that escape the problem altogether.

In The Social Contract, Rousseau presents social life under conditions of advanced civilization as a problem situation:

The problem is to find a form of association which will defend and protect with the whole common force the person and goods of each associate, and in which each, while uniting himself with all, may still obey himself alone, and remain as free as before. [Rousseau 1993b: 191] 
In Joyce's novel Ulysses, Simon Daedalus expresses the same problem-situation more succinctly, saying "History is a nightmare from which I am trying to awake". The problem facing Rousseau is how, in the context of a civilization premised on inequality, oppression, and violence, to construct an egalitarian social life that enables the free development of human faculties. Utopian solutions require an impossible erasure of the past; Rousseau's question is how to work with givens. The same attitude is expressed in the anarchist slogan, 'building a new world in the shell of the old'. The political question driving genocide scholarship is how to build the non-genocidal society in the shell of European barbarous civilization.

\section{A Figurational Sociology of Genocide}

\subsection{The Barbarous Civilization OF EUROPE AND THE WORLD}

A deconstructed Eliasian theory of genocide has important implications for the debates around the definition of the term. The concept of 'genocide' is coined in the context of modern European barbarization-civilization. In this context the terms 'nation', 'ethnicity', 'race', and 'religion' connote, among other things, definite forms of collective identity that are of special importance to nation-states. Lemkin coins the term 'genocide' for the stated purpose of protecting the right to existence of specifically national groups [Moses 2002; Lemkin 1944: 79, 91]. Lemkin's intervention presupposes a strategic situation in which there exists a potential contradiction between the specific institutional forms of the European state and the specific forms of identity understood in terms of 'genos' - the people, the nation. It indicates that that contradiction had reached a level of 
intensity which Lemkin and others found unacceptable. Subsequent mutations of the term unfold within the framework of this same situation, one engendered by European barbarous civilization. In other words, both genocide and 'genocide' are not universal to human social life, but are historically specific products of the figurational movement of barbarous civilization. This has important consequences for the scope with which we apply these terms.

I have been speaking of European barbarous civilization. This is because I have theorized the development of that civilization and its mechanisms on the basis of Elias's historical examination of the specifically European context. In this sense the term 'European' is misleading only in that the mechanisms of barbarous civilization have, through colonialism, been exported to the entire surface of the globe and have taken on any number of interrelated but differing trajectories of development in post-colonial contexts. In this respect, the indigenous peoples of the Americas are just as much enmeshed in barbarous civilization as are Manhattan socialites (although of course their specific relation to that process is very different). What is more problematic, however, is that Elias and his interpreters speak often of the civilizing process, suggesting either that there is only one civilizing process or else that the patterns they detect in European history are general to all humanity. Without a thorough comparative examination relating European cultural developments since the twelfth century to those in other areas and other eras, both of these implications are Eurocentric. If we leave off consideration of the specifically European context and examine, for instance, the Yucatan peninsula before Columbus, then we encounter a cultural context that has no direct connections 
with that of Europe. We are confronted with forms of political organization and identity (to the extent that terms like 'political' or 'identity' are applicable) which are just as sophisticated and complex as those of European civilization but which are not reducible to its terms. That is, to speak of 'nations' and 'states' in such a situation, without basing this on a detailed anthropological knowledge of the cultures in question, is spurious, and very likely to be anachronistic. That is, one cannot apply the concept of barbarous civilization to contexts that have not been colonized, or to practices that derive from an era before colonization, without making sure that the local cultural facts make such an application meaningful. Because I do not have such knowledge, I must abstain from claiming that barbarous civilization is either a unique product of European history, or a more general phenomenon widespread in human social life. Answering that question requires addition research which is, unfortunately, beyond the scope of my project here.

To return to my earlier point, because the concept of genocide is a product of cultural developments specific to European barbarous civilization, the scope of its meaningful application is restricted to the scope of that figuration. Episodes of violence engendered by completely separate figurations may resemble genocide, and they may certainly inspire a comparable sense of horror, but it is more appropriate to name them on the basis of an anthropological understanding of the cultures involved, than to blithely call them genocide because they match a shopping-list of criteria formulated in a European context. At the same time, this does not mean that genocide does not exist before the term 'genocide' is coined, in which case we could not call any event before 1944 a genocide. Genocide has a history, which is the history of barbarous civilization. 
This history concerns, amongst other things, the relation between violence and identitydifference or between violence and social différance. Barbarous civilization defines zones of safety within which individuals are protected from certain forms of violence, and so within which individuals are included in moral community - in Fein's terminology, the universe of obligation. Accordingly, the same process of definition establishes, actually or potentially, zones of relative exclusion in which individuals can be subjected to varying forms of violence. From the twelfth century onwards in European history, and from 1492 onwards in world history, we can observe a more or less continuous process of the definition and redefinition of these zones of social safety and social danger. The terms in which these zones are defined vary widely over time and space, and they are endlessly contested. What emerges from those contests is an unbroken succession of victors, the "triumphal procession" that Benjamin writes of [1969: 256]. This succession is unbroken because only a cessation of struggle could break it; the chains of defeat-victory relations form the threads that weave the history of barbarous civilization. The meaningfulness of 'genocide' travels along those threads. That is, the continuity of European barbarous civilization is constituted by the continuity of the struggles for power that produced, among other things, states and civility. Whenever we consider a situation whose history ties directly into those struggles, we face a situation that is directly connected, however tenuously, to the emergence of the concept of genocide in the mid- $20^{\text {th }}$ century. 


\subsection{Civilizing Genocides}

In this final section I discuss the concept of civilizing genocides. These are genocides produced by and productive of the process of barbarous civilization. That is, civilizing genocides are made possible by the mechanisms of civilization, and they produce an intensification or expansion of those mechanisms. If we confine ourselves to thinking only of the genocides canonized as 'great' genocides by liberal scholarship, especially the Shoah, then it is perhaps difficult to picture how genocide can contribute to the advancement of civilization. However, if we pause to consider genocides against indigenous peoples incurred during European colonial projects, then this proposition is more clear. The violent obliteration of indigenous peoples in the Americas, for example, facilitated the expansion of European civilization into that territory. Without those genocides, nation-states in the Americas would have had a very different history - if, indeed, they existed at all. In Chapter 5 below I will discuss in more detail the ways in which different genocides, colonial or otherwise, have contributed to the expansion of barbarous civilization. Still, observing that genocide can form an integral component of the expansion of civilization does not explain the dynamics of the relationship between these two processes. Civilization is not reducible to genocide, nor does it produce genocide at all times and in all places. In the remainder of this section I describe how genocide can be understood as a contingent product of processes of barbarous civilization.

The process of barbarous civilization, then, works to transform, rather than simply reduce, the operation of violence in social figurations. Direct physical force is largely 
displaced or deferred from the conduct of everyday life, and concentrated in state institutions, where it is intensified and reproduced on a continually expanding scale. Other forms of violence, notably symbolic and economic violence, persist as regular features of social life. For subjects privileged by barbarous civilization, and to a lesser extent for all civilized subjects, the threat of violence is deferred by subjects' performance of civilized self-constraint or self-governance. These performances, or tactics, attempt to maintain or improve each subject's status within a hierarchical system of social differentiation. This differential network defines relationships of identitydifference through which individuals define themselves and each other, out of which they constitute both their individual self ('I-identity') and collective selves ('we-identity'). Networks are mono-centric to the extent that extent that they converges on a single subject-position who is most privileged by the system. The topography of this network is marked by cleavages that set categorical limits on the capacity of subjects to assume the privileged subject-position, cleavages that can be coded in terms of collective identities subsidiary to the figuration: as gender, as class, as 'race', as sexual identity, and so on. To the extent that individuals, regardless of where they are placed in the network, identify their opportunities for realizing a meaningful life with participation in the system, then those individuals are enrolled or invested (practically, if not always consciously or emotionally) in identifying themselves with the subject privileged by the system, even when their location within it categorically prevents the complete realization of that identification. On the whole, then, figurations of barbarous civilization involve economies of force, in which violence circulates downwards through relations of 
domination, and upwards through individual and collective struggles to usurp or nullify superior privileges.

In barbarous civilization, then, identity and difference are always potentially a matter of violence. Violence is deferred superficially by the operation of the state to monopolize its use, but more fundamentally it is deferred through relations of interdependence, which that monopoly both produces and requires. Like all social relations, relations of interdependence involve power. The particular power dynamics of relationships of interdependence derives from their degree of symmetry or asymmetry; one party needs the other party (or needs something from them) more than they are needed in return. In an hierarchical system, most relationships ${ }^{101}$ are asymmetrical, and this asymmetry generates impunity for the superior party and vulnerability for the other. At the greatest extreme of this asymmetry, mutual dependence is a life-or-death proposition for the inferior party and a matter of contingent self-interest for the superior party. That is, in such situations the inferior party makes the superior party just dependent enough on them to spare their lives or provide the means of life. In these situations, impunity and vulnerability approach being total. In this concrete sense, the radically vulnerable subject position slips outside the universe of obligation. When this happens, civilizing genocide becomes possible.

I have said earlier ${ }^{102}$ that genocide under conditions of barbarous civilization involves a transformation of the identity-difference relationship into one of complete

\footnotetext{
101 Though not necessarily most interactions: a person who interacted only with their social equals would not necessarily have direct experience of the unequal relationships that maintain their subject position. 
negation, and the instantiation of the deferred violence of the civilizing process. The negation in question is a double one: the victim's identity within the differential network is negated, but by the same gesture, the very existence of that identity - as it is experienced by its antagonists, if not by those who occupy it - threatens to negate the network itself ${ }^{103}$. If this seems excessively psychological, one must recall that relations of identity-difference are not merely symbolic or subjective. As I have mentioned in my discussion of Marx $^{104}$, relations of production can be understood as relations of identitydifference; class is not only a group affiliation but a material relation between labour and its products. Gender, race, sexuality, all involve material relations grounded in concrete bodies. Barbarous civilization intersects with all these and other forms of identity, organizing them in terms of relations to the means of violence. In so doing, civilization organizes material and practical interests. Under some circumstances, the nonteleological and non-linear movements of processes of barbarous civilization make genocide in the interests of those who have the impunity to carry it out.

At this point in my analysis I cannot identify what those circumstances are. Rather, I will now turn to a historical examination that applies the concept of 'civilizing genocides' to six empirical examples. Some of these examples are not usually considered to be genocides, and part of my task will be to justify why the actor-network of 'genocide' should be extended to include them. My examination of these examples will in no way be exhaustive. My aim will not be to produce case studies properly so called,

\footnotetext{
103 For example: the existence of the Cathar heresy was understood as a negation of orthodox Christianity by Pope Innocent III and his agents. 104 Chapter 3, Section 2.2.
} 
but to demonstrate the applicability and broader research potential of a figurational sociology of civilizing genocides. In the conclusion to this dissertation, I will explore this broader research potential, along with some of the implications that my analysis raises for anti-genocidal praxis. 


\section{Chapter V: Genocidal Civilization}

\section{INTRODUCTION}

\section{PRELIMINARY QUESTIONS}

Scribbled in a margin of my detailed research notes on the Rwandan genocide is this statement: "considering the number of 'variables' involved, it is as if everything on the scene contributed to the genocide". A causal analysis of the Rwandan holocaust would list as independent variables: the state, the domestic economy, the global economy, the international state system, the development industry, the civil war, the Arusha accords, the IMF, the international arms trade, European neocolonialism, demography, racialization, postcoloniality, and gender. This is perhaps not surprising, given the extraordinary extent and depth of popular participation in the genocide. Whereas the Nazi genocide was executed out of sight and out of mind of ordinary citizens of the Reich, and to some extent even of direct perpetrators, the opposite is true of its Rwandan successor: the killing was organized openly on national radio; it took place in cities and villages throughout the country; it was carried out face-to-face, usually with machetes; and so many ordinary Rwandans - hundreds of thousands - were either killers or directly complicit in killing, so that in Rwanda there were not only criminals in the state but "a criminal population" [Mamdani 2001: 7]. It makes sense intuitively that such a massive social event would require a broad array of contributing factors.

But the intensely overdetermined quality that is striking in the Rwandan example also applies to genocide taken as a whole. All genocides involve dividing practices that distinguish victims from non-victims, but the terms in which this distinction can be 
expressed appear inexhaustibly polymorphous: within the moral community have stood Christians, Muslims, beings with souls, human beings, civilized men, white men, Turks, Aryans, Communists, anti-Communists, and loyal patriots of all kinds; outside it have stood heretics, pagans, heathens, savages, witches, barbarians, animals, creatures without souls, black persons, Jews, Gypsies, homosexuals, Communists, counterrevolutionaries, and rebels, insurgents or traitors of all kinds. Accordingly, all the major features of European civilization are at one time or another implicated in genocide: Christianity, Islam, nationalism, imperialism, capitalism, socialism, bureaucracy, science, racism, and patriarchy, to name the most obvious. And no one of these factors is common even to all modern European genocides: in the implementation of the Shoah, racial identity was decisive, and language, religion, and ethnic custom were secondary or irrelevant; in the Turkish holocaust, language, religion, and ethnic custom were decisive, and discourses of race were secondary at most. This complexity helps to account for the problem of generalized uniqueness that I referred to earlier; uncovering the roots of one genocidal event does not necessarily expose the roots of others.

To overcome this problem I have used deconstructive theory to modify Norbert Elias's account of the civilizing process into a theory of barbarous civilization. In barbarous civilization, direct violence (physical force) and indirect violence (exclusion from social networks) seem to disappear from everyday life, but actually are only deferred. Social actors produce this deferral by practicing various techniques of personal comportment, techniques that are simultaneously of the body and of the mind, physical and meaningful. Paradigmatic of these techniques are those that Elias analyzes in terms 
of courtesy and civility. Civility can be understood as the solution each actor implements to the problem of her own vulnerability to, and dependence on, other people. In barbarous civilization, these dependencies and vulnerabilities are, as state formation proceeds, increasingly unified around the central figure of the sovereign. Taken as a whole, the figurational movement of practices of civility produces a system of identification and differentiation of social actors; it binds each actor into a network of interdependent relationships through which she is in various respects made the same as and different from every other actor she encounters. Under conditions of barbarous civilization, at least, the interdependencies in question are asymmetrical, so that the whole figuration is relentlessly hierarchical. The prospect of gaining or losing status in the hierarchy underpins the continual threat of violence which each subject must successfully defer by habitually civilized conduct. Breaches of civility constitute a failure of deferral and are occasions for violence, which can range from trivial sanctions to lethal force. This circulating system of differentiation and deferral can be termed 'violent différance', and under conditions of barbarous civilization violent différance is the matrix out of which individual identity is formed. Actors respond with violence to breaches of civilization not only because they gain advantage thereby, but also because the more civilized the subject is, the more that civilized behaviour is habitual and natural (or is inscribed into habitus), and because civilization provides the basis of the individual's social self.

In Elias's account, genocide appears as a breakdown of civilization because civility and interdependence no longer protect subjects from violence, which erupts into 
the demilitarized spaces of everyday life from which it is normally absent. In my deconstructive account, phenomena of breakdown are subsumed within an overall expansion of civilization that successful genocides produce. Barbarous civilization operates as a network of unequal interdependencies: in practical terms, relations of economic exploitation, political domination, symbolic privilege, and so on. Social networks or figurations that are not assimilated into a given civilizing process may constitute obstacles to its expansion. Genocide removes such obstacles by constructing a relation of active negation, in which the victims of genocide are assigned an identity/difference that makes them radically vulnerable to the deferred violence of civilization. If successful, this genocide produces various concrete benefits unequally distributed among individuals in the perpetrating figuration, and intensifies the operation of violent différance by intensifying the potential stakes of failures of deferral. I refer to genocides that are produced by civilizing processes as civilizing genocides, leaving open the possibility that even within barbarous civilization some genocides may be produced in other ways.

If this account suffers from a high level of generality, there are a couple of reasons for this. The first is that, to return to the question of overdetermination, I have tried to build a model of civilizing genocides that is flexible enough to include within itself a broad array of permutations of local conditioning factors specific to individual genocides. I hope that in the process I have not constructed an unfalsifiable metaphysics. In principle, genocides can be shown not to be civilizing genocides if they do not involve an expansion or intensification of relations of civilization. For example, a genocide that 
weakens, fragments, or disperses the differential network centred on the sovereign, would not fit my model of a civilizing genocide. In practical terms, this kind of genocide would produce a lessening of state power, a decentralization of the means of physical force, or a weakening of the force of unified normative standards of personal conduct (such as civility, or morality), a proliferation of competing standards rather than merely a substitution of one standard for another. Such an event, if it happened in social spaces previously affected by the civilizing process, might appropriately be called a decivilizing genocide. The factors that produce such an event would not be explained by my theory of barbarous civilization. Consequently, one important objective in this chapter is to show how each of the examples considered can be understood specifically as a civilizing genocide.

Another factor complicating my account of barbarous civilization is the problem of overcoming Elias's reliance on psychological concepts. One important feature of Elias's figurational theory of the civilizing process is that it shows how the same historical process can simultaneously produce particular collective social institutions and particular individual emotional habits. Indeed, habits and institutions are said to codetermine each other, so that to understand state-formation we must understand, for example, the operation of shame and embarrassment in court society. This tends to introduce a problematic psychologism into Elias's social theory. In Parsonian social theory, for example, institutions and emotions belong to two completely distinct spheres, the social system and the psychological system. Elias argues against the separation of the two, and especially against conceptualizing the individual subject as existing prior to and 
independently of social interaction (as homo clausus). A reader of The Civilizing Process may reasonably ask: Is Elias merely modifying the Parsonian scheme to show how the psychological and social systems are interpenetrating and codetermining? Or is he, so to speak, assimilating a large part of the psychological domain into the social by rendering subjectivity as an entirely relational phenomenon? The very terminology of 'sociogenesis' as opposed to 'psychogenesis', and Elias's heavy use of Freudian theory, suggests the former possibility. But his critique of egocentric theory in What is Sociology? suggests the latter, for there Elias rejects the notion of individual selfhood as belonging to a putatively interior space of the mind, affirming instead that it belongs to the relational space of social interaction.

In my rendering of barbarous civilization I have tried to build on the latter reading, treating shame (for example), or identity, as crucial to the dynamics of civilization. If my use of such concepts is not to be read as begging a recourse to psychology, then I should stress their sociological content. In What is Sociology? Elias sketches briefly a conception of the self as constituted through, as made up of, ongoing interactions with others. To borrow a term from Marx [1990: 138], Elias conceives of the self as socially objective. This conception illuminates his more psychological discussion of shame in The Civilizing Process [Elias 2000: 117, 414-415, 442-445]. Feelings of shame, Elias says, are brought on by various relational phenomena: the possibility of "social degradation", "other people's gestures of superiority", dangers from which one cannot defend oneself, the possibility of "loss of the love or respect of others" [Elias 2000: 415]. Feelings of shame involve the translation of attitudes others have towards 
oneself, into attitudes one takes towards oneself. In ordinary language, however, the noun "shame" has at least two distinct connotations that are relevant to Elias's discussion: a feeling, and a condition. One can feel shame, but one also can suffer shame, humiliation, or disgrace as a social event, irrespective of how one feels about it. In The Civilizing Process, Elias logocentrically privileges the emotion as that which needs explaining, but by the same gesture he makes the condition into what accounts for the emotion. We could say that the emotion is the subjective effect of the (socially) objective condition; in non-dualist terms, we can say that feelings of shame are the emotional accompaniment to the social event of losing status. And if we treat the self as socially objective, or just plain social, then we can understand shame as the effect of harm to the self, without any recourse to psychology.

Having said all that, shame makes comparatively few appearances in this chapter, which is concerned mostly with institutional phenomena: Christianity, imperialism, nationality, and, at all points, state formation. Still, the mechanisms of violent différance should be understood as implicitly referenced throughout my exposition. Civilizing genocide is not simply and mechanically produced by presence of material interests in its favour, nor even by the interaction of these interests with local rationalities like bureaucracy or development. Binding individual subjects to the pursuit of various interests and the realization of various rationalities is the continuous desperate struggle of différance. Under conditions of barbarous civilization, subjects commit genocide in order to be themselves in a certain way, to secure some particular form of self-existence that has come to entail the nonexistence of another. 


\section{OVERVIEW}

This chapter discusses six historical examples of civilizing genocides. These are: the extermination of the Cathars of Languedoc between 1208 and $1321 \mathrm{CE}$; violence against civilians during the Guatemalan Civil War between 1962 and 1996, focusing especially on the period 1980-1983; the near-extermination of the Aboriginal Tasmanians between 1800 and 1876; megafamines in India under British colonial occupation in the years 1876-1879 and 1896-1902; the destruction by massacre, forced assimilation, and deportation, of the Armenian presence in the Ottoman Empire in the years 1915-1916; and the Rwandan genocide of April-July 1994.

The chapter is divided, apart from this introduction, into three sections. Each section discusses a pair of examples juxtaposed because they have certain important features in common. The Languedoc and Guatemalan examples both concern the attempt to exterminate an ideological enemy hidden among the general population, and because similar techniques of inquisition were employed. The Tasmanian and Indian examples both concern genocide under British colonial rule, and both raise difficult questions about what counts as genocidal intent. Finally, the Ottoman and Rwandan examples both involve elimination of a minority group within an established nation-state under conditions of modernity, the archetypical form of genocide in the popular imagination. These last two examples also both raise the question of whether genocide is better understood as a breakdown of barbarous civilization than of its production, expansion, or intensification.

Each section is divided into three subsections. First (in subsections 1.1, 2.1, and 3.1) I provide a brief historical account of each of the examples discussed in the section. 
These accounts provide only a recounting of specific incidents: massacres, policy decisions, treaties, and so on, including dates and locations of these incidents, chronologically arranged to compose a narrative account of occurrences leading up to and comprising each example of civilizing genocide, plus some relevant general data (especially numbers of persons affected by various measures) where possible. The empirical information for each of these narratives is drawn from one or two sources that represent the best available summation of historical facts of the case. Where possible, in the examples of Guatemala and Rwanda, I have relied on the reports of human rights agencies, which provide detailed and meticulously documented information on practices of violence, including the specific agents involved, within a definite frame of reference. (These reports are also convenient to use because the present information in the most transparent possible format for use in accounts of the type I construct.) For the other cases I rely on works by historians that have been recognized as significant accomplishments in their field and that have either advanced previous historiography or have been the first major works to address the events in a way that facilitates my analyzing them as genocides. The exception to this is my discussion of Languedoc, which is both briefer than the other discussions and based on a wider range of sources.

In the second subsections $(1.2,2.2$, and 3.2) I discuss, for each example, why the term 'genocide' is applicable. This is in keeping with the argument I have presented, in Chapter 2 above, that a single formal definition of genocide is impracticable, that the term 'genocide' is better regarded as connoting a network of events connected by heterogeneous resemblances, and that the decision to call any particular event a genocide 
should be justified on an individual basis with reference to this network of similarities. Nevertheless, for each example, in addition to drawing broadly on the scholarship of genocide, I will consistently refer to two established definitions of 'genocide': the 1948 United Nations Convention on the Prevention and Punishment of the Crime of Genocide ('UNGC'), and Raphael Lemkin's formulation in Axis Rule in Occupied Europe, which is the first published use of the term. Neither of these definitions marks a point of origin from which all other uses are derived, since the appropriateness of both formulations is disputed by many who write about genocide, and Lemkin's earlier formulation is not even attended to by everyone. Still, they are probably the most widely recognized points of reference for debate over the meaning of 'genocide'. Taken together, they provide a surprisingly fertile textual base from which the permutations of 'genocide' can be explored.

In the set of third subsections (1.3, 2.3, and 3.3) I show how each of these genocides may be considered an example of a civilizing genocide. In particular, each genocide involves an assertion or intensification of the process of state-formation, and an extension of networks of social interdependence. In other words, each genocide involves an expansion of the social forces to which Elias attributes the pacification of everyday life. In each example, one or more important and enduring features of European civilization are shown to be implicated in or established through genocidal violence. The study of genocide illuminates our understanding of civilization, as much as vice versa. The result is not a set of definitive causal explanations of each event, but a suggestive 
account linking disparate events to a common structural process and indicating some of their conditions of possibility.

I will discuss the overall implications that this account of genocidal civilization has for further research, and for the politics of genocide prevention, in Chapter 6, the conclusion of this dissertation.

\section{Languedoc and Guatemala}

\subsection{INTRODUCTION}

In this section I will discuss the extermination of the Cathars of Languedoc between 1208 and $1321 \mathrm{CE}$, and violence against civilians in Guatemala during the civil war of 1962-1996. These events have several features in common: both are what Chalk and Jonassohn would call ideological genocides, those committed to implement a belief, a theory, or an ideology [Chalk and Jonassohn 1990: 29]. But in this respect both examples show the limitation of Chalk and Jonassohn's typological scheme, since they also demonstrably fit into the other three categories of that scheme: genocides conducted to eliminate a real or potential threat; those conducted to spread terror among real or potential enemies; and those conducted to acquire economic wealth. More appropriately, both genocides concern violence directed at elements within a civilian population, violence mobilized to deal with a target that lacks or can disguise any outward manifestations of difference and can hide among ordinary people. I have chosen these two examples also because they both involve the use of violence according to a common and striking pattern. Both the Inquisition in Languedoc and political terror in Guatemala involved the use of guilt by suspicion, the solicitation of denunciations, secret 
interrogations, the extensive use of torture, and a preoccupation with extracting confessions and the names of co-conspirators. The striking similarity of techniques used by different parties over a wide historical interval suggests the presence of a continuous element in the civilizing process that connect these two violent episodes.

My historical account, in Section 1.1.1 below, of the events in Languedoc is based primarily on Stephen O'Shea's [2000] thoroughly researched and unromantic history of the Cathars, supplemented by a variety of other sources. So far as I have been able to determine, none of the facts in question are controversial, and the interpretation of them is entirely my own. My account in Section 1.1.2 of violence in Guatemala during the civil war is drawn entirely from two reports issued by human rights organizations. The first of these is the Recovery of Historical Memory Project, produced by the Human Rights Office of the Roman Catholic Archdiocese of Guatemala. This report is based on three years of field work by the pastoral teams of eleven dioceses and countless laypersons, obtaining the personal testimony of thousands of subjects, including not only victims but perpetrators of violence. The report focuses on "the effects of violent ordeals, diverse forms of resistance, and the survivors' demands on government and society" as well as "the types of violence employed against the civilian population, the impact of militarization, and the mechanisms that made such atrocities possible" [REMHI 1999: xxxi]. The second source is the report of the Commission for Historical Clarification, which was established by agreement between the Government of the Republic of Guatemala and the Guatemalan National Revolutionary Unity at the Accord of Oslo on 23 June 1994 "in order to clarify with objectivity, equality and impartiality, the human 
rights violations and acts of violence connected with the armed confrontation that caused suffering among the Guatemalan people" [CEH 1999: 11]. The CEH received thousands of testimonies, accompanied survivors at the exhumation of the bodies of the disappeared, interviewed former heads of State and officials from the high command of both the Army and the guerrillas, and examined thousands of pages of documents received from nongovernmental organizations in Guatemalan civil society. It benefited from the REMHI report already having been made available, from the U.S. government's decision to release "roughly a thousand sensitive documents" [REMHI 1999: xxvi], had a budget of almost $\$ 10$ million, and received support from the United Nations and international NGOs. However, it was prohibited from individualizing responsibility, i.e. naming specific perpetrators.

Once again I remind the reader that this discussion is concerned only to provide illustrative examples showing how a theory of barbarous civilization can apply to the study of genocide, and not to provide case studies that offer a full and complete explanation of these events.

\subsection{HistoriES}

\subsubsection{LANGUEDOC}

The precise origins of Catharism are still obscure, but its dualist doctrines were influenced by the Bogomil heresy that emerged in Bulgaria in the tenth century [O'Shea 2000: 22-26; Barber 2000: 2, 12-21; Burl 2002: 9]. The Cathars were practitioners of a variety of Christianity fundamentally opposed to the Church of Rome in crucial matters of doctrine and ritual. Cathars were theological dualists who believed that the material 
world had not been created by the good God of the spirit and of light, but by an evil being of darkness who was either co-divine with the God of light, or a fallen angelic being [Barber 2000: 1; O'Shea 2000: 11]. The good God, who had never been materially incarnate as the Christ, who was totally unconcerned with all things material, and to whom all things material were equally corrupt. The teachings of the Roman Church with regard to sexual chastity, for example, or social relations with Muslims and Jews, were therefore irrelevant, as were all of its rituals and sacraments. For Cathars, the path to union with God was to renounce the material for a life of ascetic self-denial, through which a man or a woman could free themselves from the otherwise eternal cycle of reincarnation in the world. Entry onto this path was marked by the only Cathar sacrament, the consolamentum [O'Shea 2000: 23]. Persons who chose this path were called 'Good Men' or 'Good Women', while those who accepted Cathar doctrine without embarking on the path of material renunciation were called credentes (believers) [O'Shea 2000: 21]. The Cathars collectively called themselves 'good Christians'; the term 'Cathars', from Greek katharos meaning 'pure', was not used by the Cathars themselves and was a sneer coined by the German Monk Ekbert von Schönau in the twelfth century [Burl 2002: 9]. Likewise, those who had received the consolamentum were called the 'Perfect' by orthodox Christians, in the sense of perfect or complete heretics [O'Shea 2000: 21]. The Cathars had no ecclesiastical hierarchy and a minimal, decentralized institutional structure, and regarded the temporal wealth and power of the Church as a sign of its corruption. 
Catharism flourished primarily in the region of Languedoc, and also in parts of northern Italy. Before the Albigensian Crusades, Languedoc was entirely independent of the Frankish monarchy, although its rulers paid nominal homage to the suzerainty of the Capetian kings [Sumption 1978: 17-18; O'Shea 2001: 57]. It was, in fact, marked by the historical impact of the centrifugal breakup of the Holy Roman Empire that Elias discusses in The Civilizing Process. That centrifugal tendency had been somewhat reversed by the steady growth of the power of the county of Toulouse since the successes of Raymond IV in the eleventh century [Sumption 1978: 18]. However, the Albigensian Crusades completely overshadowed locally centripetal tendencies through the sudden and violent incorporation of Languedoc into the Kingdom of France. Before the devastation of the Crusades and the Inquisition, Languedoc was a "flourishing, cosmopolitan culture" [Chalk and Jonassohn 1990: 114]. The region was defined linguistically, literally as the area where Occitan was spoken. It was "a rich province" [Sumption 1978: 24] thanks to commercial trade on the Mediterranean, more urbanized than northern France [ibid.: 25]. It was also home to troubadour culture [O'Shea 2000: 19-20; Sumption 1978: 29-30], a fact which injects a degree of romanticism into most contemporary accounts of the Albigensian Crusades.

The extermination of the Cathars unfolded in two phases: first, through open warfare in the so-called Albigensian Crusade from 1208 to 1228; second, through the operations of the Inquisition from 1229 to 1321 . During the years leading up to 1208 , the lords of Languedoc, especially the Count of Toulouse, Raymond VI, were increasingly pressured by the Roman Church under Pope Innocent III to suppress heresy within their 
domains, which they persistently refrained from doing [O'Shea 2001: 53-54]. On 13 January 1208 , the Papal legate Peter of Castelnau was assassinated by a man who was believed to be in the employ of Raymond VI [O'Shea 2001: 66-68; Sumption 1978: 76; Wakefield 1974: 92-93]. Raymond's protestations of innocence notwithstanding, on 10 March 1208 the Pope called for a crusade to purge Languedoc of heretics and their supporters. In June-July of 1209 the crusading army assembled at Lyons and invaded the territory of Raymond Roger Trencavel, the viscount of Albi, Béziers, and Carcassonne [Barber 2000: 254]. On 22 July 1209, the most famous massacre of the war occurred when the crusading army unexpectedly gained entry to the city of Béziers and butchered its inhabitants indiscriminately before putting the city itself to the torch; between 15,000 and 20,000 men, women, and children were killed [O'Shea: 84-86; Wakefield 1974: 102]. In mid-August 1209 , the city of Carcassonne was occupied after a siege, its inhabitants forcibly evacuated, and the city resettled [O'Shea 2001: 100-1011; Wakefield 1974: 103]. In April 1210, about 100 surviving defenders of the city of Bram were mutilated by having their eyes gouged out and nose and upper lips cit off, and then delivered to Cabaret to intimidate the defenders there [O'Shea 2000: 106; see also Burl 2002: 173-174]. Other massacres occurred at Montgey in April 1211, where the forces of Raymond Roger surprised and slaughtered a group of several hundred crusaders and their noncombatant followers [Burl 2002: 92-93; O'Shea 2000: 135; Barber: 254]; at Muret on 12 September 1213 , where at least 7,000 of the routed civilian militia were butchered by the crusaders [O'Shea 2001: 142, 148-149]; and at Marmande in June 1219, where crusaders under Louis the crown prince of France methodically slaughtered "every man, 
woman, and child" in "a cold-blooded massacre that mystified even their supporters", about 7,000 persons in total [O’Shea 2000: 169; see also Wakefield 1974: 99]. Mass executions by fire took place at Minerve on 22 July 1210, of 140 Cathar Perfect [O'Shea 2000: 116; Barber: 256]; at Lavaur on 3 May 1211, of 300 to 400 Cathar Perfect [O'Shea 2000: 131; Barber: 256]; and at Les Cassès in May 1211, of 50 to 60 Cathar Perfect [Barber: 256]. In 1226 the Capetian King Louis VIII took over leadership the crusade. In the summer of 1228, a force raised by Blanche of Castille, widow of King Louis VIII, waged a devastating scorched-earth war on the countryside of Toulouse, destroying not only crops but villages, wells, and orchards. Count Raymond VII sued for peace, and in Paris on 12 April 1229 the Albigensian Crusade was formally ended [O'Shea 2000: 182187; Barber: 255]. The persecution of the Cathars was subsequently conducted without military resistance, except for a rebellion at Montségur in 1242, which was defeated after a long siege in March of 1244, after which, 200 Cathar Perfect were burned [O'Shea 2001: 213-219; Sumption 1976: 236-241].

The first inquisition after the Crusade was established at Toulouse by CardinalLegate Romanus of St. Angelo [Ruthven 1978: 90; Barber 2000: 144-145]. It had the authority to systematically search all homes, barns, caves, etc. that might serve as hiding places for Cathars. Anyone convicted of sheltering a Cathar would lose all their property; bailiffs negligent in the pursuit of heretics would lose their goods and posts; a register was made in each parish and all persons over fourteen years of age was made to swear an oath, an activity prohibited by Cathar doctrines. Heretics who recanted were resettled; those who did not, including even the infirm who sought the consolamentum on 
their deathbeds, were burned alive ${ }^{105}$ [Ruthven 1978: 90-91; Barber 2000: 145; O'Shea 2001: 191-193]. However, because many Cathars had strong ties to the local community, and because Inquisitors could be construed as seeking to destroy orthodox Christians for their own benefit, these measures met with considerable local opposition [Ruthven 1978: 90-91]. Once the military conquest of Languedoc was complete, therefore, the Church was confronted with the task of rooting out an invisible network of heretics with whom the local population covertly collaborated.

In the spring of 1233 , papally-appointed inquisitors were established at Toulouse, Albi, and Carcassonne [O'Shea 2001: x, 196]. As O'Shea points out, “they would have successors in different parts of Europe and Latin America for more than 600 years". In each district they visited, the Inquisitors began by encouraging anyone who wished to do so, to come forward confidentially and reveal any information that might incriminate anyone else as "a heretic, a defender of heretics, or in any way unusual or unconventional in his behaviour" [Ruthven 1978: 92]. Heretics themselves were given a grace period in which to recant their beliefs and denounce their co-religionaries, in exchange for lighter penalties. This tactic created a tremendous incentive to come forward, to confess and especially to denounce others. "In a community that had had frequent contact with heretics [...] nobody was likely to be innocent in the eyes of the Church, and therefore anybody could have been written into the inquisitors' copious records" [Barber 2000:

105 Over time, the inquisitors developed a wide array of punishments of varying severity. Given [1997: 67-71] notes that the register of Bernard Gui, inquisitor of Toulouse, contains 633 penalties, ranging from milder penalties such as penitential pilgrimages and the wearing of crosses sewn into one's clothing (a stigma that barred the wearer from any participation in public life), through imprisonments of varying severity and duration, to burning alive and even the burning of 
148]. Suspects under interrogation could not know how much information the inquisitors possessed; in some districts they could not even know who had denounced them [ibid.]. Interrogations were conducted under oath, which automatically rooted out the committed Perfect, and thus were directed at credentes and fautores (protectors). Although the testimony of two witnesses was sufficient for conviction, in practice the inquisitors preferred to obtain a confession [Given 1997: 54; Ruthven 1978: 92]. The emphasis of interrogations was not on heretical beliefs but on practices, participation in rituals, and especially on obtaining names of others complicit in heresy. When more clever credentes gave the names of dead persons to satisfy their interrogators, the inquisitors dug up corpses from cemeteries and burned them as if they were living heretics, disinherited their descendents, and burnt houses they had lived in without regard to the rights of the current inhabitants [O'Shea 2000: 199-200]. Popular repute and hearsay evidence counted heavily as evidence of guilt. Even casual social exchange between unwitting persons and persons who later turned out to be Cathars formed sufficient grounds for guilt. The overall effect was to "attack any form of intercourse between the heretics and the Catholic population" [Ruthven 1978: 93].

Torture was formally added to the arsenal of inquisitorial techniques in 1252 [Ruthven 1978: 94; O'Shea 2000: 229]. Even before this development, inquisitors could use a variety of coercive measures: "prolonged solitary confinement in dark, festering cells, a starvation diet, the use of 'stool-pigeons' (fellow prisoners posing as heretic sympathizers)" as well as "the torture of delay", the drawing-out of legal proceedings for 
months or years [Ruthven 1978: 94], although these techniques were not applied to all prisoners [Given 1997: 62]. Even once they were formally permitted, the more direct forms of torture and execution were practiced only by secular authorities working on behalf of the inquisitors [Burl 2002: 213]. Torture began with the act of displaying the implements of torture to the suspect, followed by removal of clothing, followed by the torture itself: by stretching of the spine on the rack, dislocation of the shoulders on the strappado, burning of feet, immersion in water, "anything that hurt as long as bones were not broken and blood was not drawn", and always stopping just short of death.

At its peak the Inquisition was "a proficient bureaucracy employing hundreds and interrogating thousands" [O'Shea 2000: 225]. The inquisition at Toulouse "had more or less completed its work" in 1271 and in 1279 "it unofficially suspended its activities"; after this time, the main victims of the Albi and Carcassonne tribunals were political opponents of the Inquisition itself [Sumption 1978: 242]. Its success was briefly reversed by a revival led in 1300 by Peter Autier, aided by his brother William [O'Shea 2000: 233-238]. In villages in the hills of the Sabartès near Foix, the Autier brothers gathered about a dozen collaborators and succeeded in winning about 1,000 households back to Catharism. The revival faltered in 1305 with the betrayal and capture of two Perfect, and by 1310 all the leaders of the revival, including Peter Autier himself, had been captured and burned. The last Cathar Perfect in Languedoc, William Bélibaste, was captured in the spring or summer of 1321 and executed in the autumn of that year [Burl 2002: 231; O'Shea 2000: 245-246]. 


\subsubsection{GUATEMALA}

The Guatemalan civil war began with the formation of the Rebel Armed Forces (Fuerzas Armadas Rebeldes, FAR) in December 1962 [CEH 1999: 71; REMHI 1999: 193] and ended with the signing of the Accord for Firm and Lasting Peace in December 1996 [CEH 1999: 77; REMHI 1999: 284]. It was preceded by the overthrow of the elected social-democratic government of Jacobo Arbenz by "U.S.-supported and directed forces" [LaFeber 1993: 113; see also Blum: 73-83]. This coup ended the period of the October Revolution (1944-1954) during which Guatemala was characterized by greater political democracy and a greater movement towards economic equality than at any previous time since colonization [REMHI 1999: 184-187]. The civil war that began eight years after the coup was in part an expression of Cold War geopolitics: insurgent forces received "political, logistic, instructional and training support from Cuba" [CEH 1999: 20], and the Guatemalan state received direct financial and military assistance from the United States, directed especially at supporting intelligence and counterinsurgency forces [CEH 1999: 19], which was rationalized at least partly in terms of preventing the spread of Cuban-inspired Marxist revolution to mainland Latin America. Anti-communist discourse was promoted in Guatemala by the U.S. state and by private American intellectuals. As part of its counterinsurgency policy, the Guatemalan state undertook the militarization of daily life for ordinary civilians through the formation of Civilian SelfDefense Patrols (PACs) in rural communities; participation was obligatory and the PACs were directly controlled by the Army [REMHI 1999: 45-46; 115-125]. In the course of the civil war, members of the PACs were forced to participate in killing, rape, torture, and mutilation of corpses [CEH 1999: 27]. 
Between 1962 and 1996, an estimated over 200,000 noncombatant persons were killed or disappeared [CEH 1999: 17]. Human rights violations ranging from direct killing, disappearance, torture, rape, and assault, to irregular detention and threats against individuals, were committed throughout the war [REMHI 1999: 302], mostly by government forces, including the army and paramilitaries allied with the army, but also by insurgent forces and by private individuals [REMHI 1999: 304-305]. Prominent in this latter category were large landowners, acting either in concert with agents of the state for counterinsurgency purposes or independently in their own direct self-interest [CEH 1999: 44]. The CEH concludes that the responsibility for $93 \%$ of documented human rights violations rests with the state "including in this category the Army, security forces, Civil Patrols, military commissioners and death squads", and that responsibility for $3 \%$ of violations rests with guerrilla forces, and $4 \%$ with "other unidentified armed groups, civilian elements and other public officials" [CEH 1999: 86]. The vast majority of abuses were committed during the period 1980-1983 [REMHI 1999: 302] under three governments: the latter part of the elected tenure of General Romeo Lucas García; the military junta of General Efraín Ríos Montt, General Horacio Egberto Maldonado Schaad, and Colonel Francisco Luis Gordillo Martínez; and the de facto presidency of General Ríos Montt. This same period also witnessed the large majority of massacres, defined as "collective murders distinguished by myriad factors and diverse patterns of human rights violation (extreme cruelty, rape, torture, forced disappearances, and so forth)" [REMHI 1999: 303]. 
Violence was directed widely throughout Guatemalan society in the name of anticommunism and the National Security Doctrine. The definition of 'communist' and of derivative categories such as 'subversive' and 'the internal enemy' expanded readily to include "political activists, students, trade unionists, and human rights advocates", as well as "political and social leaders", who were subjected to kidnapping, murder, and forced disappearances $^{106}$ [CEH 1999: 20, 34]. Murder, forced disappearance, and torture was used so broadly as to decapitate systematically all elements of Guatemalan civil society not strongly allied with the state. Even soldiers themselves were targeted by their fellows if they were seen to lack dedication to the task of suppressing subversion.

One quarter of "direct victims of human rights violations and acts of violence" were women; women were killed, tortured, raped, either for their own actions or in "massacres and other indiscriminate actions" [CEH 1999: 23], and were left widows and single parents through the killing or forced disappearance of their husbands. Women also took a leadership role in struggles for human rights, notably through new organizations such as the Association of Families of the Disappeared and Detained of Guatemala [REHMI 1999: 85]

The largest single category of victims was Mayan Guatemalans. The CEH reports that $83.33 \%$ of identified victims of human rights violations and acts of violence were Mayan [CEH 1999: 85]. During the period 1978-1983, the Army identified the Mayans as natural allies of the insurgents, and the state used this identification in combination

106 The mutability of categories like 'communist' is noteworthy. CEH notes that up to the 1950s, the Catholic Church "qualified as communist any position that contradicted its philosophy" [CEH 1999: 20]. 
with racism to authorize "massive and indiscriminate aggression directed against communities ... massacres, scorched earth operations, forced disappearances and executions of Mayan authorities, leaders and spiritual guides", actions which "were not only an attempt to destroy the social base of the guerillas, but above all, to destroy the cultural values that ensured cohesion and collective action in Mayan communities" [CEH 1999: 23]. Violence was directed against Mayan religion, language, cultural practices, and traditional authorities [REMHI 1999: 46-49]. Massacres committed as part of the scorched-earth policy in the early 1980 s resulted in the "complete extermination of many Mayan communities, along with their homes, cattle, crops and other elements essential to survival" [CEH 1999: 34]. The Army also systematically attacked children and pregnant women through direct and indirect killing, assault, and rape (especially of young girls) [REMHI 29-34]. "In the testimonies gathered by REMHI, soldiers or patrollers frequently refer to the killing of children as a way of eliminating the possibility of rebuilding the community and of circumventing the victims' efforts to attain justice" [REMHI 1999: 31].

\subsection{GeNOCIDE}

With regard to the events in Languedoc, the UNGC would seem to (retroactively) apply in a direct and straightforward manner: the agents and allies of the Catholic Church committed, avowedly "with intent to destroy, in whole" a "religious group", "as such", acts of killing (Article II.a), causing serious bodily and mental harm (Article II.b), and (during sieges) deliberate infliction of destructive conditions of life (Article II.c). The Church wished to destroy a religious group as such, acted accordingly, and succeeded. 
Likewise, regarding the events in Guatemala, the CEH report "concludes that agents of the State of Guatemala, within the framework of counterinsurgency operations carried out between 1981 and 1983, committed acts of genocide against groups of Mayan people", acts that satisfy articles II.a, II.b, and II.c of the UNGC, and that these acts "were committed with intent to destroy, in whole or in part, groups identified by their common ethnicity, by reason thereof, whatever the cause, motive or final objective of these acts may have been" [CEH 1999: 41]. This distinction between intent and motive is consistent with established legal practice that understands intent in terms of the foreseeable consequences of actions, and not in terms of the ultimate aim towards which the actions are directed [Marchak 2003: 21].

Accordingly, it may not seem necessary to discuss further why these events count as examples of genocide. However, the UNGC is neither an unproblematic nor a universally accepted definition of 'genocide'. Starting from the observation that these examples satisfy the terms of the UNGC allows us to unravel some of the problems and complexities endemic to the wider debates around the proper use of the term 'genocide'.

\subsubsection{LANGUEDOC}

To begin with, the extermination of the Cathars was as much informed by political considerations as religious ones. Catharism did more than simply contradict orthodox Catholic theology; it presented a symbolic and practical challenge to the Church's location within relations of state sovereignty and economic appropriation. Including the extermination of the Cathars among instances of genocide therefore speaks 
to the fraught issue of whether extermination of political and social groups per se should count as genocide.

Applying Raphael Lemkin's formulation of 'genocide' brings this issue out clearly. Moses $[2002,2004]$ has shown convincingly that the concept of genocide set out in Axis Rule in Occupied Europe is oriented towards the preservation of specifically national groups. Lemkin states that genocide unfolds in two phases: the destruction of the national pattern of the victim group, and the imposition of the national pattern of the victor, either on the denationalized population or in a territory emptied of members of the victim group [Lemkin 1944: 79]. Moreover, he argues that the criminalization of genocide

is quite natural, when we conceive that nations are essential elements of the world community. [...] Essentially the idea of a nation signifies constructive cooperation and original contributions, based upon genuine traditions, genuine culture, and a well-developed national psychology. The destruction of a nation, therefore, results in the loss of its future contributions to the world. Moreover, such a destruction offends our feelings of morality and justice in much the same way as does the criminal killing of a human being: the crime in the one case as in the other is murder, though on a vastly greater scale. [Lemkin 1944: 91]

Lemkin's comments equating genocide with murder can be taken to indicate only that genocide involves mass murder, but in conjunction with his claim that nations are essential elements of the world community and that they are based on genuine culture and a national psychology, they can also be taken to mean that genocide is the murder of a collective subject, which is the nation. Inclusion of religious groups among the protected groups in Article II of the UNGC can accordingly be understood in terms of the 
Lemkinian mission of protecting nations, given that religion is often an important index of nationality.

This raises problems for treating the Languedoc example as a genocide: the Cathars were a distinct religious group but were not by any means a national group. Though concentrated in Languedoc they were not particular to that region or dominant within it. Rather, Catharism operated as a widely tolerated and influential social movement within the Occitan cultural sphere, which itself was not unified enough to constitute a national identity. With respect specifically to the question of nationality, the extermination of the Cathars as such resembles the destruction of a social or political group more than the murder of a nationality. So including the extermination of the Cathars in the category of 'genocide' strains or straddles the boundaries of that category, falling within it in some respects and outside it in others.

The destruction of social or political groups was deliberately not defined as genocidal either by Lemkin or by the UNGC. Its inclusion was proposed during the drafting process, but was not favoured by Lemkin himself [Lippman 1985: 11] and was in any event opposed by the USSR, among others, for the obvious reason that actions in its own recent past would meet such a definition. The exclusion of political groups from the definition of genocide is hotly contested among genocide scholars. Kuper argues at length against this exclusion [1981: 24-30]. Several authors have proposed their own expanded definitions that specifically include political groups among the possible victims: Churchill [1998: 432], Katz (surprisingly) [1994: 131], and Porter [1982: 12]. Chalk and Jonassohn take a slightly different approach by defining genocide in terms of 
intent to destroy "a group, as that group and membership in it are defined by the perpetrator" [Chalk and Jonassohn 1990: 23; Chalk 1994: 52; Jonassohn 1998: 10], and a similar approach is taken in the definitions proposed by Fein [1984: 4], Thompson and Quets [1990: 248], and Charny [1994: 75]. Harff and Gurr instead propose the separate concept of 'politicide' [Harff and Gurr 1988: 360], and Rummel [1994: 31] does the same. For Harff and Gurr, 'genocide' and 'politicide' are separate categories with no master category; for Rummel, they are separate sub-categories of the master category 'democide'; for Marchak [2003: 3] they are separate sub-categories of the master category 'crimes against humanity'.

This latter set of definitions reveals an interesting feature of the definitional problem. Harff and Gurr say that "in genocides the victimized groups are defined primarily in terms of their communal characteristics, i.e., ethnicity, religion, or nationality. In politicides the victim groups are defined primarily in terms of their hierarchical position or political opposition to the regime" [Harff and Gurr 1988: 360]. In the instance of the Cathars, however, as for other heretical groups, their communal characteristics and their opposition to the Church's hegemony were inseparable. The particular system of beliefs and practices that bound them together as a communality necessarily implied political opposition to the Church's claim to totality as well as to its de facto temporal power. Given the totalizing ambitions of the Church, any communality organized on principles other than its own constituted a political opposition.

Rummel, on the other hand, says that genocide is "among other things, the killing of people by a government because of their indelible group membership (race, ethnicity, 
religion, language)" and that politicide is "the murder of any person or people by a government because of their politics or for political purposes" [Rummel 1994: 31]. This distinction assumes that some forms of identity, those associated with nationality, are necessarily more indelible than others, that nationality is natural. This assumption is not necessary to Rummel's text, only invited by it. But if we don't read this assumption into Rummel's text then his list of indelible forms of identity is arbitrary. In the example of the Cathars, the doctrines and practices made up their indelible group identity were also what put them in political opposition to the Church.

In sum, the example of the Cathars shows the instability of attempts to define genocide narrowly in terms of nationality: either such attempts arbitrarily privilege nationality over other forms of collective identity, or they assert an equally arbitrary separation between relations of collective identity and relations of politics - that is, a separation between social relations and power relations.

\subsubsection{GUATEMALA}

The accusation of genocide made by the Comisión para el Esclarecimiento Histórico is limited to actions taken by the Guatemalan state against Mayan Guatemalans during the period 1981 to 1983 . The reasons for the CEH taking this position are clear: it is seeks to obtain justice for Guatemalan victims of violence, and to obtain justice it is useful to appeal to the narrow terms of existing law. For persons committed to antigenocidal praxis, the CEH report represents an important political accomplishment. However, to take it as the last word on the subject would involve commitment to a number of limiting assertions: that genocide against Mayans happened only within the 
time and space examined, and only in the context of the civil war, that the genocide happened only to Mayans, and that only the Guatemalan state is responsible. ${ }^{107}$ This set of limiting assertions is problematic.

First, the limiting assertions that result from taking the CEH report as final would imply that the situation with respect to indigenous Guatemalans was non-genocidal outside the frame of the 1981-1983 counterinsurgency. At first glance this is a plausible position: we might say that Guatemalans were subjected to racism, second-class citizenship, oppression, and so on, but not specifically to genocide. This position would seem to be supported by the fact that persons of indigenous descent form the majority of the population in Guatemala.

Stannard takes a different view, one in which the specific violence of the civil war is symptomatic of a broader genocidal process. Writing while the civil war was still ongoing, he states:

In Guatemala, where Indians constitute about 60 percent of the population - as elsewhere in Central and South America - the modern requerimento calls upon native peoples either to accept governmental expropriation of their lands and consignment of their families to forced labour under criollo and ladino overlords, or be subjected to the violence of military death squads. [Stannard 1992: 258]

This polemical statement places the specific violence of counterinsurgency in the context of the long-term effacement of indigenous social and cultural life, and relates it to the murderous violence of the first Spanish conquest of the Yucatan. When the Spanish conquistadors first arrived in Mesoamerica, they exterminated by direct massacre,

107 The $\mathrm{CEH}$ report finds that insurgents and third parties are responsible for serious human rights violations, but not for genocide. 
pillage, vandalism, and enslavement, the large part of whatever native populations had survived the wave of diseases that they had unwittingly brought and that came before them [Stannard 1992: 69, 78,-82, 86]. Alvarado alone claimed, with his brothers and followers, to have killed "more than four or five million people in fifteen or sixteen years, from the year 1525 until 1540" [Las Casas, quoted in Stannard 1992: 18]. This slaughter appears to have been accompanied by extreme cruelty: for example, reports indicate killing by slow dismemberment, or by having people, including children and infants, torn apart by dogs specially trained for the task [Stannard 1992: 71-72, 83-84]. Stannard's contention is that the holocaustic violence of this initial encounter marks the start of a continuous history of genocide in which Guatemalan Mayans, like other surviving indigenous groups throughout the Americas, are subjected to ongoing pressures towards cultural extinction, including continuous structural violence and, at times, overt physical force.

This position is supported by Lemkin's conception of genocide, which treats genocide as involving an ensemble of measures intended to destroy the national pattern of the victim group, including: the destruction of local institutions of self-government, law, and judiciary, and imposing the victor's pattern of administration in place of these; destruction of any bases of economic existence independent of the victor; suppression of the victim group's cultural activities and artistic expression; and removal of the intelligentsia and retention of only the labouring and peasant classes [Lemkin 1944: 8286]. All of these measures have been applied to Mayans in the context of colonization and state-formation in Guatemala. Conquest itself and the imposition of colonial rule 
directly implied the abolition of Mayan political and legal institutions. After colonization, the encomienda system entitled Spanish overlords to control not only of the land but of the labour of the native persons living on it; in combination with the repartimiento system of forced labour and the Catholic Church's project of reducción by which scattered Mayans were sought out and brought into the towns, Mayans were alienated from the lands they had occupied, which had religious and cultural significance to them, and forcibly integrated into the colonial social and economic system as racialized subjects and as an unskilled labour force [Handy 1984: 22-23; Loucky 2001: 158]. Conversion to Christianity was enforced, "often ruthlessly", by Dominican priests, and attempts by the church to stamp out the pagan beliefs of the Mayans were ongoing throughout the colonial period [Handy 1984: 27-29; Loucky 2001: 158]. Appropriation of Mayan lands continued through the liberal reforms of the post-colonial nineteenth century and up to the present era, such that in Guatemala $65 \%$ of land is owned by $1 \%$ of the population, and $40 \%$ of the rural population is landless [Loucky 2001: 159]. Mayans in Guatemala have continuously been subject to the damaging conditions of life resulting from severe poverty, recently exacerbated by ecological degradation stimulated by reliance on smaller and smaller landholdings [Loucky 2001: 153-161]. In this historical context, the violence of the early 1980s appears as a sharp intensification of a genocidal figuration whose virulence waxes and wanes over time, rather than as a break with a non-genocidal normal situation.

The second problematic implication of treating the CEH findings as conclusive is that doing so would imply that only Mayan Guatemalans were victims of genocide, and 
that other political violence and human rights violations were not specifically genocidal. I propose instead that genocide of Mayans overlapped with a second Guatemalan genocide. The CEH states that "from 1978 to 1982 citizens from broad sectors of society participated in growing social mobilization and political opposition to the continuity of the country's established order", and that "faced with widespread political, socioeconomic and cultural opposition, the State resorted to military operations directed towards the physical annihilation or absolute intimidation of this opposition" [CEH 1999: 22]. This opposition was in itself composed of diverse elements which were not all in league with one another; it included "political activists, students, trade unionists and human rights advocates [...] political and social leaders and poor peasants", of varying political affiliations, "democratic or otherwise, pacifist or guerilla, legal or illegal, communist or noncommunist" [CEH 1999: 34, 22]. The CEH argues that the Guatemalan state used the concepts of "internal enemy" and "subversives" to treat these diverse opponents as a unified whole; the corollary of this is that the terms "internal enemy" and "subversive" designate a collective identity constructed by the Guatemalan state and assigned to otherwise disparate elements within its territorial domain. We can infer that this identity was subjected to active negation, in the sense I discuss in Chapter 5 above. For example, the CEH notes that throughout the civil war, the state responded to the formation of human rights groups with the "elimination of their leaders", and that in the 1980s the appearance of new groups was met with "the murder or disappearance of many of their members". If we allow that genocide may be directed against a political or social group, and that subversives/internal enemies represented one such group, then the 
actions of the Guatemalan state against this group seem clearly to count as "physical debilitation and even annihilation" [Lemkin 1944: 87] and to meet the terms of Article II of the UNGC.

Two conceptual objections may be made to this inference. The first is that even if we understand the term 'subversives' to designate a coherent social group, this is not a specifically national group. and is therefore not included in Lemkin's conception of genocide. The arguments in response to this objection are the same as those I have made with respect to the Cathars.

The second and more serious objection is that, in contrast to Cathars in Languedoc, subversives in Guatemala did not self-consciously form a coherent group, nor did they even necessarily consider themselves to be subversives at all. In this respect, it is tempting to treat subversives as an imaginary group or a phantom identity. However, several considerations mitigate against such a conclusion. First, in many genocides the perpetrator's definition of the victim group is at least partially at odds with the victims' self-perceptions. Famously, the Third Reich defined Jewishness according to racial laws that in principle took no account of whether an individual practiced the Jewish faith, was part of a Jewish community, considered themselves Jewish or was considered Jewish by others [Bauer 1990: 249]. This slippage is even more dramatic in the case of the genocide in Cambodia. One official target of persecution was the rural bourgeoisie, but in conventional Marxist terms the rural bourgeoisie in Cambodia was in fact very small, so that actual victims of the genocide were usually not at all bourgeois in terms of their relations to the means of production [Chalk and Jonassohn 1990: 399-402]. Again 
famously, the category of 'intellectual' was similarly elastic to the extent that wearing glasses qualified one as an intellectual to the genocidaires. Regardless of the spurious basis of these classifications, they attained the status of social realities when they were used systematically to inflict violence on concrete individuals. Once categorized as a subversive, an individual was slated for violence whether they knew it or not - and often they had no warning. Through the use of violence, the Guatemalan state established the subversive as a tangible social identity, if a contested one. Several definitions of 'genocide', including those proposed by Chalk and Jonassohn, Fein, Thompson and Quets, and Charny (see page 274 above), recognize this process by treating the perpetrator's definition of the victim group as decisive (although this position also has problems of its own). ${ }^{108}$

A third problem arising from treating the findings of the $\mathrm{CEH}$ as final concerns the territorial scope of genocide and the responsibility for it. The CEH discusses genocide perpetrated by the Guatemalan state within Guatemala. However, violence in Guatemala must also be situated in the context of political violence throughout the region. Walter La Feber notes that the period 1979-1991 was "the bloodiest, most violent, and most destructive era in Central America's post-1820 history" and conservatively estimates that the minimum number of dead and disappeared during this period is 200,000: 40,000 in Nicaragua, 75,000 in El Salvador, 75, 000 in Guatemala, and 
10,000 in Honduras ${ }^{109}$ [LaFeber 1993: 362]. In all of these instances, violence was directed not only at soldiers of opposing armies but at civilians not directly involved in armed struggle. Mass murder of civilians does not in itself constitute genocide, but it does indicate the possibility of genocide. Lemkin states that "genocide is the antithesis of the Rousseau-Portalis Doctrine, which [...] holds that war is directed against sovereigns and armies, not against subjects and civilians" [Lemkin 1944: 80]. Given the systematic transgression of this doctrine throughout Central America, it is worthwhile to consider whether the events in Guatemala form part of a genocidal figuration that extends throughout the region.

One possible candidate for such a figuration would be American neo-imperialism, and specifically discourses of anti-communism that operate in patronage relations between the U.S. and client states or forces ${ }^{110}$ that commit severe human rights abuses. Because U.S. neo-imperialism in Latin America has not been examined in terms of 'genocide' rigorously conceptualized (at least by authors writing in English), I can only pose the notion of genocidal anti-communism as a speculative hypothesis for which some suggestive supporting evidence exists. In this hypothesis, the social category of 'communist' has been placed outside the universe of obligation by decision-makers in the U.S. state with the power to influence other state's human rights practices, such that murder and other violence against civilians by client states or client forces raises no

\footnotetext{
109 This is probably a low figure. The CEH estimates 200,000 persons killed or disappeared in Guatemala alone for the period 1962-1996, the majority of these occurring in the early 1980s (see p. 269 above).

110 In Central America, client states of the U.S. in the 1980s included Guatemala, El Salvador, Honduras, and Costa Rica, and client forces included the Contra insurgents operating to overthrow
} 
moral objection, or is actively encouraged, so long as it is organized in terms of the constructed social identity of 'communists'; or, more strongly, negation of communism as a (perceived) political force is pursued by sponsoring the destruction, partly through physical violence, of (perceived) communists as a social group. Chomsky and Herman, for example, have discussed the effectivity of nominal anticommunism in negating concerns about human rights violations by client states of the U.S. For example, American support for the 1954 coup that overthrew the Arbenz government and ended the October revolution was justified in anticommunist terms [Chomsky and Herman 1979: 274]. Anticommunist discourse interprets domestic and international politics in terms of a life-or-death struggle, waged over the American form of government and the American way of life, in which there can be no moral community between America and its enemies. For example, a statement by the former head of the U.S. Chamber of Commerce in Guatemala, Fred Sherwood, being interviewed in 1982 for CBS News by Ed Rabel, expresses the ethos or spirit of genocidal anti-communism. Asked about the assassination of political leaders in Guatemala, Sherwood stated:

No, I think that's probably exaggerated to a great extent. There were a couple of politicians assassinated a couple of years ago, but believe me, they were way out in left field and well, these people are, I think, our enemies. They're - they're against our - our way of life. And maybe assassination is not the right word for it, but I don't think they should be continue allowed (sic) to run free to try to destroy our form of government, our way of life in other words. [Sherwood, quoted in Fuentes and Ehrenreich 1984: 43]

the Nicaraguan government. All of these except the Costa Rican state committed serious and systematic human rights violations. 
In effect, Sherwood expresses approval for "the calculated murder of a segment or all of a group defined outside the universe of obligation of the perpetrator by a government, elite, staff or crowd representing the perpetrator in response to a crisis or opportunity perceived to be caused by or impeded by the victim", which is, of course, one definition of genocide [Fein 1984: 4]. This kind of evidence is suggestive. U.S. complicity in mass political violence in Central America throughout the Cold War and especially in the 1980s has been abundantly discussed, and the use of anticommunist rhetoric by Presidents and other public officials to legitimate that complicity is abundantly evident ${ }^{111}$. This conjunction may reflect a practical connection, in which the constructed identity of 'communist' operated for U.S. policymakers in the same way that the constructed identity of 'subversive' acted for their Guatemalan clients, as an object of active negation. A conclusive demonstration of this connection is beyond the present scope of my discussion, but the question is promising enough to warrant further research.

If all of the above claims are accepted, including the last, then the specific genocide of Mayan Guatemalans during the period 1981-1983 would be situated at the intersection of three other genocidal figurations with greater scope: the 500-yeear genocide of Mayans by Spanish colonizers and the post-colonial Ladino-dominated state-

111 Douglas V. Porpora [1990], for example, notes several specific instances in which anticommunism was used in the context of important policy decisions of the U.S. with respect to Central American nation-states: to legitimate the U.S.-sponsored overthrow of the Arbenz government in Guatemala [84-85]; to delegitimate the formation of the Revolutionary Democratic Front (FDR) political opposition movement in El Salvador in 1980 [92, 95]; to legitimate the outcome of the 1982 and 1984 elections in El Salvador [100-101, 159]; and to de-legitimate the Sandinista government in Nicaragua in the 1980s [108-109, 161-163, 168]. Porpora argues that the U.S. is complicit in the various genocides committed by the Guatemalan and El Salvadoran governments and by the Contra forces in Nicaragua, and that all of these taken together constitute a single Holocaust-like event. However, this argument does quite add up to the claim that this Holocaust-like event constitutes a single genocide perpetrated by the U.S. 
formation process; the genocide of the constructed identity of 'insurgents' or 'internal enemies' conducted by the Guatemalan state in response to social challenges to its legitimacy during the civil war; and the regional or possibly continental influence of genocidal anticommunism within American neo-imperialism. These claims are difficult to accept, in that they suggest a broadening of the conception of 'genocide' and hence a possible lessening of the moral opprobrium it conveys. They also involve a broadening of the temporal scope of genocide, in keeping with the requirements of non-egocentric thinking. If a set of processes implemented in a three-year period or a ten-year period would be recognizable as genocide, it is egocentric to affirm that the same processes implemented over a 500-year scale could not also amount to genocide. They further involve a broadening of the geographical scope by affirming that a genocide can unfold simultaneously in several nation-states and be implemented by several agents whose actions are not always co-ordinated. This extrapolates to an international scale the pattern of many settler genocides against indigenous peoples, which are often effected by a variety of agents over a dispersed geographical area, acting in shifting relations of coordination and conflict with one another. Understanding a local episode of genocide in terms of larger genocidal figurations provides a fuller explanation than does treating each local event in isolation. Doing this also brings out the relevance of local genocides to transnational and global social processes. 


\subsection{Civilizing Genocide}

\subsubsection{LANGUEDOC}

A defining aspect of the civilizing process is the formation of territorially sovereign nation-states. Elias's historical account of this process opens with France of the twelfth century $\mathrm{CE}$, in which the centrifugal breakup of the territorial monopolization of military force established by the Holy Roman Empire began to reverse itself. The centripetal accretion of military power in this period marked the beginning of a process that would eventually produce territorially sovereign nation-states. This state formation process is doubly important: it not only served as a material precondition for the cultural accomplishments that would define European civilization, but also entailed a gradual progressive transformation of the subjectivities of members of the warrior class, towards the particular forms of habitual self-regulation conveyed by the term 'civilized behaviour'. How did the extermination of the Cathars figure in this civilizing process?

Elias mentions the conquest of Languedoc only in passing, in the context of his discussion of the territorial accretion through which the non-contiguous holdings of the Capetian house morphed into the integrated territory of France. Elias notes that this transformation was not specifically planned or foreseen by those who brought it about, and that even Philip Augustus "did not yet have 'France' in our sense in view". What Philip Augustus aimed at was "the territorial, military, and economic expansion of his family power and the subjugation of its most dangerous competitors, the Plantagenets" [Elias 2000: 285]. Following Philip Augustus's success in achieving these goals, his 
successors simply carried the process further. The holocaust in Languedoc was part of this process:

“Louis VIII, Philip Augustus' son, secured this region [Poitou] afresh for his own dominion, as he did Saintonge, Anis and Languedoc, part of Picardy and the county of Perche. Partly in the form of a religious war, the struggle against the Albigensian heretics, the Capetian house began to advance south into the sphere of the only great territorial lord in that part who could, beside the Plantagenets, rival the power of the Capetians, the domain of the counts of Toulouse. [Elias 2000: 286]

This brief discussion locates the Albigensian Crusades firmly within the state-formation process that partially defines civilization. But more could be said.

For one thing, a centripetal accretion of power was already taking place in Languedoc before the Crusaders made their appearance ${ }^{112}$. In Eliasian terms, stateformation was already incipient in Languedoc. Moreover, the importance of troubadours in Occitan society suggests that another aspect of civilization was already well underway: the constraint to self-restraint imposed on otherwise habitually violent knights by the codes of courtoisie. Elias discusses in detail the relationship between the civilizing process and the music of the troubadours or Minnesänger [Elias 2000: 236-256]. Not only did courts provide the economic basis of support for the Minnesänger themselves, and not only were the knightly or noble Minnesänger drawn mainly from the ranks of the knights with little or no land who placed themselves in the service of greater ones, but the social relations at court provided the lyrical content of the minstrels' songs. Partly these

112 Sumption [1978: 30-31] states otherwise. Noting the continuing subdivision of property that had deprived the troubadours of many of their patrons, Sumption claims that "what the crusaders encountered in Languedoc was a society in an advanced stage of disintegration which still clung to the husk of a civilization that had all but disappeared". However, this claim ignores what Sumption himself mentions earlier in his account: the ongoing success of the counts of Toulouse in accreting power to themselves [Sumption 1978: 18]. 
were political homage to the singer's patron [245]. But another major, and famous, staple for the Minnesänger was the love song, the song expressing tender affection and unconsummated yearning towards an idealized beloved. The emergence of this type of song was enabled by two effects of court society: the relative inhibition on the use of violence against women, which gave women a relatively greater degree of freedom and power in court society than they could enjoy outside it [246-249], at least within the warrior class, and the consequent situation in which a male knight might find that the woman he desires is his social superior, a situation that required him to restrain his desires in an unaccustomed way [249-250, 255-256]. In these two aspects, stateformation and the constraint to self-constraint, Languedoc was already beginning to undergo its own barbarous civilization. Conquest by the Capetian monarchy did not simply involve an expansion of barbarous civilization into an uncivilized social space, but the destruction of one civilizing figuration and superimposition of another.

The other component of the extermination of the Cathars, the Inquisition, has an even more complex relation to barbarous civilization. To begin with, it is not directly involved in state-formation: except for the brief rebellion at Montségur from 1242 to 1244 , the Cathars were not associated with contestation over territorial sovereignty in Languedoc after 1228. Nor was the cultivation of Christian orthodoxy and orthopraxy an integral component of the civilizing process as Elias describes it. He explicitly states that the constraint to self-constraint codified in courtoisie and civilité was a phenomenon of the secular upper classes, as the title of Volume I makes plain [see also Mennell 1992: 37]. The Catholic Church attacked one of Erasmus's early texts on civility, the 
Colloquies, because of its nonconformity with clerical standards [Elias 2000: 143-144], and not until the $18^{\text {th }}$ century did the Church play a major role in the dissemination of civility [86-87]. Elias describes the Church as having presented a challenge to the particular figurational tendencies of state-formation, offering a (failed) alternative to statehood as the dominant social organization in European life [e.g. Elias 2000: 328-329]. And yet, it would be deeply counterintuitive to leave Christianity out of the ensemble of institutions that make up European civilization. If the Church's aspirations to dominance were ultimately thwarted by the state and secular society, it is still possible, indeed highly likely, that specific techniques or tactics of power developed by the Church have made their way into the enduring figurational ensemble of barbarous civilization.

Historian R. I. Moore argues that one example of such transmission is to be found with respect to practices of persecution. Briefly, his argument is that

the eleventh and twelfth centuries saw what has turned out to be a permanent change in Western society. Persecution became habitual. That is to say not simply that individuals were subject to violence, but that deliberate and socially sanctioned violence began to be directed, through established governmental, judicial and social institutions, against groups of people defined by general characteristics such as race, religion or way of life; and that membership of such groups in itself came to be regarded as justifying these attacks. [Moore 1990: 5]

Moore claims that religious persecution had "faded away with the Roman Empire, and did not reappear until the eleventh century" [4] and even then did not become regular and systematic for another century after that. This persecution did not simply reflect the formalization and rationalization of popular attitudes towards difference, but was driven by secular and ecclesiastical authorities who used persecution, with varying degrees of success, to strengthen their own temporal power. In effect, Moore chronicles the growth 
of a figurational tendency that extends continuously from the era of the Crusades and Inquisition to that of modern totalitarian and authoritarian states. The formation of this persecuting society involved the construction of social categories or identities, so that "heresy, leprosy and Jewishness lay with beauty in the eyes of the beholders, and that their distinctiveness was not the cause but the result of persecution" [67]. Heresy, in particular, "exists only in so far as authority chooses to declare its existence" [68]. The persecution of heresy served the interests both of Church and of state: it enabled the Church to overcome tendencies towards its own decentralization and dissolution, tendencies well advanced by the $11^{\text {th }}$ century [69]; but also (and this has perhaps a more enduring significance) it enabled sovereigns to construct an ensemble of permanent practices that furthered their control over the populations they dominated. Conspicuous among these are the technologies of surveillance and of the spatial exercise of power $[106,109-110]$. By about the middle of the 1100 s, the great danger of heretics was not their open opposition to the Church but the very invisibility of their existence; in seeking to reveal an enemy whose existence lacks outward evidence, the Inquisition created mechanisms for exposing the remotest corners of social life to the gaze of a central authority. I have already commented on the copious documentation compiled by the Inquisition (see p. 256 above); over time the task of documentation was taken over by secular authorities. Literate clerks replaced warriors "as the agents of government and confidants of princes" [136]; law took on a new coercive function, imposing guilt or innocence from above, even for crimes that have no tangible victims, where before it had been mediatory, seeking agreement or compromise among dissenting parties [109-110]; 
moral repression became a device for state institutions to legitimate themselves [135]; and accusations of heresy were used, not just to resolve local grievances, but to suppress resistance to the exercise of centralized power over the population [144]. Heresy was important because it constituted, at best, a communal autonomy from and, at worst, open rebellion to, seigneurial, and later bureaucratic, power [133].

Moore's account puts into a different light the decline of the warrior class and the concomitant muting of the use of direct violence in governing that is central to Elias's account of the civilizing process. What Elias glosses over as the pacification of everyday life, Moore analyzes as a transformation in the mode of governance through which violence is exercised. If a deconstructive reading of Elias brings out in the abstract the crucial and continuing importance of violence in civilization, Moore fills in some of the concrete details. Admittedly, persecution is not the same thing as genocide; a persecuting society is not quite a genocidal civilization. But the two are closely related. Persecution and genocide can be understood as different instantiations of civilizing différance.

Within the emerging framework of barbarous civilization, the institutionalization of the category of 'heretic' and the techniques of Inquisition created a zone of active negation into which anyone could potentially be put. The possibility of guilt by suspicion created an onus on the visible, active, ongoing demonstration of one's conformity. If anyone could be a heretic, then one's safety depended not only on adherence to a set of negative proscriptions or even definite positive prescriptions, but on the visible, active, ongoing demonstration of one's orthodoxy. This onus is equivalent to what Foucault, writing about a different though not altogether separate historical context, calls 
'normalization' [Foucault 1995: 183]. In both examples, power attends not only to specific rules broken but to deviation from an ideal standard, one that is open to an indefinite intensification. This mode of the operation of power is a central feature of barbarous civilization, where the civilized subject is one who adheres to an ever more intense code of conduct enforced by a broad continuum of great and small violences. Genocidal Inquisition has these things in common with barbarous civilization, in a more rudimentary form: investment in a recognizable social hierarchy (violent différance); the possibility of radical exclusion and the threat of active negation; the indeterminacy of what will bring about this negation, and hence of sufficient conformity; the opportunity for competition and innovation regarding the practices of conformity; the investment of individual subjects, through the very acts with which they protect themselves, in the maintenance and reproduction of the very figuration that threatened them.

\subsubsection{GUATEMALA}

At first glance, the Guatemalan example might seem to be an example of the breakdown of civilization. The genocide took place in the context of a civil war during which the state's territorial monopoly of force was compromised. The existence of military insurgency involves by definition a reversal of the state-formation dimension of barbarous civilization. However, this very context provides an indication as to the civilizing impetus of the genocide. That the eruption of physical violence in Guatemalan society was not simply a breakdown of social relations per se is suggested by the enormous effort of production required: the considerable expenditure by the Guatemalan state, with negative effects on the economy, and substantial financial, training, and 
logistical support form the U.S. over a period of several decades. The object of all this productive activity was the reassertion of the territorial sovereignty of the Guatemalan state, and it was to this civilizing end that violence against civilians was directed. The Mayans in particular were targets of genocidal violence because they were perceived to be natural allies of the guerillas [CEH 1999: 34]; destruction of Mayan communities was intended to deprive the guerillas of their civilian base of support, to catch the Marxist fish by draining the sea in which they swam. At stake was not just ownership of the state, but the form of social order that would be underwritten by state power. Following the demise of the September Revolution, state power in Guatemala supported the landed oligarchy and export-oriented business elite. The armed insurgency challenged this power structure not only militarily but socially. In this sense the social and community leaders and human rights activists murdered en masse in the 1970s and 1980s did have something in common with the insurgents; all were threats to the established order in Guatemala. They represented an alternative course of barbarous civilization in Guatemala, one that gave less advantage to the existing elite. The escalation of violence up to and including genocide indicate the lengths to which that elite was willing to go to perpetuate its preeminence within the civilizing process. In its proximate goals it was unsuccessful: the guerilla movement was not defeated. This defeat should not obscure the direction of movement of that genocide: towards the reassertion of sovereignty on status quo terms. In terms of state-formation, genocide in Guatemala was a (re)civilizing response to the decivilizing situation entailed by the civil war. 
So far I have neglected a more fundamental element of the civilizing process: the cultivation of relations of dependence, relations that form chains of interdependence that extend broadly throughout a figuration, giving it what, in Parsonian terms, would be called a higher degree of functional integration. It is the extension of these chains of interdependence that, in Elias's account, deprives the military class of its autonomy and brings about the pacification of that class and the removal of direct physical force from the conduct of everyday life. This process unfolds on an ever-larger territorial scale:

first one castle stands against another, then territory against territory, then state against state, and appearing on the historical horizon today are the first signs of struggles for an integration of regions and masses of people on a still larger scale. We may surmise that with continuing integration even larger units will gradually be assembled under a stable government and internally pacified [...] until, with a further integration, a still greater reduction of distances, they too gradually grow together and world society is pacified" [Elias 2000: 254].

The formation of these ever-larger territorial monopolies of force is at the same time the formation of ever-larger social networks bound together by extended chains of interdependence, relations which have the effect of shaping the conditions of individual subjects' lives and of shaping their habits and their very subjectivity. Genocide, in Guatemala or elsewhere, would seem by definition to involve a reversal of this process through a severing of the chains of dependence that bind sovereigns to subjects and through which pacification is effected.

However, it is precisely through the extension of chains of dependence and the construction of supra-national territorial monopolies of force that genocide in Guatemala was made possible. In this situation, the figurational movement of barbarous civilization is shown to be more complex than a simple unilinear equation of sovereignty, 
interdependence, and pacification. The period of the September Revolution under the Arbenz government can be understood as an intensification of relations of dependence within the territory of Guatemala, an assertion of relative power gains by middle and lower classes in Guatemalan society. But it did more than this: through the proposed program of land reform, the Arbenz government threatened the very survival, at least in its accustomed form, of the social identity of the Guatemalan oligarchy, an identity that had until then served as the core or crux of barbarous civilization in Guatemala. The 1954 coup managed to undo the dependency of the Guatemalan elite on the middle and lower classes, but only through the production (or intensification) of its dependence on other forces: the armed forces, which carried out the coup; and, indirectly, the United States, which orchestrated and supported it. The escalation of violence throughout the civil war up to the 1980 s was made possible by the growing importance of the army within Guatemalan state structures and by the continuing support of the U.S. for the Guatemalan state and its power elite. This latter relationship was one of genuine interdependence: the Guatemalan state needed U.S. support to help prevent a successful revolution, and the U.S. needed the Guatemalan state to further its own geopolitical goals, which included maintaining undisputed hegemony over the Americas, in keeping with both the Monroe Doctrine and the Cold War. But with the integration of Guatemala into a supra-state territorial configuration of power, the power balance between the Guatemalan state and its subjects shifted radically against the latter. In relation to processes of violent différance, we can say the deferral of violence stopped when an extension of the overall network made particular, local dependencies dramatically 
weaker. This set the stage for the formation of a zone of active negation, through which the privileged subject of civilization reasserted its own identity (and its own privilege, which is crucial to that identity). Genocide in Guatemala brings out clearly the sense in which the formation of extended relations of interdependence can produce impunity for powerful actors with respect to groups not privileged by those networks.

Finally, the specific prominence of Guatemalan Mayans as targets of genocidal violence can be assimilated to the civilizing process in a relatively straightforward manner. As long as the Mayans retained elements of an independent culture, through language, religion, social organization, and economic practices, they remained partially outside the field of European barbarous civilization. Partially outside, they were also partially inside, and this partial insider status was necessary. As Patricia Marchak notes,

It is not strangers who are 'them' compared to 'us'. Strangers are outside the realm of recognition and beyond status comparisons. Until they become relevant to a population, they are neither enemies nor friends. 'Us' compared to 'them', by contrast, involves populations who are neighbours, friends or enemies, but known, identified, put in their place by the existing system of inequalities. [Marchak 2003: 41]

One important dimension of the long-term genocidal pressures on Mayans concerns the forcible erosion, by Ladino Guatemalan society, of Mayan practices of collective ownership of land. This conflict brings out concretely an aspect of figurational theory that I discussed abstractly in Chapter 4: the extent to which 'identity' refers not only to so-called subjective or psychological processes but to material social relations such as class. For Mayans, land was simultaneously a basis for economic independence and for collective identity. Conversely, appropriation and other measures to diminish Mayan land holdings served both to assimilate Mayans to a dependent location in the capitalist 
economy, and by the same token to assimilate them to a dominated position within the system of identification entailed by European barbarous civilization. This dynamic helps account for the sense in which struggles for Mayan survival both are and are not class struggles, and hence for the ambivalent relationship between the Mayans and the Marxist guerrilla groups.

\subsection{Conclusion}

In closing this section, I would like to note the importance of diachronic or historical analysis, such as that offered by figurational sociology, to understanding contemporary social developments. An understanding of contemporary Christianity or contemporary capitalism premised on an entirely synchronic structural analysis would require a demonstrably false assumption: that the reasons for the existence of the current situation are contained or embedded within that situation itself. That is, we would think that Christianity has the form that it does for reasons immanent to that form. However, an examination of history shows that European Christianity takes the form that it does in significant part because of a large-scale social process, the deliberate extermination of heretics, that has since been largely forgotten. A similar point applies with regard to global capitalism. A consideration of economic globalization, and of the politics of structural adjustment programs and global neo-liberalism, is incomplete without a consideration of the effects that past political violence has had, to thwart or weaken tendencies in alternative directions. The decimation of independent civil society in Guatemala during its decades-long civil war is a case in point. With regard to both of 
these examples, the study of genocidal violence tells us something about the roads not taken in the development of barbarous civilization.

\section{Tasmania and India}

\subsection{INTRODUCTION}

The examples discussed in this section are both connected with colonialism, and specifically with British imperialism. This has personal significance for me; as the son of an Ontario WASP, my childhood involved a steady diet of movies and books extolling the virtues of the British Empire: Zulu, and Khartoum, and Kim, and so on. I have also chosen these cases because of certain difficulties they present. They are not cases in which genocide is effected primarily through direct massacre. They are both largely administrative genocides, in which the tools of civil governance impose on a group conditions of life that physically destroy part or nearly all of that group. At first glance, they both appear to be examples of accidental genocides, if one may speak of such a thing. In Tasmania, the colonial authority made some attempt to prevent the physical extinction of the Aboriginal Tasmanians by assimilating them into the settler culture. In India, there was no question of any intent to destroy physically the Indian people as a whole, and the nominal purpose of colonial policy was not to destroy Indian persons at all but, quite the converse, to administer an economic system intended to increase overall productivity and efficiency in Indian agriculture. However, by re-examining the concept of 'intentional social action', I show for both examples how intent does not reduce to the terms in which actors legitimate their actions to bystanders, and how the actions justified 
in the name of progress and civilization were not only genocidal but intentionally genocidal in ways the actors themselves may not have been aware of.

My narrative in Section 2.1.1 of the near-extermination of the Aboriginal Tasmanians is drawn primarily from the second edition of Lyndall Ryan's The Aboriginal Tasmanians. This work provides a comprehensive overview of the evolving relationship between Aboriginal Tasmanians and European civilization. The first edition, published in 1981, was remarkable in that it broke with previous historiographic convention which assumed that the Aboriginal Tasmanians had in fact been completely exterminated [e.g. Turnbull 1966; Travers 1968; Morris 1972; Davies 1973]. It also differs from previous accounts in the extent to which it portrays active Aboriginal resistance to colonization. The first edition was well-reviewed [Markus 1982-1983; Gale 1982], and a review of the second edition remarks that the book is "a well accepted profile of the Tasmanian Aboriginal experience of white invasion", even among Tasmanian Aborigines themselves [Everett 1999]. However, one reviewer notes that Ryan's quantitative account of Aboriginal population prior to and after settlement, and her estimate of the causes of population decline, contain serious inconsistencies [Markus 1982-1983: 468]. I have noted this problem in my discussion below.

The historical events making up my narrative of genocidal famine in India are drawn almost entirely from Mike Davis's Late Victorian Holocausts. This work has been greeted with general acclaim from reviewers [Rotella et. al. 2001; Marks 2001; Herring 2002; Epstein 2003; Stoll 2002; Crais 2003; Moore 2003]. His historical data have not been called into question, although his inferences from them have, not surprisingly, been 
disputed by some [Economist 2001]. The discussion of Indian famines is only a small part of a work that also analyzes famine in China and Brazil, and provides a detailed discussion of the climatology of the El Niño Southern Oscillation (ENSO). Davis argues that the global capitalist economy created through imperialism exacerbated the effects of chronic rainfall shortages, themselves caused by ENSO, to create massive famines in the short term, and leave behind a long-term legacy of underdevelopment and hunger in the Third World. Most of that argument is not relevant to my own investigation. However, Davis's account is superior to some other economic histories of colonial famine [e.g. Greenough 1982; Rothermund 1993] in that it does not treat famine simply as the result of administrative mistakes or even corruption per se, but takes pains to make explicit the relations of force through which food was systematically kept away from starving people. In appropriating historical data from these sources, I have been at pains to separate my analysis from that of my source material. In particular, both Ryan and Davis are concerned to express moral condemnation of the agents they consider responsible for the human suffering they document. As such, substantial parts of their narratives especially Davis's - speak to the characterization of certain key historical figures: George Augustus Robinson and Lieutenant-Governor George Arthur in Tasmania; Lord Lytton, Lord Buckingham, Sir Richard Temple, and other individual administrators in India. Although I hardly wish to dismiss the importance of moral questions in relation to this topic, my concern is not to make a moral point but a sociological one: to show how each of these series of historical events may usefully be considered to represent an example of genocide, and how that genocide can be understood as an extension or product of a 
specific figuration, barbarous civilization, that in itself is neither good nor evil, but which produces various effects, some of which we may find evil and wish to prevent from recurring.

\subsection{HISTORIES}

\subsubsection{TASMANIA}

It is estimated that the aboriginal population of Tasmania is descended from humans who migrated across a land bridge from Australia at least 36,000 years ago [Ryan 1996: xxii], and that after the end of the last ice age this population was virtually isolated until the arrival of Europeans in the $17^{\text {th }}$ century CE. Ryan estimates the precontact population to have been between 3000 and 4000 individuals [Ryan 1996: 14] but, as I have noted, this estimate is unreliable [Markus 1982-1983: 468]. Regardless, the first European to sight the island was Abel Tasman in 1642, but from then until 1802, contact between Europeans and Tasmanians involved only brief encounters between European explorers and would-be scientists, mostly French, and small coastal bands [Ryan 1996: 47-65]. Early explorers such as Nicholas Marion du Fresne saw the Tasmanians through lens of Rousseau's claims about the condition of noble savagery [49], while subsequent visitors, such as François Péron, tended towards the more negative view that of all human beings, the Tasmanians were the most savage and most remote from European civilization ${ }^{113}$ [63]. The first official settlement was formed in 1803 by

113 The trajectory of European scientific attitudes was therefore a descending arc from the idealized conception of the 'noble savage', through the 'ignoble savage' [Ryan 1996: 50], and on downwards. By the 1860 s, there "was a renewed interest in the Aboriginal Tasmanians from the scientific world, based upon the conviction that they were the missing link between ape and man" [Ryan 1996: 214]. This trajectory was perhaps implicit in the very idea of the 'noble savage', inasmuch as it assumed that the Tasmanians were merely underdeveloped Europeans, people 
the British at Risdon Cove in the southeast corner of the island [Robson 1983: 35], partly in the effort to forestall any attempt by France of the United States to claim the island for their own domains [Robson 1983: 32-33].

In 1800, Captain Charles Bishop discovered the abundant sealing grounds in the islands off the northeast corner of Tasmania. In the following years, hundreds of sealers made seasonal settlements and harvested massive numbers of sealskins. Aborigines entered into trade relations with the sealers, and "offered women in an attempt to incorporate the visitors into their own society" [Ryan 1996: 67]. Through their skills at survival in the local ecosystem, these women made a valuable contribution to the sealers' lives $^{114}$ [69]. By 1810 , the seals were mostly gone and only a few sealers stayed behind with their Aboriginal wives to found a permanent community [ibid.]. By 1820 the colonial government was beginning to evict the sealers from the area; those who stayed behind shifted their economic activity from sealing to mutton-birding, at the initiative of the Aboriginal women. "The sealers were instrumental in the destruction of a number of Aboriginal tribes on the north coast of Tasmania through exchange and abduction of women, but they also saved Aboriginal Tasmanian society from extinction because their economic activity enabled some of its traditions to continue" [Ryan 1996:71]. This is important inasmuch as the only surviving descendents of Aboriginal Tasmanians are

simply lacking culture and hence ready to be filled up with it, rather than people with a highly developed and specialized culture of their own.

Robson and Ryan disagree over the extent to which sealer-Aboriginal relations should be characterized as violent or mutually beneficial. Robson's account says "the sealers in the northeast had already disrupted the Aborigines' lives by abducting or buying or securing loans of their women and murdering the men" [Robson 1983: 210]. Ryan frames this dynamic differently, claiming that sealers participated in pre-existing feuds between competing tribes [Ryan 1996: 69]. Regarding the place of women in the sealer society, Ryan says "their skills at first made them 
from unions between Aboriginal women and European men; as I will discuss below, the Islanders community survived up to the present day and constituted the core of the Tasmanian Aboriginal community. Throughout the $20^{\text {th }}$ century, however, mainstream Australian society considered the Aboriginal Tasmanians to have been made extinct. That view is correct only inasmuch as all Aboriginals who did not join European families, who attempted to preserve their cultural autonomy outside European society, did die out completely.

This near-extinction happened in two phases: the settler war, and the internments at Flinders Island and Oyster Cove. The first English settlement having been formed in 1803, the European population of Tasmania was 2000 by 1817 and 23,500, including 6,000 free settlers, by 1830 [Ryan 1996: 83] The free settlers were mainly sheep farmers, who converted to sheep pasture the unforested plains that the Aborigines had used for hunting kangaroo. Violent Aboriginal resistance to the settlers began in 1823 when members of the Oyster Bay tribe killed two stock-keepers, for which the leaders of the raid were captured, tried, and hung in 1824. Ryan notes that "no European was ever charged, let alone committed for trial, for assaulting or killing an Aboriginal" [88]. Small murderous raids by Aboriginals continued, and in 1826 the British brought military forces to defend the settlers, and gave settlers the right to use force against Aboriginals [90]. Sporadic killing on both sides proceeded until martial law was declared against the so-called "bushrangers" in 1828 [99]. Until 1832, warfare continued in the settled districts in the south of the island, with military forces and settlers attempting to either 
capture, kill, or drive away all Aborigines in the settled southern portion of the island. In 1830 the famous "Black Line" operation took place, in which 2,000 men were assembled to form a line stretching clear across the southern end of the island, moving southwards, hoping to drive the native population south and east towards a concentrated area where they could be taken into captivity. Superficially the operation was a failure, with only two Aborigines captured [112]. However, in actuality it accomplished its objective in that Aborigines escaping through the gaps in the line fled the area, moving northeast where many were soon captured. By January 1832 the settled area was cleared of its native population.

Settler-Aboriginal conflict was still endemic throughout the rest of the island, however. Reports indicate that Europeans, including sealers, not only killed but tortured Aborigines and kidnapped women and children [Robson 1983: 231-232, 239]. To resolve the issue of Aborigines living in the unsettled central and northern interior of the island, George Augustus Robinson was appointed to act as missionary and conciliator. In 1829-1830 he traveled throughout the island making contact with every surviving tribe, negotiating a cessation of Aboriginal attacks on settlers. Important to his efforts were Aboriginal collaborators, including a young Truganini, who acted as ambassadors to facilitate his contact with new groups. In 1831, Robinson estimated that only 700 Aborigines were left alive, although the real number turned out to be much lower [Robson 1983: 239]. In that year, Robinson met with Lieutenant-Governor George Arthur to discuss plans for the future of the Aboriginal Tasmanians [Ryan 1996: 151- 
152]. The two agreed that all Aborigines should be removed for their own welfare to an island in the Bass Strait, off the northeast coast of Tasmania. Chief Justice John Lewes Pedder objected to this plan on the grounds that the Aborigines would wither away in such an unaccustomed environment, and advocated instead the formation of a territorial reservation, modeled on those in the U.S., on Tasmania itself. Robinson disagreed, arguing that the Aborigines could only be Christianized if their land and culture were stripped away. Despite the failure of two previous such civilizing efforts on the Australian mainland, Arthur agreed with Robinson's position. From 1831 to 1834, therefore, Robinson traveled again throughout the island persuading, and in some cases compelling, Aborigines to surrender themselves, promising them safety from the depredations of settlers. He was completely successful; in the years 1832-1835 nearly all remaining Aborigine tribespeople ${ }^{115}$ were transported to the Flinders Island Aboriginal Establishment [170], later nicknamed "Wybalenna" (usually translated as “black men's houses" [183]). Historian C.D. Rowley notes that Robinson hoped for the Establishment to serve as "the prototype of the multi-purposed institution, asylum, hospital, training centre, school, agricultural institution, rationing centre, pensioners' home, prison" [Rowley, quoted in Ryan 1996: 181$]$.

Although Robinson had promised to allow Aborigines to keep their culture, at Flinders Island he implemented a regime forcibly to erase their culture and make them civilized subjects according to the British model [Ryan 1996: 183-185]. Traditional

115 A single family refused voluntary withdrawal and eluded capture by Robinson: "However, on 20 November 1836, George and Charles Robinson, with the usual company of domesticated Aborigines, came up with a husband, wife and four children near Cradle Mountain, but this little 
dances and religious practices were forbidden. The men were urged to cut their hair in European fashion. All Aboriginal names were changed, though Ryan notes that this measure was popular and voluntary. Children, women, and men were subjected to a rigid daily routine, which for children at least was tightly regulated by the clock. Children were taught Christianity, went to school, and were taught gender-segregated occupations: trades for the boys, domestic skills for the girls. Women were required to cook and clean like European housewives, and received English literacy training and Bible studies; single women were forbidden to cohabit with European men. Men were less regimented, but were expected to "cultivate the gardens, build roads, clear forest land, erect fences, and shear sheep". European dress was expected for all and enforced by routine inspections, and meals were set on the British model. In 1837 Robinson required the Aborigines to build brick houses for themselves, and started a weekly newsletter written by the boys [Ryan 1996: 187-189]. A weekly market was implemented to involve the Aborigines in the money economy. Robinson abstained from using physical force, but used "moral and coercive force with devastating results" [187]: isolating groups, denying rations, prohibiting hunting, encouraging spies and informants, and appointing salaried constables among the men. The Aborigines resisted this program, engaging in traditional practices secretly and refraining from more than superficial adherence to Christianity. After the non-arrival of supply ships in the winter of 1837 , resistance became more overt. Robinson left in frustration in 1839 [193].

group refused to go to Flinders Island and made off. In 1842 it was probably this final remnant of the people of Van Diemen's Land who were taken near the Arthur River." [Robson: 253] 
After Robinson's departure, the contradictions of the situation continued to intensify. Three boards of inquiry between 1839 and 1847 into living conditions at the Establishment only blamed the Aborigines for being ungrateful, lazy, and indolent [Ryan 1996: 195]. Jailing was used in response to insubordination. The strict disciplinary regime was relaxed for a while after Robinson's departure, but was re-intensified in 1842 under Henry Jeanneret, who came to epitomize the coercive relationship between the Aborigines and the colonial government. Jeanneret was suspended for insubordination in December 1843 [200]. When he applied for reinstatement in 1845, the Aboriginal man Walter George Arthur, who had earlier been one of Robinson's ambassadors, wrote to an influential Quaker in Hobart saying that his people could support themselves economically, and wanted greater autonomy rather than another commandant. In 1846 the Aborigines sent a petition to Queen Victoria asking that Jeanneret not be reinstated, accusing him of threatening to shoot them, putting them in jail, withholding rations, and forcing them to work without remuneration [201]. After Jeanneret was nevertheless reinstated that same year, the Aborigines petitioned the lieutenant-governor, complaining of ill-treatment and asking for their independence. The Colonial Office in London responded by ordering the removal of the Aborigines to a new colony at Oyster Cove on the Tasmanian mainland [202-203]. This relocation took place in October 1847.

Robinson had expected the Flinders Island colony to be temporary [Ryan 1996: 183], but it lasted for eight years, at which point the survivors were moved to the colony on the mainland at Oyster Cove; this colony lasted in turn until 1869, when the last two survivors were put in the direct care of its last supervisor [Ryan 1996: 217]. The last 
survivor, Truganini, died in 1876 at the age of $64^{116}$ [Ryan 1996: 218]. Between

Robinson's expeditions in 1831-1834 and Truganini's death in 1876, mortality among the Aborigines under European care was continual and drastic. When Robinson arrived at the Flinders Island Aboriginal Establishment in 1835, of the "three hundred he had originally captured", only 123 were alive to meet him. "Most had died in the various transit camps set up to process them on capture." [Ryan 1996: 183, 193]. Captives on Flinders were at first housed in a penitentiary building and began "almost at once" to die of pulmonary disease [Robson 1983: 249]. "In 1833, 43 Aborigines arrived at the establishment to join the 78 already there. But 37 died, leaving 84 . In 1834, 42 arrived, but 14 died, leaving 112 . [...] several children were born, but most died within a few days." [Ryan 1996: 180]. Flinders Island has a colder, rainier, and windier climate than the Aborigines were used to. Their diet was insufficient: in December 1834 daily rations for each adult were one pound of salt beef, one pound of flour, half a pound of biscuit, and one quarter ounce each of sugar, soap, and salt; child rations were half this. "Since the Aborigines would not eat salt meat, to stave off malnutrition they were forced to hunt, even though they were often too ill to hunt, or forbidden to hunt, or had nothing to hunt" [Ryan 1996: 180]. Prior to contact, the Tasmanian diet was high in Vitamin C, iron, and thiamine [175], and but in captivity their intake of these nutrients was chronically insufficient. By 1837 flour, sugar, and soap rations were increased and tobacco and tea were added, supplemented by local cabbage and turnip, and the Aboriginals were eating the salt meat, and in 1838 fresh mutton was added to their rations, but the diet was still

116 "Truganini was not the last 'fullblood' to die. On Kangaroo Island, Suke, a woman taken from 
nutritionally inadequate [186]. Water supplies on the island were also inadequate. Fatal epidemics of pulmonary disease swept the camp periodically. Between Robinson's arrival in 1835 and his departure in 1839, 59 of the original 123 Aborigines died, 11 were born or arrived separately, and 15 left with him for the Australian mainland [193]. Of these remaining 60, from 1839 to 1847, 30 died, 14 arrived from elsewhere, and "at least five children, all part-Aboriginal, had been born" [Ryan 1996: 203]

Although the Aborigines hoped for a better life back on the mainland, their situation deteriorated even further at Oyster Cove. The Oyster Cove Aboriginal Station was built on a mudflat with poor drainage, and for much of the year was a repository for waste water from farms upland. Buildings were made of wood and offered insufficient protection from cold south winds; houses were damp and vermin-infested [Ryan 1996: 204]. Still, rations were improved and shellfish, a traditional staple, were in abundance; the Aborigines' health improved for a time. Christianization, especially of children, continued, but otherwise the Aborigines were more autonomous. "[A] visiting magistrate made weekly inspections of the Aborigines' clothes, houses, treatment and behaviour, and the quality and condition of their rations" [Ryan 1996: 205-207]. Community leaders Walter George Arthur and Mary Ann Arthur bought land and tried to live as farmers. However, by 1849 morale declined and mortality rose. The population declined from 47 in 1847 to 30 in 1851 , to 17 in 1854 [209]. Self-government was granted in 1855, but this only worsened their situation, as government expenditure on the station was cut in half, rations were reduced, magistrates' visits became monthly, and housing repairs were 
curtailed. By 1859 the station was in severe disrepair, its occupants afflicted with mental illness, senility, alcoholism, and severe respiratory complaints [210]. Community leaders like William George Arthur and later William Lanney complained to the authorities, but to no avail. Deaths continued over the next few years, William George Arthur dying in a boating accident in 1861 [212]. The last male of the group, William Lanney, died in 1868. His corpse was dismembered by members of the Royal Society of Tasmania in the name of scientific investigation, although pieces of his body were kept as relics by various individuals afterwards ${ }^{117}$ [214-217]. With only two residents remaining, the colony was disbanded in 1869. Mary Ann died in July 1871 and Truganini survived until 1876. Against her wishes, her body was exhumed by the Royal Society, and her skeleton was put on display from 1904 to 1947; it was finally cremated in 1976 [217-220].

After 1876, European Tasmanians believed that the Aboriginal Tasmanians were extinct. However, Aboriginal social identity survived via the community of European sealers and Aboriginal women living in the islands in the eastern Bass Strait. In 1847, this community consisted of thirteen families totaling about fifty people [Ryan 1996: 222]. This community involved a culture that mixed European and Aboriginal Tasmanian elements. Over the years, it resisted various attempts by the colonial government and by commercial interests to disintegrate it or impede its economic self-sufficiency. By 1980 the population was two hundred [239]. A reserve was created for them on Cape Barren Island in 1912 [Ryan 1996: 242]; it was terminated in 1951, at which time the

117 Dr. George Stokell, a leading member of the Royal Society, "had a tobacco pouch made out of a portion of his skin, and other worthy scientists had possession of the ears, the nose, and a piece of Lanney's arm. The hands and feet were later found in the Royal Society's rooms in Argyle Street, but the head never reappeared." [Ryan 1996: 217] 
government hoped to assimilate the Islanders into Australian society [248]. A small community remained, however, and those that relocated to Launceston also retained their sense of community, partly because they faced discrimination in Anglo-Tasmanian society. Struggle over ownership of land on Cape Barren Island continued through the 1960s, and in 1971 a 'community development officer' was appointed by the Commonwealth to assist in redevelopment of the island [251]. In 1973 the Commonwealth established an Aboriginal legal service which became a vehicle for Aboriginal political and cultural self-assertion [263]. In 1993, the High Court of Australia ruled in favour of land rights for an aboriginal group in the Murray Islands, abandoning the principle of terra nullius that had been operative throughout Australian history [292]. This decision encouraged further activism by Aboriginals in Tasmania, leading to land claims negotiations between the federal government and the Aboriginal community in the mid-1990s.

\subsubsection{INDIA}

It was Rosa Luxembourg [2003: 348-357] who first drew my attention to the possibility that changes to economic structures imposed by colonial authorities might constitute a form of genocide. She observes that previous conquests had not had the devastating effects on India that British conquest did, because previous conquerors were content to usurp the institutions of central taxation, and leave intact the economic practices of rural households operating communally and producing mostly for immediate consumption, whereas the British were determined to shatter that household and rebuild it to meet the wants of market capitalism. Luxembourg's account shows vividly how mass 
starvation may result as a superficially unintended byproduct of intentional social change imposed on a population by a conquering power.

Briefly, in the late nineteenth century India suffered two periods of enormous famine, "the worst famines in perhaps 500 years": in 1876-1879 and in 1896-1902. Mortality for the first famine is estimated from 6.1 to 10.3 million dead; for the second, 6.1 to 19.0 million dead, for a total combined mortality between 12.2 and 29.3 million persons dead [Davis 2001: 7-8]. These facts are not controversial or even new, although according to Davis they have been strangely neglected [8]. What is not self-evident is the status of famine as a social event, rather than simply a natural one. For both Weber [1978: 7-8] and for Durkheim [1982: 50], natural events, such as variations in rainfall, are data that sociologists must consider but are not part of the subject matter of sociology: rainfall is not social action or a social fact. Parsons [1951: 541-545; 1966] expresses this by defining the natural world as one of the environments within which social systems operate. According to Davis, economic history has usually treated famine as a direct mechanical consequence of natural and demographic phenomena, without attending to the role played by social relations as such. Famine can only play a part in my account of civilizing genocides if it can be understood as a social phenomenon.

In this respect, attention to concepts is important. Both 'drought' and 'famine' refer not simply to natural events but to their effects on socially organized food production, and these effects have social as well as meteorological determinants [Davis 
2001: $18-22^{118}$ ]. Inadequate or poorly timed rainfall will cause crop failure only if stored water is inadequate or inaccessible. Stored water can occur in naturally formed streams, lakes, and aquifers, or in socially constructed reservoirs, wells, and canals; so the impact of deficient rainfall on food production depends, among other things, on whether artificial irrigation systems can distribute water to plots, and - if water is commodified - on whether cultivators can afford to buy it. Similarly, whether crop failure or simple food availability decline (FAD) leads to famine mortality depends on the availability of alternate sources of food, and on whether people affected can secure access to them. In a commodified food economy this depends not only on the local price of food, but on regional or global market conditions; if it is more profitable to sell Bengal grain in Lancashire than in Bengal, Bengalese may starve. It also depends on political conditions: on public relief efforts, on the effectiveness of extra-legal action such as protests and riots to appropriate food for the non-entitled, on the willingness of state or private authorities to use force against such actions, and so on. In this respect famine can operate as a form of upwardly redistributive class struggle. Finally, how famine is defined also reflects power relations among social groups: whether famine is considered simply "mass starvation unto death"; whether death from disease is considered; whether chronic hunger, destitution, and social breakdown are considered. Treating drought and famine as simply natural events masks the operation of social relationships of production and distribution. A fuller account understands famine as a figurational event.

118 For the theoretical basis of Davis' argument see Arnold 1988, Sen 1984, Desai 1988, Rangasami 1985, Watts 1987, and Watts 1991. 
The ecological trigger for the great Indian famines of the late nineteenth century was extreme drought and flooding that correlated with El Niño and La Niña weather events $^{119}$. The summer monsoons failed in south and central India in the summer of 1875 , and the winter rains failed even more precipitously in 1876 . Severe and intense famine ensued, affecting much of southern India in an area fanning out widely west and northwest from Madras, and also a large area in central northern India east, west, and south of Delhi [Davis 2001: 25-29]. Heavy rain returned to southern India in the fall of 1877, bringing a malaria epidemic that further disrupted agricultural production; dry weather continued in the north until 1878 [50-51]. Again in 1896, the monsoons failed throughout large areas of central and northern India [142], and famine ensued over a huge swath of the country, from contemporary Punjab to Bihar, south to Madhya Pradesh, Maharashtra, and parts of Karnataka [145]. Rains returned in 1898, only to disappear again catastrophically in 1899, except in Assam where record rainfall caused widespread flooding [158]. Famine was intense in contemporary Gujarat, north into Rajasthan, and east and south into Madhya Pradesh and Maharasjtra; severe famine struck the rest of central India and north into Punjab [163]. Low rainfall persisted until late 1902 [170]. In

119 El Niño and La Niña are effects of a climatic system with global effects called the E1 Niño Southern Oscillation (ENSO). "Rapid warmings of the eastern tropical Pacific (called El Niño events), for example, are associated with weak monsoons and synchronous drought throughout vast parts of Asia, Africa and northeastern South America. When the eastern Pacific is unusually cool, on the other hand, the pattern reverses (called a La Niña event), and abnormal precipitation and flooding occur in the same 'teleconnected' regions. The entire vast see-saw of air mass and ocean temperature, which extends into the Indian Ocean as well, is formally known as 'EI NiñoSouthern Oscillation" (or ENSO for short)." [Davis 2001: 13] However, this causal relationship is very complex, and is masked by regional variations: for example "the devastating drought of 1896-97 in central India, for instance, is masked by positive rainfall anomalies elsewhere" [Davis 2001: 247]. Major ENSO events took place in 1876-78, 1891, 1896-97, and 1899-1900; all of these correlate with drought and famine in India [Davis 2001: 271]. 
Gujarat district, an estimated one-sixth of the population died [173]; death rates reached as high as one-third for some individual districts [171].

But ENSO was not the only global system that interfered with food supply in India during this time. By the 1770s, India's agricultural economy had been thoroughly integrated into the global capitalist market. Through the imposition of cash taxes and other systematic measures, peasant farmers were induced en masse to switch from producing locally consumed food crops like millet and rice to growing wheat, cotton, opium, sugar, indigo, and other products for export to foreign markets [Davis 2001: 312324]. In English markets, their primary destination, Indian commodities competed on unfavourable terms with identical raw goods from other parts of the world, such as cotton from the southern U.S., or wheat from the Argentine pampas [319-320]. Local handicrafts were also taxed to encourage Indian consumption of imported English manufactured goods [313-314]. However, small producers could not sell directly to the world markets, so throughout India local elites found a new role as combined middlemen and moneylenders who could control the local market, reap the benefits of rising global prices, and pass the costs of falling prices on to the direct producers $[313,320-323,325$ 326]. Since the penalty for nonpayment of taxes was loss of land ownership, and taxes were set at fixed amounts based on estimated market value of the land, economic downturns meant the expropriation of large numbers of small producers, to the benefit of wealthier landowners and merchant/moneylenders. Forest and pasture commons, formerly an integral source of free resources for the peasant economy, were transformed into taxable private property or revenue-generating state property [326]. Water, another 
free commons, was also privatized [331]. State investment in irrigation systems declined on the grounds that it did not generate revenue [334], while massive investments were made in a national railway system. The combined effect of these changes was to increase both the ecological and economic vulnerability of the rural Indian population. On the one hand, hydrological reserves declined, forested areas were cleared, and agricultural soil was depleted through overuse. On the other hand, the conversion of a communal and subsistence-oriented agricultural economy to an individualist, cash-based economy meant that, when markets fluctuated, millions of people could be unable to obtain food even if food was physically present nearby. These two global systems intersected with devastating effect in 1876,1896 , and 1899 , to produce the famines of $1876-79$ and $1896-$ 1902

\section{THE FIRST FAMINE, 1876-79}

When the monsoons failed in 1876 , drought turned immediately into famine as food prices rose above what agricultural labourers and small landowning peasants could afford. "The traditional system of household and village grain reserves regulated by complex networks of patrimonial obligation had been largely supplanted since the Mutiny by merchant inventories and the cash nexus." [Davis 2001: 26] The previous three years of above-average wheat and rice production counted for nothing, as those crops had been exported to England. In the absence of price controls, scarcity promoted speculation and hoarding $[26-27,51]$. New transportation infrastructure - the railroads, expected to make famine impossible - was used not to ship food to famine districts, but to ship it away to central depots for hoarding and protection. Telegraph communication 
enabled local price hikes to be translated regionally or nationally. Indian wheat exports to the U.K. actually rose during the famine, from 308,000 quarters in 1875 to 757,000 quarters in 1876 , to $1,409,000$ quarters in 1877 [27]. Meanwhile, the Indian Viceroy, Lord Lytton, was committed to other large expenditures that impeded the scope for food relief: a lavish celebration to honour Queen Victoria, and a military campaign in Afghanistan [28]. Relying on Adam Smith's claim that state intervention would only exacerbate famines, Lytton issued "strict, 'semi-theological' orders that 'there is to be no interference of any kind on the part of Government with the object of reducing the price of food"' [31].

The famine intensified in 1877 , as families that had sold their means of production to survive the drought were unable to sow emergency rape and cumboo crops when a little rain fell in April-May [Davis 2001: 33]. As millions who did not simply starve to death reached a stage of acute malnutrition, cholera and dysentery became mass killers. Peasants fled the countryside en masse to large cities seeking work or food relief; some rural regions were entirely depopulated. In February, Viceroy Lytton appointed Sir Richard Temple to clamp down on any relief efforts organized by local authorities [36]. After organizing a successful relief effort during the 1873-74 drought and almost losing his career for it, Temple was an uncompromising enforcer of strict laissez-faire principles. Temple purged hundreds of thousands from relief work, required that relief be given only in exchange for heavy labour, further stipulated that this labour be performed in militarized work camps located outside a ten-mile radius of the homes of those requiring it; and set the relief ration at a mere one pound of rice per diem [38]. This 
so-called 'Temple wage' provided only 1627 calories: fewer than the 1750 calories of the ration at the Buchenwald concentration camp, less than the traditional amount available to British prison inmates, and $40 \%$ of a 1981 estimate of the caloric requirements for an adult performing heavy labour [39]. It was also completely lacking in protein. By the summer of 1877 , most of the inmates of the relief camps in Madras were dead. In addition, Temple implemented the Anti-Charitable Contributions Act of 1877, which imposed prison sentences for any private relief donations that could interfere with the market fixing of grain prices. He also took active measures to stop officials in Madras from remitting land taxes in the famine districts. [40]

Indian resistance to the relief regime began with food riots in 1876 , but intensified in January 1877 with a movement among relief camp inmates to protest the rice reduction and the distance tests. The movement was one of passive resistance, in which starving peasants refused to perform labour or left the camps entirely [Davis 2001: 41]. This relief strike stirred up "the broadest demonstration of Indian anger since the Mutiny" [4243]. Lytton came under attack from the Indian press and from British reformers (including Florence Nightingale), but ordered his subordinates to hold fast [43]. Officials in Bombay refused to publish mortality estimates, and the throughout the famine the official government line was to deny its very existence. One Indian civic association, however, compiled its own estimates in the Sholapur district, as did the Governor of Madras. Reports indicate that by summer 1877 , at least 1.5 million had already died in the Madras districts alone. 
Viceroy Lytton “was kept well-informed of such grisly details" [Davis 2001: 47] and in August 1877 made a personal visit to inspect conditions in Madras. By this time, relief camps had become "fetid, disease-wracked boneyards where a majority of refugees quickly died" [46]. Neither public opposition, nor reports of the famine's effects, nor the entreaties of his subordinates, nor personal observation deterred the Viceroy's policy, however. He rejected out of hand the request of Sir George Couper, the executive of the North Western Provinces, to remit land taxes during the famine, and instead ordered his district officers to discourage relief works "in every possible way", and to "put the screw" on landowners who were slow to pay their taxes [52]. In Madras city, "famished peasants dropped dead in front of the troops guarding pyramids of imported rice" [45]. In the Mysore countryside, where the famine was worst, women and children stealing grains from fields were tortured, disfigured, and sometimes killed, while rural mobs assaulted landowners, stealing their stores and sometimes burning them alive. There are reports of cannibalism, otherwise "extremely rare" in Indian history. In northern districts affected by famines, there were 150 grain riots in August-September 1877, to which the governor responded by filling the jails and prisons [52]. In 1879-80, the government conducted a "militarized campaign" in the Deccan region to collect by force any tax arrears that had accumulated during the famine; the resulting wave of foreclosures on small holdings effected a substantial redistribution of land upward through the class structure [50].

In September and October 1877, heavy rains eased the drought in southern India but brought a malaria epidemic that killed hundreds of thousands and was followed by great locust plagues that inflicted further devastation on crops [Davis 2001: 49]. Prices 
remained high in early 1878. Drought continued for another season in the northern districts. There, ample food reserves would have existed had not the export economy siphoned away the surplus crops of 1874-76. In the North West Provinces it was most obvious that the "staggering death toll was the foreseeable and avoidable result of deliberate policy choices" [51].

\section{THE SECOND FAMINE: $1896-1902$}

Low rainfall became drought and famine in India again in 1889 and 1891-92, where again India's integration into global markets translated crop failures into rising food prices, entitlement scarcity, and starvation. The real catastrophe, however, struck in 1896 and again in 1899, when the monsoons "simply 'jammed" [Davis 2001: 159]. Although relief works were temporarily shut down in 1898 [158], famine did not abate until 1902.

In 1878 a Famine Relief and Insurance Fund had been established to enable financing of relief efforts independently of the government's other financial commitments. After the investigations of a Famine Commission in 1880, regional famine codes had been implemented to allow local relief efforts and also to restrict mass population movements during food crises. Integration of Burma's rice production into the imperial system and the construction of 10,000 miles of new railway track were expected to make absolute food scarcity impossible in India. However, these measures were shown to be ineffective soon after the 1896 drought began. Again, grain reserves had been depleted by large exports; again, communications networks served to translate high prices throughout the country rapidly and efficiently; again, railways "could not 
bring grain into districts where mass purchasing power was insufficient". A substantial portion of the Famine Fund had been diverted to another military campaign in Afghanistan [141-142]. Curiously, just as both the 1876 and 1896 famines were connected to military campaigns in Afghanistan, the onsets of both were simultaneous with a large and expensive celebration of empire: in 1897, the British Empire celebrated the Diamond Jubilee of Queen Victoria, for which the colonial administration of India sponsored a lavish festival [150-151]. In addition, a large portion of the Indian population was already malnourished before the rains failed in 1896 .

"Acute distress was already visible in the North Western and Central Provinces in August 1896; by October the police were opening fire on grain looters in Bihar and the Bombay Deccan" [Davis 2001: 143]. Davis's account of the 1896 famine brings out the use of direct physical force to maintain the existing food distribution system and thereby keep food out of the mouths of the starving. When peasants in the Central Provinces assaulted grain depots, the Lancashire Regiment was sent in to reinforce native infantry [148]. When bubonic plague struck Bombay in the summer of 1896, the governor's Plague Committee responded by sterilizing with fire, lime, and carbolic acid the tenement neighbourhoods where the plague was most virulent, a measure that did not combat the plague's true vector (rats) but did make thousands of people homeless. "In England, some of the press proposed the 'radical purification' of burning the entire native city to the ground" [149]. In the Deccan, the Epidemic Disease Act authorized the use of troops to raid slum neighbourhoods and forcibly detain suspected plague carriers; a "huge number of people" entered the plague camps apparently healthy and came out as corpses 
[150]. During the second wave of famine in 1900, Viceroy Curzon decided to deport refugees who had fled into British India from adjoining native states, a practice that was "virtually a death sentence for hundreds of thousands of desperate people" [167]. In 1900-01 the government decided to redeploy militarized collection of land taxes, based on land value assessments inflated by the famine-induced spike in food prices, in hard-hit areas like Gujarat and the Central Provinces; those who could not make their payments had their land confiscated [172-173].

Beyond overt episodes like these, direct physical force played a more constant function of guaranteeing an economic order that inflicted massive economic violence on the starving. Throughout the entire course of the famine, the government determinedly abstained from any measures to control the price of grain [142-144, 162-164]. Starvation was a consequence of rising prices rather than of absolute scarcity: in Bombay, "immense grain stores" sat "piled up at the docks" while thousands of refugees from rural areas starved "openly in the streets"; one American missionary observed fat pigeons gorging themselves on open sacks of grain at railway stations "in the sight of scores of miserable, famine-stricken villagers crying aloud for food" [Davis 2001: 167-168]. Near the outset of the famine, Viceroy Elgin created poorhouses for those too weak for heavy labour. The rations provided at these sites had even fewer calories than the Temple Ration [166]. Moreover, the poor houses were insufficiently regulated, so that administrators were able to confiscate food from its intended recipients, for their own profit [154-157]. In at least one case, a visiting American official observed that relief grain was adulterated with earth before being ground into flour and distributed [147], and merchants sometimes 
adulterated the grain that they sold at inflated prices [148]. Economic violence within India was also connected with the direct force of empire-building elsewhere: during the first wave of famine in 1896-98, the Secretary of State for India offered famine aid to Viceroy Elgin, but in the second wave of 1899-1902 the Secretary took the opposite course, refusing appeals to organize a famine charity in England and urging Viceroy Curzon to launch a War Fund in India to help pay for the Boer War [164].

In 1901 the British medical journal The Lancet estimated that total excess mortality in India over the previous decade had been at least 19 million, equal to half of the population of the United Kingdom at that time [174]. The two great famines I have discussed, along with another in 1907-08, "cast a long mortality shadow over the first decade of the twentieth century", contributing via weakened immune systems to epidemics of malaria, tuberculosis, and plague that claimed millions of lives. Productive forces in the countryside were severely damaged, with great losses to plough cattle and declines in net cropped area in some provinces [175]. Population growth for India declined appreciably, and came to a standstill in some areas. The 1901 Famine Commission report estimated that barely one-fifth of famine victims received any British assistance, but nevertheless stated that "relief distributed was excessive".

\subsection{GENOCIDE}

\subsubsection{INTRODUCTION}

Both of these examples strain the limits of the category of genocide. In particular, for both examples the presence of genocidal intent is problematic. The UNGC states that genocide is action taken "with intent to destroy, in whole or in part, a national, ethnic, 
racial or religious group as such". The internment of Aboriginal Tasmanians was legitimated precisely in terms of guaranteeing their physical survival in the face of European expansion; internment was explicitly considered to be the best alternative to extermination by the guns of settlers and soldiers [Ryan 1996: 151]. The viceroys of India during the great Victorian famines expressed a deep conviction that free market mechanisms were the surest guarantee against famine, and that interfering with these mechanisms would only exacerbate the situation [Davis 2001: 32]. Based on a superficial reading of events, it seems that one could construe both the nearextermination of the Tasmanians and the massive famines in India as the products of mistaken decisions, of neglect and misjudgment, rather than of any deliberately exterminatory intent.

One possible response to this is to dispense with genocidal intent as a necessary condition of genocide. In both of these cases, a group defined in national or in racial terms was in fact destroyed, partially or almost wholly, as a direct consequence of a particular course of action pursued by colonial elites. Intent is important to legal proceedings where the guilt or innocence of individuals is at stake. It is likewise important to moral discourses that pass judgment on individuals. However, as Thompson and Quets point out [1990: 246] intent as a necessary condition is problematic if 'genocide' is to be used as an analytical concept for social-scientific purposes. They draw the analogy to the concept of 'stratification':

A definition of stratification as constituted by actions committed with the intent to produce it would be quite inappropriate. It would mean that even where one social collectivity was known to have been systematically disadvantaged by the actions of another, if it could not be shown that these 
actions were committed with the intent of producing stratification as such, we would be unable even to claim that stratification had occurred.

[Thompson and Quets 1990: 247]

Like stratification, genocide is a "large-scale composite social action involving multiple actors and multiple actions"; therefore the same considerations that make defining stratification in terms of intent apply to genocide. Thompson and Quets distinguish between 'intentional' and 'purposive' action. They do not clarify the meaning of this distinction, but it is implied that purposive action may produce unintended outcomes. If, following this usage, we understand genocide as "the destruction of a group by purposive action", then the relevance of specifically genocidal intent to any given genocidal event is an empirical question. Genocide may be intended, or may be an unintended consequence of actions whose purpose lies elsewhere.

Consistent with this approach, Tony Barta [1987] treats the ongoing destruction of Aboriginal peoples in contemporary Australia as the unintended consequence of the expansion of a post-colonial society that systematically makes no place for an Aboriginal presence within itself. In this respect Barta argues that Australia is a genocidal society, independently of whether this is intended by any of its members. Barta's definition of genocide involves a certain problem, however. He says:

My conception of a genocidal society - as distinct from a genocidal state is one in which the bureaucratic apparatus might officially be directed to protect innocent people but in which a whole race is nevertheless subject to remorseless pressures of destruction inherent in the very nature of the society. [Barta 1987: 240]

Two words leap out: 'race' and 'nature'. Barta's formulation implicitly presents these as objectively existing entities. 'Race', used without qualification, is of course problematic 
because it reproduces racializing discourse, and because it narrows the range of possible victims of genocide beyond even the terms of the $\mathrm{UNGC}^{120}$. 'Nature' makes Barta's definition susceptible to Moses's [2002: 27] accusation of determinist structuralism. To claim that colonialism by its very nature produces genocide creates a number of problems: it ignores the subjective and the agential aspects of social relations generally; it ignores the question of why colonial projects resort to physical extermination in some instances and not in others; it implies that genocide was inevitable; it interferes with any attempt to hold concrete subjects morally accountable for genocide. Barta's attempt to circumvent completely the question of intention involves him in a structure-agency dilemma (or, perhaps more specifically, a determinist-voluntarist dilemma). As I have discussed in Chapter 4, Elias argues that structure-agency dilemmas are a product of egocentric thinking in which social structures are understood to be external to individual subjectivity [Elias 1978: 17]. Given such externality, the relation between structure and agency must be one of greater or lesser constraint of the former on the latter. Elias claims to displace such dilemmas with the concept of figurations, in which social structures are the product of horizontal relations among interdependent subjects rather than vertical relations between autonomous individuals and reified social facts. This implies that genocide, like any other social event, always contains an irreducibly subjective dimension ${ }^{121}$ and therefore cannot adequately be conceptualized as a purely objective phenomenon. This means that dealing with the problem of intentionalism by denuding genocide. 
the subjective dimension from genocide is untenable; it leads to treating 'genocide' as a roving ahistorical essence.

Still, 'subjective' is not synonymous with 'intentional'. One can avoid Barta's perhaps inadvertent essentialism about social groups by understanding these in terms of intersubjectively constructed collective identity rather than with reference to fixed categories like 'race'. With respect to perpetrators, Thompson and Quets's use of the distinction between 'intentional' and 'purposive' would seem to let us sidestep the tired structure-agency dilemma. The notion of 'unintended consequences' is a familiar one in sociology; certainly, Elias makes free use of it in The Civilizing Process and elsewhere [e.g., Elias 2000: xiii, 348-349, 384-386]. Nevertheless, there are a few problems with the notion of genocide as an unintended consequence.

First, this notion implies a clear separation between the (presumably subjective) intentions of actors and the (presumably objective) consequences of actions. In Weberian terms, it implies that the consequence of an action is disconnected from its meaning ${ }^{122}$

[Weber 1978: 4, 8]. For example, Patricia Marchak states that

The legal definition of intention to commit genocide refers to actions that have the foreseeable consequence of harm or destruction, whereas motivation is the reason for such actions. This definition presents

121

To use the terms 'subjective' and 'objective' at all is to sacrifice precision for convenience. A thoroughly figurational sociology abolishes the boundary, and therefore the opposition, between 'subjective' and 'objective'.

122
It may be objected that an unintended consequence requires only that consequence be disconnected from the motive, not the meaning, of the action. This objection is unsound, however. Weber says, for example, "we understand the motive of a person aiming a gun if we know that he has been commanded to shoot as a member of a firing squad, that he is fighting against an enemy, or that he is doing it for revenge" [Weber 1978: 9]. In this example, aiming a gun is still aiming a gun regardless of the motive, although its significance depends on context. With regard to genocide, the phrase "intent to destroy, in while or in part, a national, ethnical, racial, or religious group, as such" does not imply that such destruction is an end in itself; like aiming a gun, genocide may be fitted into any number of motivational contexts. 
something of a conundrum for the theorist, since it lumps together those who deliberately set out to eradicate a civilian population and those who destroy a population incidentally and without deliberation. [Marchak 2003: 33]

Marchak's formulation implies a situation in which the consequences in question are unknown to the actor, either because they are unforeseen and unfold after action has ceased, or because they are invisible while action is ongoing. However, the genocides I examine in this section do not fit either of these criteria. In both examples, genocide required a sustained program of action in which the outcomes of action were continually being made known to the actors. In Karin Knorr-Cetina's phrase, these events were decision-laden [Knorr-Cetina 1981: 5]. They involved "chains of decisions and negotiations through which their outcomes are derived". In these sequences, actors, who themselves had been selected for the institutional locations they occupied, made further selections - of personnel, of expenditures, of the use of force, and so on - on an ongoing basis, with the effect of producing and sustaining a genocidal outcome. Different decisions could have produced different, non-genocidal, outcomes. My argument, simply put, is that because actors intentionally acted in ways which they could see were causing the destruction of social groups, that destruction should be considered intentional.

One important objection to this argument needs to be mentioned: that in both examples, the destruction in question was rationalized by the colonial authorities as being inevitable, the result not of the colonizers' own choices but of mechanical processes beyond human control. This suggests that intent to destroy was not a feature of meaningful social action, because the actors did not see the destruction as originating from themselves. Resolving this objection would seem to entangle us in the fraught, and 
possibly irresolvable, question of whether the actors in question actually believed their own claims about inevitability. Framing the problem of intent in this manner obeys the logocentric and egocentric model in which individual minds, existing prior to social relations, contain various meaningful contents including intents, and in which these contents are knowable most immediately by speech, less immediately by writing and other forms of practice. If we conceive meaning to be relational, on the other hand, then actions can be intentional without intent being present to consciousness. Consider the following statement:

Sixty years after the Holocaust, we are still searching for the document signed by Hitler ordering the total extermination of the Jews of Europe. In the case of the Holocaust, it is through the actions of the Nazis, their nearly successful attempt at the total extermination of the Jews of Europe that we know their "intent". [Sinnreich 2004]

This statement can be read in two ways: first, that we know genocidal intent was present to Hitler's consciousness even though there is no record of it; second, that we can know his intent regardless of what he knew about his intent. In the following section I will show how genocide was intended in ways that even the genocidaires likely did not understand at the time. If I can show how someone's intentions may be genocidal without their realizing it, I can perhaps add another analytical tool to the contemporary struggle for early detection and prevention of genocide.

\subsection{TASMANIA}

By an entirely consequentialist standard, what the Aboriginal Tasmanians experienced in the early nineteenth century was genocide. As a result of European invasion and occupation, through murder, massacre, displacement from food sources, 
kidnapping of women, and internment, the form of life practiced before colonization was irrevocably destroyed and the Tasmanians were brought to the very brink of cultural and physical annihilation. However, we need not simply adopt a consequentialist standard. Certainly we want to understand how this event happened, and that involves taking into account the social action of the perpetrators. Was this an accidental genocide? Even if we consider only the events up to 1835 , we can do away with the notion of unintended consequences: the colonization of Tasmania was an intended process, and it quickly became clear that this process was tending towards the complete destruction of the aboriginal population. After 1835, awareness of the destructive effects of colonial policies is reflected in the concern of people like Chief Justice Pedder, who objected to the relocation of the Tasmanians to Flinders Island in the first place [Ryan 1996: 151]; or Major Thomas Ryan, who visited the settlement, reported that the Aborigines' living conditions were so poor as to be likely to bring about their extinction, and recommended both a new site and "vastly improved rations" [ibid.: 186]; or James Stephen, undersecretary in the Colonial Office in London, who stated "why we should persevere in a policy at once so costly to the author, and so fatal to the objects of it, I cannot imagine" [quoted in Ryan 1996: 202]. Ryan is careful to argue that destruction of the Aboriginal Tasmanians was not a consequence simply of contact with Europeans, or even of coexistence with them. Although relations between sealers and aboriginals in the coastal regions were fraught and occasionally violent, stable and mutually beneficial social relationships could be formed between the two groups. The key issue was land: European presence became a threat to Aboriginal survival with the introduction of sheep- 
farming, which usurped the kangaroo-fields that provided a key element in the diet of the southern tribes. Ryan notes ironically that sheep-farming was discontinued in the western part of the island after 1832 , so that tribes in these areas might have survived had they not been taken to Flinders Island [Ryan 1996: 172]. In sum, the destruction of the Tasmanians was not a product of the European presence or European colonization as such, but of the specific forms that that presence took. Another major source of destruction for the Aboriginals was murders by settlers. It seems likely that the colonial authority could have done more to stop these murders, if only because it actually did so little - for example, no colonist was ever charged with the murder of an Aborigine (see p.304 above). In Ryan's account, culpability for the destruction of the Aboriginals is not confined to the upper tiers of the colonial hierarchy; choices were made by sealers and other settlers. Nevertheless, the genocide of the Tasmanians was not an uncontrollable decentralized process. It could have been halted if the colonial authority had been willing to make certain costly and difficult choices:

Certainly, colonialism in Australia, as elsewhere, could not be halted in the manner of flicking a light switch. [...] But only a miserably attenuated concept of intention would absolve it in these circumstances. The rhetoric of inevitability also served to mask choices open to policymakers, choices they were not prepared to entertain because they fundamentally approved of the civilizing process in which they were engaged. The fact is that they did not take their own humanitarian convictions seriously enough to implement the radical measures necessary to prevent indigenous deaths, whether caused by massacre or disease, for it would entail relinquishing control of the land and jeopardizing the colonizing mission. [Moses 2002: $30]$

Once the genocidal effects of settlement had become apparent, continuation of the colonial project in its current form involved a decision to accept those consequences. 
Discourses of the inevitability of Aboriginal extinction reflected the non-negotiability of a colonial vision that intentionally made no place for Aborigines qua Aborigines.

How this problematizes the distinction between purposive and intentional action can shown by transposing Knorr-Cetina's claim regarding the decision-laden quality of scientific research to the field of empire-building. The destruction of the Aboriginal Tasmanians did not involve one instance of purposive action followed by a series of automatic and uncontrollable consequences; it involved a multitude of intentional decisions taken over a continuous period of time. These included not only the decision to remove the Tasmanians to a colony, but the decision of where to locate it, of what sorts of facilities to construct, of how to govern the colony - how much freedom the Tasmanians would be given to practice their own culture, for example. There were decisions regarding what kinds of material supports, including food provisions, clothing, and housing, would be provided. In the making of these decisions, the desire to minimize expenditure had high priority [Ryan 1996: 203]. Each of these decisions represents an instance of intentional social action, inasmuch as there is no appreciable slippage between intent and consequence. There is no doubt that the deculturation of the Tasmanians was specifically intended by Arthur, Robinson, and to a varying extent all those who came after [Ryan 1996: 152, 183, 196, 209]. However, the physical suffering and death of the Tasmanians could be an unintended consequence if the colonial authority were not in a position to foresee it in advance, or observe it at the time. As it happened, material support for the colony was insufficient for the health and well-being 
of its Aboriginal tenants, though not for its British staff ${ }^{123}$. The inadequacy of food and housing was pointed out to the responsible authorities by Major Ryan and, later, by the Tasmanians themselves, but was improved only marginally and insufficiently. The resettlement to Oyster Cove only underscores the intended quality of the physical nearextinction of the Aboriginal Tasmanians. Here was an instance where the colonial authority did deliberately alter its policy, in response to complaints from the Tasmanians themselves. It was a moment at which all the priorities that could have been changed were instead reaffirmed: the priority of low expenditures for support of the Aboriginals, of placing the interests of British settlers categorically ahead of Aboriginal well-being, of making Europeanization of the Tasmanians a precondition for their inclusion in colonial Tasmania. If the Aboriginal survival had been given precedence over these other priorities, the Aborigines would not have been placed in inadequate housing on a cold, vermin- and disease-infested mudflat, with an ever-decreasing budget devoted to their welfare.

In 1905, in the context of a war against the German colonial invader, the Herero of South Africa were driven into the Omaheke Desert by German armed forces and kept there by a 250-km cordon; there they died a "slow, agonizing death" [Drechsler 1990: 243]. In 2004, so-called 'black' residents of the Darfur region of Sudan have been driven from their homes by government-sponsored paramilitaries in the context of a civil war and confined to huge refugee camps; the government of Sudan has taken active measures to prevent international aid from reaching those camps, thereby threatening those in the

123 Tellingly, the cost of the salaries of Europeans stationed at Wybalenna was "nearly double that of 
camps with mass death by starvation and disease [Nolen 2004]. Both events have been labeled genocide [Chalk and Jonassohn 1990: 230; Fein 2004; Reeves 2004]. For both, exclusion from the community of obligation has a spatial dimension: expulsion from homes and confinement to a space where the necessities of life are unavailable. If the extermination of the Tasmanians was not a declared policy of the colonial government, a similar exclusion and confinement was. Inside the boundaries of the Flinders Island and Oyster Cove settlements, the Aboriginal Tasmanians were outside the community of obligation, where inexorably they died of attrition.

I think we can make a distinction in this situation between 'decision' and 'choice'. Just as scientists in a laboratory may feel that the research decisions they make are not ultimately up to them but are determined by prior considerations, so the option of modifying or aborting the colonial process may not have seemed viable or realistic to Lieutenant-Governor Arthur, to Robinson, or others whose decisions were crucial to the near-extinction of the Aboriginal Tasmanians. If 'choice' implies a degree of indeterminacy or underdetermination, 'intention' does not; intentional action may be determined, and yet remain intentional. That the genocide of the Aboriginal Tasmanians resulted from intentional social action does not necessarily mean that a high priority was ever attached to this outcome or that it was ever pursued as an end in itself. To think otherwise is to conflate the importance an event has to us as observers with the importance it has to its architects. Rather, in the history of the Aboriginal Tasmanians, the fact of genocide testifies to the unimportance of its victims. Or, more precisely, it 
attests to the unimportance of the fact of their physical and cultural survival. The Tasmanians were tremendously important as long as they served as an obstacle to the construction of a civilized, British Tasmania. Once interned, they lost this importance. They continued to be important to Robinson as a test case of the universal validity of Europe's defining cultural accomplishments, its civilization. They were important to Jeanneret mainly as objects of domination and exploitation. But at every turn these various ways in which they were important worked against their survival; the nature of their importance placed them outside the community of obligation. Their physical extermination was produced almost casually, as a byproduct of the active negation of their political and cultural existence.

\subsubsection{INDIA}

As in the Tasmanian example, a purely consequentialist definition of genocide is applicable to the great famines of Victorian India. British policies imposed on Indians conditions of life that destroyed in substantial part the nation of India by bringing about the deaths of tens of millions of people. If specific regions are considered, the extent of destruction is greater: during the 1876-78 famine, for example, "in scores of drought districts, at least 10 percent of the population perished; in Gujarat, the toll soared to a sixth of the population, perhaps even more" [Davis 2001: 173]. Again, if the Indian famines are treated in the same manner as the Ukrainian famine of 1932-33 and specific social groups within Indian society are considered, then the collective dimension of mortality is more evident, as the famine disproportionately affected agricultural labourers and poor farmers. Comparison with the Ukrainian famine, which is easier to recognize as 
the product of intentional action, brings out other parallels: both countries were under imperial domination; both imperial powers were imposing a program of broad social change that involved fundamental alterations to the relations of production; in both situations absolute food stocks available were sufficient to feed the affected population, but this food was actively made unavailable, at least in part through direct physical coercion by agents of the state. In both the 1932-33 Ukrainian famine and the 1876-79 Indian famine, food exports from the famine-stricken country actually increased substantially. One substantial difference between the two episodes is that in Ukraine, food was confiscated directly from producers by agents of the state, whereas in India the affected population had already been separated from direct access to food by the capitalization of agriculture.

Again, however, an entirely consequentialist understanding of events gives an incomplete picture. Characterizing the viceroyalty of Lord Lytton, Davis says:

In zealously following his instructions to the letter, he [Temple] became to Indian history what Charles Edward Trevalyan - permanent secretary to the Treasury during the Great Hunger (and, later, governor of Madras) had become to Irish history: the personification of free market economics as a mask for colonial genocide. [Davis 2001: 37]

What justifies applying the category of 'genocide' to the Indian famine of 1876-79, or the double famine of 1896-1902 after it? After all, famine was significantly determined by natural phenomena - abnormally low rainfall, for the most part - to which social systems could only respond. Viceroy Lytton, along with British Finance Minister Sir Evelyn 
Baring, and presumably others ${ }^{124}$, expressed dogmatic conviction in the objective correctness of Adam Smith's claim that interfering with market mechanisms would only worsen the famine, and in Malthusian claims that famine in India resulted from sheer overpopulation [Davis 2001: 31-32]. Just as Arthur and Robinson's 1831 decision to intern the Aboriginal Tasmanians was informed by an erroneous but superficially sincere belief that this course of action would save their lives, it can be claimed that the intention of the British colonial administration was to avert famine, and that it failed despite its intentions because its understanding of the situation was inadequate. In this event, the famines would have to be treated as, at most, an accidental genocide.

As it happens, several aspects of the Indian famines problematize their status as accidents. As in the Tasmanian genocide, events in India did not proceed inexorably from a single early decision, but required ongoing decisions both before and after the extent of the famine became evident. For example, the so-called Temple wage was immediately met with medical testimony to its insufficiency, which Temple chose to disregard; by May 1877 officials in Madras reported that half the inmates of relief camps (receiving the Temple ration) were too weakened to carry out any physical labour, and shortly thereafter Dr. Cornish observed that monthly mortality in the camps had risen to a rate equivalent to $94 \%$ per annum. Temple responded only by blaming the victims, accusing them of laziness and of choosing starvation over "submission to even simple and reasonable orders" [Davis 2001: 38-41]. Following the relief strike, conditions on

124 Davis says that "Smith's injunction against state attempts to regulate the price of grain during famine had been taught for years in the East India Company's famous college at Haileybury. Thus the viceroy was only repeating orthodox curriculum when he lectured Buckingham that high 
the country were reported by dissident journalists such as William Digby, and "a group of old Indian hands and Radical reformers" in England "kept The Times's letters column full of complaints about Calcutta's callous policies" [Davis 2001: 43]. Viceroy Lytton dismissed these reports as hysterics, but the secretary of state for India wrote to Lytton advising him to loosen restrictions on the discretionary ability of local governments to provide relief. Mortality estimates showing the extent of the famine were published by the Sarvajanik Sabha (Civic Association), and by Lord Buckingham. Evidence of mass famine was visible in large cities such as Madras, where refugees from the countryside dropped dead in the streets. Lytton himself visited Madras in August 1877 and was in a condition to observe with his own eyes the skeletal bodies of the starving, but following this visit he took active measures to prevent the Duke of Buckingham from raising relief funds in England [47-48]. Pleas for relief efforts from all levels of the civil service were rebuked, and even civilians who opened private relief efforts were sanctioned [51-53]. The final report of the Famine Commission of 1878-80 affirmed that the correct course of action had been taken, and policy remained the same under two different Viceroys during the famines of 1896-1902. In sum, the maintenance of relations of famine required a program of intentional social action sustained over considerable time, against opposition, and in the face of accumulating information regarding its consequences.

The fact that genocidal famine resulted from intentional social action does not imply that genocide was an end in itself or even an specific goal for the British in India. Rather, famine was a byproduct of the pursuit of priorities more important than the 
preservation of human life. One consistent priority was that relief efforts should not threaten the profitability for England of the occupation of India.

Both Calcutta and London feared that 'enthusiastic prodigality' like Buckingham's would become a Trojan horse for an Indian Poor Law. [...] None of the principle players on either side of the House of Commons disagreed with the supreme principle that India was to be governed as a revenue plantation, not an almshouse. [Davis 2001: 33]

British authorities expressed concerns that "the embarrassment of debt and weight of taxation consequent on the expense" would be "more fatal than the famine itself" [37]. In 1876, Britain planned to invade Afghanistan in order to pre-empt Russian imperial aspirations there. Sir John Strachey, chief budgetary advisor to Viceroy Lytton, "constantly reminded" him that Indian taxpayers were to bear the entire costs of the Afghanistan campaign. Expenditures for famine relief were therefore delegated to the status of a distraction from or drain on the war effort [28, 51]. Again in 1896, the possible expense of systematic poor relief in India was considered prohibitive [143]. Again, expenditure on a military campaign took precedence over expenditure on famine relief, to the extent that the Famine Fund itself had been eaten up by appropriations for military expenditure. One periodical estimated that over a hundred million dollars was spent on Queen Victoria's Diamond Jubilee [157-8]. Thompson and Quets's distinction between purposive and intentional action breaks down the more that we consider a complex event in its small historical detail. Famine may not have been a specific goal of British policy, but it was implicit in the intentions of that policy, even if the actors

situation"" [Davis 2001: 31]. 
involved were not conscious of this fact. This is corroborated by the fact that once famine became apparent, the anti-relief policy did not waver, but actually intensified.

Unsurprisingly, the implicitly genocidal intentions of those who governed India's economic system were occasionally accompanied by explicitly genocidal affirmations of Malthusian ideology. Sir Evelyn Baring, finance minister during the 1876-79 famine, said afterwards: "every benevolent attempt made to mitigate the effects of famine and defective sanitation serves but to enhance the evils resulting from overpopulation" [Davis 2001: 32]. In the same vein, an 1881 report concluded that " $80 \%$ of the famine mortality were drawn from the poorest $20 \%$ of the population, and if such deaths were prevented this stratum of the population would still be unable to adopt prudential restraint. Thus, if the government spent more of its revenue on famine relief, an even larger proportion of the population would become penurious"[32]. These quotations indicate a deliberate intent to decimate the Indian population in order to improve it: to withhold food from a portion of the population that is considered congenitally unfit, understood in terms of 'prudential restraint' according to the rule of utilitarian political economy. This is a specifically genocidal intent, framed after the deed had been done. India's starving found themselves in the wasteland outside the community of obligation, just as surely as the Tasmanians, the Herero, and the Ukrainian Kulaks.

Moreover, the devastation of famine unfolded within the context of larger genocidal tendencies integral to the colonial project. In Axis Rule in Occupied Europe, Lemkin defines genocide in terms of the destruction of the national pattern of the affected group and the imposition of the national pattern of the oppressor [Lemkin 1944: 70]. For 
Lemkin, genocide goes beyond denationalization, but is in some ways an extension of it. British policy in India did not aim at the complete obliteration of Indian culture through its total Anglicization (which in any case would have contradicted racist assumptions about the essential basis of Englishness), but it did pursue the partial obliteration and Anglicization of India: through the takeover of local political and juridical institutions; by destroying the basis of economic autonomy for Indians; and by imposing English culture and language, especially through the school system. In addition, we should consider the Sepoy Rebellion (also called the Indian Mutiny) of 1857, which left behind indelible memories of "sepoys blown apart at the mouths of cannons and whole forests of peasants writing at the noose" [54]. The violence with which the Sepoy Rebellion was suppressed served as a precondition for the 1876 famine, at least to the extent that memories of that suppression inhibited Indians from responding to famine with another violent rebellion against British rule. More broadly, victory over the Rebellion was a precondition for British domination in India at all. Taken together, the several violences of colonial rule murderous repression of rebellion; cultural denationalization; structurally produced famine - form part of the same figuration. Partial genocide was one dimension or element of the British occupation of India. This genocidal element was balanced against other elements, such as economic exploitation and geopolitical power, that made the British dependent on the Indian population to some degree and prevented the occupation from becoming a complete extermination. But extermination could come to the fore where it was a byproduct of the very act of establishing domination, as it was during the late Victorian holocausts. 


\subsubsection{RECAPITULATION}

In Tasmania the colonizer's intention was to create a British Tasmania with no place for Aboriginal identity. In itself this is a genocidal intent. Even if the detail of physical extermination is not a specific element of that intent, it accords with it and is a logical extension of it. As a result, the evident progress towards extinction of the captured Aborigines failed to create a sense of contradiction that could provoke a change in the colonizers' course of action. Similarly, in India the intention was to create an economic system that was governed by the rules of laissez-faire capitalism, and which could be directly exploited through taxation for the benefit of British imperial goals. This intention made expendable the lives of people whose class location put them in an insecure relationship to cash-mediated food supply, which was made to be the only food supply. In both of these examples, colonizers' intentions placed certain categories of people beyond the community of obligation. The genocidal relation inscribed in colonizers' intentions was instantiated only in conjunction with other, contingent events, however. If the climate and local food supply at Flinders had been better, the Aborigines might have survived. If there had been no rainfall shortages, the famines in India would never have occurred as they did. The operation of these contingencies masks the protogenocidal quality of the intentions involved, and hence masks the genocidal quality of the events themselves. A figurational analysis that takes account of material factors and uses a non-logocentric conception of intentions brings out an intentionality that can then be expressed in the following terms: in both cases the perpetrators knew that they were destroying populations, but rationalized that destruction as inevitable and necessary 
because they were not willing to consider abandoning the course of action that was producing that destruction.

That makes their actions genocidal, not just in scholarly terms but in the most conventional moral language. But my account is not primarily concerned with moral judgment. Davis says "it is the burden of this book to show that imperial policies towards starving 'subjects' were often the exact moral equivalents of bombs dropped from 18,000 feet. The contemporary photographs used in this book are thus intended as accusation, not illustrations." [Davis 2001: 22] Davis is therefore concerned with the moral culpability of Lytton and other important figures; hence his attention to such psychological details as Lytton's arrogance, or his possible madness [30-31]. In contrast to this, my sociology is not directly concerned with passing moral judgment on individuals, but attends instead to practices and the fields they engender. A materialist and figurational sociology aims to find, in the unfolding dynamic structures of practice, the geneses of genocidal violence. It is guided by the idea that "the inferno of the living ... is already here, the inferno where we live every day, that we form by being together" [Calvino 1979: 124], and by this objective: in the midst of civilization's holocausts, to "seek and learn to recognize who and what, in the midst of inferno, are not inferno, then make them endure, give them space."

\subsection{Civilizing Genocides}

\subsubsection{TASMANIA}

A crucial part of my argument is to show how genocide can be understood as socially produced rather than as the consequence of social breakdown. Both the 
historical examples in this section illustrate this: both are produced by the expansion of the British Empire, and hence by the expansion of European civilization. Colonialism involved the extension, through a process of competition between sovereign powers, of territorial monopolies of force, the reproduction of sovereignty on an expanding scale, which burst the boundaries of Europe itself to colonize the rest of the world. And by the same gesture, colonialism entailed an expansion of specifically European forms of civilized habitus, of European ways of performing subjectivity. In the colonization of Tasmania, this expansion happened primarily through direct demographic transplant: the Aboriginal Tasmanians were displaced from their land, and British subjects arrived. But another aspect is also important: the resubjectification of the Tasmanians themselves.

Recall Rowley's statement that Robinson hoped Flinders to be "the prototype of the multi-purposed institution, asylum, hospital, training centre, school, agricultural institution, rationing centre, pensioners' home, prison". We are instantly reminded of Foucault's observation that "prisons resemble factories, schools, barracks, hospitals, which all resemble prisons" [Foucault 1995: 228]. So this formal resemblance is striking; it suggests a common process, or processes with a common ancestry. But it points to something else as well: the considerable investment of Robinson, captor of the Tasmanians, in their civilization. Both Robinson and Arthur assumed that if the Tasmanians were to survive they would have to be civilized, and that assumption informed the entire subsequent fate of the interned population. In fact, the whole Tasmanian question, from the early encounters with French explorers, through settlement, war, and captivity, was chronically framed in terms of their status as savages 
and their capacity to be civilized. At stake was a question about the mutability and the natural equality of human beings.

On paper Robinson was committed to allow the Aborigines to pursue their own culture, but in practice he intended to use the artificial environment of Flinders Island to prove that his captives wished to advance towards civilization, which consisted of an appreciation of the main tenets of Christianity and a disposition to adopt European standards of personal cleanliness, dress, and housing, develop a desire to accumulate money and material possessions, and pursue agriculture. [...] Robinson was determined to prove wrong the natural inference drawn by the colonists that the Aborigines possessed certain 'anti-civilizing properties' which prevented change. [Ryan 1996: 183]

This helps explain Robinson's determination to go on civilizing them even while they were dropping dead before his eyes. Under conditions of barbarous civilization, conformity to the norms of civilized habitus is a precondition for the maintenance of identity, of selfhood; symbolically, and ultimately practically, this conformity is a precondition for each actor's survival. If enrolment in barbarous civilization was made to be a precondition for the survival of the Aborigines, this was an extension of the fact that Robinson himself, and every other civilized subject involved in colonization, was subject to the same imperative. That the Tasmanians could continue to exist without being civilized was consequently unthinkable. This accounts for Robinson's curious intransigence:

To achieve all this Robinson not only needed a willing Aboriginal community but also regular supplies of European food, reasonable living conditions, a sympathetic European staff, and an awareness of the psychological dislocation that this would create among his victims. That he had none of these did not deter him. [op. cit.]

This civilizing requirement continued until the extinction of the Oyster Cove colony. 
What the Europeans wanted of the Tasmanians was their voluntary collaboration in the active negation of their being, a negation effected through the fundamental reconfiguration of their relationship to themselves, each other, and the world. It is no wonder that the Tasmanians resisted for so long, and never succeeded in taking it on. It was a negation that could never pay off: For one thing, Tasmanians were expected to adopt an English habitus, but not to stand up for their rights like English subjects. Elias observes that as colonized groups succeed in adopting the habitus of the colonizer, the distance between colonizer and colonized shrinks and so the system of difference that reinforces the civilized status of the colonizer is threatened [Elias 2000: 385]. This happens at the same time that the civilizing process itself tends to reduce these differences through propagation of its own standards. So one can see what a contradiction is created for civilized persons at any given moment. Elias notes that colonizers may respond by increasing the refinement of their conduct; he does not consider what other methods they may adopt, but these are not difficult to imagine: a refusal to provide the colonized with the means to civilize themselves successfully, a refusal to recognize civilized behaviour even when the colonizer successfully performs it.

This process is exemplified in the tragic experiences of Walter George Arthur, "the one 'fullblood' Aboriginal Tasmanian who tried to conform to European mores":

He had developed a schizophrenic personality: sometimes he was a resistance leader demanding better conditions for his people; at other times he was a desperate conformist aching for the acceptance of white society. But he was never 'good enough'. [Ryan 1996: 212]

Walter George Arthur's experience dramatizes, in the context of poverty and marginality, the dynamic Elias describes in his analysis of Levantinism in the upper classes of 
colonized groups, which he poses in terms of the challenges facing the upwardly mobile within a class structure.

... people in this situation acknowledge in one part of their consciousness the upper-class norms and manners as binding on themselves, without being able to adopt them with the same ease and matter-of-factness. It is this peculiar contradiction between the upper class within themselves [...] and their incapacity of fulfilling its demands, it is this constant inner tension that gives their affective life and their conduct its particular character. [Elias 2000: 431]

Walter George Arthur had been groomed to become a catchetist, but this road was closed to him because his relationship with Mary Ann Cochran in 1838 had not met Christian standards of chastity. After the move to Oyster Cove, he and Mary Ann had lived independently in a three-room bush cottage "surrounded by the trappings of European civilization", but they "preferred the communal warmth of the [Oyster Cove] station, where they could relax and share a bottle with their own people" [Ryan 1996: 212]. An alcoholic, Walter George Arthur died in a boating accident in 1861, a victim of the "constant inner tension" resulting from a self divided between identification with European civilization and with his "own people". It is small wonder that Robinson's project was a failure. The captured Aboriginal Tasmanians were literally civilized to death.

The civilizing genocide of the Tasmanians shows most clearly an aspect of barbarous civilization not considered by Elias: its capacity to produce relations of social independence as well as interdependence. In Elias's account, the production of more and more extended relations of interdependence is an important element in the pacification of the warrior class and of social life in general. The extension of interdependence is 
theorized as a direct product of the extension of the civilizing process as such. But in Tasmania, as the extension of civilization involved the sudden construction of relations of independence, or of impunity. Through colonization, the Tasmanians and British were brought into social relations with each other where none existed before. But the British did not need the Tasmanians as labour, or for any other purpose that involved Tasmanian survival; therefore this active relationship was one where the more powerful party did not depend either on the less powerful or on some other moderating agent. It was a relation of almost total impunity. The production of relationships of impunity is a general feature of all of the examples I discuss in this chapter, and of civilizing genocides in general.

\subsubsection{INDIA}

The late Victorian mega-famines of India occurred as a result of the implementation of particular economic policies, the commercialization of Indian agriculture for the benefit of the English economy, that were in themselves one of the raisons-d'être of colonialism itself. Colonialism is both effectively and explicitly an extension of the civilizing process as Elias conceives it. Colonialism involves the extension of territorial monopolies of force, in the context of competition with other sovereign powers, into new spaces. It also involves the exportation of European standards of civilized conduct, of the European habitus, to the colonized territory: both demographically, via the British who made India their home temporarily or permanently; and through dissemination, through schools, cultural institutions, propaganda, and so on, and also by making such conduct a necessary tool of social advancement for Indian elites. 
It is also explicitly a part of the civilizing process because 'civilization' was one of the key concepts used to legitimate the colonial project.

Elias says: "It is not a little characteristic of the structure of Western society that the watchword of its colonizing movement is "civilization"" [2001: 431]. Barbarous civilization requires both the production and the reduction of difference. On the one hand, civilized behaviour is a means of distinction and all the social power that that conveys. On the other, by presenting itself as normative it entails its own dissemination.

This civilization is the characteristic which confers distinction and superiority on Occidentals. But at the same time Western people, under the pressure of their own competitive struggle, are bringing about in large areas of the world a change in human relationships and functions in line with their own standards. [...] Largely without deliberate intent ${ }^{125}$, they work in a direction which sooner or later leads to a reduction in the differences both of social power and of conduct without colonists and colonized. [Elias 2000: 385]

This double movement is preceded by a similar double movement within Europe itself: standards of civilization both enhance class distinctions and gradually efface them, as civility spreads, via upwardly mobile individuals and groups, into the lower strata of the class structure [Elias 2000: 386; 432-433]. By implication, this double motion means that barbarous civilization depreciates, so the renewal of civilizing distinction requires the expansion of the civilizing-barbarizing process into new social spaces and the constitution of new uncivilized subjects. In addition to the geopolitical and economic gains from colonization - which "doubtless play no small part in Western expansion"

125 My comments on intent, above, apply to Elias's frequent use of the notion of unintended consequences. This notion is imprecise at best; if a consequence is built in to the structure of an intentional action, neither calling it unintended nor calling it intended quite fits. With respect to the specific use that Elias wishes to make of the term, he would do better to speak of unforeseen consequences than unintended ones. 
[Elias 2000: 431-432], and can be understood as intimately connected with the civilizing process - this engine of expansion helps account not only for the fact of colonization but for the particular form of its legitimation, the myth of 'the white man's burden' fervently subscribed to by so many colonizers and not a few of the colonized.

The preconditions for the late Victorian famines in India were produced by the implementation of a particular system of economic relations, by a complete rearrangement of the relations of production and consumption. As Elias observes, "the transformation of the whole of social existence is the basic condition of the civilization of conduct" [384]. In economic terms this involved producing a commodified, exportoriented agricultural economy governed by unregulated capitalist markets. This system placed Indian agricultural producers in a relation of dependency with respect to the world markets, a dependency that persists to this day. The production of these relations incorporated Indians into the extended chains of interdependency that characterize the civilizing process in Elias's account. It transformed their subjectivity in an individualizing direction, at least in economic terms. Being guaranteed by the colonizers' legal system, it was thereby underpinned by the territorial monopoly on military and police force that the British Empire possessed in India. In these ways, famine emerged as a contingent extension of the civilizing process.

The social production of famine did involve a breakdown, however, although this was a deliberate, planned, intentional breakdown. Davis notes that Mogul India was "generally free of famine until the $1770 \mathrm{~s}$ ", and that "food security was also probably better in the Deccan during the period of Maratha rule" [285-286]. The Moguls regarded 
the protection of the peasant population as an obligation, and "relied on a quartet of fundamental policies - embargoes on food exports, antispeculative price regulation, tax relief and distribution of free food without a forced-labour counterpart - that were anathema to later British Utilitarians" [286]. Both the Mogul and the Maratha regimes made a point of subsidizing the maintenance of irrigation systems, and employed flexible laws that placed lower tax demands on peasants when crops were bad, taking account of "the crucial ecological relationships and unpredictable climate fluctuations of the subcontinent's drought-prone regions" [287] In short, practices were in place before colonization to lessen the chance that low rainfall would turn into hydrological drought and drought into famine. The extension of civilization into India involved the suppression of these practices.

It also involved the production of new relations of impunity. Prior to the British transformation of rural life, large local landowners had been enmeshed in relations of patrimonial obligation with their social inferiors. These relations inhibited their ability to use famine as a vehicle for upward redistribution of wealth. Under British rule, these obligations were severed. The capitalist world-economy could provide benefits that outweighed the cost of breaking local ties. This meant that large landowners could combine the role of grain merchant and moneylender to their own profit; they could benefit by the default of smaller landowners; they could hoard food grain speculatively, or export it to foreign markets. The colonial government itself was dependent on the agricultural population as a whole, but was not dependent on the short-term survival of any specific fraction of it. The death of millions of small farmers and agricultural 
labourers, and their families, and even the depopulation of districts, would have been a severe blow to previous rulers but did not register as a prohibitive material loss in Imperial calculations. The majority of Indians were therefore brought into a relation of asymmetrical dependence: they depended greatly on persons who did not depend on them. The production of these asymmetrical relations was an integral part of the barbarous civilization of India. Indeed, Davis argues that the dependency cultivated in the Victorian period helps to explain food insecurity in contemporary India and around the world. If that analysis is correct, then the production and maintenance of the Third World is one of the effects of the figurational expansion of European barbarous civilization.

\section{Ottoman Empire and Rwanda}

\subsection{INTRODUCTION}

In the third and final part of this chapter I will discuss the destruction of the Armenian cultural presence within the Ottoman Empire by the Young Turk government during the First World War, and the genocide that unfolded in Rwanda between April and July of 1994. Both of these examples belong to the type of event that is most widely recognized as genocide: the systematic destruction by a state of an effectively defenseless civilian population within its own borders, carried out in the context of war but independently of any immediate military objectives. Both involve the attempt of an elite within the state to maintain its own dominance by fostering ethnically or racially exclusive nationalism. Both examples easily satisfy both the UNGC and Lemkin's conception of genocide. Indeed, if the Nazi holocaust was the event that prompted the 
formation of the concept of 'genocide', the Turkish ${ }^{126}$ genocide was its direct precedent. It was in response to the destruction of the Ottoman Armenian community that Raphael Lemkin, in 1933, submitted to the International Conference for the Unification of Criminal Law in Madrid a proposal "to declare the destruction of racial, religious, or social collectivities a crime under the law of nations" [Lemkin 1947: 146] The 1933 proposal specified two new crimes: 'barbarity', defined as "action against the life, bodily integrity, liberty, dignity, or economic existence" of a person, if performed "out of hatred towards a racial, religious, or social collectivity, or with a view to the extermination thereof', and 'vandalism', defined as destruction of cultural or artistic works for the same reason. The 1994 genocide in Rwanda marks a comparable turning point: more than similar events such as those in Yugoslavia, the Rwandan genocide highlighted the failure of the United Nations to fulfill the mandate of the UNGC through effective genocide prevention. That failure has served as a catalyst for political processes that, ten years later, have led to the appointment of a Special Advisor for Genocide Prevention and the creation of a Genocide Prevention Focal Point in the United Nations [Stanton 2004a, 2004b] - although, like the UNGC itself, the effectiveness of these new measures still remains to be seen.

My narrative in section 3.1.1 of the obliteration of the Ottoman Armenians is drawn primarily from Vahakn Dadrian's The History of the Armenian Genocide. Dadrian's account, the culmination of two decades of research, is based on extensive

126 Although technically the Ottoman Empire had not yet been replaced by the nation-state of Turkey when the genocide of the Armenians took place, most authors speak as if it already had. Amongst other considerations, this usage reflects the fact that the genocide was perpetrated to further the ends of Turkish nationalism. 
research into Turkish and German documents, including autobiographical writings, secret and top secret Ottoman and Turkish state documents, and other documents produced by the perpetrators of genocide and the most immediate bystanders, supplemented by documents from foreign diplomats and Ottoman Armenians themselves. I have, however, drawn on other works in the field where convenient, especially Robert Melson's Revolution and Genocide: On the Origins of the Armenian Genocide and the Holocaust. My narrative in Section 3.1.2 of the Rwandan genocide is mostly drawn from two massive and detailed human rights reports, issued by African Rights and by Human Rights Watch, and is supplemented by several other works on the topic. Both the African Rights and the Human Rights Watch reports are based on extensive field research involving hundreds of interviews with witnesses and detailed investigation of state documents. The African Rights report, which appeared in 1995, organizes evidence by the prefecture and city in which abuses happened and concentrates on identifying the specific perpetrators of specific acts; the Human Rights Watch appeared in 1999 and provides a more synthetic analysis of the institutions and mechanisms through which genocide was effected $^{127}$.

\subsection{HiSTORIES}

\subsubsection{OTTOMAN EMPIRE}

In Biblical-epic tradition, Armenian identity originates with the landing of Noah's ark on Mount Ararat; in historical scholarship, it emerges sometime around $600 \mathrm{BCE}$ [Hovannisian 1990: 251]. Armenians converted to Christianity at the turn of the $4^{\text {th }}$

127 This report is available online at $<$ http://www.hrw.org/reports/1999/rwanda/index.html $>$. Also of 
century CE, and the last Armenian kingdom collapsed at the end of the $14^{\text {th }}$ century, after which the Armenian population was divided between Turkish dominions in the west, and Persian and Russian dominions in the east. In the Ottoman Empire, which governed diverse ethnic and religious groups through multiple, hierarchically ordered categories of citizenship, Armenians enjoyed partial but not full political enfranchisement. They were subject to special taxes, prohibited from bearing arms, unable to give legal testimony, forbidden in some regions to use the Armenian language except in prayer, and occasionally subjected to the devshirme or child levy. Most lived as tenant farmers or sharecroppers under the Muslim feudal-military elite, but some lived as merchants, traders, artisans, and professionals. Despite their partially underprivileged status, they lived in relative peace until the decline of the Empire in the $18^{\text {th }}$ and $19^{\text {th }}$ centuries [Hovannisian 1990: 252]. Their first major opportunity for full citizenship within the Empire came during the tanzimat era of 1839-1876 [Hovannisian 1990: 252]. To appease increasingly self-assertive nationalist movements by dominated groups within the Empire, and to forestall any potential intervention by foreign powers, the Ottoman state passed liberal reform legislation in 1839 and 1856 which gave formal equality to nonMuslims within the Empire [Dadrian 1997: 14, 19], and even promulgated a new, liberal constitution in 1876 [Hovannisian 1990: 253; Dadrian 1997: 29-30]. However, none of these measures was ever substantially put into effect. Over the course of the $19^{\text {th }}$ century, separatist nationalist movements gained strength throughout the Empire, but the Armenians did not take this route [Hovannisian 1990: 252]. Partly because they were 
geographically dispersed throughout the empire and not a majority even in their historic homelands, Ottoman Armenians instead for a long time attempted to use their loyalty to the Sublime Porte to obtain its protection from corruption and persecution. This strategy ultimately failed, and as the Empire unraveled over the $19^{\text {th }}$ century, Armenians became increasingly subject to violent persecution, especially in rural regions where Kurdish tribal paramilitaries, armed and organized by the Sultan, raided non-Muslim villages with impunity [Dadrian 1997: 45-48]. In the 1880s Armenians began to form underground local self-defense groups, which evolved into secret political societies in the $1890 \mathrm{~s}$ [Hovannisian 1990: 256; Dadrian 1997: 114-117].

Between 1894 and 1896, Ottoman Armenians were subjected to a series of massacres that foreshadowed the later genocide. In 1894, Armenian villagers in the Sassun district in Bitlis province refused to pay the protection tax being extorted from them by Kurdish chieftains [Hovannisian 1990: 256; Dadrian 1997: 114-117]. The Kurds charged the villagers with sedition, and obtained Turkish army support to lay siege to the village. Once the defenders were convinced to lay down their arms in exchange for a promise of amnesty, that promise was immediately broken as the combined Kurdish and Turkish forces plundered Sassun and indiscriminately massacred several thousand Armenians. People were killed primarily by bayonet, although there are also reports of young men being burned alive, children being torn apart by main force, and of gross sexual violence including mass rapes of women and girls, and pregnant women being torn open. 
The Sassoun massacre was the first instance of organized mass murder of Armenians in modern Ottoman history that was carried out in peace time and had no connection with any foreign war. [Dadrian 1997: 117]

The government portrayed the event as an attempted coup, establishing a "legacy of denial" [ibid.] that would be taken up by the Turkish state following the 1915 genocide.

The next atrocities were occasioned by foreign intervention on behalf of the Armenians. Such intervention dated back to the Russo-Ottoman Treaty of Küçük Kaynarca of 1774 [Dadrian 1997: 8], and included English and Russian intervention in the Greek War of Independence of 1821-1830 [13]; French and English military intervention in 1860 in response to the massacre of 40,000 Catholic Maronites [23]; direct financial supervision of the Empire beginning in 1881 following its bankruptcy in the 1870s [Hovannisian 1990: 252]; and the Russo-Ottoman Treaty of Stan Stefano in 1878, which compromised Ottoman sovereignty on behalf of national minorities and facilitated the separation of Serbia, Montenegro, and Rumania ${ }^{128}$ [Hovannisian 1990: 253-254; Dadrian 1997: 31]. Between May and October 1895, British, French, and Russian diplomats negotiated with the Ottoman government for measures that would give physical security and greater political enfranchisement to Armenians. On October $1^{\text {st }}$ of

This treaty (established on 3 March 1878) was obtained by force following a unilateral Russian military intervention into and occupation of eastern portions of the Empire near the Russian border, in the Ottoman portion of the traditional Armenian homelands, after the Ottoman Empire had formally rejected the London Protocol of 31 March 1877 . Under the terms of the Treaty of San Stefano, Russian withdrawal was to be conditional on the implementation of effective reforms protecting Armenians from further persecution. These terms were challenged by Britain and Austria, who were concerned to allay growing Russian dominance in the region [Hovannisian 1990: 254; Dadrian 1997: 31]. Aided by the other European powers, Britain and Austria diplomatically impelled Russia to substitute the Treaty of San Stefano for a new accord, the Treaty of Berlin of 13 July 1878 . The main difference was that Russia had to withdraw immediately rather than wait for reforms to be implemented. Hovannisian notes that these events first made the Armenian Question an international issue, but only in symbolic terms. On a practical level, this 
that year, a march in Constantinople of 4,000 Armenian demonstrators protesting the Sassun massacre and demanding equal rights was met with police officers and an organized mob armed with cudgels, and was massacred [Dadrian 1997: 119, 153]. Massacres continued in the city for the next two days, and were followed by "hundreds of small and large massacres throughout the length and breadth of the Ottoman Empire" that continued for the next twelve months [Dadrian 1997: 152, also 153-156; Hovannisian 1990: 256]. Hovannisian estimates that between 100,000 and 200,000 people were killed in these massacres; Dadrian estimates $80-100,000$ killed by December 1895 and 200-250,000 killed by October 1896. Armenians put up military resistance, successfully at Zeitoun from 24 October 1895 to 2 February 1896, and unsuccessfully at Van from 15 to 23 June 1896 (where, again, the defenders were massacred after a negotiated ceasefire). An Armenian paramilitary cell staged a temporary occupation of the Ottoman Bank in Constantinople in August 1896, but this was unsuccessful and only provoked further massacres in that city [Dadrian 1997: 127-129, 131-145]. Dadrian comments that the massacres of 1895 served as a test of foreign willingness to intervene, in which respect they were successful - foreign intervention was minimal and ineffective. In July 1908, the Ittihadist (Young Turk) movement came to power in a relatively bloodless coup that deposed Sultan Abdul Hamit [Dadrian 1997: 179]. The fall of the Sultanate was followed by the partial disintegration of the empire: Bosnia-Herzegovina, Bulgaria, and Crete fell away and Tripoli and Libya were threatened by Italy [Hovannisian 1990: 258]. On 13 April 1909, a counter-revolution was unsuccessfully 
attempted by "an assortment of Islamic fundamentalists, opponents of Ittihad, and Abdul Hamit loyalists" [Dadrian 1997: 181]. Between 14 and 27 April 1909, 20,000 to 25,000 Armenians in the city of Adana and its environs were massacred [Dadrian 1997: 182; Hovannisian 1990: 257]. Anticipating the attacks, several hundred young Armenians had obtained weapons and engaged in a successful armed defense of the Armenian wards of the city. Eventually, however, their resources were depleted, and they agreed to a truce arranged by the British Consul. By this time new regular army contingents had arrived, ostensibly to restore order, and the attackers supported by these new forces "descended upon the totally disarmed and defenseless Armenians, butchering and burning them alive by the thousands. Schools, hospitals, and churches were especially selected for this purpose" [Dadrian 1997: 183]. Warships from England, France, Italy, Austria, Russia, Germany, and the U.S., entered nearby coastal waters, but refrained from intervening in an internal affair of the Ottoman state. The massacres were organized secretly, but appear to have involved government functionaries in concert with Ottoman military authorities, who made use of the arsenals of local garrisons [Dadrian 1997: 182]. The central government, however, publicly and officially recognized the Armenians as victims of wrongdoing, and local tribunals and military courts-martial convicted and executed 124 Turks, along with 7 Armenians, in connection with the attacks. The Ittihadist party officially repudiated the bloodshed and conducted a public memorial to Muslim and Christian sons of the fatherland.

provinces. 
Tendencies towards genocide accumulated over the next few years. Later in 1909 , the Young Turk cabinet declared a state of siege and suspended normal constitutional rights for the next four years [Hovannisian 1990: 258]. During this period, exclusive nationalism grew to dominate in the Young Turk party. "The Ittihadist program of national renewal essentially aimed at discarding as useless, and even as pernicious the traditional concept of multi-ethnic Ottomanism based on the premise of harmony among the various nationalities" [Dadrian 1997: 195]. During the Balkan war of 1912, Ottoman territory in the Balkan Peninsula was entirely taken by Serbia, Bulgaria, and Greece [188-192]. The disastrous outcome of the war "left the very survival of that empire hanging in the balance" [185]. In 1913, the ultra-nationalist faction of the Ittihadist party staged a successful coup [Hovannisian 1990: 258]. From then until 1918, the government was run by the triumvirate of Enver Pasha, minister of war; Talaat, minister of internal affairs; and Jemal, military governor of Constantinople. Despite the rise of these ultra-nationalist tendencies, the most influential Armenian political party, the Dashnaktsutiun, stayed allied to the Ittihadist party until the start of the First World War, in another attempt to win security through loyalty [Hovannisian 1990: 258]. Nevertheless, armed Kurdish bands given impunity by the state continued to maraud Armenian villages in the eastern provinces. In February 1914, the European powers (Britain, France, Russia, Germany, Austria-Hungary, and Italy) agreed on a reform plan to combine six Armenian provinces in the Ottoman Empire into two regions with substantial local autonomy; this was the most comprehensive proposal for resolving the Armenian Question yet put forward [Hovannisian 1990: 258-259]. However, the 
Ottoman Empire officially entered on the German side of the war on 14 November 1914, and officially annulled the agreement on 16 December 1914 [Dadrian 1997: 212]. Armenian homelands lay on both sides of the Ottoman-Russian border, and the Young Turk government hoped to extend its territory into Russian Transcaucasia and central Asia. In the winter of 1914-15, Enver Pasha sacrificed an entire army in a failed attempt to break through to the Caspian Sea; in April 1915 Allies landed at Gallipoli in a failed attempt to capture Constantinople [Hovannisian 1990: 259]. Following these events, Young Turk extremists accused Armenians of treachery, making them scapegoats for the Empire's military insecurity. However, observations by foreign diplomats suggest that the Young Turks had decided some years before to take advantage of the next opportunity to eliminate finally the Armenian Question [Dadrian 1997: 207-209].

In August 1914, following the general mobilization of Turkish armed forces preparatory to its entry into the war, male Armenians between the ages of 15 and 60 were inducted into the military, those under 45 organized into unarmed labour battalions, those over 45 to be used as "pack animals for the transport of military equipment" [Dadrian 1997: 221]. After Turkey entered the war in November, the military was given powers of emergency war requisitions through which provincial Armenians were stripped of most of their personal property. On the night of 23-24 April 1915, "scores of Armenian political, religious, educational, and intellectual leaders in Constantinople, many of them friends and acquaintances of the Young Turk Rulers, were arrested, deported to Anatolia, and put to death" [Hovannisian 1990: 260]; an estimated 2,345 leaders were arrested "in Istanbul alone in a matter of weeks" [Dadrian 1997: 221]. The deportation program 
officially began on 26 May 1915, when Minister of Internal Affairs Talaat Pasha requested the enactment through Cabinet of a Temporary Law of Deportation, authorizing "Commanders of Armies, Army corps, Divisions, and commandants of local garrisons to order the deportation of population clusters on suspicion of espionage, treason, and on military necessity" [Dadrian 1997: 221]. However, deportations were already "well underway" at this time [235]. Supplementary laws on 10 June and 26 September made provisions for the confiscation and handling of property, debts, credits, and assets of deportees [222]. Between 4 October and 13 December 1915, a lone Senator, Ahmed Riza, opposed the measure, submitting a draft bill proposing to postpone application of the Temporary Law until after the end of the war, argued against the constitutionality of the Law, and requested relief measures for the deportees; he was unsuccessful [222-225]. The Minister of the Interior began by ordering the deportation of all Armenians from war zones to the deserts of Syria and Mesopotamia [Hovannisian 1990: 260; Melson 1992: 143]. As deportations unfolded, Armenians were systematically expelled from the whole of the empire, except for Constantinople and Smyrna, where many foreign diplomats were stationed. On 8 April 1915, Armenians serving in the army, already segregated into unarmed labour battalions, were massacred under the authority of Ever Pasha's Ministry of War [Hovannisian 1990: 260; Melson 1992: 144-145]. In the deportation process, adult and teenage males were systematically separated from deportation caravans and executed under direction of Young Turk officials and agents, the gendarmerie, and bandit groups employed by the state. Women 
and children were "driven for weeks over mountains and deserts", and subjected to physical and sexual assault en route.

In 1916, Arnold Toynbee estimated that the pre-genocide Armenian population in the Ottoman Empire was 1.6 million, that 600,000 escaped the deportations or were spared, and that 400,000 persons survived the deportations, so that mortality in 1915 1916 was 600,000 [Melson 1992: 146-147]. Three very large massacres took place after 1916: at Res-ul-Ain, with 70,000 victims; at Intilli, with 50,000 victims, and at Der Zor, with 200,000 victims. In sum, Melson estimates that the total number of Armenian killed by genocide during the First World War was nearly 1 million. Dadrian [1997: 225] states: "By official Turkish accounts alone, those directly killed numbered about 800,000, not counting the tens of thousands of wartime conscripts liquidated by the military." In a footnote he adds:

Excluded from this figure [the 800,000] are all other categories of victims such as those executed while serving in the Turkish army, the multitudes of young females forced into concubinage, Muslim marriages, or adoption, victims of coercive religious conversions, and countless others who eventually perished as a result of the extraordinary hardships of deportation. [233 n. 40]

The net effect was to obliterate the Armenian cultural presence within the Ottoman Empire. Through murder, expulsion, and forced conversion, a pre-war Armenian population estimated to be between 1.6 and 2.1 million [Melson 1992: 146] was reduced to a tiny vestige surviving only in Constantinople [ibid.; Adalian 1992: 86]. The elimination of Armenia averted continued European intervention into Turkish affairs over the Armenian Question, and removed an ethnic barrier between Ottoman Turks and 
Turkic peoples of the Caucasus and Transcaspia [Hovannisian 1990: 260]. In these respects, it was a successful genocide.

Moreover, this event was followed by another genocide, this time of Russian Armenians. Following the collapse of the Russian Army after the Bolshevik Revolution, the Turkish army crossed into Russian Armenia in the Transcaucasus, and proceeded to massacre Armenians there [Dadrian 2001: 159]. In September 1920, the Turkish army invaded the Republic of Armenia, and in five months of conquest and occupation before being driven out by the Red Army, Turkish forces killed 200,000 Armenians in that region [Dadrian 2001: 161; 1997: 361]. Part of the motivation for this was to forestall implementation of the Sèvres Treaty of 10 August 1920, agreed to among the Allied forces, to establish an Armenian state "bestriding eastern Turkey and the Caucasus" [Dadrian 1997: 356].

The 1915 genocide of Ottoman Armenians was not simply an event within the Ottoman Empire; it had significant international dimensions. One of these is the ambivalent history of foreign intervention on behalf of the Armenians which I have noted above. Another is the possible direct complicity of the German state in the genocide. At the outset of the war, German officials indicated to the Ottoman government that the Armenian Question was not a concern for them, aided the formation of internal espionage organizations by the Ittihadists, and encouraged the reactivation and expansion of the Special Organization, which was instrumental in implementing the genocide [Dadrian 1997: 206, 237]. More directly, in December 1914 the German military “supplied evidence of Armenian acts of sabotage and atrocities, committed in the rear of the army; 
they, therefore, requested the initiation of counter-measures (tedbir) to stamp out this danger" [Dadrian 1997: $\left.256^{129}\right]$. A number of German military officers working in the Ottoman Empire before and during the genocide appear to have some direct complicity. Documentary evidence shows that several ${ }^{130}$ very high-ranking officers directly ordered or advised the deportation of Armenians, on grounds that they threatened the war effort, and a number of others expressed approval of the deportation and massacre of the Armenians $^{131}$ : [Dadrian 1997: 255-265]. Two diplomats in a position to exert pressure on the Ottoman government to alter its actions towards the Armenians meticulously refrained from doing so: Ambassador Hans Frieherr von Wangheim, who did not hesitate to dominate even the Grand Vizier when he felt that German national interests were concerned; and Lieutenant Commander and Marine Attaché Hans Humann, who had a close personal relationship with Enver, and who actually expressed approval for the genocide [268-273]. A variety of Turkish sources, including statements by civil servants and reports by journalists, suggest that the impetus to deport the Armenians actually originated with the Germans [273-277]. Broadly speaking, there is evidence of "the willingness of a number of German officials, civilian and military, to aid and abet the Turks in their drive to liquidate the Armenians", roughly in three forms: co-perpetration,

129 This collaboration is comparable to the contribution that United States made to the genocide of the Indonesian Communist Party (PKI) by the Indonesian state in 1965-1966. While the Indonesian state was in the process of slaughtering 500,000 members of the PKI, the U.S. Central Intelligence Agency provided the genocidaires with names of PKI members. General Bronsart, Chief of Staff at Ottoman High Command; Field Marshal von der Goltz; and Lieutenant Colonel von Feldmann, head of the Operations department; and Lieutenant Colonel Boettrich, Chief of Railroad Services. Turkish Fleet and chief of the Mediterranean Arm of the German Navy; Lieutenant General Seeckt, successor to Bronsart as Chief of Staff, who also helped Enver and Talaat flee the country 
as in those officers who actually signed deportation orders; incitement or suggestion that encouraged the genocide, and passive consent [294].

Aside from any such direct complicity, there exists an important relationship between the genocide of the Armenians and the Nazi holocaust, inasmuch as the former may have served as a direct precedent to the latter, indicating to Hitler that destruction of a national minority would be tolerated by the international community or even considered a normal act. Hitler appears to have been knowledgeable about the Armenians and Turks, and the annihilation of the Armenians. In a statement made during or prior to 1924 , Hitler claims that unless Germany deals with its Jewish question, "the German people will end up becoming just like the Armenians" [Dadrian 1997: 402]. Similarly, in 1943 he blamed the fate of the Armenians on pernicious Jewish influence. Somewhat inconsistently, in 1933 he expressed great admiration for Turkish nationalism [402], and on another occasion he emphasized the urgency of "the task of protecting the German blood from contamination, not only of the Jewish but also of the Armenian blood" [409]. Most famously, in 1939 in a speech to the Chief Commanders and Commanding Generals, admonishing them to be brutal and merciless in battle, Hitler is recorded as saying "Who after all is today speaking of the destruction of the Armenians" $[403]^{132}$ In the same document he also says "The world believes only in success" [404], echoing (perhaps unknowingly) a remark made long before by Ottoman Minister of the Interior

after the war; and Major Count Eberhard Wolffskeel von Reichenberg, who engaged in military operations against Armenians between April and October 1915. about its authenticity have since been dispelled; see Dadrian 1997: 407-409. 
Talaat saying "I have the conviction that as long as a nation does the best for its own interests, and succeeds, the world admires it and thinks it moral" [383].

The Turkish state denies to this day that a genocide took place, and has threatened repercussions against states that recognize the genocide. When France recognized the genocide in 2001, for example, Turkey temporarily blocked French companies from receiving defense contracts and suspended official visits to France. When a private members' bill recognizing the genocide was passed in a free vote in the Canadian House of Commons in April 2004, the Turkish Foreign Ministry condemned the decision, the Canadian Prime Minister and other cabinet members absented themselves from the vote, and Foreign Minister Bill Graham played down the significance of the resolution [CBC News Online 2004].

\subsubsection{RWANDA}

\section{STATE-FORMATION IN RWANDA BEFORE 1990}

It is difficult to sort out the reality of pre-colonial Rwanda, since most sources speak about "Rwanda" without marking any fundamental discontinuity between the preand post-colonization periods, as if 'Rwanda' was an established fact only found, not constituted, by the colonial powers. In addition, the specific meaning that the concepts of 'Tutsi' and 'Hutu' conveyed before colonization is unclear. Different authors understand the terms to have referred, alternately, to distinct ethnic groups within the Rwandan figuration, or to a social status akin to class or caste [see Uvin 1998: 13-14; Prunier 1995: 5; Des Forges 1999: 31; Mamdani 2001: 41-75]. The account provided by the UN Joint Evaluation of Emergency Assistance to Rwanda [Sellström and Wohlgemuth 1996: 21- 
49] conveys some of this complexity. In that account, Bantu-speaking Hutu

agriculturalists arrived in the current area of Rwanda around 1,000 CE, clearing forests and displacing the Twa, who had been there since 2,000 BCE. From the $11^{\text {th }}$ to the $15^{\text {th }}$ centuries, the Hutu formed into statelets that collectively covered the territory corresponding to modern Rwanda. In the $15^{\text {th }}$ century, Tutsi cattle-farmers arrived and assimilated to the local culture, taking on Hutu language, religion, mythology, and so on. Tutsi lived among and side-by-side with Hutu, and members of the two groups often cohabitated and sometimes intermarried [Mamdani 2001: 53]. Tutsi nevertheless remained economically distinct from Hutu as cattle-herders, living among the Hutu agriculturalists. Between the $15^{\text {th }}$ and $19^{\text {th }}$ centuries, the statelet of Nyiginya expanded by conquest to dominate all of present Rwanda except what are now the Gisenyi and Ruhengieri prefectures in the northwest. By 1860, the categories 'Hutu' and 'Tutsi' were fluid; Hutu who rose in status could become Tutsi and vice-versa; but also, some Hutu were higher status due to wealth or location in incipient state structures. Rwandan social structure was complex, involving a three-tier system of administration. Each province was governed by an army chief or 'chief of men'; within each province, each district was governed by two independent chiefs, the 'chief of landholding' responsible for the agricultural economy, and the 'chief of pastures' responsible for the pastoral economy; and each district was divided into hills, each with a single hill chief [Prunier 1995: 11-12; Mamdani 2001: 68]. Chiefs of men and of pastures were usually of Tutsi ancestry, chiefs of landholding and hill chiefs usually Hutu. Running throughout Rwandan society from top to bottom were complex networks of patron-client relationships. Although at one 
time these relations involved a degree of reciprocity, by the reign of Rujugira (17561765) they had become a highly asymmetrical system of social dominance that tended to privilege Tutsi cattle-owners [Prunier 1995: 13-14; Mamdani 2001: 64-66]. Patron-client relationships also involved a system of compulsory group work (ubuletwa), a tradition that would later be exploited during the genocide. It was during the reign of Rujugira that Rwanda developed a standing army, began to intensify its mechanisms of centralized state power, and took on expansionist tendencies [Mamdani 2001: 66-68]. These tendencies culminated in the reign of Mwami Kigeri Rwabugiri (1860-1895), during which the Hutu-Tutsi relation was further polarized.

European colonization of Rwanda began in 1897 through the establishment of protectorate treaties with Germany ${ }^{133}$. The Germans, and Belgians after them, subscribed to the 'Hamitic hypothesis', which regarded the Tutsi as racially superior to Hutu, even 'white' in every characteristic save skin colour, and naturally suited to ruling. German indirect rule further centralized the state and stratified Hutu-Tutsi relationships dramatically. In 1916, the Belgians took Rwanda by force from the Germans; their title to Rwanda was confirmed in 1923 by the League of Nations and again in 1946 by the United Nations. In the 1930s, the Belgian colonial authority engaged in the 'Tutsification' of Rwandan state structures: removing Hutu chiefs and replacing them with Tutsis, abolishing the division between chiefs of men, landholding, and pastures, and thereby constructing a Tutsi monopoly of political authority in Rwanda. In 1926, the Belgians first introduced the identity card system designating each Rwandan as Hutu, 
Tutsi, or Twa ${ }^{134}$. In 1933 the identity cards were made mandatory for all Rwandans.

This system remained in place until the 1994 genocide; designation was initially based on self-declaration, and some Hutu sought and obtained re-designation as Tutsi even after the 1930s [Des Forges 1999: 37-38].

Rwanda and Burundi were granted formal independence in 1962. In the years leading up to this, Hutu ethnic nationalism became a powerful force in Rwanda, as epitomized in the 1957 Bahutu Manifesto. In 1959-1961 Rwanda underwent the 'social revolution', in which Belgium reversed its policy of Tutsi dominance within the colonial state. A complete turnover of the administrative structure was effected, producing a state that was still stratified by lineage group but that now privileged Hutu over Tutsi. During this time, Tutsi chiefs and sub-chiefs were subjected to murder, expulsion or exile. In 1961 , the monarchy was abolished, a referendum was held deciding in favour of a republic, and a $78 \%$ Hutu majority was elected to form the first independent government. Following independence, Tutsi Rwandans were subjected to increasing persecution, which escalated in 1963 to mass killings of Tutsi and the dissolution of Tutsi political parties. Large numbers of Tutsi fled the country, primarily to Uganda where they created a permanent exile community that, by 1990 , would number 600,000 persons. By 1965 , Rwanda had become a one-party state, power being completely usurped by Kayibanda and his personal allies from Gitamara prefecture. Wohlgemuth 1996: 21-49. 
The years 1962-1973 are known as the years of the 'first republic' in Rwanda, 1973-1994 as the 'second republic'. In 1972 and again in 1973 the Tutsi-dominated government in Burundi engaged in genocidal killings of Hutu in that country. This was followed by civil unrest in Rwanda; there was violence in schools, administrative offices, and businesses, initially directed against Tutsi but later against Hutu also. On 5 July 1973, a faction led by Juvénal Habyarimana staged a coup (afterwards known as the 'moral revolution') and established a new government that would last until the 1994 genocide. Initially fuelled by "majoritarian aspirations" [Mamdani 2001: 133], the revolution nevertheless failed to reform the authoritarian character of Rwandan governance. It succeeded only in transferring power from one elite to another, the new one being rooted in the northern prefectures of Gisenyi and Ruhengieri. The Habyarimana regime succeeded in modernizing Rwandan trade and infrastructure and stimulating economic growth. The years of the Second Republic were years of urbanization in Rwanda, and of relative prosperity until 1990. However, the exportoriented economy was also riddled with structures of embezzlement that maintained traditional networks of patron-client relationships. In the late 1980s the Rwandan economy declined, partly because of fluctuating coffee prices on international markets, and in 1990 the Rwandan state agreed to an IMF-sponsored Structural Adjustment Programme.

\section{THE BUILDUP TO GENOCIDE, 1990-1994}

The early 1990s were years of severe economic and political crisis in Rwanda. The price of coffee declined precipitously in 1989, a Structural Adjustment Programme 
was imposed by the IMF in 1990 , military spending rose dramatically once the civil war began, and a disease affecting coffee trees began to spread in some parts of the country [Mamdani 2001: 147-148]. Income from coffee sales declined by almost four-fifths between 1985 and 1993. GDP per capita fell by $40 \%$ from 1985 to 1989 , and continued to drop sharply in the early 1990s. The currency was devalued by $67 \%$ in 1990 , and the Structural Adjustment Programme required the government to reduce subsidies to coffee farmers and to reduce its budget deficit. The effects of these developments fell primarily on working people and small producers. Some areas of the country were affected by drought, and "for the first time since independence, people could not afford to buy food, emergency stocks were reduced, and people died of hunger" [Jeffremovas 2002: 110]. This economic crisis, common to many African economies at that time, intersected with Rwanda's political crisis. From 1989 to 1992 , military spending as a portion of the GDP quadrupled [Mamdani 2001: 148]. On 1 October 1990, Rwanda was invaded from Uganda by the armed forces of the Rwandan Patriotic Front (RPF), a political organization ${ }^{135}$ formed by Tutsis in exile but nominally committed to equality of Hutu and Tutsis in Rwanda. The Rwandan state was supported throughout the war by French troops, which provided training to the Rwandan Defense Force, and took part in actual fighting against the RPA in 1990 and 1993 [Human Rights Watch Arms Project 1994: 6]. The international community provided military aid to the Rwandan government with no effective conditionality, with the exception of a threat to cut aid in March 1993 which "is widely believed to have incited the Rwandese President to resume peace talks with the

135 The armed forces of the RFP were called the Rwandan Patriotic Army (RPA). 
RPF” [Sellström and Wohlgemuth 1996: 41]. Peace talks between the government and the RPF took place in two rounds, the Mwanza round from October 1990 to April 1992, and the Arusha talks between May 1992 and August 1993. The latter round produced the Arusha accords, signed 4 August 1993. The accords prescribed a major structural transformation of the Rwandan state: the government would shift from a Presidential to a parliamentary form; multi-party politics would be established; and Hutu Power extremists would be excluded from the new regime.

'Hutu Power' is the name for a constellation of social, political, and paramilitary forces oriented towards preserving the racialization of Hutu and Tutsi identity and maintaining or intensifying Hutu supremacy [Melvern 2000: 13, 19]. Its political organization was the Coalition pour la Défense de la République (CDR), formed in March 1992 [Prunier 1995: 128]. Its propaganda organs were the newspaper Kangura, which launched in mid-1990, and Radio Télévision Libre des Milles Collines (Free Radio and Television of the Thousand Hills, 'thousand hills' referring to Rwanda) (abbreviated as RTLMC), which opened its radio station in June 1993. Both Kangura and RTLMC issued a steady stream of anti-Tutsi propaganda. During the genocide, RTLMC also broadcast instructions to those who participated in massacres [African Rights 1995: 71, 80; Des Forges 1999: 206]. The paramilitary forces of Hutu Power were derived from the youth wings of the ruling party and of the CDR, the Interahamwe ("those who stand together") and the Impuzamugambi ("those who have the same goal") respectively [Mamdani 2001: 204], and from "civilian self-defense groups" formed by the government independently of the party militias [Des Forges 1999: 102; Human Rights Watch Arms 
Project 1994: 27]. The distinction between these militias, which collapsed once the genocide began [Des Forges 1999: 228], was never very strong because the Hutu Power movement was led by figures in the highest tiers of the state. Its leadership excluded President Habyarimana himself but included his wife Agathe Habyarimana; Colonel Théoniste Bagosora; and other members of the akazu ('little house'), a network of people close to the President but not entirely loyal to him [African Rights 1995: 100-112]. The fact that the Arusha accords proposed to exclude the Hutu Power movement from the Rwandan state therefore implied the disenfranchisement of the most powerful clique within the state.

As early as the spring of 1992, the Belgian ambassador in Kigali, Johan Swinned, reported to Brussels: "This secret group is planning the extermination of the Tutsi of Rwanda to resolve once and for all, in their own way, the ethnic problem and to crush the internal Hutu opposition" [Melvern 2000: 43]. The French government may have received similar warning even earlier ${ }^{136}$. Propaganda emitted by Kangura and RTLMC referred to the Tutsi as inyenzi, or 'cockroaches" ${ }^{137}$, portrayed Tutsis as wanting to commit a genocide of the Hutu like the one in Burundi ${ }^{138}$, and warned Hutu to be vigilant against the enemy and ready for violence. The Hutu Power regime began accumulating weapons in 1990 , and over the three years prior to the genocide spent US $\$ 112$ million to arm the people of Rwanda [Melvern 2001: 66-67]. Arms were paid for out of foreign

\footnotetext{
136 Kuperman [2001] reports that it is disputed how much foreign governments actually knew, and how early, regarding plans for genocide. 
loans obtained under the auspices of the Structural Adjustment Programme; arms expenditures were disguised by fraudulent accounting, and the negative impact of arms expenditures on social spending was disguised by the SAP-mandated austerity measures [African Rights 1995: 68]. Large arms deals were made with Egypt, South Africa, and France; direct military aid was provided by France and the U.S. [Melvern 2001: 65-66; Human Rights Watch Arms Project 1994: 14-17; African Rights 1995: 67]. By April 1994, "85 million tons of munitions are thought to have been distributed", including 581, 000 machetes $^{139}$, and hundreds of thousands of hoes, axes, hammers, and razor blades [Melvern 2001: 64-65; Des Forges 1999: 127]. As early as September or October 1992, the army was directed to compile lists of people said to be accomplices of the RPF, and district prefects secretly ordered burgomeisters to compile lists of those who had left the country surreptitiously [Des Forges 1999: 99-100]. During the genocide, Radio RTLMC "involved the public in hunting down named individuals, directed killers where to find them and then announced their murders" [Des Forges 1999: 206], which suggests that these lists may have been used in the genocide.

\section{THE GENOCIDE: 6 APRIL TO 18 JULY 1994}

At about 8:30 pm on 6 April 1994, President Habyarimana's airplane, coincidentally containing President Ntaryamira of Burundi, was shot down on its approach to Kigali airport. The identity of the assassins was not determined, but based on the speed with which the genocide followed, it seems likely that the assassination was following the assassination by Tutsi soldiers, on 21 October 1993, of the first Hutu elected president of Burundi, Melchior Ndadaye. 
ordered by the genocidaires [Prunier 1995: 213, 222-225]. News of the assassination was broadcast on RTLMC within half an hour, and by 9:15 pm roadblocks were set up throughout Kigali and houses were being searched [Prunier 1995: 223]. The roadblocks limited movement and made it more difficult for persons targeted for killing to flee to safety; they also make it difficult for United Nations forces, Médecins sans Frontières workers, and other third parties to interfere with the implementation of the genocide. Killing unfolded in several stages. Almost immediately there began a "selective assassination of opposition politicians, of which most were Hutu from parties opposing the party in power" [Sellström and Wohlgemuth 1995: 51]. The second group targeted for assassination were dissenting civilians, both Hutu and Tutsi. Following this killing of political opposition, the generalized massacre of Tutsi began. The first targets were Tutsi men and boys, including even infant male children, and also educated men and women. Women, including young girls, were tortured and raped extensively. As the genocide progressed, killing shifted from focusing on men to including men and women alike [Jones 2002]. The mass killing itself unfolded in three stages [Des Forges 1999: 9-10]. Starting from "the middle of the first week of the genocide", Tutsi were driven out of their homes to public sites such as churches, schools, offices, etc. where they were "massacred in large-scale operations". "Towards the end of April", authorities ordered the strategy of 'pacification', to decrease the visibility of the genocide; large-scale killings were halted in many areas and victims were brought into custody and then murdered. This also functioned as a way of luring Tutsi out of hiding. "By mid-May, the authorities ordered the final phase, that of tracking down the last surviving Tutsi." 
Targeted were those who had hidden successfully so far; those who has been spared because of age, gender or status in their communities; and, in the face of the RPF advance, those who could testify about the genocide.

All scholarly and NGO observers agree that the killings were highly organized; Prunier [1995: 242] notes that the efficiency with which they were carried out testifies to careful advance planning. Claims that killings were spontaneous, tribal, irrepressible, and chaotic come from the perpetrators themselves, and were a deliberate tactic used to conceal what was going on and forestall international involvement [African Rights 1995: 250-254], and to facilitate recruitment for the genocide within the Rwandan population [Des Forges 1999: 252-260]. Prunier compares these disinformation tactics to those used by Holocaust deniers [Prunier 1995: 241]. At the same time, however, "the genocide was not a killing machine that rolled inexorably forward but rather a campaign to which participants were recruited over time and by the use of threat and incentives" [Des Forges 1999: 6]. Amongst other devices, the genocidaires took advantage of the historical practice of compulsory collective labour, going back to the ubuletwa tradition in precolonial Rwanda, and of the post-colonial state's conduct of "campaigns of various kinds" that operated "through the existing administrative and political hierarchies, requiring agents to go beyond their usual duties for a limited period of time for some national goal of major importance" [Des Forges 1999: 222]. The genocidaires thereby used existing administrative, political, and military structures to apply pressure to the entire Rwandan Hutu population, either to participate actively or to acquiesce passively in the slaughter. Every aspect of Rwandan society made active contributions to the 
genocide: the military and the National Police; political leaders at every level; civil servants in the central government, préfets, bourgmestres, and local councilors; Radio Rwanda and the RTLMC; the Anglican Church, from Archbishop Augustin Nshamihigo to local pastors; academics in the university system; private business owners; members of the militias; and ordinary Rwandans, mostly those living in poverty but also many who were not, and including women and even children ${ }^{140}$ [Des Forges 1999: 223, 226-228, 231, 234-235, 241-242, 244, 246, 248, 261; Prunier 1995: 244]. These contributions ranged from helping to legitimate killing, providing logistical and material support, helping to locate and identify victims, and direct killing. Some Rwandans opposed the genocide, including the préfet of Butare, the Tutsi Jean-Baptiste Habyarimana ${ }^{141}$. Killing in Butare préfecture did not begin until April $20^{\text {th }}$, when Habyarimana was removed from his office and replaced by the extremist Sylvain Ndikumana [Prunier 1995: 244]; this incident testifies to the importance of local administrative collaboration to the genocidal effort $^{142}$. The chief organizer of the genocide is generally held to be Colonel Théoniste Bagosora, director of services in the Ministry of Defense and the architect of the Provisional Government that took power following the assassination of President Habyarimana. Bagosora was a central figure in the Hutu Power movement and a

140 One UNAMIR officer remarked: "I had seen war before, but I had never seen a woman carrying a baby on her back kill another woman with a baby on her back" [Des Forges 1999: 261]. Nevertheless, women and children were more often involved in pillaging and destroying property than in direct killing.

141 No relation to the president.

142 Prunier notes that "it was also a time of undisputed heroism by people who expected no reward but the satisfaction of a clear conscience" [Prunier 1995: 259]. Human Rights Watch notes that "Tens of thousands of Hutu refused to join the killing campaign and saved Tutsi lives. Hundreds of thousands more disapproved of the genocide but did nothing to oppose it or to help its victims. They did not answer the call of the local cell leader but neither did they respond to the cries of Tutsi in distress." [Des Forges 1999: 262] 
founding member of the CDR [Prunier 1995: 240-242; Des Forges 1999: 223]. Still, the genocide was not his brainchild, nor was he the sole instigator. African Rights, discussing those responsible for the genocide, spends twelve pages discussing other genocidaires before turning Bagosora and other military figures, listing first the members of the akazu, especially Agathe Habyarimana, along with members of the interim government and other politicians [African Rights 1995: 100-112].

With respect to the general massacre of Tutsi, killers at first worked in small bands and killed their victims "where they found them" [Des Forges 1999: 209]. But very shortly thereafter, it became possible to effect large-scale massacres, because potential victims fled to what they perceived as places of refuge: churches, schools, hospitals and government offices. [ibid.] Beginning on April 11, people were even encouraged by the government to go to these places with the expectation of safety, and people not willing to go there were coerced into doing so [210]. In some cases these sites were bulldozed to kill the people inside [211]. In some places the armed forces would use artillery on crowds of people, as when a group of thousands gathered at Amahoro stadium in Kigali under UNAMIR protection [African Rights 1995: 724-725]. Wounded persons were presumed to be Tutsi, so hospitals were entered, patients shot, and medical staff massacred [Prunier 1995: 254]. But despite the key role played by bureaucratic organization, the massacres in Rwanda bore little resemblance to the faceless and impersonal killings of the Nazi holocaust that Bauman analyzes. For example, in the case of the massacre at the École Technique Officielle at Kicukiro (in Kigali), RDF soldiers initiated the killing by firing and throwing grenades into the crowd, then the militia 
"came in and started with the machetes, hammers, knives and spears" [Melvern 2000: 3-

4]. This appears to have been a common pattern with the large-scale massacres: soldiers from the army or the Presidential Guard would begin things by shooting and using grenades, militias armed with hand-to-hand weapons would carry out the bulk of the killing, and soldiers would reappear if the militias started to flag or encountered resistance. African Rights notes that:

One of the most common methods of killing was hacking with a machete. The killers often wielded their weapons in ways designed to inflict the maximum pain on the victim before death ensued. ... Such was the fear of the machete that many killers were able to extort money out of their victims-to-be by demanding payment for the privilege of being killed with a bullet - a much quicker and less painful way to die. [African Rights 1995: 629]

Even considering the brutality of the routine killing practices, many perpetrators committed acts of astonishing cruelty: people killed with machetes were systematically mutilated in the face, limbs, and genitals before being killed; people were burned alive; people were thrown alive into pit latrines and buried; people were forced to kill their family members and loved ones [African Rights 1995: 624-641]. Women and girls were subjected to rape and torture, and could be sold into sexual slavery [African Rights 1995: $748 \mathrm{ff}$.$] Such practices take on added significance given the prevalence of AIDS in the$ country; for example, at least $35 \%$ of Rwandese soldiers were HIV-positive before the genocide [Jones 2002: 82]. At peak efficiency, the rate of killing by militias reached 1,000 persons every twenty minutes [Melvern 2000: 5]. Gourevitch [1998: 3] claims that "the dead of Rwanda accumulated at nearly three times the rate of Jewish dead during the Holocaust. It was the most efficient mass killing since the atomic bombings of 
Hiroshima and Nagasaki". The number of persons killed is not easy to determine, partly because it is not clear how many Tutsi there were in Rwanda to begin with. Human Rights Watch estimates conservatively that "at least half a million persons were killed in the genocide, a loss that represented about three quarters of the Tutsi population of Rwanda" [Des Forges 1999: 16]. Prunier estimates 800,000 to 850,000 killed, $86 \%$ of the Tutsi population of Rwanda and 11\% of the total Rwandan population [Prunier 261265].

\section{THE U.N., THE RFP, AND THE END OF THE GENOCIDE}

One aspect of the Rwandan genocide that has become prominent in subsequent discussion of the event is the role that United Nations forces played and did not play in opposing the genocide. In June of 1993, the U.N. Security Council created the United Nations Observer Mission Uganda-Rwanda (UNOMUR), with Canadian General Romeo Dallaire as commander [Melvern 2001: 243-248]. Dallaire arrived in Kigali with a reconnaissance mission in August, roughly as the Arusha Accords were being signed. In October, Security Council resolution 872 created the U.N. Assistance Mission in Rwanda (UNAMIR); UNOMIR was integrated into UNAMIR and Dallaire appointed force commander. By November, UNAMIR was brought up to its mandated strength of 2,548 [Melvern 2001: 89]. Dallaire had asked for a minimum of 4,500 troops. Melvern says that

How half-hearted was the UN's effort for Rwanda was plain to see. Dallaire lacked the barest essentials. He was reduced to borrowing petty cash from another UN agency. He lacked everything from ammunition to sandbags, fuel, and barbed wire. The mission lacked essential personnel; there was not public affairs officer, legal adviser, humanitarian or human rights expert. [Melvern p. 85] 
In December, UNAMIR peacekeepers were in place in throughout Rwanda, with a contingent in Kigali, as per the Arusha Accords. On 11 January 1994, Dallaire informed UN headquarters in New York that he had an informant within the Hutu Power movement warning him that genocide was being planned and informing him of the locations of hidden weapons stockpiles. Dallaire tried to persuade his superiors to allow him to conduct arms seizures, but was denied. On 5 April 1994, Security Council resolution 909 renewed the mandate for UNAMIR, but with threat to pull out in six weeks unless the Arusha accords were obeyed. Until the genocide was well underway, the United Nations treated UNAMIR as a peacekeeping force intended to help facilitate the Arusha peace process, without significant consideration given to the possibility that Rwandan civilians needed to be protected from their own government.

On April $7^{\text {th }}$, the day after Habyarimana's assassination, ten Belgian peacekeeper soldiers were captured, and then killed in a Rwandan army barracks in Kigali. On April $10^{\text {th }}$ Dallaire requested a reinforcement of 5,000 soldiers, with which he believed he could put an end to the massacres [Melvern 2001: 146]. The next day, Belgian peacekeepers withdrew from the École Technique Officielle at Kicukiro (in Kigali), leaving 2000 people behind who "literally two minutes" later begin to be massacred [Melvern 2001: 1-4; African Rights 1995: 1113]. The Belgian force, approximately 400 troops, left Rwanda by the $20^{\text {th }}$ of April. Throughout the genocide, UNAMIR was short of essential supplies: water, fuel, ammunition, medical supplies, etc. Only very limited support was provided by a few individual governments, including Canada [Melvern 2001: 233]. On April 22 ${ }^{\text {nd }}$, Security Council resolution 912 ordered the withdrawal of all 
but 270 peacekeepers from Rwanda, the remnant being mandated to secure a ceasefire between the Rwandan army and the RFP [Melvern 2001: 174]. Dallaire, with Ghanaian Brigadier Henry Kwami Anyidoho and his troops, defied the order; 456 soldiers remained. On May $4^{\text {th }}$, nearly a month after mass killings began, U.N. Secretary-General Boutros Boutros-Ghali made his first public use of the word 'genocide' to refer to events in Rwanda. On May $17^{\text {th }}$, Security Council resolution 918 approved the deployment of 5,500 troops; however, no actual troops, transportation, or plan were available. In late May the United States, which owed the UN more than $\$ 1$ billion in back dues, charged $\$ 4$ million for the use of 48 APCs, plus another $\$ 6$ million for transport; the APCs arrived in Entebbe without radios or machine guns, making them useless [Melvern 2001: 196]. On June $6^{\text {th }}$ the Security Council resolution 925 extended UNAMIR's mandate until December. On June $17^{\text {th }}$, France announced a plan to deploy its own troops, free of charge, as an interim peacekeeping force. The United States and Boutros-Ghali supported the plan. Under the title "Operation Turquoise", French troops entered Rwanda through Zaire on June $21^{\text {st }}$, and by July $5^{\text {th }}$ had established control of a 'safe zone' in southwest Rwanda. However, by this time the RFP had conquered most of the country, and the most notable effect of the safe zone was to enable genocidaires, and Hutu afraid of the RFP, to flee into Zaire. The war ended on July $18^{\text {th }}$, and on August $16^{\text {th }}$ Dallaire left Rwanda, succeeded by Canadian General Guy Tousignant. At this point, UNAMIR still only had 1,624 soldiers.

After the genocide, an assessment by the Carnegie Commission on Preventing Deadly Conflict, the Institute for the Study of Diplomacy at Georgetown University, and 
the US army found that "a force with air support, logistics and communications would have prevented the slaughter of half a million people" if deployed between 7 and 21 April, and that "US forces, backed by air power, could have protected Rwandan civilians with little or no risk to US soldiers" [Melvern 147]. In the actual course of events, killing was only brought to an end by the RFP advance and, to a lesser extent, by Operation Turquoise. However, the RPF itself committed mass killings during its takeover of the country. These killings are not well documented, but appear to have been serious. The 1995 African Rights report [1079-1085] denied that any large-scale or systematic killings had been perpetrated by the RPF, but the 1999 Human Rights Watch report accused the RFP of "indiscriminate massacre of individuals and group, bearing no arms, and posing no threat to them" and of summary execution of selected individuals, and estimates the death toll to be between 25,000 and 30,000 at least for the period April-July 1994 [Des Forges 1999: 734].

\subsection{GenOCIDE}

\subsubsection{INTRODUCTION}

With respect to the question of whether these events should count as examples of genocide, the answer in both instances seems to be a straightforward 'yes'. Next to the Nazi holocaust, the obliteration of Ottoman Armenians and the massacres of Rwandan Tutsis are probably the events in the $20^{\text {th }}$ century whose status as genocide is least in dispute. As I mentioned earlier, the Armenian experience is what inspired Lemkin to begin his campaign for the protection in international law of the right to life of national groups. The Rwandan experience was the first event ever officially described by the 
United Nations as a "genocide" [Gourevitch 1998: 7] and was the occasion for the emergence of the problem of genocide prevention as an issue in international politics. And yet, it is still worth while discussing why the category of 'genocide' should include these events. The status of the Armenian experience as a genocide is disputed by some scholars who want to defend the uniqueness of the Shoah [e.g. Katz 1994, 2001], and the terms on which that dispute can be refuted have important implications for how the word 'genocide' can be used. And, similarly, it is precisely because the Rwandan massacres are so generally accepted as genocide that it is worthwhile to consider what makes them genocidal, for that has implication for how we extend the term to include other events.

\subsubsection{TURKEY}

It was in response to the obliteration of Ottoman Armenians that Lemkin formulated, and sought to have criminalized in international law, two concepts that would later be synthesized into the concept of 'genocide': "barbarity, consisting in the extermination of racial, religious or social collectivities", and "vandalism, consisting in the destruction of cultural and artistic works of these groups" [Lemkin 1947: 146]. Along with the Nazi holocaust, therefore, the Ottoman atrocities serve as a prototype or exemplar for the concept 'genocide'. The two events are formally similar in that both involve the calculated annihilation by a state of a portion of the population over which it enjoys sovereignty, on the basis of an indelible collective identity. In some ways the earlier event fits more closely with Lemkin's concern for the protection of national groups, since Armenians perhaps more fully constituted a national group than did German Jews. Ottoman Armenians were still concentrated on and near the territory of a 
former Armenian state, and were less assimilated into Turkish culture than Jews were into German culture. The formation of an Armenian nation-state out of part of the territory of the Ottoman Empire was a possibility in a way that the formation of a Jewish nation-state out of German territory was not. And the actions committed against Ottoman Armenians amply satisfy the terms of the UNGC: the Ittihadists and their agents killed, inflicted bodily and mental harm, and imposed destructive conditions of life on members of a group defined by its nationality, ethnicity, and religion.

On the other hand, it is important to note that the Ottoman state did not pursue the complete physical extermination of the Armenians as such. Nominally the policy was one of deportation, and in fact many Armenians did survive the horrible forced march out of the empire. Toynbee estimated that about $50 \%$ of those subjected to the deportation process actually survived [Melson 1992: 146]. Other survivors included those who were converted to Islam and those who were spared in large cities; Katz [2001: 68] estimates that persons in each of these categories numbered in the hundreds of thousands. Moreover, the extermination of the Armenians was not primarily rationalized in racialist or biological terms, as was the Shoah. On these bases, Katz argues against placing the Armenian experience in the same category as the Shoah. The aim of Turkish policy was the elimination of the Armenian Question via the elimination of the Armenian presence in Turkey, and later the elimination of another potential impediment to Turkish sovereignty through the genocide of Russian Armenians. Physical extermination was not an end in itself but a means to goals that were also pursued by other means. 
However, in that respect the Turkish practice was not so different from German practice. As functionalist interpretations of the Nazi holocaust emphasize [Bauman 1991: 105], German policy evolved in stages, producing over time various different solutions to the problem of creating a Reich that was judenrein ("clean of Jews"). In that respect, deportation to eastern Europe, concentration in ghettoes, and systematic mass slaughter all appeared over time as different expedient solutions to this problem. The combination of deportation and massacre was similarly an expedient solution to the problem of eliminating the Armenian Question. In this respect it was successful: "the Turkish revolution initiated by the CUP was successful in creating a new Turkey, but it also came close to destroying an ancient people in the process" [Melson 1992: 170]

If we accept the Armenian experience as genocide, this has several implications for the concept. First, extermination does not have to be an end in itself. This accords with the expectations of figurational analysis: if genocide is a tactic in struggles for dominance within social formations, then it is necessarily always directed towards expected consequences. Second, physical destruction of the group does not have to be total, or be intended to be total. Genocide can be understood as involving the destruction of the social existence of a group, for which purpose the physical annihilation of its members is not always necessary. Third, genocide is directed not just at concrete human beings but at particular patterns in the relationships among them, at what Durkheim would call social facts or what Elias would call figurations. For Elias, social phenomena are real and have properties that do not simply reduce to the properties of individuals, but they are not outside individuals as social facts are said to be, and individuals are not prior 
to society. The irreducibility of figurations results from their relational quality; if social facts exist outside or above the individual, figurations exist among and between people, as synchronic patterns in the ever-shifting networks of dynamic interactions that we create by being together. A nationality is one example of a figuration, and so the holocaust of the Armenians directs our attention to this feature of the concept 'genocide': that it designates a form of violence directed against figurations, or against certain types of figurations. This insight helps to re-contextualize debates over the meaning of 'genocide'. Definitions that attempt to specify the meaning of genocide in terms of specific acts, committed against specific types of people, under specific circumstances (such as the defenselessness of the victim), even by a specific type of perpetrator (such the state) or for specific ends (such as total extermination) are always unstable, are chronically open to being shown that they are incomplete or, alternately, too inclusive. This results from their an implicit essentialism which assumes that acts are acts, that acts have the same meaning irrespective of their context. If we understand genocide as involving, amongst other things, violence directed specifically at a figuration, then definitions that take do not account of figurations, that reduce genocide to individualistic terms, seem patently insufficient. Finally, we can ask with what type of figuration genocide is concerned. In the case of Ottoman Armenians, the figuration in question was a nationality. This is in keeping with Lemkin's stated concern in Axis Rule that the concept of genocide should protect the existence of nations as such. However, if we accept the arguments that $I$ have presented in Section 1.2 above, then any type of social identity could be pertinent. Social identity is a labile and mercurial thing: not only do 
specific identities change continually over time, but the forms into which identity is organized change, shifting in different eras from communities of the faithful to stateless nations to races to ethnicities, and identity is likely to take unforeseeable forms in the future. Opening ourselves to these contingencies, we can regard genocide as involving, amongst other things, violence directed towards the destruction, in figurational terms, of a social identity, of which the obliteration of Armenian identity in the Ottoman Empire is only one example.

\subsubsection{RWANDA}

The lability of identity is even more pertinent to a consideration of the Rwandan massacres. The status of these events as genocide is, if anything, even less controversial than that of the obliteration of Ottoman Armenians. In Rwanda a campaign was carried out of systematic extermination of Tutsis, tending towards their total physical extermination. The event amply satisfies the terms of the UNGC, but held up to Lemkin's earlier formulation it reveals certain complications. One may reasonably ask, what were the Tutsis exactly? They were not a national group, for they belonged to the same nation as the Hutus, sharing fully in its culture and its institutions. They were defined as a group in terms of race, but this racialization was a phenomenon of the twentieth century only, of colonial rule and its post-colonial legacy. Even in the context of this racialization, the boundaries of identity were porous: Hutu could and did obtain Tutsi status when it was advantageous to do so, and vice versa. And perhaps more than any other social categorization, the concept of 'race' uses a fiction to produce a reality. Biological human races do not exist. With respect to human beings, race is not simply a 
social construct which is real to the extent that it organizes social action. Identification by 'race' refers not only to social figurations but to claims about biological fact, claims that are false. Racial identity is a real figuration, but one that is premised on a lie.

'Genocide' cannot, therefore, refer to the destruction of actual races, i.e. to the nonexistent biological fact; for the massacres of Tutsis to count as genocide, the term must refer to the figuration. This consideration also enables us to distinguish genocide as such from mass murder or democide: the massacre of Tutsis was genocide not simply because of the numbers of people killed, but because killing was a tactic directed at the destruction of a figuration, the racialized subject of the Rwandan Tutsi.

Like the elimination of the Armenians, the elimination of the Tutsis was not simply an end in itself, but served as a means to other objectives. These objectives took on particular salience in the context of the civil war and the Arusha accords, events that threatened a ruling elite with demotion. The negative goal of the genocide, the elimination of Rwandan Tutsi, can be understood in positive terms as the creation of a homogenously Hutu social space via the demographic elimination of the Tutsi population. The genocide operated partly as a way of relieving the economic violence of the late 1980 s and early 1990 s by redistributing the property of the murdered ${ }^{143}$. It operated partly to remove the primary basis of potential support for the

143 This redistribution was an important incentive with which ordinary Rwandans were enrolled in the militias and thereby in killing: "Before April 6, the militia - in the sense of those who had at least some training and experience fighting as a unit - numbered some two thousand in Kigali, with a smaller number outside the capital in communes where the MRND and the CDR were strong. Once the genocide began and militia members began reaping the rewards of violence, their numbers swelled rapidly to between twenty and thirty thousand for the country as a whole." [Des Forges 1999: 227] 
RPF. Partly it effected a massive affirmation of the form of Hutu identity championed by the Hutu Power movement and the CDR. The negation of Tutsi identity provided a means for producing a network of authority relations that extended throughout Rwandan society and that benefited a power elite within the state. If it had been successful, the Rwandan genocide would have produced a new basis for that moral unity deriving from shared historical experience and collectively shared emotions that the genocide of the Armenians produced for Turkey.

\subsection{Civilizing Genocides}

\subsubsection{INTRODUCTION}

The greatest challenge to understanding both of these genocides as civilizing genocides is that both examples are associated with moments of decay and breakdown of social institutions, and with challenges to the sovereignty of the state. They would therefore appear to fall outside the scope of the notion of civilizing genocides, understood as products of the expansion and intensification of barbarous civilization. However, it would be a mistake to reify barbarous civilization as something that exists apart from its individual instantiations, by conceiving of it only as the cause of which civilizing genocides are the effect. It is at least as accurate to say that barbarous civilization advances and intensifies, among other means, through the instantiation of civilizing genocides, that it is produced by civilizing genocides, as to say that it produces these genocides. So one way of evaluating whether these genocides are civilizing or not is to attend not only to what produces them but to what they produce. 


\subsubsection{TURKEY}

The Ottoman genocide of the Armenians is clearly associated with the breakdown of the empire, in terms of the decline of its sovereign and territorial monopoly of the means of violence, and in terms of the associated decay of Ottoman forms of multi-ethnic citizenship. This latter process involved an alteration of the relations of dependency that protected minorities from violent annihilation. Ottoman power was premised on the need to maintain the relative acquiescence of various minority national and religious groups. Just as Elias portrays the dynamics of monarchic France in terms of growing dependency of both the aristocracy and the monarchy itself on the industrial classes, so we can understand the multi-ethnic and cosmopolitan quality of Ottoman social life in terms of the dependency of the Empire on social groups that were weaker than the sovereign authority but still had enough power to prevent its total impunity; although the sovereign dominated the non-Turkish segments of the Empire, it depended on them inasmuch as without them there would be no Empire as such. The secession of the non-Turkish nationalities on European territory fundamentally altered this strategic situation; it diminished the territorial scope of sovereign power but by the same token removed dependencies that checked or limited that power. Correspondingly, this breakup generated new relations of impunity: as the various subject nationalities broke away from the empire, they no longer operated as a de facto collective force counterbalancing Turkish dominance and maintaining the partially multicultural quality of state institutions. The Armenians were left virtually alone in a predominantly Turkish polity that, moreover, was facing the possibility of complete dissolution. The vulnerability of the Armenians can be understood as a function of the breakdown of relations of 
dependence, and the manufacture of relations of impunity, that in Elias's terms would seem to constitute a decivilizing movement.

However, the production of relations of impunity was not simply a consequence of the decline of dependency, for in some respects it was simultaneous with or even a precondition for that decline. This can be shown if we pursue two opposed lines but converging lines of inquiry. On the one hand, why did the demands of subject nationalities (Serbs, Bulgarians, Greeks, Romanians, and so on) find their realization only in separatism? Why were they not resolved through the liberal reforms, nominally promulgated but never practically implemented, that would have given them equal citizenship and both democratized and decentralized state power in the Empire? On the other hand, why did the separation of such large portions of its territory and population not occasion the complete collapse of Ottoman sovereignty, leading directly to the formation of a Turkish nation-state and the autonomy of Arab and possibly Armenian territories? Both questions are answered if we assume that certain relations of impunity existed well before 1914: that the Sublime Porte occupied a strong enough power position that it could risk losing parts of its territory, up to a point, in order to avoid democratizing reforms that would threaten the relative privilege of Turkish and Moslem identity within the (shrinking) figuration. And the gamble was for a time successful, inasmuch as the imperial state was not simply torn apart by its centrifugal forces, but survived until military defeat at the hands of foreign powers at the end of the First World War, an event produced by forces beyond the control of the Ottoman-Turkish figuration. 
Rather than viewing the Armenian holocaust as simply the product of social breakdown, it is useful to regard it as a strategic response to breakdown, one that aimed at reversing centrifugal tendencies and at strengthening Turkish civilization. The formation of the Armenian Question took place in the context of the formation of the Eastern Question, occasioned by the failure of Ottoman sovereignty with respect to Great Power intervention. The existence of the Eastern Question testified to the limits of Ottoman sovereignty, since the substance of the Eastern Question concerned how the Great Powers of Europe were going to organize state structures in the Empire and its environs. In this context, the existence of Armenian Question as a problem of international relations provided an ongoing occasion for foreign intervention in Ottoman affairs. Moreover, after the secession of the Balkan states from the Empire, the very survival of the state itself was seen to be imperiled, making the prospect of Armenian secession intolerable. The 1915 genocide solved at one stroke both of these problems. It removed the source of the Armenian Question. It also activated a network of force relations that extended throughout Turkey, by deploying centrally organized military and paramilitary force in every city, town, and village where Armenians were to be massacred or deported. The threat of Armenian insurgency, although vastly exaggerated by the genocidaires, nevertheless had a real basis in the self-defense organizations by which Armenians periodically attempted to resist persecution. The production of genocidal violence multiplied the force relations that were subject to the central control of the state, and eliminated those that were not. Genocide was a means of reasserting state sovereignty in 
response to its erosion, and not simply a product of that erosion per se. It effected a reassertion of centripetal development after decades of centrifugal dissolution.

Moreover, the genocide enabled the accomplishment of something that had not previously been possible in the Ottoman empire: the organization of all of social life within a common scheme of différance. Previously, the multi-ethnic quality of the Empire meant that the differential network guaranteed by the Sublime Porte was to some extent polycentric: multiple schemes of différance existed, and, although they intersected substantially, they did not altogether coincide. Especially in the case of non-Muslim groups, the potential for those lower in the hierarchy to identify with those higher was limited by deep differences regarding the ultimate standards by which subjectivity was vindicated. Hegemonic Islam reconciled these cleavages with the demands of a hierarchically integrated figuration by categorizing Christians and Jews as people of the book, different from and inferior to Muslims but still within the outer circles of moral community. The Young Turk movement, in contrast, subscribed to an essentially secular social vision, even though it eventually made effective tactical use of a polarized or fundamentalist Islamic identity to enroll people in massacre [Dadrian 1997: 5]. This secularity constituted enough of a break with Islamic tradition to enable the Young Turks to replace traditional hierarchical pluralism with a singular differential scheme. The genocide of the Armenians was therefore not just a way of removing a threat to Ottoman sovereignty, but a way of asserting or confirming the value of the national identity that was still in the process of being produced for the first time. Turkish identity, and Ziya 
Gökalp's ${ }^{144}$ vision of moral unity based on shared historical experience and shared collective emotions, was realized through the active violent negation of Armenian identity. The success of this is evident in the persistence of official denial regarding the genocide, even though the government that committed it is no longer in power, even though the Ottoman Empire has been transformed into the Turkish state, and even though the generation that participated in the genocide has passed away.

\subsubsection{RWANDA}

As in the previous example, the genocide in Rwanda appears at first glance to be symptomatic of the breakdown of structures of civilization rather than of their production. It occurred in the context of a civil war, and hence of the compromise of Rwandan sovereignty; it involved the violent severing of all ties of interdependency between people who had lived in close physical and social proximity; and it involved the flooding of violence into everyday life. In fact, given the extent of direct popular participation, a more complete suspension of the prohibition of violence in everyday life can hardly be imagined. These considerations suggest that genocide was produced by decivilizing developments in the Rwandan figuration.

The first indication of the inadequacy of such an explanation is this: that although the genocide occurred in the context of a contest over sovereignty in Rwanda, it was not committed by the force challenging that sovereignty, but by the Rwandan state itself. For this reason, it did not involve a transgression of the state's monopoly on the use of force.

144 Gökalp was a sociologist and a major intellectual proponent of exclusivist Turkish nationalism. For a more detailed discussion of the relationship between sociology and chauvinism in Turkey, see Appendix II. 
The genocide was instigated by faction of politicians, business owners, and military and administrative officials who seized control of the state following Habyarimana's assassination. Genocide was overtly intended as a measure to prevent Tutsi rule in Rwanda and, less overtly, for the Hutu Power movement to consolidate its hold on state power. If the RPF had been defeated instead of achieving military victory, then the genocide might have been successful, its effects comparable to those of the successful genocide of Ottoman Armenians. Furthermore, state power was a practical precondition for the genocide. The immense logistical challenge of mounting a nation-wide campaign of systematic massacre was resolved by the active participation of the civil service and official administrative structures at all levels of government. Prunier notes that, until the genocide was nearly over,

the killers were controlled and directed in their task by the civil servants in the central government, préfets, bourgmestres and local councilors, both in the capital and in the interior. It was they who received the orders from Kigali, mobilised the local Gendarmerie and Interahamwe, ordered the peasants to join in the man-hunts and called for FAR support if the victims put up too much resistance [Prunier 1995: 244].

Not only were the administrative mechanisms of state involved in the production of genocide, but the genocidaires took advantage of an existing tradition of state-instigated collective action:

In the past, the Rwandan government had often mobilized the population for campaigns of various kinds, such as to end illiteracy, to vaccinate children, or to improve the status of women It had executed these efforts through the existing administrative and political hierarchies, requiring agents to go beyond their usual duties for a limited period of time for some national goal of major importance. The organizers of the genocide similarly exploited the structures that already existed - administrative, political, and military - and called upon personnel to execute a campaign to kill Tutsi and Hutu presumed to oppose Hutu Power. Through these 
three channels, the organizers were able to reach all Rwandans and to incite or force most Hutu into acquiescing in or participating in the slaughter. [Des Forges 1999: 222]

As was the case in the Nazi holocaust, the institutions of the modern state in Rwanda enabled massacre to take place on a scale and with a systematicity that would otherwise be impossible. And although Rwanda had been undergoing its own state-formation process before 1897 , these institutions were still comparatively rudimentary. It was the extension of the military dominance of sovereign European states into African territories, and the concomitant civilizing project by which European institutions were exported to the colonies, that transformed the Rwandan kingdom into a modern nation-state. With respect to state-formation, then, the expansion of barbarous civilization from Europe into Africa was a direct precondition for the Rwandan genocide. Put differently, the genocide presupposed a relatively high degree of civilization.

The civilizing process was also involved in the production of a second precondition for the Rwandan genocide: the racialization of Hutu and Tutsi identity. As my narrative in Section 3.1.2 has already shown, this racialization was substantially a result of the colonial process. German and the Belgian colonizers subscribed to the Hamitic hypothesis, according to which the tall, fine-featured, lighter-skinned Tutsi were believed to be racially similar to white Europeans and hence racially superior to the shorter, darker Hutu. Hutu-Tutsi relations had already begun to polarize prior to colonization, but the institution of the identity card system and the preferential assignment of Tutsis to administrative positions by the colonial authorities intensified this polarization dramatically. Moreover, the association between the racialization of identity 
and the civilizing process is not merely accidental. Racism is one means for implementing the system of identification through hierarchical differentiation that $\mathrm{I}$ have labeled 'violent différance'. By racializing Rwandan identity, the colonizers incorporated Africans into their own differential network on terms that privileged themselves. But once instituted, that network generated a self-sustaining effectivity of its own that did not require direct colonial rule for its perpetuation. State-formation simultaneously enforced this identification, through measures like the identity card system, and provided the stakes: whichever group controlled the state, enjoyed the dominant position in Rwandan society. More precisely, the identification process engendered a strategic situation in which it was possible and advantageous for actors to mobilize group membership in order to seize and hold onto state power. And because barbarous civilization entails a singular differential scheme, in which one particular identity is privileged over and defines the others, the Hutu-Tutsi relationship in Rwanda was always a zero-sum-game, especially where control of the state was concerned. It is important that the genocidaires accused the RPF of pursuing the reinstatement of Tutsi dominance; it is equally important that the actual stated RPF agenda was one of the de-racialization of Rwandan society, and hence the abolition of the particular mode of differentiation into which the leaders of Hutu Power had invested their futures. Aversion of the genocide would have required the reorientation of the Rwanda's barbarous civilization away from an identity-scheme premised on alleged race, to one that privileged some other form of identification - or, alternatively, to a multiple differentiation that did not uniquely privilege any singular identity, which would constitute a genuinely decivilizing development. 
The production of genocide by civilization in Rwanda was also effected through the process of capitalist development. Rwanda had one of the highest concentrations of development agencies in the world [Uvin 1998]. Though considered underdeveloped by conventional standards, Rwanda's economy during its Second Republic was, relative to its condition before or even immediately after colonization, a highly developed engine geared to export to world markets. The considerable development achieved by the Habyarimana regime produced new relations of asymmetrical interdependency. These relations involved ordinary Rwandans in global economic processes that could turn violent when market conditions altered, as they did in the late 1980 s with the declining coffee prices; Rwandans would not have been so hurt by the drop in coffee prices if the export economy had not been so developed in the first place ${ }^{145}$. This economic violence intensified under structural adjustment regimes, and as a result of the state's expenditures to maintain its own sovereignty in the face of civil war. Economic violence - socially produced poverty - provided a basis for enrolling people in genocide, both because Tutsis could be made scapegoats for popular misery and because the property of Tutsis could be redistributed to those who participated in killing. Human Rights Watch notes that by the start of the genocide, $86 \%$ of Rwanda's population lived in poverty, and that most (though not all) of those who were recruited for killing came from this stratum [Des Forges 1999: 260]. This strategic situation was a product of Rwandans' integration into the extended chains of interdependency that Elias claims are characteristic of the argument is that barbarous civilization can produce violence, not that it is the only source of violence in the world. 
civilizing process - but also, more specifically, of the asymmetrical character of those interdependencies, which were more often relations of impunity.

Finally, the Rwandan genocide was not simply an event internal to Rwanda. Aside from the role of the global economy in generating a reserve army of potential genocidaires, genocide was also a product of dynamics in the international state system. It is of course important that the RFP had been sheltered in Uganda, where many RPA members received their military training by serving in the Ugandan armed forces. It is also important that the dynamics of violence set in motion during the genocide did not simply end with the RPF victory, but have been perpetuated in a different form by the thousands of persons, including genocidaires, who fled to eastern Zaire. And of course it was the prospect of the implementation of the U.N.-brokered Arusha peace accords, and the threat to the Hutu Power leadership that they represented, which was likely the trigger for the implementation of genocide. But the international state system also provided a more direct and concrete aid to the genocide: it was international aid, and the international arms trade, that enabled the Rwandan state to accumulate the weapons with which genocide was conducted. The Structural Adjustment Programme of 17 September 1990 promised to Rwanda some $\$ 260$ million in 'balance of payments support' [African Rights 1995: 68]. As I noted in section 3.1.2 above, it was this money that was fraudulently siphoned away to pay for arms, just as the IMF-imposed austerity measures made it easier to conceal the negative impact that arms purchases had on other government expenditures. Arms were obtained on international markets, from Egyptian or South African arms dealers amongst others, and from military aid given by France and 
the U.S. Finally, the state system operated in another way to enable genocide: it was in part because of their preoccupation with the civil war, with the issue of violence between contenders for sovereignty, that that U.N. decision makers overlooked the growing evidence for genocide, for violence of a state against its subjects.

My point is not to simply blame external actors for what happened in Rwanda, but to situate the genocide within a matrix of processes that transgress the boundaries of the nation-state. The existence of nation-states in post-colonial Africa at all is a product of the globalization of Europe's civilizing process. That process is not a mechanical cause of genocide; nor is all genocide necessarily its product, even in space which it has infiltrated. However, the figurational developments that facilitated genocide in Rwanda; that created a strategic situation where genocide both was possible and promised certain rewards, are integral aspects of the process of barbarous civilization, which at the same time organizes force into territorial monopolies, and produces networks of différance through which identity-difference becomes an occasion for violence. The Rwandan genocide, then, is symptomatic of the ways in which barbarous civilization has only deferred, and not solved, the problem of violence in social life. 


\section{Chapter VI: Inconclusions}

To conclude is to come to the end, to finish. What I have written here doesn't finish anything. These comments I write now are not intended to be a last word, but a first word, not to settle arguments but to start them. They are, if anything, the opposite of conclusions: they are inconclusions.

\section{Recapitulation}

In this dissertation I have argued that civilization produces genocide. I began this argument in Chapter 1 by claiming that genocide studies is hampered by a metaphysics of rupture that separates genocide categorically from all other social phenomena, that this rupture prevents the construction of an effective sociological understanding of genocide, one that theorizes genocide in the context of social relations generally. To overcome this rupture, I proposed to guide my theoretical inquiry by three conceptual commitments: to understand genocide in the context of a continuous matrix of practices of power; to understand power symmetrically; and situate genocide in a globalizing field of force relations. I identified my aim as that of producing an open-ended problematization of genocide. In Chapter 2, I addressed the question of what 'genocide' should be taken to mean. I identified the point of my dissertation as contributing to anti-genocidal praxis, and its purpose as formulating a figurational sociology of genocide. Working through the debates around the meaning of 'genocide', I argued that genocide is an essentially contested concept, and that clarification must proceed by way of a historical examination. I used Foucault and Elias to situate the emergence of 'genocide' in relation to processes 
of state formation and the exercise of state power to intervene in the formation of collective identities. I concluded by arguing that, rather than construct a definition of genocide, I should conceive of 'genocide' as the product of a network of resemblances, and that the addition of any new event to this network must be justified on a case-by-case basis, by examination of resemblances capable of tying the event in question to those already established within the network. In Chapter 3, I discussed heroic and anti-heroic modes of theory. Heroic modes privilege identity and formulate praxis in terms of the submergence of difference through the constitution of a heroic collective subject capable of resisting genocide by force; anti-heroic modes privilege difference and formulate praxis in terms of the unmaking of social relations that produce genocide. Durkheim, Marx, Bauman, and Foucault all make valuable contributions to the anti-heroic dimension of the sociology of genocide. However, the works of Durkheim and Marx are limited by the predominance of their heroic mode, that of Bauman by an ahistorical moral universalism, and of Foucault by the restricted scope of his historical analysis.

In Chapter 4, I used a deconstructive reading of Norbert Elias to produce a theoretical framework for understanding genocide. Central to this framework is the concept of barbarous civilization, which involves a twofold redistribution of force relations that simultaneously produces zones of the pacification of everyday life and the intensification, on an expanding scale, of the capacity for violence within a figuration. In this twofold redistribution, military force is concentrated in the state, where it is reproduced on an expanding scale, and the conduct of civilized behaviour produces a circulating economy of deferred violence. This circulating economy of organized into a 
hierarchical system of social differentiation, which it reproduces, and which I call violent différance. Through violent différance, barbarous civilization produces a network of identities-differences that define both individual and collective selves and others.

Occasionally, barbarous civilization produces an identity-difference relation that locates certain people outside the universe of obligation and subjects their identity to violent negation. When this happens, the deferred violence of the system is actualized and civilizing genocide takes place. Civilizing genocides both presume barbarous civilization and produce it; civilizing genocides can be recognized by their use of the dynamics of civilization to mobilize genocidal violence and by their contribution to extending and intensifying civilization along particular lines.

In Chapter 5, I discussed six historical examples of civilizing genocides. I justified inclusion of each example in the network of 'genocide' by careful search for resemblances an analogies relating it to other events already established as genocide and to documents established as contributing to the definition of 'genocide'. In particular, I showed the difficulty of specifying any fixed list of the types of social identity that could be subjected to genocide, emphasizing especially the political dimension of the annihilation of social groups. I showed how the concept of 'intent', crucial to many definitions of genocide, can be understood in a non-logocentric manner, so that intent does not reduce to consciousness and evidence of intent can be inferred from the consequences of actions rather than merely from the statements of perpetrators. And I showed how the notion of 'genocide' is clarified if the object of genocide is understood in terms of figurations rather than in terms of types of individuals. I also argued that each 
of these examples could be understood as integral to the process of barbarous civilization, rather than as a symptom of its reversal or breakdown. Genocide presumes the formation of a concentrated capacity for violence which is provided by the territorially sovereign state. It also presumes the formation of intense relations of identity-difference, relations that produce hierarchies in which certain subject-positions grant actors impunity of action with respect to others, and in which difference is linked with violence. Moreover, genocide has made crucial contributions to the advancement of European civilizationbarbarism at various points throughout the history of that figuration, aiding in the formation of territorially sovereign states and of the mechanisms through which everyday life is governed, and in the forceful dissemination, through colonialism, of European civilization throughout the rest of the world. Of the six genocides I examined, three were successful, two were partially successful, and only the Rwandan genocide failed to reassert, in the face of a severe decivilizing challenge, the power of the state and the privilege of the perpetrator's social identity.

\section{Implications for Understanding}

The project of understanding genocide is distinguishable but inseparable from that of anti-genocidal praxis. In regard to both of these projects my dissertation is, inevitably, less than complete. My hope is that this research opens avenues for further investigation. In the remaining two sections of this chapter, I will discuss some of those avenues, first with respect to the project of understanding, and then with respect to anti-genocidal praxis. 
I perceive three major areas for further investigation pursuant to a sociological understanding of genocide. The first concerns the fraught question of the meaning of 'genocide'. Because I have desired to use the term 'genocide' rather than merely examine it, my genealogical and figurational unearthing of its buried historical contexts (presented in Chapter 2) has been brief. My use of 'genocide' has been informed at all times by a fundamental nominalism. That is, I have assumed that the meaning of 'genocide' is an effect of socially established convention, and is not determined by any ultimately intransigent structure or objective reality. My use has assumed that the conceptual practice of 'genocide' is contested and contestable, such that my individual performance of genocide scholarship has at least the potential of introducing a modification into others' use of the term. I have taken some account of the strategic situation within which my performance is intervening, particularly through my examination of the politics of particular and general uniqueness and, to a lesser extent, of the divisions between liberal and post-liberal scholarship. Nevertheless, a great deal remains to be done into the conditions of possibility for both using and modifying the word genocide. On the one hand, a full examination of the definitional debate requires that that debate be situated within a more general sociological account of the operation of language. On the other hand, the specific history of the relationship between state power and the various forms of identity which 'genocide' is aimed at protecting deserves a much fuller investigation than I have been able to give it here. The very etymology of 'genocide' points towards this investigation; its first syllable, for example, relates it to words like 'gens', 'genre', 'genetic', 'genus', which taken together have connotation both 
of relation defined biologically by ancestry, and of type or classification in the more abstract sense. This etymology is suggestive of a historical relation between the formation of social groups and the formation of general concepts of classification, a relation that I have tried to incorporate into my discussions of identity-difference. At the same time, the normative content of genocide implicitly refers to a history of the uses and limits to use of the state's military capacity, especially against civilians. This history is undoubtedly relevant to the puzzle of why the UNGC has been so singularly ineffective for the vast bulk of its history. I have only discussed one dimension of this history in my analysis of civilizing genocides. In these various ways, a fully adequate response to the debates over the meaning of 'genocide' involves a history of the politics of classification.

Second, throughout the dissertation I have insisted that barbarous civilization produces hierarchies of identity-difference, without making very specific claims, apart from my investigation of particular cases, regarding the forms of identity that it privileges or the ways in which identity-difference, under conditions of barbarous civilization is not organized by it. I have claimed that a figurational analysis allows us to understand multiple forms of identity - class, gender, religion, and so on - as horizontally intersecting, as being often constituted through the same practices. In other words, I have claimed that in any given figuration, one action can produce effects of identity-difference along multiple dimensions, and that this helps account for the protean ability of barbarous civilization to organize identity-difference without privileging the same identity across different historical and cultural contexts. I have implied that the subject privileged by barbarous civilization is defined by multiple intersecting vectors of identity, constituted 
through concrete practices. However, my historical investigations have focused primarily on the relations between states and subjects. To fully explain the relationship between civilization and genocide, this analysis must be supplanted with an examination of forms of identity and practices of identification-differentiation that are not centered specifically on the state, but that provide the broad milieu in which state power operates. Any one of the examples I analyze can be fleshed out by investigation of the concrete and material practices through which subjects perform relations of gender, of class, of 'race', of religion, and so on. Such analysis would clarify in figurational terms how concrete individuals, not only those who belong to elites, who plan and instigate genocide, but also those who do not and who implement the nuts and bolts of genocidal violence, are enrolled in the massive social undertakings that genocides almost invariably represent. This analysis would help to produce in concrete terms a horizontal analysis of the dynamic interactions among various processes of identification-differentiation, relating them to each other without privileging any one over others, either normatively or analytically.

Third, I have described the figuration of barbarous civilization as a process with a specifically European ancestry. This was a practical rather than a principled position. As I have mentioned earlier, the historical account provided by Norbert Elias, on which I base my account of barbarous civilization, is concerned entirely with processes generated within Europe that are subsequently exported to the rest of the world. Where Elias has been oblivious to the dangers of Eurocentrism, I have been careful neither to assume that the processes I examine are a unique product of European culture, nor to assume that they 
are universal of human social existence. I expect that neither extreme is correct, and that careful empirical study would reveal important resemblances and important contrasts in the relationship between the social organization of violence and the social production of identity-difference in nineteenth-century England, in Japan under the shoguns, in the Aztec empire, and perhaps even in more egalitarian cultures. A passage from Stannard, citing the Jesuit Pierre de Charlevoix's observations on parenting practices among the Iroquois is suggestive in this regard:

[Charlevoix] marveled at the early age at which Indian children were encouraged, with success, in seemingly contradictory directions - toward both prideful independence and cooperative, communal socialization. Moreover, he noted, the parents accomplished this goal by using the gentlest and subtlest of techniques. [...] An emphasis on pride and honor and thus on the avoidance of shame - was the primary means of adult guidance. For example, notes Charlevoix: "A mother on seeing her daughter behave ill bursts into tears; and upon the others' asking her the cause of it, all the answer she makes is, Thou dishonourest me. it seldom happens that this sort of reproof fails to be efficacious". [...] The most violent act of disapprobation that a parent might use on a misbehaving child, Charlevoix and other visitors observed, was the tossing of a little water in the child's face, a gesture obviously intended more to embarrass than to harm. [Stannard 1992: 29-30]

If we accept for a moment again Elias's equation between civilization and peaceful selfconstraint, the Iroquois seem more civilized than even contemporary Anglo-Americans. A comparative figurational study of the relation between violence and identification would provide a broader context within which to situate and, as it were, de-exalt the peculiarities of European or Western or modern social dynamics. It would also make it possible to analyze the colonially induced modernization of the world in terms of the interaction of competing figurations, of conflict between figurations that lay claim to the same aspects of social action, and the effects of resistance produced even in the face of 
the most successful domination. This analysis would map a topography of global dispositions of violence in relation to identity, and thereby provide a welcome antidote to inane talk of the so-called clash of civilizations.

\section{Implications for Praxis}

My analysis has not been the sort that produces definite policy recommendations. I have tried to re-frame the basic categories with which we think about genocide and the task of anti-genocidal praxis. In any case, the notion of 'policy recommendations' presupposes an identification between the scholar who prescribes them and the state authority that is expected to follow them. Like human rights ${ }^{146}$, anti-genocidal praxis is not a way of extending the state project, but of placing limits on it. Nevertheless, a number of implications for praxis are suggested by my analysis.

First, I suggest modestly that anti-genocidal praxis must not be limited to tactics that rely on states to act against genocide, and it especially must not treat armed humanitarian intervention as a sufficient solution to the problem of genocide. It may very well be that such intervention is a necessary tool for preventing or stopping genocides, in situations where civilizing différance has created a proto-genocidal situation that is ready to be instantiated. Certainly, intervention in the early stages of the Rwandan genocide could have prevented the slaughter of hundreds of thousands of people, and there is no reason to think that was a uniquely preventable genocide. The consistent and effective practice of armed humanitarian intervention, backed by 
international law, to prevent genocidal massacres would alter the entire topography of struggles over genocide, and would probably make other forms of intervention easier. Nevertheless, such intervention is not a sufficient response. Genocide is not produced merely by bad persons or bad groups of people in elite positions of power, but by social relations of impunity generated by hierarchical systems of social differentiation that privilege certain identities over others. Removing a few genocidaires from power does not address this underlying figurational problem, and leaves open the possibility that mobilization for genocide may recur. Just as problematically, it leaves open the possibility that an intervention force may, to maintain order and prevent overt violence, reinforce power relations that continue to distribute violence through existing differential networks; in other words, without attention to civilizing différance, a humanitarian intervention force risks becoming a vehicle for the maintenance of privilege and of injustice. Furthermore, a program of armed humanitarian intervention is only equipped to address certain types of genocides: those that proceed by way of mass violence over a short term, and not those where violence is continuous and prolonged without ever becoming spectacular. This latter form of violence is more characteristic of the genocidal pressures faced by indigenous peoples in post-colonial states; intervention on behalf of such groups requires more subtle and long-term strategies than an occupation force can provide. Finally, attention to relations of violent différance is necessary if response to

146 "If governments make human rights the structure and the very framework of their political action, that is well and good. But human rights are, above all, that which one confronts governments with. They are the limits that one places on all possible governments." [Foucault 2000c: 471] 
genocide is to move beyond policing towards a permanent elimination of the causes of the problem.

This points to the second implication that I would like to describe: the struggle to end genocide is bound up in a wider arena of the contestation of power relations in social life, not only those relations defined in terms of state power, but relations across all the cleavages produced through violent différance: those of class, of gender, and so on. A figurational analysis suggests that genocide is a stake in all struggles to unmake relations of domination, even in contexts where its occurrence is unlikely. Local forms of domination exist in the context of global figurations of inequality, especially as economic globalization continues to progress. Just as different forms of inequality within a particular context tend to reinforce one another, so does inequality and privilege anywhere in the global network of interdependencies that barbarous civilization has produced contribute to inequality and privilege everywhere in it. And among other things, genocides are always a vehicle for maintaining or intensifying inequality. Local genocides therefore have global consequences, however attenuated they are. At the same time as struggles to end diverse forms of domination beg the importance of ending genocide, so the project of ending genocide is simultaneously a struggle against domination in its various forms. Genocide is made possible by the construction of relations of impunity in the context of asymmetrical interdependence; ending genocide involves imparting at least some degree of mutuality and symmetry to those interdependencies - the more, the better. In this double respect, anti-genocidal praxis is 
fundamentally connected to struggles for human rights struggles, for feminism, for socialism.

Finally, my analysis suggests a rethinking of the relationship between states and individuals and, more broadly, a rethinking of the very notion of collective and individual identity. Certainly, the state's capacity to commit genocide in the name of ethnically exclusive nationalisms constitutes an obvious argument against taking nationalism to its extremes. But my analysis suggests that nationalist genocides are only one form taken by the genocidal moments of barbarous civilization. If genocide in Turkey or in Bosnia, for example, raises doubts about nationalism, the genocides of indigenous peoples in the Americas and Australia, or against colonial subjects in Africa and Asia, more pervasive doubts about modern civilization as a whole. A person capable of identifying with the victims of civilizing genocides can no longer identify with civilization itself. And yet civilization is not something that we can simply dispense with in order to return to a mythical pre-genocidal natural condition; civilization is itself a resolution, however inadequate, of the possibility for violence in social life. Civilization, in other words, is something to be superceded. This involves a critical examination of the practices of identification and differentiation that civilization has engendered. Viewed from this angle, social identity, both collective and individual, loses some of its mystique or its romance. Within the process of barbarous civilization, our performance of identity both protects us from harm and reproduces the harm we are threatened by. It enrolls us in a violence against others that is in many ways a violence against our selves. Antigenocidal praxis confronts us with at least this minimal question: how is our identity 
premised on the negation of difference? At the very least it urges us to abandon our identification with the civilization that has produced us. In my discussion of the antiheroic mode of theory I emphasized strategies of unmaking, the unmaking of the relations that produce genocide. But this is not strictly a negative task: in social life, at least, unmaking a relation always requires making a new one. The construction of nongenocidal social relations therefore demands a special labour from us, the labour of producing a world after civilization. 


\section{Appendix I: Definitions of Genocide}

\section{United Nations}

[Excerpted from the Convention on the Prevention and Punishment of the Crime of Genocide, United Nations, 9 December 1948:]

\section{ARTICLE I}

The Contracting parties confirm that genocide, whether committed in time of peace or in time of war, is a crime under international law which they undertake to prevent and to punish.

\section{ARTICLE II}

In the present Convention, genocide means any of the following acts committed with intent to destroy, in whole or in part, a national, ethnical, racial, or religious group, as such:

(a) Killing members of the group;

(b) Causing serious bodily or mental harm to members of the group;

(c) Deliberately inflicting on the group conditions of life calculated to bring about its physical destruction in whole or in part;

(d) Imposing measures intended to prevent births within the group;

(e) Forcibly transferring children of the group to another group

\section{ARTICLE III}

The following acts shall be punishable:
(a) Genocide;
(b) Conspiracy to commit genocide;
(c) Direct and public incitement to commit genocide;
(d) Attempt to commit genocide;
(e) Complicity in genocide.

[Source: Chalk and Jonassohn, 1990: 44-45.]

\section{Other Definitions:}

\section{BARTA, TONY}

In Australia very few people are conscious of having any relationship at all with Aborigines. My thesis is that all white people in Australia do have such a relationship; that in the key relation, the appropriation of the land, it is fundamental to the history of the society in which they live; and that implicitly 
rather than explicitly, in ways which were inevitable rather than intentional, it is a relationship of genocide. [...] My conception of a genocidal society - as distinct from a genocidal state - is one in which the bureaucratic apparatus might officially be directed to protect innocent people but in which a whole race is nevertheless subject to remorseless pressures of destruction inherent in the very nature of the society. [Barta 1987: 239-240]

\section{CHALK, FRANK AND KURT JONASSOHN}

Genocide is a form of one-sided mass killing in which a state or other authority intends to destroy a group, as that group and membership in it are defined by the perpetrator. [Chalk and Jonassohn 1990: 23; Chalk 1994: 52Jonassohn 1998: 10]

We need to begin with a question: what elements do we look for in evaluating situations and events before determining whether we are dealing with a case of genocide? We used three major criteria: (1) there must be evidence, even if only circumstantial, of the intent of the perpetrator; (2) there must be a group whose victimization threatens its survival as a group; and (3) the must be one-sided. We realized that these conditions can, in some cases, be problematic; therefore we recognized as 'genocidal massacres' those events that violate one of our conditions. [Jonassohn 1998: 10]

\section{CHARNY, ISRAELW.}

The generic definition of genocide:

Genocide in the generic sense is the mass killing of substantial numbers of human beings, when not in the course of military action against the military forces of an avowed enemy, under conditions of the essential defenselessness and helplessness of the victims. [Charny 1994: 75]

Charny elaborates on this generic definition by including under it the following possible variants:

- Genocidal Massacre (mass killing 'on a smaller scale');

- Intentional Genocide;

- Genocide in the Course of Colonization or Consolidation of Power;

- Genocide in the Course of Aggressive ("Unjust") War;

- War Crimes Against Humanity;

- Genocide as a Result of Ecological Destruction and Abuse. 
He also adds, parallel to the generic definition of genocide, the categories of 'Accomplices to Genocide' and 'Cultural Genocide', the latter of which includes the variant 'Linguicide'. [Charny 1994: 76-77]

He further adds, like Churchill (see below), definitions of first, second, and third degrees of genocide, war crimes, and ethnocide [Charny 1994: 85].

\section{CHURCHILL, WARD}

\section{Proposed Convention on Prevention and Punishment of the Crime of Genocide (1997)}

\section{ARTICLE II}

In the present convention, genocide means the destruction, entirely or in part, of any racial, ethnic, national, religious, cultural, linguistic, political, economic, gender or other human group, however such groups may be defined by the perpetrator. It is understood that, historically, genocide has taken three (3) primary forms, usually, but not always, functioning in combination with one another.

(a) Physical Genocide, by which is meant killing members of the targeted group(s) either directly, by indirect means, or some combination. [...]

(b) Biological Genocide, by which is meant the prevention of births within the target group(s), either directly, indirectly, or both. [...]

(c) Cultural Genocide, by which is meant the destruction of the specific character of the targeted group(s) [...]

\section{ARTICLE IV}

[I]t is understood that several degrees of culpability pertain to the commission of genocide. These may be taken into consideration for purposes of determining the appropriateness of punishment.

(a) Genocide in the First Degree, which consists of instances in which evidence of premeditated intent to commit genocide is present.

(b) Genocide in the Second Degree, which consists of instances in which evidence of premeditation is absent, but in which it can be reasonably argued that the perpetrator(s) acted with reckless disregard for the probability that genocide would result from their actions.

(c) Genocide in the Third Degree, which consists of instances in which genocide derives, however unintentionally, from other violations of international law engaged in by the perpetrator(s). ${ }^{147}$ 
(d) Genocide in the Fourth Degree, which consists of instances in which neither evidence of premeditation nor other criminal behavior is present, but in which the perpetrator(s) acted with depraved indifference to the possibility that genocide would result from their actions and therefore to effect adequate safeguards to prevent it. ${ }^{148}$

[Churchill 1998: 432-435]

\section{FEIN, HELEN}

Genocide is the calculated murder of a segment or all of a group defined outside the universe of obligation of the perpetrator by a government, elite, staff or crowd representing the perpetrator in response to a crisis or opportunity perceived to be caused by or impeded by the victim. The universe of obligation is the range of people to whom the common conscience extends: the people toward whom rules and obligations are binding, who must be taken into account, and by whom we can be held responsible for our actions. [Fein 1984: 4]

\section{HARFF, BARBARA, AND TED GURR}

By our definition, genocides and politicides are the promotion and execution of policies by a state or its agents which result in the deaths of a substantial portion of a group. The difference between genocide and politicide is in the characteristics by which members of a group are identified by the state. In genocides the victimized groups are defined primarily in terms of their communal characteristics, i.e., ethnicity, religion, or nationality. In politicides the victim groups are defined primarily in terms of their hierarchical position or political opposition to the regime. [Harff and Gurr 1988: 360]

\section{HOROWITZ, IRVING LOUIS}

A formal distinction between genocide and assassination is also required. Genocide is herein defined as a structural and systematic destruction of innocent people by a state bureaucratic apparatus, whereas assassination designates random and sporadic efforts of people without power to illegally seize power and liquidate paramount central figures in a given regime as a means to that goal. [Horowitz 20002: 23] 


\section{KATZ, STEVEN}

On genocide:

I shall employ the notion of genocide as applying to, and only as applying to, "the actualization of the intent, however successfully carried out, to murder in its totality any national, ethnic, racial, religious, political, social, gender or economic group, as these groups are defined by the perpetrator, by whatever means." [Katz 1994: 131]

On cultural genocide:

Cultural genocide being understood as "the actualization of the intent, however successfully carried out, to destroy the national, ethnic, religious, political, social, or class identity of a group, as these groups are defined by the perpetrators." [Katz 1994: 1371

\section{LEMKIN, RAPHAELL}

By 'genocide' we mean the destruction of a nation or of an ethnic group. This new word, coined by the author to denote an old practice in its modern development, is made from the ancient Greek word genos (race, tribe) and the Latin cide (killing), thus corresponding in its formation to such words as tyrannicde, homocide, infanticide, etc. ${ }^{149}$ Generally speaking, genocide does not necessarily mean the immediate destruction of a nation, except when accomplished by mass killings of all members of a nation. It is intended rather to signify a coordinated plan of different actions aiming at the destruction of essential foundations of the life of national groups, with the aim of annihilating the groups themselves. The objectives of such a plan would be disintegration of the political and social institutions, of culture, language, national feelings, religion, and the economic existence of national groups, and the destruction of the personal security, liberty, health, dignity, and even the lives of the individuals belonging to such groups. Genocide is directed against the national group as an entity, and the actions involved are directed against individuals, not in their individual capacity, but as members of the national group. [Lemkin 1944: 79]

The crime of genocide involves a wide range of actions, including not only the deprivation of life but also the prevention of life (abortions, sterilizations) and also devices considerably endangering life and health (artificial infections, working to death in special camps, deliberate separation of families for

${ }^{149}$ [Note by Lemkin:] Another term could be used for the same idea, namely, ethnocide, consisting of the Greek word 'ethnos' - nation - and the Latin word 'cide'. 
depopulation purposes, and so forth). All these actions are subordinated to the criminal intent to destroy or to cripple permanently a human group. [Lemkin 1947: 147]

\section{PORTER, JACK NUSAN}

Genocide is the deliberate destruction, in whole or in part, by a government or its agents, of a racial, sexual, religious, tribal, ethnic, or political minority. It can involve not only mass murder, but also starvation, forced deportation, and political, economic, and biological subjugation. Genocide involves three major components: ideology, technology, and bureaucracy/organization. [Porter 1982: 12]

\section{RUMMEL, R.J.}

The short version:

Genocide: among other things, the killing of people by a government because of their indelible group membership (race, ethnicity, religion, language).

Politicide: the murder of any person or people by a government because of their politics or for political purposes.

Mass Murder: the indiscriminate killing of any person or people by a government.

Democide: The murder of any person or people by a government, including genocide, politicide, and mass murder. [Rummel 1994: 31]

The long version:

In detail, democide is any action by government:

(1) designed to kill or cause the death of people

(1.1) because of their religion, race, language, ethnicity, national origin, class, politics, speech, actions construed as opposing the government or wrecking social policy, or by virtue of their relationship to such people;

(1.2) in order to fulfill a quota or requisition system;

(1.3) in furtherance of a system of forced labor or enslavement;

(1.4) by massacre;

(1.5) through imposition of lethal living conditions; or

(1.6) by directly targeting noncombatants during a war or violent conflict; or 
(2) that causes death by virtue of an intentionally or knowingly reckless and depraved disregard for life (which constitutes practical intentionality), as in

(2.1) deadly prison, concentration camp, forced labor, prisoner of war, or recruit camp conditions;

(2.2) murderous medical or scientific experiments on humans;

(2.3) torture or beatings;

(2.4) encouraged or condoned murder, or rape, looting, and pillage during which people are killed;

(2.5) a famine or epidemic during which government authorities withhold aid, or knowingly act in a way to make it more deadly;

(2.6) forced deportations and expulsions causing deaths.

$[\ldots]$

(h) Excluded from this definition are:

(h.1) execution for what are internationally considered capital crimes, such as murder, rape, spying, treason, and the like, so long as evidence does not exist that such allegations were invented by the government in order to execute the accused;

(h.2) actions taken against armed civilians during mob action or riot (e.g., killing people with weapons in their hands is not democide); and

(h.3) the death of noncombatants killed during attacks on military targets, so long as the primary target is military (e.g., during bombing of enemy logistics).

[Rummel 1994: 37-38]

\section{THOMPSON, JOHN L. P., AND GAIL A. QUETS}

In short, given the problems which arise from restrictions, we define genocide as the destruction of a group by purposive action. This allows the role of intentional action to be explored, different subtypes of genocide to be compared, and the impact of different factors on genocide to be examined empirically. [Thompson and Quets 1990: 248] 


\section{Appendix II: Sociology and Genocide}

One remarkable feature of the obliteration of the Armenians concerns the role that sociology, and specifically Durkheimian theory, played in the legitimation of exclusionary nationalism and genocide.

Ziya Gökalp has been called "the father of Turkish nationalism" [Melson 1992: 164] and is regarded by many as "the pre-eminent Turkish thinker of the century" [Smith $1995 ; 46]$. He was also a sociologist who considered Durkheim to be his major intellectual influence. He rose to prominence in the wake of the 1908 revolution, and was a member of the Central Committee of the Ittihadist party from 1911 to 1918 [ibid; Melson 1992: 165]. In this capacity he was recognized as "the leading intellectual of the new regime" [Smith 1995: 46] and influenced the ideas of both Talaat and Enver. He was given the mandate of investigating the conditions of minorities, especially the Armenians. During the genocide he wrote an internal party document titled "The Two Mistakes of the Tanzimat", lambasting the reform edicts of 1839 and 1856 and asserting that the Empire should be a nation of overlords "with the watchword: 'Islam mandates domination"" [Dadrian 1997: 180]. He was also involved, with War Minister Enver, in directing The Association for the Promotion of Turkish Strength and other Ottoman youth groups that combined para-military training and nationalist indoctrination [Dadrian 1997: 196]. He was arrested on 21 September 1919 along with Enver and other senior Ittihadist officials, and tried by the Turkish Military Tribunal, during which time he admitted to having approved of the deportation of the Armenians, but denied that there had been massacres, 
stating instead that the Armenians had been "killed in a war between them and the Turks, whom they had stabbed in the back" [Heyd, quoted in Melson 1992: 165]. The result of his trial was that he was deported to Malta; after the war he was an ardent supporter of the Ataturk regime. He published his most important work The Principles of Turkism in 1923, and died in 1924 [Smith 1995: 48].

Gökalp was also a sociologist. He established the first chair of sociology, in 1912, in the Department of Philosophy in Istanbul University [Ertürk 1990: 39]. He became professor of sociology at Istanbul in 1915 [Kahveci 1995: 52]. He was instrumental in ensuring that sociology was taught in intermediary schools, and after his death he occupied a "dominant position within mainstream sociology" [Ertürk 1990: 40]. His integral or organic nationalism is intertwined with his sociology, and specifically with his particular reading of Durkheim. His 'National Sociology', symbolized by the slogan 'Turkify, Islamize and modernize', at the theoretical level, incorporated the organic assumptions of Comte, Darwin and Spencer" within a nominally Durkheimian framework [Ertürk 1990: 39]. Specifically, he justified an "ultra-nationalist perspective which left no room for individual liberties and initiative" [Smith 1995: 48] by appropriating Durkheim's ideas about social solidarity, moral unity, the division of labour, and corporatist political structures [Smith 1995: 47-49; Kahveci 1995: 52-55; Melson 1992: 164]. There is no doubt that Gökalp substantially modified Durkheim's ideas. As Melson says, "it was Gökalp's reading of Durkheim and his adaptation of the French sociologist to the [Turkish] political landscape that proved to be seminal" [Melson 1992: 164, emphasis added]. But this connection, however tenuous, raises an interesting 
question regarding the relationship between sociological theory and the genocide of the Armenians.

In Gökalp's vision, a nation is "a society consisting of people who speak the same language, have had the same education and are united in their religious and aesthetic ideals - in short those who have a common culture and religion" [Heyd 1950: 63]. Nationalism is accordingly premised on moral unity deriving from shared historical experience and collectively shared emotions [Kahveci 1995: 53]. For Gökalp, the nation was "the basic principle of moral action" [Melson 1992: 167]. The individual is therefore absolutely subordinate to the nation, and to authority that acts in the name of the nation, as Gökalp expressed in a poem:

I am a soldier it is my commander I obey without question all its orders With closed eyes I carry out my duty. [quoted in Heyd 1950: 124]

Gökalp's integral nationalism broke with the Ottoman tradition that "not only accorded minorities a place in the empire but also defined certain moral and political responsibilities of the state toward them and toward all millets" [Melson 1992: 167]. ${ }^{150}$ It also broke with Islamic tradition that recognized Christian Armenians as people of the book [Melson 1992: 169]. It sanctioned genocide in two ways: it implied that any action is good if carried out for the good of the nation, and it excluded the Armenians from the Turkish nation (and, by implication, from the community of obligation).

$150 \quad$ In the Ottoman Empire, the term "millet" designated one of the religious communities that made up the empire. Different millets were given different forms of citizenship and were subject to different laws. [Melson 1992: 54-56] 
How much of this is properly Durkheimian? Certainly, Gökalp's militarism, ethnocentrism, and conformist nationalism contrast sharply with Durkheim's consistent lifelong opposition to ethnically chauvinist tendencies in French nationalism, especially during the Dreyfus affair and the First World War [Turner 1992]. Gökalp, whose "writings show the influence of many Durkheimian texts, including essays and lectures that were quite obscure at the time" [Smith 1995: 49], seems to have ignored Durkheim's Montesquieuian insistence, in Professional Ethics and Civic Morals (which was originally given as a lecture series at Istanbul), that the power of the state be counterbalanced by the power of secondary institutions so that individual liberty is not stifled - an argument that also appears in the second preface to Division of Labour. Ethnically chauvinist nationalism is incompatible with Durkheim's arguments to the effect that social solidarity and interdependence can be premised on difference as well as, or better than, on sameness [Durkheim 1997: 16-24]. Overall, one may accuse Gökalp of perversely wanting to build a modern society on the basis of mechanical, not organic, solidarity.

And yet a nationalist celebration of the nation as the principle of moral action harmonizes with Durkheim's claim that social solidarity is the essence of all morality [Durkheim 1997: 329-332], that society is the ultimate object of moral action, and that the good of society is the basis of all morality [Durkheim 2002: 55-61]. If Durkheim affirms the value of democracy, it is a democracy defined not by popular control over the mechanisms of government, but by close communication between the state, as the organ of social thought, and the vague representations diffused throughout the social body 
[Durkheim 1992: 81-84]. If Durkheim at times shows a concern to reconcile social solidarity with individual liberty, at other times he celebrates the insignificance of the individual in the face of the godlike magnificence of society [Durkheim 1995: 208-209]. Speaking of the division of labour, Durkheim argues that the question of which class controls the means of production matters less than the nature of the moral code that governs economic life [Durkheim 1992: 9-13]. Taking all these points together, one may read in Durkheim an analysis of power in which concrete human individuals disappear, and only the objective functional needs of society [Durkheim 1982: 85-97] have any significance. In sum, an attempt like Gökalp's to appropriate Durkheim in the service of genocidal nationalism can be seen as an extension of certain themes in Durkheim's writing at the expense of others, rather than a wholesale distortion of his thought.

In deconstructive theory, the distinction between reading and misreading is itself deconstructed: all readings are misreadings. This means that we can't take the easy way out of claiming that Gökalp simply misread Durkheim (or that Stalin simply misread Marx, for example). We can say that Gökalp's reading synthesizes aspects of Durkheim with ideas quite foreign to Durkheim. We can also say that it is a reading with manifest liabilities, and that a reading such as Turner's, for example, makes a much more fruitful and relevant use of Durkheimian texts with respect to the current concerns of sociology and its relation to liberal and communitarian politics. But this conclusion minimizes the importance of the Gökalp-Durkheim connection that I have elaborated. Is there a greater significance? 
Nicole Vartanian claims that "the danger lies in Durkheim's one-sided analysis of the power dynamic."

Durkheim simply offers no conceptual opportunity for this power dynamic to be abused or for the balance of power to be misappropriated. [...] Considering the context of his writing, at a time when he generally saw the modern French state as a manifestation of organic solidarity, perhaps this is reasonable. Nonetheless, for his theory of society to be fully developed, and for it to have applicability outside his particular moment and place in history, this seems to be a significant void. [Vartanian 2000: 8]

One of Elias's criticisms of Parsons [Elias 2000: 466-467] applies to Durkheim also: that Durkheim's model of a functionally integrated organic society in which the state is the organ of social thought and in which society is the foundation and object of morality refers to an idealized version of the late Victorian French nation-state rather than to the concrete actualities of modern nation-states in general. The validity of this criticism depends in part on whether one reads Durkheim's sociology of the state as referring to states in their actually existing form. There is some ambiguity as to whether Durkheim's discussion of the state, in the Division of Labour or in Professional Ethics, for example, refers to any concrete state or to one dimension of a hypothetical model of the perfectly functional society. At the very least, we can say that the ambivalence between descriptive and normative connotations of statements like "the state is the very organ of social thought" [Durkheim 1992: 51] provides an opportunity for ideologues like Gökalp to appropriate Durkheim in the service of authoritarianism and genocide.

None of this implies a direct causal or practical relation between Durkheimian sociology and the Turkish genocide. Even if Durkheim's writings helped Gökalp provide an ideological legitimation for integral nationalism and genocide, it does not follow that 
Durkheimian texts formed part of a discursive formation, in the strict Foucaultian sense [Foucault 1972: 31-39] through which relations of genocide were implemented. More research could be done on this. Nor am I trying to intervene in the long-running debate on the relationship between Durkheimian thought and Fascist versions of corporatism. However, as concrete individuals writing sociological texts today, texts that we do not want to see appropriated for the ends of atrocity, Durkheim's fallibility serves as an object lesson. In "The Work of Art in the Age of Mechanical Reproduction", Benjamin states: "The concepts which are introduced into the theory of art in what follows differ from the more familiar terms in that they are completely useless for the purposes of Fascism" [Benjamin 1969: 218]. Durkheim, had it occurred to him, might very well have prefaced his own work similarly. But how can we carry through on such promises? Durkheim's failure, comparable to Marx's, underscores the difficulty of the problem. 


\section{Sources}

"Late Victorian Holocausts (Book Review)". 2001. The Economist, 358, 78.

Adalian, Rouben. 1992. "The Armenian Genocide: 1915-1923". In M. N. Dobkowski \& I. Wallimann (Eds.), Genocide in Our Time: An Anotated Bibliography with Analytical Introductions (pp. 86-88). Ann Arbor: Pierian Press.

African Rights. 1995. Rwanda: Death, Despair, and Defiance (Revised ed.). London: African Rights.

Alexander, Edward. 1980, November. "Stealing the Holocaust". Midstream, 26.

- 1994. The Holocaust and the war of ideas. New Brunswick: Transaction Publishers.

Alvarez, Alex. 2001. Governments, citizens and genocide: a comparative and interdisciplinary approach. Bloomington, Indiana: Indiana University Press.

Arendt, Hannah. 1994. Eichmann in Jerusalem: A Report on the Banality of Evil (Revised and Enlarged Edition ed.). New York: Penguin Books.

Axtell, James. 1992. Beyond 1492 : encounters in colonial North America. New York: Oxford University Press.

Barber, Malcolm. 2000. The Cathars: Dualist Heretics in Languedoc in the High Middle Ages. Harlow, England: Longman.

Barnes, Barry. 1977. Interests and the Growth of Knowledge. London: Routledge.

Barnes, Barry, David Bloor, \& John Henry. 1996. Scientific Knowledge: A Sociological Analysis. Chicago: University of Chicago Press.

Barta, Tony. 1987. "Relations of Genocide: Land and Lives in the Colonization of Australia". In I. Wallimann \& M. N. Dobkowski (Eds.), Genocide and the Modern Age: Etiology and case studies of mass death (pp. 237-252). New York: Greenwood.

Bauer, Yehuda. 1978. The Holocaust in Historical Perspective. Seattle: University of Washington Press.

—. 1980, November 1980. "Whose Holocaust?" Midstream, 26.

—. 1990. "The Evolution of Nazi Antisemitic Policy, 1933-1938". In F. R. Chalk \& K. Jonassohn (Eds.), The History and Sociology of Genocide (pp. 332-353). New Haven: Yale University Press. 
-. 1991. "Holocaust and Genocide: Some Comparisons". In P. Hayes (Ed.), Lessons and Legacies: The Meaning of the Holocaust in a Changing World. Evanston, Ill.: Northwestern University Press.

-. 1998. "A past that will not go away". In M. Berenbaum \& A. J. Peck (Eds.), The Holocaust and History. Bloomington: 1998: Indiana University Press.

—. 2001. Rethinking the Holocaust. New Haven, CT: Yale University Press.

Bauman, Zygmunt. 1991. Modernity and the Holocaust. Ithaca, NY: Cornell University Press.

Benjamin, Walter. 1969. Illuminations. New York: Schocken Books.

-. 1969. "Theses on the Philosophy of History" (H. Zohn, Trans.). In H. Arendt (Ed.), Illuminations. New York: Schocken Books.

Bhabha, Homi K. 2001. "Of mimicry and man: The ambivalence of colonial discourse". In M. McQuillan (Ed.), Deconstruction: A Reader (pp. 414-421). New York: Routledge.

Bloor, David. 1976. "The Strong Programme in the Sociology of Knowledge", Knowledge and Social Imagery (pp. 1-19). London: Routledge and Kegan Paul.

Bourdieu, Pierre, \& Loïc J. D. Wacquuant. 1992. An Invitation to Reflexive Sociology. Chicago: University of Chicago Press.

Braudel, Fernand. 1994. A History of Civilizations. New York: Allen Lane, The Penguin Press.

Breuer, S. 1991. "The denouements of civilization: Elias and modernity". International Social Science Journal, 43(2 (128)), 400-416.

Burl, Aubrey. 2002. God's Heretics: The Albigensian Crusade. Gloucestershire: Sutton Publishing.

Callon, Michel. 1988. "Some elements of a sociology of translation: domestication of the scallops and the fishermen of St. Brieuc Bay". In J. Law (Ed.), Power, Action, \& Belief. London: Routledge.

Calvino, Italo. 1974. Invisible Cities. London: Picador Books.

Carpenter, Humphrey (Ed.). 1990. The Letters of J. R. R. Tolkien. London: Unwin Paperbacks. 
CBC News Online Staff. 2004, 24 April. Turkey condemns Canada's Armenian genocide vote [Web page]. CBC. Retrieved 9 July, 2004, from the World Wide Web: http://www.cbc.ca/stories/2004/04/22/canada/armenia040422

CEH, Comisión para el Esclarecimiento Histórico. 1999. Guatemala Memory of Silence: Report of the Commission for Historical Clarification, Conclusions and Recommendations (English ed.). Guatemala City.

Chalk, Frank Robert. 1994. "Redefining Genocide". In G. J. Andreopoulos (Ed.), Genocide: Conceptual and Historical Dimensions (pp. 47-63). Philadelphia: University of Pennsylvania Press.

- 2000, 26 November. Panel Discussion. Paper presented at the Genocide and Collective Memory, National Gallery of Canada.

Chalk, Frank Robert, \& Kurt Jonassohn. 1990. The history and sociology of genocide : analyses and case studies. New Haven: Yale University Press.

Charny, Israel W. 1994. "Toward a Generic Definition of Genocide". In G. J. Andreopoulos (Ed.), Genocide: Conceptual and Historical Dimensions (pp. 6494). Philadelphia: University of Pennsylvania Press.

Chomsky, Noam, \& Michel Foucault. 1997. "Human Nature: Justice versus Power". In A. I. Davidson (Ed.), Foucault and His Interlocutors (pp. 107-145). Chicago: University of Chicago Press.

Chomsky, Noam, \& Edward S. Herman. 1979. The Political Economy of Human Rights Volume I: The Washington Connection and Third World Fascism. Montréal: Black Rose Books.

Churchill, Ward. 1998. A little matter of genocide : holocaust and denial in the Americas, 1492 to the present. San Francisco, Calif.: City Lights.

Colson, Charles. 2000, 8 February 2000. Genocide of the Unborn: The Problem with Stem Cell Research. Prison Fellowship Ministries. Retrieved 21 December, 2003, from the World Wide Web: http://www.cin.org/archives/cinnews/200002/0005.html

Comte, Auguste. 1998. "Cours de Philosophie Positive". In G. Lenzer (Ed.), August Comte and Positivism: The Essential Writings (pp. 69-306). New Brunswick: Transaction Publishers.

Crais, Clifton. 2003. "Late Victorian Holocausts (Book Review)". Journal of Social History, 36(3), 759-765. 
Culler, Jonathan. 1982. On Deconstruction:Theory and Criticism after Structuralism. Ithaca, NY: Cornell University Press.

Cunningham, Gregg. 1998. Why Abortion is Genocide. Centre for Bioethical Reform. Retrieved 21 December, 2003, from the World Wide Web:

http://www.carmical.net/articles/genocide.html

Curry, Patrick. 1997. Defending Middle-Earth: Tolkien, Myth and Modernity. New York: St. Martin's Press.

Dadrian, Vahakn N. 1997. The History of the Armenian Genocide: Ethnic Conflict from the Balkans to Anatolia to the Caucasus (Third, Revised ed.). Providence: Berghahn Book.

- 2001. "The Comparative Aspects of the Armenian and Jewish Cases of Genocide: A Sociohistorical Perspective". In A. S. Rosenbaum (Ed.), Is the Holocaust Unique? Perspectives on Comparative Genocide (Second ed., pp. 133-168). Westview Press: Boulder.

Danner, Mark. 1998. The horrors of a camp called Omarska and the Serb strategy [Website]. PBS Frontline Online. Retrieved 30 March, 2003, from the World Wide Web:

http://www.pbs.org/wgbh/pages/frontline/shows/karadzic/atrocities/omarska.html

Davies, David Michael. 1973. Last of the Tasmanians. London: Muller.

Davis, Mike. 2001. Late Victorian Holocausts: El Niño Famines and the Making of the Third World. London: Verso.

Dawidowicz, Lucy S. 1981. The Holocaust and the Historians. Cambridge, Mass.: Harvard University Press.

Day, David. 1999. Tolkien's Ring. London: Pavillion Books Limited.

Deleuze, Gilles. 1995. Negotiations, 1972-1990 (M. Joughin, Trans.). New York: Columbia University Press.

Deleuze, Gilles, \& Félix Guattari. 1987. A Thousand Plateaus (B. Massumi, Trans.). Minneapolis: University of Minnesota Press.

Derrida, Jacques. 1976. Of Grammatology (G. C. Spivak, Trans.). Baltimore: Johns Hopkins University Press.

Des Forges, Alison Liebhafsky. 1999. "Leave None to Tell the Story": Genocide in Rwanda. New York: Human Rights Watch. 
Drechsler, Horst. 1990. "The Herero Uprising". In F. R. Chalk \& B. R. Johnston (Eds.), The History and Sociology of Genocide: Analyses and Case Studies (pp. 231248). New Haven: Yale University Press.

Durkheim, Emile. 1982. "The Rules of Sociological Method" (W. D. Halls, Trans.). In S. Lukes (Ed.), Durkheim: The Rules of Sociological Method and Selected Texts on Sociology and its Method. New York: The Free Press.

- 1984. The Division of Labour in Society. New York: The Free Press.

-. 1992. Professional Ethics and Civic Morals. London: Routledge.

- 1995. The Elementary Forms of Religious Life (K. E. Fields, Trans.). New York: The Free Press.

—. 1997. The Division of Labour in Society (W. D. Halls, Trans.). New York: The Free Press.

-. 2002. Moral Education (E. K. Wilson \& H. Schnurer, Trans.). Mineola, NY: Dover Publications.

Elias, Norbert. 1970. "The genesis of sport as a sociological problem". In E. Dunning (Ed.), The Sociology of Sport (pp. 88-115). London: Frank Cass.

-. 1978. What is Sociology? (S. Mennell \& G. Morrissey, Trans.). New York: Columbia University Press.

-. 1983. The Court Society (E. Jephcott, Trans.). Oxford: Basil Blackwell.

- 1986. Quest for Excitement: Sport and Leisure in the Civilizing Process. Oxford: Basil Blackwell.

—. 1987. Involvement and Detachment. Oxford: Basil Blackwell.

-. 1994. The Established and the Outsiders. London: SAGE Publications Ltd.

-. 1996. The Germans (E. Dunning \& S. Mennell, Trans.). New York: Columbia University Press.

-. 2000. The Civilizing Process: The History of Manners and State Formation and Civilization (E. Jephcott, Trans. Revised ed.). Oxford: Blackwell.

Elias, Norbert, \& Eric Dunning. 1969. "The Quest for Excitement in Leisure". British Journal of Sociology, 2, 50-85. 
Engels, Frederick. 1972. The Origin of the Family, Private Property, and the State, In Light of the Researches of Lewis H. Morgan. New York: International Publishers.

-. 1988. "The Materialist Conception of History". In D. McLellan (Ed.), Marxism: Essential Writings (pp. 69-71). Oxford: Oxford University Press.

—. 1988. "Revolution: Peaceful or Violent?" In D. McLellan (Ed.), Marxism: Essential Writings (pp. 71-75). Oxford: Oxford University Press.

Epstein, James. 2003. "Late Victorian Holocausts: El Nino Famines and the Making of the Third World (Book Review)". Victorian Studies, 45(3), 529-530.

Ertïrk, Yakin. 1990. "Trends in the Development of Sociology in Turkey". Journal of the Human Sciences, IX(2), 37-55.

Evans, Richard J. 1989. In Hitler's shadow : West German historians and the attempt to escape from the Nazi past. New York: Pantheon Books.

Everett, Jim. 1999. "The Aboriginal Tasmanians (Book Review)". Oceania, 69(3), 219220.

Fackenheim, Emil L. 1977. "The Holocaust and the State of Israel: Their Relation". In E. Fleischner (Ed.), Auschwitz: Beginning of a New Era? Reflections on the Holocaust. New York: Ktav Publishers.

- 1978. The Jewish Return Into History: Reflections in the Age of Auschwitz and a New Jerusalem. New York: Schocken Books.

Farhi, Donna. 2000. Yoga Mind, Body \& Spirit: A Return to Wholeness: Henry Holt \& Company.

Fein, Helen. 1979. Accounting for Genocide: National Responses and Jewish Victimization During the Holocaust. New York: The Free Press.

-. 1984. "Scenarios of Genocide: Models of Genocide and Critical Responses". In I. W. Charny (Ed.), Toward the Understanding and Prevention of Genocide: Proceedings of the International Conference on the Holocaust and Genocide (pp. 3-31). Boulder: Westview Press.

- 1993. Genocide : a sociological perspective. London: Sage.

-. 1994. "Genocide, Terror, Life Integrity, and War Crimes: The Case for Discrimination". In G. J. Andreopoulos (Ed.), Genocide: Conceptual and Historical Dimensions. Philadelphia: University of Pennsylvania Press. 
-. 2004, 22 June. Darfur [Discussion Log]. H-Genocide. Retrieved 5 August, 2004, from the World Wide Web: http://h-net.msu.edu/cgibin/logbrowse.pl?trx=lx\&list=h-genocide\&user=\&pw=\&month=0406

Finkelstein, Norman. 2000. The Holocaust Industry: Reflections on the Exploitation of Jewish Suffering. London: Verso.

Fletcher, Jonathan. 1997. Violence and Civilization: An Introduction to the Work of Norbert Elias. Cambridge: Polity Press.

Foucault, Michel. 1972. The Archaeology of Knowledge (A. M. Sheridan Smith, Trans.). London: Tavistock.

—. 1980. "Two Lectures" (K. Soper, Trans.). In C. Gordon (Ed.), Power/Knowledge: Selected Interviews and Other Writings 1972-1977 (pp. 78-108). New York: Pantheon Books.

—. 1984. "Nietazsche, Genealogy, History". In P. Rabinow (Ed.), The Foucault Reader (pp. 76-102). New York: Pantheon Books.

-. 1988. "The Political Technology of Individuals". In L. H. Martin \& H. Gutman \& P. H. Hutton (Eds.), Technologies of the Self: A Seminar with Michel Foucault (pp. 145-162). Amherst: University of Massachussetts Press.

- 1990. The History of Sexuality, Volume 1: An Introduction (R. Hurley, Trans. Vintage Books Edition ed.). New York: Vintage Books.

-. 1994. "Interview with Michel Foucault". In J. D. Faubion (Ed.), Power: Essential Works of Michel Foucault 1954-1984, Volume 3 (pp. 239-325). New York: The New Press.

-. 1995. Discipline and Punish: The Birth of the Prison (A. Sheridan, Trans. Second ed.). New York: Vintage Books.

—. 1997. "What is Enlightenment?" (C. Porter, Trans.). In P. Rabinow (Ed.), Ethics, Subjectivity, and Truth: Essential Works of Michel Foucault 1954-1984, Volume I (Vol. 1, pp. 303-320). New York: The New Press.

—. 1998. "Structuralism and Post-structuralism" (J. Harding, Trans.). In J. D. Faubion (Ed.), Aesthetics, Method, and Epistemology: Essential works of Foucault, 19541984, Volume 2 (pp. 431-458). New York: The New Press.

-. 2000a. "Confronting Governments: Human Rights". In J. D. Faubion (Ed.), Power: Essential Works of Foucault 1954-1984, Volume 3 (pp. 474-475). New York: The New Press. 
-. 2000b. "Interview with Michel Foucault". In J. D. Faubion (Ed.), Power: Essential Works of Foucault 1954-1984, Volume 3 (pp. 239-297). New York: The New Press.

-. 2000c. "The Moral and Social Experience of the Poles Can No Longer Be Obliterated". In J. D. Faubion (Ed.), Power: Essential Works of Foucault 19541984, Volume 3 (pp. 465-473). New York: The New Press.

-.2003. Society Must Be Defended: Lectures at the Collège de France, 1975-1976 (D. Macey, Trans.). New York: Picador.

Fuentes, Annette, \& Barbara Ehrenreich. 1983. Women in the Global Factory. Boston: South End Press.

Gale, Fay. 1982. "The Aboriginal Tasmanians (Book Review)". The Australian Journal of Politics and History, 28(2), 292.

Given, James B. 1997. Inquisition and Medieval Society. Ithaca, NY: Cornell University Press.

Goodman, Lisl Marburg, \& Lee Ann Hoff. 1990. Omnicide: The Nuclear Dilemma. New York: Praeger.

Gourevitch, Philip. 1998. We wish to inform you that tomorrow we will be killed with our families: Stories from Rwanda. New York: Farrar Straus and Giroux.

Graves, Robert. 1992. The Greek Myths (Combined Edition ed.). London: Penguin Book.

Greenough, Paul R. 1982. Prosperity and Misery in Modern Bengal: The Famine of 1943-1944. Oxford: Oxford University Press.

Griffin, John Howard. 1977. Black Like Me (Second ed.). Boston: Houghton Mifflin.

Hacking, Ian. 1983. Representing and Intervening: Introductory Topics in the Philosophy of Science. Cambridge: Cambridge University Press.

-. 1999. The Social Construction of What? Cambridge, MA: Harvard University Press.

Hancock, Ian. 2001. "Responses to the Porrajmos: The Romani Holocaust". In A. S. Rosenbaum (Ed.), Is the Holocaust Unique? Perspectives on Comparative Genocide (Second ed., pp. 69-96). Boulder, Colorado: Westview Press.

Handy, Jim. 1984. Gift of the Devil: A History of Guatemala. Toronto: Between The Lines. 
Hannum, Hurst, \& David Hawk. 1986. The Case Against the Standing Committee of the Communist Party of Kampuchea. New York: Cambodia Documentation Commission.

Hardt, Michael, \& Antonio Negri. 2000. Empire. Cambridge, MA: Harvard University Press.

Harff, Barbara, \& Ted R. Gurr. 1988. "Toward empirical theory of genocides and politicides: identification and measurement of cases since 1945". International Studies Quarterly, 37(3), 359-371.

Herring, Horace. 2002. "Late Victorian Holocausts: El Nino Famines and the Making of the Third World (Book Review)". Organization and Environment, 15(1), 91-96.

Heyd, Uriel. 1950. Foundations of Turkish Nationalism. London: Luzac.

Hilberg, Raul. 1980. "The Anatomy of the Holocaust". In H. Friedlander \& S. Milton (Eds.), The Holocaust: Ideology, Bureaucracy, and Genocide. Millwood, N.Y.: Kraus International.

Hitchens, Christopher. 1992, 19 October. "Minority Report". The Nation, 255, 422.

Horowitz, Irving Louis. 1982. Taking Lives: Genocide and State Power (Third ed.). New Brunswick, NJ: Transaction Press.

-. 2002. Taking Lives: Genocide and State power (Fifth Revised ed.). New Brunswick, N.J.: Transaction Publishers.

Hovannisian, Richard G. 1990. "The Historical Dimension of the Armenian Question, 1878-1923". In F. R. Chalk \& K. Jonassohn (Eds.), The History and Sociology of Genocide: Anayses and Case Studies (pp. 250-266). New Haven: Yale University Press.

Human Rights Watch Arms Project. 1994. Arming Rwanda: The Arms Trade and Human Rights Abuses in the Rwandan War: Human Rights Watch.

Huntington, Samuel P. 1993. "The Clash of Civilizations?" Foreign Affairs, 72(3), 22-49.

-. 1996. The Clash of Civilizations and the Remaking of World Order. New York: Simon \& Schuster.

Huttenbach, Henry. 1988. "Locating the Holocaust on the genocide spectrum". Holocaust and Genocide Studies, 3(3), 289-304.

—. 2001. "From the Editor: in search of genocide-(re) focusing on the existential". Journal of Genocide Research, 3(1), 7-9. 
Ibn Khaldun, Wali al-Din 'Abd al-Rahman. 1996. "The Muqaddimah: An Introduction to History". In N. Abdo (Ed.), Sociological Thought: Beyond Eurocentric Theory (pp. 37-61). Toronto: Canadian Scholars' Press.

Itwaru, Arnold Harrichand. 1994. "Literature as Cultural Imperialism in Canada Glorious and Free, you say?" In A. H. Itwaru \& N. Ksonzek (Eds.), Closed Entrances: Canadian culture and imperialism (pp. 5-70). Toronto: TSAR Publications.

Jeffremovas, Villia. 2002. Brickyards to Graveyards: From Production to Genocide in Rwanda. Albany: State University of New York Press.

Jonassohn, Kurt, \& Karin Solveig Björnson. 1998. Genocide and gross human rights violations : in comparative perspective. New Brunswick, N.J.: Transaction Pub.

Jones, Adam. 2002. "Gender and genocide in Rwanda". Journal of Genocide Research, 65-94.

Kahveci, Erol. 1995. "Durkheim's Sociology in Turkey". Durkheimian Studies/Etudes durkheimiennes, 1, 51-57.

Katz, Steven T. 1983. Post-holocaust dialogues : critical studies in modern Jewish thought. New York: New York University Press.

- 1988. "Quantity and Interpretation: Issues in the Comparative Analysis of the Holocaust". In Y. Bauer (Ed.), Remembering for the Future: Jews and Christians During and After the Holocaust (Vol. 3, pp. 200-216). Oxford: Pergamon.

—. 1991. "The Pequot War Reconsidered". New England Quarterly, 64(2), 206-224.

-. 1992. Historicism, the Holocaust, and Zionism: Critical Studies in Modern Jewish Thought and History. New York: New York University Press.

—. 1994. The Holocaust in Historical Context (Vol. 1). New York: Oxford University Press.

—. 2001. "The Uniqueness of the Holocaust: The Historical Dimension". In A. S. Rosenbaum (Ed.), Is the Holocaust Unique? Perspectives on Comparative Genocide (pp. 49-68). Boulder, Colorado: Westview Press.

Keefer, Edward C. (Ed.). 2001. Foreign Relations of the United States, 1964-1968, Volume XXVI: Indonesia; Malaysia-Singapore; Philippenes. Washington: United States Government Printing Office.

Knorr-Cetina, Karin D. 1981. The Manufacture of Knowledge: An Essay on the Constructivist and Contextual Nature of Science. Oxford: Pergamon Press. 
Kuhn, Thomas S. 1996. The Structure of Scientific Revolutions (Third ed.). Chicago: University of Chicago Press.

Kuper, Leo. 1981. Genocide : its political use in the twentieth century. New Haven: Yale University Press.

Kuperman, Alan J. 2001. The Limits of Humanitarian Intervention: Genocide in Rwanda. Washington, D.C.: Brookings Institution Press.

La Feber, Walter. 1993. Inevitable Revolutions: The United States in Central America (Second ed.). New York: W. W. Norton \& Company.

Lacouture, Jean. 1978. Survivre le peuple cambodgien. Paris: Le Seuil.

LaFeber, Walter. 1993. Inevitable Revolutions: The United States in Central America (Second ed.). New York: W.W. Norton.

Lavoie, Vincent. 2000, 26 November. Panel Discussion. Paper presented at the Genocide and Collective Memory, National Gallery of Canada.

Legters, Lyman H. 1984. "The Soviet Gulag: is it genocidal?" In I. W. Charny (Ed.), Toward the Understanding and Prevention of Genocide: Proceedings of the International Conference on the Holocaust and Genocide (pp. 60-66). Boulder/London: Westview Press.

Lemkin, Raphael. 1944. Axis rule in occupied Europe : laws of occupation, analysis of government, proposals for redress. Washington: Carnegie Endowment for International Peace Division of International Law.

—. 1947. "Genocide as a Crime Under International Law". American Journal of International Law, 41.

Lenin, Vladimir. 1988. "The State and Revolution". In D. McLellan (Ed.), Marxism: Essential Writings (pp. 163-177). Oxford: Oxford University Press.

Lippman, M. 1984. "The Drafting of the 1948 Convention on the Prevention and Punishment of the Crime of Genocide". Boston University International Law Journal(3).

Lipstadt, Deborah E. 1993. Denying the Holocaust : the growing assault on truth and memory. New York: Free Press.

Loucky, James. 2001. "The Tz'utujil Maya of Guatemala". In S. C. Stonich (Ed.), Endangered Peoples of Latin America: Struggles to Survive and Thrive. Westport, Connecticut: Greenwood Press. 
Luxemburg, Rosa. 2003. The Accumulation of Capital. London: Routledge.

Lyotard, Jean-François. 1984. The Postmodern Condition: A Report on Knowledge (G. Bennington \& B. Massumi, Trans.). Minneapolis: University of Minnesota Press.

Mamdani, Mahmood. 2001. When victims become killers: colonialism, nativism, and the genocide in Rwanda. Princeton, N.J.: Princeton University Press.

Marchak, Patricia. 2003. Reigns of Terror. Montreal \& Kingston: McGill-Queen's University Press.

Marks, Robert B. 2001. "Late Victorian Holocausts: El Nino Famines and the Making of the Third World (Book Review)". The Journal of Economic History, 61(3), 871.

Markus, Andrew. 1982-1983. "The Aboriginal Tasmanians (Book Review)". Australian Historical Studies, 20, 467-469.

Marrus, Michael Robert. 1987. The Holocaust in history (1st ed.). Toronto: Lester \& Orpen Dennys.

-. 2000, 26 November. Panel Discussion. Paper presented at the Genocide and Collective Memory, National Gallery of Canada.

Martineau, Harriet. 1966. Society in America (Vol. 1). New York: AMS Press.

Marx, Karl. 1979. "The 18th Brumaire of Louis Bonaparte", Karl Marx, Frederick Engels: Collected Works, Volume 11, Marx and Engels: $1851-53$ (pp. 99-197). Moscow: Progress Publishers.

-. 1990. Capital: A Critique of Political Economy, Volume I (B. Fowkes, Trans.). Toronto: Penguin Books Canada Ltd.

-. 2000a. "Economic and Philosophical Manuscripts". In D. McLellan (Ed.), Karl Marx: Selected Writings. Oxford: Oxford University Press.

-. 2000b. "Theses on Feuerbach". In D. McLellan (Ed.), Karl Marx: Selected Writings (Second ed., pp. 171-174). Oxford: Oxford University Press.

-. 2000c. "Wage-Labour and Capital". In D. McLellan (Ed.), Karl Marx: Selected Writings (2nd ed., pp. 273-293). Oxford: Oxford University Press.

Marx, Karl, \& Frederick Engels. 1976. "The German Ideology", Karl Marx, Frederick Engels: Collected Works, Volume 5, Marx and Engels: 1845-47. Moscow: Progress Publishers. 
—. 1988a. "The Communist Manifesto", Marxism: Essential Writings (pp. 20-49). Oxford: Oxford University Press.

—. 1988b. "The German Ideology". In D. McLellan (Ed.), Marxism: Essential Writings (pp. 3-19). Oxford: Oxford University Press.

Massumi, Brian. 1987. "Translator's Foreword: Pleasures of Philosophy". In G. Deleuze \& F. Guattari, A Thousand Plateaus: Capitalism and Schizophrenia (pp. ix-xv). Minneapolis: University of Minnesota Press.

McMillen, Liz. 1994. "The Uniqueness of the Holocaust". Chronicle of Higher Education, 40(42).

Melson, Robert. 1990. "Provocation or Nationalism: A Critical Inquiry into the Armenian Genocide of 1915". In F. R. Chalk \& K. Jonassohn (Eds.), The History and Sociology of Genocide: Analyses and Case Studies (pp. 266-289). New Haven: Yale University Press.

-1992. Revolution and Genocide: On the Origins of the Armenian Genocide and the Holocaust. Chicago: University of Chicago Press.

Melvern, Linda. 2000. A People betrayed; the role of the West in Rwanda's genocide. London: Zed Books.

Mennell, Stephen. 1989. Norbert Elias: Civilization and the Human Self-Image. Oxford: Basil Blackwell.

—. 1992. Norbert Elias: An Introduction. Dublin: University College Dublin Press.

Mennell, Stephen, \& Eric Dunning. 1996. "Preface". In N. Elias (Ed.), The Germans (pp. vii-xvi). New York: Columbia University Press.

Milgram, Stanley. 1974. Obedience to Authority: An Experimental View. London: Tavistock.

Mirowski, Philip. 1989. More Heat Than Light: Economics as Social Physics, Physics as Nature's Economics. Cambridge: Cambridge University Press.

Moore, Jason. 2003. "Ecology and Imperialism". Monthly Review, 55(2), 58-62.

Moore, R.I. 1990. The Formation of a Persecuting Society: Power and Deviance in Western Europe 950-1250. Oxford: Blackwell Publishing.

Morris, James. 1972. "The Final Solution, Down Under". Horizon, 14(1), 60-71. 
Moses, A. Dirk. 2002. "Conceptual blockages and definitional dilemmas in the 'racial century': genocides of indigenous peoples and the Holocaust". Patterns of Prejudice, 36(4), 7-36.

—. 2004. "The Holocaust and Genocide". In D. Stone (Ed.), The Historiography of the Holocaust. London: Palgrave.

Nolen, Stephanie. 2004, Saturday, June 5, 2004. The Next Rwanda? Sudan's Neglected Nightmare. The Globe and Mail.

O'Shea, Stephen. 2000. The Perfect Heresy: The Revolutionary Life and Death of the Medieval Cathars. Vancouver: Douglas \& McIntyre.

Oxford English Dictionary. 2004, 1989. OED Online [Website]. Oxford University Press. Retrieved 19 May, 2004, from the World Wide Web: http://www.dictionary.oed.com

Parsons, Talcott. 1951. The Social System. New York: The Free Press.

-. 1966. Societies: Evolutionary and Comparative Perspectives. Englewood Cliffs: Prentice-Hall, Inc.

Porpora, Douglas V. 1990. How Holocausts Happen: The United States in Central America. Philadelphia: Temple University Press.

Porter, Jack N. 1982. "Introduction". In J. N. Porter (Ed.), Genocide and Human Rights: A Global Anthology (pp. 2-33). Washington, DC: University Press of America.

Powell, Christopher. 2001. "What's Social About Social Construction? How to Bridge a Political Schism by Reaffirming An Ontological Divide". Social Studies of Science, 31(2), 299-307.

Prunier, Gérard. 1995. The Rwanda crisis: history of a genocide. New York: Columbia University Press.

Reeves, Eric. 2004, 29 June. Darfur [Discussion Log]. H-Genocide. Retrieved 5 August, 2004, from the World Wide Web: http://h-net.msu.edu/cgibin/logbrowse.pl?trx =lx \&list=h-genocide \&user $=\& p w=\&$ month $=0406$

Reisman, W. Michael, \& Charles H. Norchi. 1988. "Genocide and the Soviet Occupation of Afghanistan". ISG Newsletter, 1(1), 4-6.

REMHI, Recovery of Historical Memory Project. 1999. Guatemala, Never Again! The Official Report of the Human Rights Office, Archdiocese of Guatemala. Maryknoll, NY: Orbis Books. 
Resnick, Stephen, \& Richard Wolff. 1995. "Lessons from the USSR". In B. Magnus \& S. Cullenberg (Eds.), Wither Marxism? Global Crisis in International Perspective. New York: Routledge.

Robson, L. L. 1983. A history of Tasmania. Melbourne ; New York: Oxford University Press.

Rorty, Richard. 1989. Contingency, irony, and solidarity. Cambridge: Cambridge University Press.

-. 1991. Objectivity, Relativism, and Truth: Philosophical Papers Volume 1. Cambridge: Cambridge University Press.

—. 1993. "Is Derrida a Transcendental Philosopher?" In G. B. Madison (Ed.), Working Through Derrida (pp. 137-149). Evanston, IL: Northwestern University Press.

Rosenfeld, Alvin H. 1997. "The Americanization of the Holocaust". In A. H. Rosenfeld (Ed.), Thinking About the Holocaust After Half a Century (pp. 119-150). Bloomington: Indiana University Press.

Rotella, Mark, Charlotte Abbott, \& Sarah F. Gold. 2001. "Late Victorian Holocausts: El Nino Famines and the Making of the Third World (Book Review)". Publishers Weekly, 248(4), 317.

Rothermund, Dietmar. 1993. An Economic History of India from Pre-Colonial Times to 1991. London: Routledge.

Rousseau, Jean-Jacques. 1993a. "A Discourse on the Origin of Inequalaity" (G. D. H. Cole, Trans.). In J. H. Brumfitt \& J. C. Hall \& P. D. Jimack (Eds.), The Social Contract and Discourses (Everyman ed., pp. 31-126). London: J. M. Dent.

- 1993b. "The Social Contract or, Principles of Political Right" (G. D. H. Cole, Trans.). In J. H. Brumfitt \& J. C. Hall \& P. D. Jimack (Eds.), The Social Contract and Discourses (Everyman ed., pp. 179-309). London: J. M. Dent.

Rubenstein, Richard L. 2001. "Religion and the Uniqueness of the Holocaust". In A. S. Rosenbaum (Ed.), Is the Holocaust Unique? Perspectives on Comparative Genocide (pp. 33-40). Boulder, Colorado: Westview Press.

Rummel, R.J. 1994. Death By Government. New Brunswick: Transaction Publishers.

- 2003, September 25th. Democracies and Genocide (Rummel) [Discussion Log]. HGenocide. Retrieved, from the World Wide Web: http://h-net.msu.edu/cgibin/logbrowse.pl?trx=lx\&list=h-genocide \&user=\&pw=\&month=0309 
Ruthven, Malise. 1978. Torture: The Grand Conspiracy. London: Weidenfeld and Nicolson.

Ryan, Lyndall. 1996. The Aboriginal Tasmanians (Second ed.). St. Leonards, NSW, Australia: Allen \& Unwin.

Sané, Pierre. 2000. "Foreword". In A. International (Ed.), Report 2000 (pp. 5-9). London: Amnesty International Publications.

Sartre, Jean-Paul. 1968. On Genocide. Boston: Beacon Press.

Schleuner, Karl A. 1970. The Twisted Road to Auschwitz. Urbana: University of Illinois Press.

Sellström, Tor, \& Lennart Wohlgemuth. 1996. The International Response to Conflict and Genocide: Lessons from the Rwanda Experience, Study 1: Historical Perspective: Some Explanatory Factors: Steering Committee of the Joint Evaluation of Emergency Assistance to Rwanda.

Shippey, Tom. 1992. The Road To Middle-Earth: How J.R.R. Tolkien created a new mythology. London: Grafton.

Sinnreich, Helene J. 2004, 20 June. Is the brutality in Sudan genocide? [Discussion Log]. H-Genocide. Retrieved 29 July, 2004, from the World Wide Web: http://hnet.msu.edu/cgi-bin/logbrowse.pl?trx=lx \&list=hgenocide $\&$ user $=\& \mathrm{pw}=\&$ month $=0406$

Smith, David Norman. 1995. "Ziya Gokalp and Emile Durkheim: Sociology as an Apology for Chauvinism?" Durkheimian Studies/Etudes durkheimiennes, 1, 4550 .

Smith, Roger. 1987. "Human Destructiveness and Politics: The Twentieth Century as an Age of Genocide". In I. Wallimann \& M. N. Dobkowski (Eds.), Genocide and the Modern Age: Etiology and case studies of mass death (pp. 21-40). New York: Greenwood Press.

Stannard, David E. 1992. American Holocaust: The Conquest of the New World. Oxford: Oxford University Press.

—. 2001. "Uniqueness as Denial: The Politics of Genocide Scholarship". In A. S. Rosenbaum (Ed.), Is The Holocaust Unique? Perspectives on Comparative Genocide (Second ed., pp. 245-290). Boulder, Colorado: Westview Press. 
Stanton, Gregory. 2004, 9 April 2004. Kofi Annan Announces Plan for Genocide Prevention [Discussion Log]. H-Genocide. Retrieved 30 July, 2004, from the World Wide Web: http://h-net.msu.edu/cgi-bin/logbrowse.pl?trx=lx\&list=hgenocide\&user $=\& p w=\&$ month $=0404$

-. 2004, 13 July 2004. Kofi Annan Names Juan Mendez as Special Adviser on the Prevention of Genocide [Discussion Log]. H-Genocide. Retrieved 30 July, 2004, from the World Wide Web: http://h-net.msu.edu/cgibin/logbrowse.pl?trx=lx\&list=h-genocide\&user=\&pw=\&month=0407

Stanton, Gregory H. 1998. Eight Stages of Genocide [Website]. Retrieved 16 March, 2003, from the World Wide Web: http://www.genocidewatch.org/8stages.htm

-. 2003. How We Can Prevent Genocide: Building An International Campaign to End Genocide [Website]. Genocide Watch. Retrieved 16 March, 2003, from the World Wide Web: http://www.genocidewatch.org/HOWWECANPREVENTGENOCIDE.htm

Stoll, Steven. 2002. "Late Victorian Holocausts (Book Review)". The Journal of Interdisciplinary History, 33(1), 98-99.

Subramaniam, Garimella. 2003, 11 January 2003. Genocide of the Unborn? The Hindu: Online Edition of India's National Newspaper. Retrieved 21 December, 2003, from the World Wide Web: http://www.hindu.com/thehindu/2003/01/11/stories/2003011104821300.htm

Sumption, Jonathan. 1978. The Albigensian Crusade. London: Faber \& Faber.

Tal, Uriel. 1979. "On the study of the Holocaust and genocide". Yad Vashem Studies, 13, $7-52$.

Thompson, John L., \& Gail A. Quets. 1987. Redefining the Moral Order: Towards a Normative Theory of Genocide. New York: Colombia University.

-. 1990. "Genocide and Social Conflict: A Partial Theory and Comparison". In L. Kriesberg (Ed.), Research in Social Movements, Conflicts and change (Vol. 12). Greenwood, CN: JAI Press.

Tilly, Charles. 1985. "War Making and State Making as Organized Crime". In P. B. Evans \& D. Rueschemeyer \& T. Skocpol (Eds.), Bringing the State Back In. Cambridge: Cambridge University Press.

Tolkien, J. R. R. 1977. The Silmarillion. London: George Allen \& Unwin.

- 1997a. "Beowulf: The Monsters and the Critics". In C. Tolkien (Ed.), The Monsters and the Critics and Other Essays (pp. 5-48). London: Harper Collins Publishers. 
—. 1997b. "On Fairy-Stories". In C. Tolkien (Ed.), The Monster and the Critics and Other Essays (pp. 109-161). London: Harper Collins Publishers.

Tolkien, J.R.R. 1991. The Lord of the Rings. London: Harper Collins Publishers.

Travers, Robert. 1968. Tasmanians; the story of a doomed race. Melbourne: Cassell.

Turnbull, Clive. 1966. Black war: the extermination of the Tasmanian aborigines. Melbourne: Lansdowne.

Turner, Bryan S. 1992. "Preface to the Second Edition". In E. Durkheim, Professional Ethics and Civic Morals. London: Routledge.

Uvin, Peter. 1998. Aiding violence; the development enterprise in Rwanda. West Hartford, Conn: Kumarian Press.

van Krieken, Robert. 1998. Norbert Elias. London: Routledge.

Vartanian, Nicole E. 2000, Spring. In a perfect world: Durkheim's Imperfect Conception of Power and the Legitimation of Nationalism and Genocide in Turkey. Paper presented at the American Sociological Association.

Vartanian, Nicole Elise. 1999. In a Perfect World: Durkheim's Imperfect Conception of Power and the Legitimation of Nationalism and Genocide in Turkey: American Sociological Association (ASA).

Wakefield, Walter L. 1974. Heresy, Crusade and Inquisition in Southern France 11001250. Berkeley: University of California Press.

Walker, R.B.J. 1993. Inside/outside: International Relations as Political Theory. Cambridge: Cambridge University Press.

Weber, Max. 1978. Economy and Society (Vol. 1). Berkeley: University of California Press.

Weston, Burns H. 1989. "Human Rights". In B. H. Weston \& R. P. Claude (Eds.), Human Rights in the World Community: Issues and Action. Philadelphia: University of Pennsylvania Press.

Wollstonecraft, Mary. 1997. "A Vindication of the Rights of Woman". In D. L. Macdonald \& K. Scherf (Eds.), The Vindications: The Rights of Men, The Rights of Woman (pp. 99-343). Peterborough, ON: Broadview Literary Texts. 